\title{
The Impact of Economic Shocks on Workers' Labor Market Outcomes
}

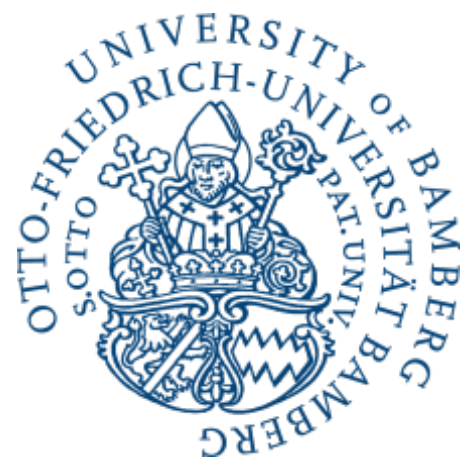

Freie wissenschaftliche Arbeit

zur Erlangung des akademischen Grades

"Dr. rer. pol."

eingereicht an der

Fakultät für Sozial-und Wirtschaftswissenschaften

Otto-Friedrich-Universität Bamberg

vorgelegt bei

Professor Dr. Uwe Blien

Otto-Friedrich-Universität Bamberg

von

Hannah Illing, M.A.

11.06.2021 


\section{Mitglieder der Promotionskommission}

Erstbetreuer und Sprecher

Weitere Mitglieder:

Datum der Abschlussprüfung:
Professor Dr. Uwe Blien

Otto-Friedrich-Universität Bamberg

Professor Dr. Wolfgang Dauth

Otto-Friedrich-Universität Bamberg

Professor Dr. Guido Heineck

Otto-Friedrich-Universität Bamberg

08.09.2021

Dieses Werk ist als freie Onlineversion über das Forschungsinformationssystem (FIS; https://fis.uni-bamberg.de) der Universität Bamberg erreichbar. Das

Werksteht unter der CC-Lizenz CC-BY.

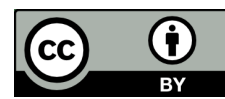

Lizenzvertrag: Creative Commons Namensnennung 4.0

http://creativecommons.org/licenses/by/4.0.

URN: urn:nbn:de:bvb:473-irb-517557

DOI: https://doi.org/10.20378/irb-51755 


\section{Acknowledgments}

I am grateful to my supervisors Uwe Blien and Wolfgang Dauth for their invaluable guidance and support during the process of writing this thesis. This thesis has highly gained from their advice, critique, and continuous encouragement.

I have moreover learnt a lot from numerous discussions with my coauthors Theresa Koch, Johannes Schmieder, and Simon Trenkle. I owe thanks to Johannes Schmieder in particular for his mentoring during the job market process (and beyond).

In addition, I would like to thank Michael Moritz, my mentor in the GradAB PhD program who has always lended me an open ear and never got tired discussing Czech politics with me. Similarly, I am grateful to Anette Haas for proof-reading my research papers several times, and for her encouragement at all stages of the dissertation process.

This thesis would not exist without the IAB's graduate program ("GradAB"), from which I have highly gained both in terms of financial and non-financial support. I am grateful for the exchange with my fellow PhD students in the GradAB, as well as for the exchange with all other colleagues at IAB. Being part of the IAB community has been an invaluable experience and I could not have found a more supportive environment for my $\mathrm{PhD}$. Apart from discussions with my colleagues, this thesis has benefited from comments made by participants at several workshops and conferences.

On top of this, numerous workshops and summer schools as part of my non-financial scholarship from Studienstiftung further enriched my $\mathrm{PhD}$ experience. I am grateful that I could remain a part of Studienstiftung during my PhD.

This list of acknowledgments would be incomplete without reference to my family and to Michal, to whom I dedicate this thesis. 


\section{Contents}

List of Figures vi vi vis

List of Tables viii

$\begin{array}{ll}\text { Preface } & 1\end{array}$

$\begin{array}{ll}\text { Synopsis } & 5\end{array}$

1 State of the Art in Labor Economics 9

1.1 Immigration Shocks . . . . . . . . . . . . . . . . . . . . . . 10

1.1.1 The Mariel Boatlift Study . . . . . . . . . . . . . . . . 11

1.1.2 Labor Market Effects of Immigration Outside the US . . . . . 13

1.1.3 Labor Market Effects of Cross-Border Commuting . . . . . . . 15

1.2 The Effects of Job Displacement . . . . . . . . . . . . . . . . 17

1.2.1 Estimating Costs of Job Displacement in the US . . . . . . . 18

1.2.2 Displacement Costs and The Business Cycle . . . . . . . . . . 20

1.2.3 Heterogeneity in Job Displacement Costs . . . . . . . . . . . . 21

2 Crossing Borders: Labor Market Effects of European Integration 24

2.1 Introduction . . . . . . . . . . . . . . . . . . . . . 25

2.2 The Policy Reform: EU Enlargement . . . . . . . . . . . . . . . . 33

2.3 Conceptual Framework . . . . . . . . . . . . . . . . . . . . . . . . . 34

2.4 Czech and German Labor Market Data . . . . . . . . . . . . . . . . . 36

2.5 Empirical Strategy: Difference-in-Differences Combined With Matching 40

2.5.1 Propensity Score Matching . . . . . . . . . . . . . . . . . 41

2.5.2 Eventstudy Regression Model . . . . . . . . . . . . . . 47

2.5.3 Worker Reweighting . . . . . . . . . . . . . . . 47

2.6 Results . . . . . . . . . . . . . . . . . . 52 
2.6.1 Regional-Level Analysis . . . . . . . . . . . . . . . 52

2.6.2 Worker-Level Analysis . . . . . . . . . . . . . . . . . . 59

2.7 Robustness Checks . . . . . . . . . . . . . . . . . 63

2.8 Conclusion . . . . . . . . . . . . . . . . . . . . . . . . . . 69

3 The Gender Gap in Earnings Losses After Displacement 71

3.1 Introduction . . . . . . . . . . . . . . . . . . . . . . . . 72

3.2 Conceptual Framework . . . . . . . . . . . . . . . . . . . . . . 78

3.3 Data and Methods . . . . . . . . . . . . . . . . . . . 79

3.3.1 German Administrative Data . . . . . . . . . . . . . 79

3.3.2 Measuring Job Displacement . . . . . . . . . . . . . . . . 80

3.3.3 Constructing a Sample of Displaced and Non-Displaced Workers 80

3.3.4 Comparing Men and Women Displaced from Similar Jobs: Reweighting .................. . 84

3.3.5 Estimation Strategies: Eventstudy and Matched Diff-in-Diff Design . . . . . . . . . . . . . . . . 86

3.4 Earnings and Employment Losses after Displacement of Men and Women . . . . . . . . . . . . . . . . . . . . . 89

3.4.1 Comparing Raw Earnings Losses for Men and Women . . . . . 89

3.4.2 The Gender Gap in Earnings Losses for Men and Women Displaced from Comparable Jobs . . . . . . . . . . . . . . . 93

3.4.3 The Role of Wage and Employment Losses after Displacement 96

3.5 Understanding the Gender Gap in Wage Losses . . . . . . . . . . . . 98

3.5.1 Changes in Job and Establishment Characteristics after Displacement . . . . . . . . . . . . . . . . . . . . . 99

3.5.2 Sources Underlying the Gender Gap in Wage Losses . . . . . . 102

3.5.3 Robustness of Main Results . . . . . . . . . . . . . . . . . . 104

3.6 Displacement in the Household Context . . . . . . . . . . . . . . . . . 109

3.6.1 The Added Worker Effect . . . . . . . . . . . . . . . . . 109

3.6.2 The Role of Children . . . . . . . . . . . . . . . . . . . . 111

3.7 Conclusion . . . . . . . . . . . . . . . . . . . . 116

4 Who Suffers the Greatest Loss? Costs of Job Displacement for $\begin{array}{ll}\text { Migrants and Natives } & 117\end{array}$

4.1 Introduction . . . . . . . . . . . . . . . . . . . . . . . . 118

4.2 Data and Sample Construction . . . . . . . . . . . . . . . . 124 
4.2.1 German Administrative Employer-Employee Data . . . . . . . 124

4.2 .2 Identifying Mass Layoff Events . . . . . . . . . . . . . . . . . 125

4.2.3 Sample of Displaced Workers . . . . . . . . . . . . . 126

4.2.4 Propensity Score Matching . . . . . . . . . . . . . . . . . 126

4.3 The Effect of Job Loss on Migrants and Natives . . . . . . . . . . . . 130

4.3.1 The Evolution of Earnings without Controls . . . . . . . . . . 130

4.3.2 Event Study Regression Model . . . . . . . . . . . . . . . . . 133

4.3.3 Making Migrants and Natives Comparable: Reweighting . . . 135

4.4 The Role of Establishment Sorting and Geographic Mobility . . . . . 139

4.4.1 Establishment Characteristics . . . . . . . . . . . . . . . . 139

4.4 .2 Geographic Mobility . . . . . . . . . . . . . . . . 140

4.5 Location at Time of Displacement: Difference-in-Differences Analysis 144

4.6 Robustness Checks . . . . . . . . . . . . . . . . . . . . . . 153

4.6.1 Robustness of Main Results . . . . . . . . . . . . . . . . . 153

4.6.2 Layoffs vs. Complete Closures . . . . . . . . . . . . . . . . . 154

4.7 Conclusion . . . . . . . . . . . . . . . . . . . . 155

$\begin{array}{ll}\text { Concluding Remarks } & 157\end{array}$

$\begin{array}{ll}\text { Bibliography } & 160\end{array}$

Appendix: Chapter 2 175

$\begin{array}{ll}\text { Appendix: Chapter } 3 & 202\end{array}$

Appendix: Chapter $4 \quad 216$ 


\section{List of Figures}

2.1 Inflow of Czech Workers - No Controls . . . . . . . . . . . . . 26

2.2 EU Eastern Enlargement: The Process . . . . . . . . . . . . . . . 33

2.3 Matched Treated and Control Regions: Germany and the Czech Republic . . . . . . . . . . . . . . . . . . . . . . 42

2.4 Migrant Worker Inflow to German Municipalities . . . . . . . . . . . 51

2.5 Regional Labor Market Effects in the Czech Republic . . . . . . . . 53

2.6 Native Wages and Employment in Germany - Municipality Level . . 56

2.7 Labor Market Outcomes of Native Incumbents in Germany . . . . . 60

2.8 Labor Market Outcomes of Native Incumbent Movers in Germany 62

2.9 Native Incumbent Workers by Tenure and Skill . . . . . . . . . . . . 64

3.1 The Gender Gap in Earnings Losses after Displacement without Controlling for Pre-Displacement Characteristics . . . . . . . . . . . . . 90

3.2 The Gender Gap in Earnings Losses after Displacement, Controlling for Pre- Displacement Job and Worker Characteristics . . . . . . . . 95

3.3 The Gender Gap in Wage and Employment Losses after Displacement 97

3.4 Changes in Job Characteristics after Displacement . . . . . . . . . . 101

3.5 Job Loss at the Household Level - The Added Worker Effect . . . . . 110

3.6 The Gender Gap and Children . . . . . . . . . . . . . . . . . . . 112

4.1 Migrant and Native Workers' Earnings - No Controls . . . . . . . . . 132

4.2 The Difference in Earnings Losses for Migrants vs. Natives . . . . . 134

4.3 Differences in Labor Market Outcomes after Displacement for Migrants vs. Natives . . . . . . . . . . . . . . . . . . 137

4.4 Sorting into Establishments after Displacement for Migrants vs. Natives . . . . . . . . . . . . . . . . . . . . 141

4.5 Differences in Geographic Mobility after Displacement for Migrants vs. Natives . . . . . . . . . . . . . . . . . . . . . . . . . . . . . . . 143 
4.6 Costs of Job Loss and Share of Same-Nationality Working Age Population in $t=-1 \ldots \ldots \ldots \ldots$. . . . . . . . . . . . . . . . . . . . . . . .

A.2.1 Migrant Worker Inflow to German Municipalities by Distance . . . . 176

A.2.2 Synthetic Control Group Matching as Robustness Check for the Czech Republic . . . . . . . . . . . . . . . . . . . . . . . 177

A.2.3 Synthetic Control Group Matching as Robustness Check for Germany178

A.2.4 Migrant Worker Inflow to East German Municipalities - Eventstudy Coefficients . . . . . . . . . . . . . . . . . . . 179

A.2.5 Native Wages and Employment in East Germany - Municipality Level180

A.2.6 Synthetic Control Group Matching as Robustness Check for East Germany . . . . . . . . . . . . . . . . . . . . 181

A.2.7 Czech Worker Inflow to German Municipalities by Distance (in km) 182

A.2.8 Native Wages and Employment in German Municipalities by Distance183

A.3.1 Binscatter Plots: AKM Establishment Effects . . . . . . . . . . . . . 203

A.3.2 Robustness Checks: Adjusting Sample Restrictions . . . . . . . . . . 204

A.3.3 Robustness Checks: Alternative Reweighting and Matching . . . . . 205

A.3.4 Robustness Checks: Reweighting Men to Women, Non-Couples . . . 206

A.3.5 Log Earnings and Days Worked - East vs. West Germany . . . . . . 207

A.3.6 The Gender Gap and Children . . . . . . . . . . . . . . . . . . . . 208

A.4.1 Distribution of the Share of Same-Nationality Working Age Population216 


\section{List of Tables}

2.1 Native and Czech Workers in the German Border Region . . . . . . 39

2.2 Summary Table of Matched Czech Counties in 2010 . . . . . . . . . 43

2.3 Summary Table of Matched German Municipalities in 2010 . . . . . 46

2.4 Characteristics of German Control and Treated Workers in 2010 . . 49

2.5 Regional Characteristics - Czech Counties . . . . . . . . . . . 54

2.6 Municipality-Level Difference-in-Differences Germany . . . . . . . . 58

3.1 Summary Table of Displaced Workers in the Year Before Displacement 83

3.2 The Gender Gap in Earnings Losses and Other Characteristics . . . 91

3.3 Explaining the Gender Gap in Wage Losses After Displacement . . . 103

3.4 The Gender Gap in Earnings Losses - Robustness Checks . . . . . . 105

3.5 Labor Market Outcomes for Couples with Children . . . . . . . . . . 115

4.1 Worker Characteristics of Displaced Workers and Matched Nondisplaced Workers One Year Prior to Displacement $(t=-1)$. . . . . 128

4.2 Explaining Earnings Losses by Local Labor Market Concentration . 148

4.3 Explaining Costs of Job Loss by Local Labor Market Concentration 152

A.2.1 Sorting into Industries by Czech vs. German Workers . . . . . . . . 185

A.2.2 Sorting into Occupations by Czech vs. German Workers . . . . . . . 186

A.2.3 Industries in Matched West German Municipalities in 2010 . . . . . 187

A.2.4 Matched East German Municipalities in 2010 . . . . . . . . . . . . 188

A.2.5 Industries in Matched East German Municipalities in 2010 . . . . . . 189

A.2.6 Labor Market Outcomes in Czech Republic: Regression Results . . . 190

A.2.7 Worker Inflow and Labor Market Outcomes in Germany: Regression Results . . . . . . . . . . . . . . . . . . . . 191

A.2.8 Regression Results for Regional-Level Event Study East Germany . 192

A.2.9 Labor Market Outcomes of Native Incumbent Workers in Germany . 193

A.2.10 Labor Market Outcomes of Native Incumbent Movers in Germany 194 
A.2.11 Labor Market Outcomes of Native Incumbent Workers in Germany By Tenure . . . . . . . . . . . . . . . . . . . . . 195

A.2.12 Labor Market Outcomes of Native Incumbent Workers in Germany By Skill . . . . . . . . . . . . . . . . . . . . 196

A.2.13 Robustness I: Inflow of EU8/Czech Workers . . . . . . . . . . . . . . 197

A.2.14 Robustness II: Regional Native Wages and Employment . . . . . . . 198

A.2.15 Robustness III: Worker-Level Results Without Construction and Health Sectors . . . . . . . . . . . . . . . . . . 199

A.2.16 Robustness IV: Worker-Level Results Without Construction and Health Sectors by Tenure . . . . . . . . . . . . . . . . . 200

A.2.17 Robustness V: Worker Level Results Without Construction and Health Sectors by Skill . . . . . . . . . . . . . . . . . . . . 201

A.3.1 Summary Statistics for Displaced Workers and Matched Controls in

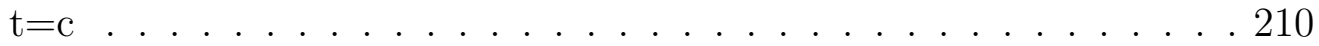

A.3.2 Industry Distribution for Displaced Workers and Matched Controls in $t=c \ldots \ldots \ldots \ldots$. . . . . . . . . . . . . . . . . . . . . . . . . . .

A.3.3 Top 10 3-Digit Occupations in the Five Years Before Displacement . 212

A.3.4 Top 10 3-Digit Occupations in the Five Years After Displacement . . 213

A.3.5 Robustness Checks: More Outcomes . . . . . . . . . . . . . . . . . . 214

A.3.6 Robustness Checks: Varying Estimation Samples . . . . . . . . . . . 215

A.4.1 Comparing Displaced Workers in $t=-1$ to a Random Sample of Workers . . . . . . . . . . . . . . . . . . 218

A.4.2 Workers' Distribution Across Industries in $t=-1 \ldots . . . . .219$

A.4.3 Workers' Distribution Across Occupations in $t=-1$. . . . . . . . 220

A.4.4 Event Study Regression Table with Reweighting: Labor Market Outcomes . . . . . . . . . . . . . . . . . . . . . 221

A.4.5 Event Study Regression Table without Reweighting: Labor Market Outcomes . . . . . . . . . . . . . . . . . 222

A.4.6 Event Study Regression Table: Days Worked . . . . . . . . . . . . . 223

A.4.7 Event Study Regression Table with Reweighting: Geographic Mobility224

A.4.8 Event Study Regression Table without Reweighting: Geographic Mobility . . . . . . . . . . . . . . . . . 225

A.4.9 Event Study Regression Table with Reweighting: Establishment Characteristics . . . . . . . . . . . . . . . . . 226 
A.4.10 Event Study Regression Table without Reweighting: Establishment Characteristics . . . . . . . . . . . . . . . . . . 227

A.4.11 Robustness Check: Restricting to Baseline Years up to 2007 (Pre Financial Crisis) . . . . . . . . . . . . . . . . . . . . 228

A.4.12 Robustness Check: Restricting Sample to Workplace in West Germany at Time of Displacement . . . . . . . . . . . . . . . . . . . . . 229

A.4.13 Robustness Check: Reweighting Natives to Migrants . . . . . . . . . 230

A.4.14 Explaining Costs of Job Loss by Local Labor Market Concentration and Controlling for Displacement Establishment . . . . . . . . . . . 231

A.4.15 Explaining Costs of Job Loss by Local Labor Market Concentration

- Only Complete Closures . . . . . . . . . . . . . . . . . . . . . . . 232

A.4.16 Log Earnings Losses by Origin Group . . . . . . . . . . . . . . . . . 233

A.4.17 Differences in Labor Market Outcomes for Women . . . . . . . . . . 234

A.4.18 Robustness Check: Restricting to Baseline Years up to 2003 (Pre Financial Crisis . . . . . . . . . . . . . . . . . . . . . 235

A.4.19 Overview Origin Groups as in Battisti et al. (2021) . . . . . . . . . . 236 


\section{Preface}

Economists have long aimed to understand the causes and consequences of economic shocks, such as financial crises. Such shocks can have profound impacts on workers, firms, and even societies as a whole. While shocks may be costly for some agents in the economy, others can benefit. One example is an increase in immigration flows, which may suppress native workers' wages but boost firms' productivity at the same time. Likewise, bankruptcies and subsequent job displacement can harm an individual worker's career, but - in line with Joseph Schumpeter's theory of destructive creation - may lead to the survival of more innovative firms and thus eventually transform societies in a positive way.

This thesis empirically analyzes how labor market shocks affect workers in Germany. I take advantage of the rich administrative employer-employee data provided by the Institute for Employment Research (IAB) to analyze two different types of shocks: In Chapter 2, I analyze a labor supply shock in the form of an increase in cross-border migration from Czech Republic to Germany, and its impact on the affected regions and workers. The second part of the thesis combines two studies investigating costs of job displacement and how they differ by workers of different gender (Chapter 3) and migration status (Chapter 4). Both the migration policy reform and job displacement are small economic shocks - nevertheless, they have the potential to affect a local labor market's equilibrium, and workers' careers in the long run. My aim is to investigate the effect of these small shocks on workers' labor market outcomes, e.g., their subsequent employment trajectories.

In the first part of this thesis (Chapter 2), my focus is a labor supply shock in the form of cross-border migration. Given that migration flows are increasing all over the world, a better understanding of the effects of immigration on origin and destination countries' labor markets is of high relevance. This holds both for understanding the underlying mechanisms from the perspective of theoretical and empirical research, 
as well as for policy advice. In destination countries, there is an ongoing public debate about the labor market effects of immigration: On the one hand, ageing Western societies desparately need worker migration to counteract skilled worker shortages. On the other hand, native workers worry about competition from migrant workers, and such worries have contributed to rising xenophobia in countries such as Germany. In origin countries such as the Eastern EU member states, policy-makers worry about brain drains, skilled worker shortages, and accelerating demographic change.

What is often missing in these public debates is empirical evidence: How are local labor markets really affected by emigration and immigration? How does immigration impact native workers' labor market trajectories in the long run? While there is a large body of literature studying immigration and emigration, the evidence is mixed (for a discussion of the empirical literature, see Chapter 1 of this thesis). Some studies report negative wage and/or employment effects on native workers, others find no or even positive labor market effects. I add empirical evidence to this puzzle by focusing on an immigration reform that is of high political relevance: The opening of the German labor market to workers from Central and Eastern Europe in 2011. Even though this reform granted access to the German labor market for citizens in countries with a total size approximately equaling that of the German population, little is known so far about the reform's effects on the German labor market. In Chapter 2 of this thesis, I fill this gap and thus offer relevant empirical evidence for researchers and policy-makers alike.

Chapters 3 and 4 in the second part of this thesis focus on the labor market impact of job displacement, resulting from a mass layoff, on individual workers' careers. The main innovation in this part is that so far, there exists little evidence on the extent to which the labor market effects of mass layoffs differ by worker type (for an overview of the job displacement literature, see Chapter 1 of this thesis). I add to the existing literature by providing evidence both on how costs of job loss differ by gender (Chapter 3), and by migration status (Chapter 4).

Economic history in the past 100 years has shown that economic up- and downturns arrive repeatedly. Economic downturns, such as the Great Depression and the Great Recession, have led to job losses for millions of workers, and may have even fuelled social unrest in some countries. The recent economic downturn as a result of the Covid-19 Pandemic is another example of how quickly, and unexpectedly, jobs can 
be destroyed. A number of empirical studies since the 1990s have documented that job loss leads to large and persistent economic costs for displaced workers. Yet in order to optimally shape labor market policies during recessions, policy-makers need to be informed about heterogeneities in costs of job loss by worker type. This holds in particulary for groups which are minorities in the labor market but which - in times of demographic change and skilled worker shortages - firms cannot risk to lose to inactivity in the long run. In Chapters 3 and 4 of this thesis, I thus analyze how women (migrants) react to job displacement compared to men (natives).

Contrasting women with men is interesting in particular, because the two groups may have different outside options after job loss. In societies where the male bread winner model dominates, women may choose to specialize in home production after job loss. While women may not drop out of the labor force completely, they may still differ from men in terms of their job search behavior after job displacement: E.g., they may prefer job arrangements with lower commuting distances and flexible working time. Similarly, migrants may react differently to job displacement than natives, e.g. in terms of geographic mobility. Migrants may moreover face greater difficulties to re-integrate into the labor market, particularly during recessions, if employers worry about asymmetric information or display taste-based or statistical discrimination. Knowing the challenges that different worker groups face after job displacement is crucial for policy-makers to design optimal labor market policies.

For several reasons, the focus of this thesis is Germany. First, being the largest economy in the eurozone, the German labor market offers a nearly ideal case study for the analysis of labor market dynamics. With the single market closely connecting European economies, and with many European countries having similar labor market institutions and welfare systems as Germany, I expect that the evidence I provide is also relevant for other European countries. Second, immigration, which I study in Chapters 2 and 4, is of high relevance for the German labor market. Germany belongs to the top immigration countries in the OECD, and one in four Germans has migration background (meaning that either he/she or at least one parent were born without German citizenship). Third, for my empirical analyses, I use the rich, highly reliable administrative employer-employee data for Germany, which is provided by the IAB. This data covers about $80 \%$ of the German workforce and contains a number of relevant individual characteristics such as education, migration status, and occupation. It is thus particularly suited to analyze labor market 
dynamics.

The remainder of this thesis proceeds as follows: I first provide a synopsis which gives an overview of the thesis' four chapters. I then start with an overview of the state of the art Labor Economics literature on immigration and job displacement and my contribution to it in Chapter 1 . Then, I add three separate research projects in three different chapters. I start with Chapter 2 which analyzes the labor market effects of cross-border commuting in the course of European integration. In Chapter 3, I provide evidence on the gender gap in earnings losses after job displacement. Finally, Chapter 4 investigates differences in costs of job loss for migrants compared to native workers. Following the concluding remarks, I present the bibliography and the appendices at the end of the thesis. 


\section{Synopsis}

The first chapter of this thesis provides an overview of the state of the art literature and my contribution to it; in the subsequent three chapters, I present my own empirical research. In Chapter 2, I study labor market effects of out-migration and in-migration in the context of cross-border commuting. I thus contribute to the large literature on the labor market effects of emigration and immigration (e.g., Beerli et al. (2021), Bütikofer et al. (2020), Dustmann et al. (2017), Dustmann et al. (2015), Aydemir and Borjas (2007)) by providing evidence on a new policy reform: The opening of the German labor market for workers from Central and Eastern Europe in 2011. My focus is the German border region to Czech Republic, which experienced a substantial increase in the share of Czech workers as a result of the policy change. While prior studies typically focus on either out-migration or in-migration, my study is the first to combine both the effects of the negative labor supply shock on Czech Republic, and the positive labor supply shock on Germany in one analysis.

In the second part of the thesis, I go on to analyze the effects of job displacement following a mass layoff on individual workers' labor market trajectories. In Chapter 3 , I start with evidence on the extent to which costs of job loss differ between men and women. In Chapter 4, I add evidence on labor market outcomes after job displacement for migrants compared to native workers. Essentially, displacement is the result of a negative shock to firms' demand. Existing research has documented that such a shock can lead to long-lasting earnings losses for displaced workers (e.g., Jacobson et al. (1993), Couch and Placzek (2010), Davis and von Wachter (2011), Lachowska et al. (2020), Schmieder et al. (2020)) but studies focusing on women and migrants are scarce. Chapters 3 and 4 thus contribute to the emerging literature analyzing costs of job loss by worker type (e.g., Meekes and Hassink (2020), Blien et al. (2020)) and investigate these heterogeneities. 
In the following, I will give a short outline of the three main chapters:

\section{Chapter 2: Crossing Borders: Labor Market Effects of European Integration}

In this chapter, I analyze the labor market effects of an EU policy reform granting, amongst others, Czech citizens free access to the German labor market from 2011 onwards. This policy reform led to a substantial increase in the share of Czech crossborder commuters and I exploit this spatial variation for a difference-in-differences analysis. On the Czech side, the commuter outflow led to a negative labor supply shock and a positive demand shock at the same time. In Germany, the commuter inflow resulted in a positive labor supply shock.

A key innovation of my study is that while most studies in the immigration literature so far focus on either emigration or immigration, I investigate both shocks at the same time. For this purpose, I combine a novel dataset on Czech regions with administrative employer-employee data on Germany from the IAB. I show that municipalities in the Czech border region experienced a decline in unemployment rates as result of the worker outflow, while vacancies increased. For German municipalities, I find no effects on regional native employment, and lower native wage growth in the long term.

For another key contribution to previous literature, I extend the analysis from the regional to the worker level, enabling me to investigate labor market effects of native incumbent workers in Germany. These workers experienced lower wage growth but increased employment such that their earnings relative to workers in the control group remained constant. A heterogeneity analysis shows that low-tenure and medium-skilled workers particularly suffered in terms of lower wage growth, suggesting that the worker inflow increased inequality in the German border region. Overall, this chapter shows that small labor supply and demand shocks can affect local labor markets across borders.

\section{Chapter 3: The Gender Gap in Earnings Losses After Displacement}

In Chapter 3, which is joint work with Johannes Schmieder and Simon Trenkle, we analyze the gender gap in earnings losses after displacement. For this purpose, we exploit displacement resulting from a mass layoff as an unexpected, exogenous shock to job search. We focus on job displacement in 2002-2012 in Germany.

Our key contribution to the literature is that we use an event study design in combination with propensity score matching and a reweighting technique to directly 
compare men and women who are displaced from similar jobs and firms. We thus account for pre-displacement differences in individual and establishment characteristics of women compared to men, enabling us to quantify both the raw gender gap in earnings losses after job displacement, and the composition-adjusted gender gap. We moreover exploit a novel dataset on married couples in Germany, such that we can analyze household dynamics and the role of children.

Our results show that after job displacement, women's earnings losses per year are about 35 percent higher than men's, with the gap persisting five years after job displacement. This is partly explained by a higher propensity of women to take up part-time or marginal employment following job loss, but even full-time wage losses are almost 50 percent higher for women than for men. We then show that on the household level there is no evidence of an added worker effect, independent of the gender of the job loser. Finally, we document that parenthood magnifies the gender gap sharply: while fathers of young children have smaller earnings losses than men in general, mothers of young children have much larger earnings losses than other women.

Chapter 4: Who Suffers the Greatest Loss? Costs of Job Displacement for Migrants and Natives

Chapter 4, which is joint work with Theresa Koch, closely follows Chapter 3 but focuses on the differences in costs of job displacement for migrants compared to native workers. We contribute to two bodies of literature: First, we add heterogeneity with respect to migration status to the literature on job displacement. Second, we also contribute to the literature investigating how sensitive migrants are to adverse economic shocks (e.g., Kondo (2015), Speer (2016), Kahn (2010), Altonji and Blank (1999)). We use the IAB's administrative employer-employee data and focus on job displacements in 2001-2011.

Previous studies have documented that during recessions, migrants are laid off first (e.g., Borjas and Cassidy (2020) and Hoynes et al. (2012)) but there is little evidence on how migrants react to displacement. Given the evidence collected so far, the underlying mechanisms are unclear: On the one hand, if migrants face discrimination in destination countries' labor markets, they may need more time to become re-employed after job loss. On the other hand, migrants may have accumulated less wealth than Germans and thus be particularly motivated to find a new job quickly. This may, for example, translate into a higher geographic mobility of migrant work- 
ers, improving their job search success. Our key contribution in this chapter is that we are the first to quantify differences in costs of job loss for migrants compared to native workers in the German labor market.

For this purpose, we compute each displaced worker's earnings, wage, and employment loss after a mass layoff in comparison to a matched, nondisplaced, control worker. We find that migrants face substantially higher earnings losses than natives due to both higher wage and employment losses. Differences in individual characteristics and differential sorting across industries and occupations can fully explain the gap in wage losses but not the employment gap after displacement. Laid-off migrants are both less likely to become re-employed and work fewer days than laid-off natives. In terms of channels, we show that i) migrants sort into worse establishments and ii) migrants' slightly lower geographic mobility across federal states may explain part of their lower re-employment success; iii) our results suggest that competition from other migrants, rather than natives, negatively contributes to migrants' costs of job loss.

Overall, the results from Chapters 3 and 4 confirm previous evidence that job loss has large and persistent detrimental effects on workers. They moreover show that these displacement effects vary substantially across worker types: Women and migrants, which are minorities in the German labor market, are more negatively affected.

This thesis provides important insights into the economic forces at play as a result of labor market shocks. In particular, it sheds light on how individual workers react to labor market disruptions, and the challenges they face. The ultimate goal of my work is to both add new aspects to the scientific discussion, as well as to provide relevant evidence for policy-makers designing active labor market policies. The empirical methods used in this thesis can moreover be applied to future research. I describe some of the possible avenues for future research in the concluding remarks. 


\section{Chapter 1}

\section{State of the Art in Labor Economics}

Before starting with the empirical part of the thesis, this chapter introduces the state of the art in the relevant Labor Economics literature with respect to immigration and displacement shocks. Starting with immigration, I summarize the first study using a natural experiment to estimate the labor market effects of an immigration shock, Card (1990), and the debate around it. Card (1990) inspired a number of studies in empirical migration research to use natural experiments, and I will discuss a selection of them. I conclude with a review of studies focusing on recent intraEU immigration. ${ }^{1}$ This is also the most relevant literature that I contribute to empirically with Chapter 2 in this thesis.

The second part of this chapter focuses on displacement shocks, where I first introduce the pioneering literature empirically investigating costs of job loss with large administrative datasets in the US. The study by Jacobson et al. (1993), in particular, served as a starting point for many papers exploring costs of job loss. More recent studies slightly shifted the focus, looking at displacement costs over the business cycle, and heterogeneity by worker type in costs of job loss. Chapters 3 and 4 in this thesis contribute to this literature by empirically investigating costs of job loss separately by gender and migration status.

\footnotetext{
${ }^{1}$ Note that while I focus on migration flows in the context of European integration, there exists also a large literature analyzing labor market effects of foreign direct investment after the fall of the iron curtain. Examples are Borrs and Eppelsheimer (2020), Körner et al. (2021), and Bachmann et al. (2014).
} 


\section{$1.1 \quad$ Immigration Shocks}

This section summarizes the state of the art literature on immigration shocks with a focus on empirical evidence rather than structural economic models. In each subsection, I picked papers whose research question and empirical approach I found particularly relevant for this thesis. ${ }^{2}$

From a theoretical point of view (see also Section 2.3 in Chapter 2 of this thesis), an immigration shock corresponds to a positive labor supply shock (Borjas (2014)). Assuming that firms cannot adjust capital in the short run, the neoclassic model would thus predict a decrease in native workers' wages, and possibly employment, as a result of an immigrant worker inflow. This holds if labor markets are perfectly competitive. At the same time, consumption of goods and services by immigrants in their destination country may counteract some of the negative effects. It is moreover important to understand whether immigrant workers are substitutes or complements for native workers. If they are substitutes, one would expect negative wage effects; if they are complements, native workers could even benefit.

In general, it is difficult to identify causal effects of migration flows in empirical work. The reason for this is that migrant workers choose their destination workplace endogenously. If migrant workers strive to maximize their returns from migration, they will sort into areas which are economically thriving, where labor demand for their type of skills is high, and where firms pay high wages (Edo (2019)). Put differently, migrants may move to places where they can maximize returns to their skills (Borjas (1987)). Now suppose that migrants moved exclusively to places with thriving economic conditions - then, empirical research would underestimate labor market effects from these migration flows. To circumvent this problem, starting with Card (1990), researchers use so-called natural experiments as exogenous immigration shocks to estimate their effects on native workers.

The basic idea in these papers is that some regions are more affected by migrant inflows (e.g., because they are geographically closer to origin countries), and that this is exogenous to their economic prosperity. The key identifying assumption of empirical approaches using such natural experiments is that before the shock happens, outcomes in the treated region and in adequate control regions evolve in parallel

\footnotetext{
${ }^{2}$ For a comprehensive overview of migration literature including both structural and empirical work, see Edo (2019). For an overview of immigration in OECD countries, see Edo et al. (2020).
} 
trends. Trends then start diverging only after the shock, such that all differences in labor market outcomes must be due to the consequences of the treatment.

With respect to their findings, existing studies are quite inconclusive. Some find positive wage effects for native workers (e.g., Beerli et al. (2021)), others find neither wage nor employment effects (e.g., Friedberg (2001) and Card (1990)), and further studies find small negative effects on native wages and/or employment (e.g., Dustmann et al. (2017), Glitz (2012) and Cohen-Goldner and Paserman (2011)). When comparing these studies, one has to keep in mind that they investigate immigration in different contexts: The countries under study and the time periods differ, and this can partly explain differences in findings.

In the following, I will first discuss the famous Mariel Boatlift Study by Card (1990) and the debate evolving around it. In this part, I will also emphasize the challenges researchers face when empirically estimating the labor market effects of immigration. The Mariel Boatlift Study has inspired a number of studies in empirical migration research using natural experiments, some of which I summarize in Sections 1.1.2 and 1.1.3. In Section 1.1.2, I first discuss three studies on labor market effects of immigration outside the US. In Section 1.1.3, I then give an overview of recent immigration studies focusing on cross-border commuting in the context of European integration. These studies also inspired Chapter 2 in this thesis, in which I contribute to the literature with evidence on a policy reform which permanently suspended immigration restrictions in the European Union.

\subsubsection{The Mariel Boatlift Study}

The most prominent of the migration studies using a natural experiment to quantify the labor market effects of a migration shock is Card (1990) (Mariel Boatlift Study) who was the first to exploit such a natural experiment. It focuses on Cuban migration to the US in 1980 and provides a text book setting for an unexpected, exogenous immigration shock. In April 1980, a declaration by Fidel Castro allowing out-migration from a specific Cuban port led to the unexpected outflow of about 125,000 Cubans $^{3}$ to Miami (Card (1990)). The idea behind the empirical approach

\footnotetext{
${ }^{3}$ At the time, this corresponded to an increase in the labor force in Miami of $7 \%$, a relatively large shock compared to other settings.
} 
is that the Cubans did not move to Miami because of its economic conditions but because it was the geographically closest US port.

More than $50 \%$ of these Cuban immigrants did not have a high school degree, meaning that they were predominantly unskilled. Using a difference-in-differences approach where he compares wage and employment trajectories of native workers in Miami to workers in four comparison cities, Card (1990) shows that wages and unemployment rates of unskilled workers in Miami were barely affected by the inflow. He explains this by the fact that Miami had already received other large waves of immigration before the Mariel Boatlift, and its labor market was therefore well prepared to absorb the immigration shock.

While the Mariel Boatlift Study is very famous, it has also been subject to a fierce academic debate. Starting point for this debate is the paper by Borjas (2017) who argues that it is not enough to investigate labor market effects on the lower educated pre-existing workforce; instead, it is crucial to focus on the group which comes closest to Cuban workers in terms of skills: High-school dropouts. Borjas (2017) finds that for this group of workers, wages indeed decreased by 10 to $30 \%$ (depending on the control group).

Shortly afterwards, Peri and Yasenov (2019) published a paper where they compare the Miami labor market around 1980 to a synthetic control group which matches labor market characteristics in the eight years preceding the inflow of Cubans. Their results are in line with those by Card (1990), suggesting that native workers' wages and unemployment rates remained unaffected. They argue that the findings in Borjas (2017) are partly due to his focus on a narrow sub-sample which excludes women, non-Cuban Hispanics, and workers outside the age range 25-59. As a result, the estimation sample is very small and subject to large measurement error. In his reply, Borjas (2016) argues that Peri and Yasenov (2019), amongst other factors, ignore the effect of an increase in female labor supply, which contaminates their results.

In another study on the debate, Clemens and Hunt (2019) present one explanation for the differences in results: They argue that the discrepancies are largely due to a change in the Current Population Survey's (CPS) race composition. The CPS is the dataset which all three studies - Card (1990), Borjas (2017), and Peri and Yasenov (2019) - use for their research. Clemens and Hunt (2019) show that in 1981, the CPS started to survey more black men without a high school degree relative to black 
men with a high school degree. This means that almost coinciding with the Cuban inflow, the CPS now contained a much higher share of black high school dropouts. Clemens and Hunt (2019) show that this can entirely explain the negative wage effects found by Borjas (2017).

The Mariel Boatlift Study and the debate around it is a good example for how careful researchers have to be when collecting empirical evidence on the labor market effects of migration flows. This holds in particular because this evidence has the potential to impact policy debates, e.g., on barriers to immigration. As the Mariel Boatlift Study debate shows, it is thereby particularly important to know the pitfalls of one's dataset and to be transparent about the subgroups excluded.

\subsubsection{Labor Market Effects of Immigration Outside the US}

In this section, I introduce three studies following Card (1990) in using natural experiments to quantify the labor market effects of immigration outside the US. I will start with Glitz (2012) who analyzes the impact of ethnic German immigration from Eastern Europe and the former USSR to Germany following the fall of the iron curtain. Related to this study is the paper by Cohen-Goldner and Paserman (2011) who analyze the impact of immigration from the former USSR to Israel. Finally, I summarize the study by Angrist and Kugler (2003) who estimate the effects of the refugee inflow as a result of the Balkan wars on European labor markets.

In his study, Glitz (2012) exploits a policy implemented shortly after the fall of the iron curtain, as part of which ethnic Germans from Eastern Europe and the former USSR could move to Germany and become German citizens. Importantly, these migrants were - with respect to their skill levels - exogenously distributed across Germany according to a law introduced in 1989, and modified in 1996 (Wohnortzuweisungsgesetz). The distribution mechanism was based on the proximity of family members and involved sanctions in case of non-compliance. Glitz (2012) therefore argues that the scope for ethnic Germans to select into thriving labor markets was very limited.

The empirical identification in Glitz (2012) hinges on differences in the relative skill supplies across regions induced by the immigrant inflow of ethnic Germans. In his regression model, he exploits time variation in a region's skill composition, and uses immigrant inflows to instrument for potentially endogenous changes in 
this composition. All in all, Glitz (2012) does not find significant effects on native workers' wages. With respect to employment, he finds that for 10 immigrant workers entering the German labor market, 3.1 native workers lose their job.

Cohen-Goldner and Paserman (2011) analyze a very similar immigration policy: The post-1990 inflow of migrants from the former USSR to Israel. They exploit time variation in the share of immigrants in a particular labor market segment ${ }^{4}$ and focus on differences in short and long run effects. Cohen-Goldner and Paserman (2011)'s line of argument is that they expect negative effects in the short run if migrants are substitutes for natives; in the long run however, they expect capital to adjust, leading to an increase in labor demand. Their empirical results support this theoretical expectation: They show that a 10 percent increase in the immigrant share reduces native workers' wages by $1-3 \%$ in the short run. In the long run, this negative wage effect disappears. For employment, they find no effect neither in the short nor long run.

The last paper to which I refer in this subsection investigates the employment effects of refugee migration from the Balkans to Western European countries. In the paper, Angrist and Kugler (2003) focus on the extent to which these employment effects vary by flexibility of destination countries' labor market institutions. They exploit the fact that the Balkan wars in the 1990s led to large refugee waves from Bosnia and Kosovo to Western Europe ${ }^{5}$. For their empirical strategy to identify causal effects, Angrist and Kugler (2003) thus instrument the immigrant share by the distance from Sarajevo (the capital of Bosnia) and the distance from Pristina (the capital of Kosovo) which they interact with dummies for the years of the Balkan war. For male native workers in Western Europe, they find that in countries with less flexible institutions, the refugee inflow led to a decrease in employment.

The studies I discussed in this subsection all focus on the permanent relocation of a group of migrants to their destination country. Recent research has also investigated cross-border commuter flows in the context of European integration. Commuting is a particularly interesting type of migration, since it allows to isolate labor supply

\footnotetext{
${ }^{4}$ Note that Cohen-Goldner and Paserman (2011) introduce different definitions of labor market segments. These are: 2-digit occupations, schooling interacted with potential experience, and 1digit occupations interacted with i) residence district, ii) schooling, and iii) 1-digit industry.

${ }^{5}$ Throughout their paper, Angrist and Kugler (2003), when they refer to "Western Europe", focus on the 15 states which were members of the EU before its enlargement in 2004. They moreover add Iceland, Switzerland, and Norway.
} 
effects (migrant worker inflow) and labor demand effects (consumption by migrant workers). In the next subsection, I present three studies analyzing cross-border commuting.

\subsubsection{Labor Market Effects of Cross-Border Commuting}

A number of recent studies analyze the effects of intra-EU migration. One prominent example is Dustmann et al. (2017) who investigate the labor market effects of a crossborder commuting policy reform at the beginning of the 1990s. ${ }^{6}$ This reform allowed Czech workers to commute to the German border region, and Dustmann et al. (2017) investigate the impact of this cross-border migration on native workers in the affected counties. In a similar direction, Beerli et al. (2021) analyze the labor market effects of a Swiss commuting policy change in the early 2000s. Finally, Bütikofer et al. (2020) focus on the construction of the Öresund bridge which connects Sweden to Denmark. In contrast to the papers by Dustmann et al. (2017) and Beerli et al. (2021), they study labor market effects of out-migration rather than in-migration.

Let me first start by summarizing the study by Dustmann et al. (2017) which served as a starting point for Chapter 2 in this thesis. For their empirical strategy, Dustmann et al. (2017) exploit a policy reform which opened the German labor market for Czech workers in districts located up to 80 kilometers from the West German border. They show that two years after the implementation of this policy, the share of Czech workers in the border region had increased from virtually zero to about 3 percent. Using the IAB's worker-level data, Dustmann et al. (2017) estimate the effect of this worker inflow on regional native wages and employment.

They use several strategies to identify causal effects: First, they estimate instrumental variable regressions where they instrument the share of Czech commuters in a given region by distance to the Czech-German border. In one approach, they compare the evolution of native wages and employment in the border region with the employment and wage trajectories in a sample of matched control counties. In another approach, they focus on variation in the share of Czech commuters within the German border region itself. Last, they show that their results also hold if they generate a synthetic control group to which they compare the evolution of labor

\footnotetext{
${ }^{6}$ Note that Moritz (2011) exploits the same commuting policy to study its wage effects on the German labor market.
} 
market outcomes in the border region. Their main result is that the policy reform decreased native workers' wages by about $0.13 \%$, and native employment by $0.93 \%$. While Dustmann et al. (2017) find negative effects of a commuter inflow on native wages, Beerli et al. (2021) find that certain subgroups of native workers may also benefit. They analyze a commuting policy reform in Switzerland at the beginning of the 2000s, which gave European cross-border commuters free access to the Swiss labor market. For their empirical strategy, similar to Dustmann et al. (2017), they exploit the fact that this policy reform only affected Swiss border regions. For their baseline analysis, they estimate the differential effects on native workers in regions located up to 30 minutes from the border compared to natives in the rest of the border region (i.e., regions in the border region, but located more than 30 minutes from the border).

The policy change led to a substantial increase in the share of cross-border commuters, which amounted to 10 percentage points in municipalities located up to 15 minutes from the border. Beerli et al. (2021)'s main finding with respect to workers' labor market outcomes is that as a result of the commuter inflow, high-skilled native workers' wages increased by $4.6 \%$. The major innovation of their study is that they complement this result with evidence from the firm side: They show that one channel driving the positive labor market effects of the policy reform is an increase in skill-intensive firms' labor demand.

Recent studies on intra-EU migration have focused not only on the destination country's point of view, but also on the sending country's. One example is the study by Bütikofer et al. (2020) who investigate the labor market effects of the construction of the Öresund bridge connecting Sweden and Denmark on the Swedish labor market. In their empirical approach, they rely on a difference-in-differences framework where they compare the region most affected by the bridge's construction, Malmö, to other municipalities and cities in Sweden, before and after the opening of the bridge in 2000 .

They show that 8 years after the opening of the bridge, residents of Malmö were 5.3 percentage points more likely to work in Denmark than residents of control municipalities. As a result, wages in Malmö increased by $15 \%$ compared to the control group. Interestingly, the benefits of wage increases concentrated in particular worker groups: High-skilled men gained the most, whereas low-skilled women gained the least. 
In Chapter 2 of this thesis, I add to this part of the literature by analyzing a policy reform which allowed workers from Central and Eastern Europe to work in Germany without formal restrictions such as work permits. As a contribution to the existing literature, my data allow me to investigate local labor market effects on both one origin and one destination country simultaneously: Czech Republic and Germany. As I will argue in Chapter 2, this enables me to better understand the general equilibrium effects of immigration shocks.

\subsection{The Effects of Job Displacement}

Immigration shocks can have a lasting impact on workers' employment biographies. However, the effects are ambiguous: Depending on the immigration policy and migrant workers' skills, the impact can be both positive and negative. In contrast, it is a well-established empirical fact that job displacement is devastating for a displaced worker's career in the long term. According to theory, (involuntary) job displacement is costly for several reasons: First, workers may lose firm-specific human capital when forced to switch jobs (e.g., Becker (1962), Mincer (1962)), they may lose worker-firm match quality (e.g., Jovanovic (1979)), and they lose wage benefits stemming from seniority (e.g., Lazear (1981)). ${ }^{7}$ ) In this section, I summarize existing empirical studies on the labor market effects of displacement which exploit mass layoffs as exogenous shocks.

Similar to the labor market effects of immigration, it is a challenge to identify causal effects of job loss. First of all, in administrative data, one typically cannot observe why workers leave their jobs. For example, workers may quit to switch to a position with higher pay, or firms may lay off workers if they are bad matches. To circumvent this issue, existing research - starting with the seminal study by Jacobson et al. (1993) - exploits mass layoffs as exogenous shocks to workers' employment biographies. These studies typically focus on high-tenured workers, where it is plausible to assume that displacement is involuntary and unexpected.

Ideally, one would like to observe outcomes of a displaced worker both in a situation where he/she loses his/her job, and in a situation where he/she does not lose his/her

\footnotetext{
${ }^{7}$ Note that in addition to its economic costs, job loss can come along with other costs, such as poorer health and higher mortality (e.g., Schaller and Stevens (2015), Sullivan and Von Wachter $(2009)))$.
} 
job, simultaneously. The difference in outcomes, e.g. earnings, would then indicate the economic effects of displacement. Since this is not possible, researchers have chosen a different approach: They compare displaced workers to their statistical twins, where they assign each displaced worker a twin based on individual characteristics before displacement.

With this empirical strategy, the key identifying assumption is that displaced and non-displaced workers' labor market trajectories would have evolved in the same way in absence of the treatment - job displacement. The main idea is that the probability of losing one's job is basically identical between a displaced worker and his non-displaced worker match before treatment. All differences in outcomes must therefore be due to the displacement shock.

Starting with Jacobson et al. (1993), existing studies on job displacement have documented large and persistent earnings losses for displaced workers, both for the US and Germany. While Jacobson et al. (1993) inspired other researchers to investigate costs of job loss empirically, their empirical approach was subsequently developed further: For example, Couch and Placzek (2010) were the first to combine the fixed effects model à la Jacobson et al. (1993) with a matching strategy. Other research has shown that costs of job loss are highly cyclical, meaning that displaced workers particularly suffer from displacement in economic downturns (e.g., Davis and von Wachter (2011) and Schmieder et al. (2020)). Most of the displacement literature so far has focused on men, but more and more papers are exploring heterogeneity across worker types (e.g., Blien et al. (2020) and Meekes and Hassink (2020)).

In the following subsections, I will first introduce three studies on the US which are using administrative data to estimate displacement costs from the 1980s until the Great Recession. Then, I continue summarizing studies focusing on how costs of job loss vary with the business cycle. Finally, I discuss research with a focus on heterogeneity in the labor market effects of displacement. By providing evidence on difference in costs of job displacement by gender and migration status, Chapters 3 and 4 in this thesis contribute to this latter part of the literature, in particular.

\subsubsection{Estimating Costs of Job Displacement in the US}

In the following subsection, I summarize three studies estimating costs of job loss using large administrative datasets from the US. This approach was pioneered by 
Jacobson et al. (1993) who focused on job displacement in the 1980s in Pennsylvania. About 20 years later, Couch and Placzek (2010) extended their empirical approach by a matching model, enabling them to find suitable controls for their sample of displaced workers. More recently, Lachowska et al. (2020) investigated the sources behind earnings losses after displacement.

Jacobson et al. (1993) were the first to analyze costs of job loss using a large administrative dataset spanning several years - a $5 \%$ random sample of the workforce in Pennsylvania. In the displacement literature, their study is regarded as pioneering work, since they were the first to estimate a panel model with time and worker fixed effects to investigate costs of job loss. This allowed Jacobson et al. (1993) to control for unobserved, time-constant worker heterogeneity and for time-specific shocks. Moreover, their event study regression model allowed them to quantify earnings losses by quarter since job displacement.

In their paper, Jacobson et al. (1993) focus on a sample of prime-age workers with 6 or more years of tenure at time of displacement. Then, they identify a sample of workers displaced in a mass layoff ${ }^{8}$ in 1980-1986. They go on to compare earnings of workers identified to have been displaced in a mass layoff to workers who remained at their respective firm up to 1986. Their main finding is that displaced workers face earnings losses of, on average, $25 \%$ per year.

One critique of the study by Jacobson et al. (1993) is that they may overestimate costs of job loss, given that they compare displaced workers to a sample of workers with very stable employment biographies. Moreover, displaced workers may constitute a negative selection in terms of observable characteristics. To take this into account, Couch and Placzek (2010) improve on their empirical strategy by using propensity score matching to match displaced workers to a suitable control group based on pre-displacement characteristics.

With this extended empirical approach and for a sample of workers in Connecticut from 1993-2004, the long-term earnings losses Couch and Placzek (2010) identify are $12 \%$, and thus about half the size of the earnings losses estimated by Jacobson et al. (1993). Couch and Placzek (2010) argue that their results may be more externally valid for two additional reasons: First, Jacobson et al. (1993) work with data from Pennsylvania in the 1980s; at that time, the state struggled with several economic

\footnotetext{
${ }^{8} \mathrm{As}$ in most of the subsequent literature, Jacobson et al. (1993) define a decrease in a firm's workforce by at least $30 \%$ in a given year as a mass layoff event.
} 
issues, e.g., changes in the industry structure and high import penetration. Second, the economy in Pennsylvania was dominated by the manufacturing sector, but the service sector has become more and more important since the 1980s.

While Jacobson et al. (1993) and Couch and Placzek (2010) focus on estimating overall earnings losses for displaced workers, recent work investigates the sources of these earnings losses. One example is the study by Lachowska et al. (2020) who analyze three components of earnings losses: Employer effects, match effects, and a residual which they argue includes scarring effects and losses in seniority. Lachowska et al. (2020) use worker-level data from Washington State and follow Jacobson et al. (1993) and Couch and Placzek (2010) in their empirical approach. Their data allows them to decompose earnings losses into wage and employment losses, and they show that a decline in hourly wages can account for $70 \%$ of displaced workers' earnings losses.

To identify employer effects as a proxy for firm wage premiums, Lachowska et al. (2020) compute firm-specific fixed effects following Abowd et al. (1999). Then, they analyze to what extent switches from firms with high fixed effects to firms with lower fixed effects can explain displaced workers' wage losses. They find that such switches can only explain $17 \%$ of wage losses. Instead, changes in match effects ${ }^{9}$ can account for $57 \%$ and thus the large part of wage losses.

\subsubsection{Displacement Costs and The Business Cycle}

It is undisputed that individual workers' costs of displacement can be large and persistent, and there is also evidence that these costs vary with the underlying economic situation. In the following, I will briefly introduce two studies analyzing costs of job loss during the business cycle. The first study by Davis and von Wachter (2011) focuses on the US, while the second study by Schmieder et al. (2020) focuses on Germany.

Davis and von Wachter (2011) show that earnings losses are particularly high during recessions. To illustrate this, they use administrative data for male workers in the US spanning over more than three decades (1974-2008). They show that the higher the national unemployment rate, the higher displaced workers' earnings losses: If the

\footnotetext{
${ }^{9}$ Lachowska et al. (2020) compute these match effects, which proxy worker-employer skill fits, using the fixed effects estimator introduced by Woodcock (2015).
} 
unemployment rate is below $6 \%$, displaced workers lose, on average, 1.4 years of predisplacement earnings. With an unemployment rate above $8 \%$, this loss increases to 2.8 years of pre-displacement earnings. Davis and von Wachter (2011) moreover use survey data to show that not only economic costs, but also psychological costs are higher during recessions: Fear of job loss substantially increases.

A recent paper by Schmieder et al. (2020) analyzes sources of job displacement costs over the business cycle in Germany. For this purpose, they use linked employeremployee data spanning from 1975 to 2009, provided by the IAB. Similar to Davis and von Wachter (2011), they find that yearly earnings losses from job displacement are twice as high during recessions.

With respect to the underlying channels, Schmieder et al. (2020) show that while re-employment rates explain initial earnings losses, cyclical wage losses are one important driver behind displaced workers' long-term earnings losses. These cyclical wage losses can to a large extent be explained by a decrease in establishment size and - most importantly - wage premia after displacement, which are substantially larger during recessions.

\subsubsection{Heterogeneity in Job Displacement Costs}

Most of the standard job displacement literature using large administrative data sets to identify costs of job loss focuses on men, with little effort to explore heterogeneities. Recent papers, however, acknowledge that costs of job loss can differ dramatically by worker type. In this subsection, I introduce three of them: Blien et al. (2020) explore heterogeneity in costs of job displacement by an occupation's routine intensity, Helm et al. (2021) focus on differences by low- and high-wage workers in the manfacturing sector, and Meekes and Hassink (2020) study heterogeneity by gender. Note that this is also the part of the job displacement literature to which I contribute to with Chapters 3 and 4 of this thesis.

Blien et al. (2020) investigate to what extent costs of job loss vary by the extent of routine intensity in workers' occupations. Using German administrative employeremployee data from the IAB, they focus on job displacements in 1980-2010. Given that technological change decreases firms' demand for workers in routine-intensive occupations, they explore whether these workers particularly suffer from displacement. 
Comparing similar workers in similar occupations, but at different quartiles of the distribution of routine intensity, Blien et al. (2020) find that workers in routineintensive occupations face substantially higher costs of job loss. Decomposing earnings losses into wage and employment losses, Blien et al. (2020) show that this result is mainly driven by a much larger decline in days worked for these types of workers. They conclude that workers need time to adjust to technological change.

In a similar direction, Helm et al. (2021) explore displacement costs in the German manufacturing sector, where they differentiate between low- and high-wage workers. They use the same dataset as Blien et al. (2020) for the time period 1975-2014. They focus on the extent to which losses in firm wage premia (particularly for displaced workers switching to the service sector) can explain wage losses. Their main result is that these losses in firm wage premia are particularly large for lowwage manufacturing workers, and that they increased over time. This is partly due to a trend of displaced manufacturing workers switching to lower-quality jobs in the service sector.

Another type of heterogeneity recent research explores is differences in costs of job loss by gender (see also Chapter 3 of this thesis). Meekes and Hassink (2020) use Dutch administrative data in 2006-2017 to explore differences in how men and women react to job loss following a firm bankruptcy. They find that women experience longer unemployment durations after displacement. In contrast, women's losses in hourly wages are slightly smaller than men's.

Exploring this result in more detail, Meekes and Hassink (2020) show that displaced women are more likely to reduce hours worked and their commuting distance after job loss, suggesting that they particularly value flexibility in working conditions. Meekes and Hassink (2020) argue that women's longer unemployment duration suggests that they extended the job search period to find a job allowing more flexibility. This holds in particular for women who are pregnant at time of job loss.

All of these three studies show that when quantifying the costs of job displacement, it is important to consider who is laid off. Chapters 3 and 4 of this thesis contribute to the existing empirical literature on job displacement by highlighting the importance of these heterogeneities. In both chapters, my coauthors and I apply a reweighting algorithm which enables us for the first time to compare men and women (Chapter 3) and migrants and natives (4) with similar pre-displacement individual characteristics, and displaced from similar jobs. 
To conclude, let me emphasize that analyzing these heterogeneities also has implications for theoretical and empirical research outside the study of job displacement. For example, analyzing costs of job displacement by gender can help to understand the gender gap in wages and earnings over the lifecycle. This thesis (and in particular Chapter 3) thus also ties into the literature investigating the gender wage gap across countries and time (e.g., Blau and Kahn (2003), Olivetti and Petrongolo (2008), Albrecht et al. (2018), Goldin et al. (2017)).

Similarly, investigating to what extent costs of job displacement differ by migration status as in Chapter 4 is particularly relevant to understand the challenges migrants face with respect to labor market integration. This thesis thus also relates to previous research which has shown that migrants are more vulnerable than natives during recessions (e.g., Freeman et al. (1973), Borjas and Cassidy (2020), Couch et al. (2020), Montenovo et al. (2020)). It is moreover connected to studies showing how important it is for migrants to successfully integrate into destination countries' labor markets, both for them to become important fiscal contributors (Dustmann and Frattini (2014)) and for the second generation (e.g., Gang and Zimmermann (2000), Riphahn (2003), Casey and Dustmann (2008), Dustmann (2008), Algan et al. (2010), or Dustmann et al. (2012)). 
Chapter 2

Crossing Borders: Labor Market Effects of European Integration 


\subsection{Introduction}

The consequences of worker outflows and worker inflows are at the core of recent policy debates in OECD countries. Origin countries, some of which struggle with ageing populations and skilled worker shortages ${ }^{1}$, worry about dampened economic growth as a result of talent outflows. In destination countries, the policy debate often revolves around fears that migrant inflows depress wages and take away native workers' jobs. In both, there are public discussions on whether emigration and immigration may have contributed to the rise of populism in recent years.

While there is a large literature on the labor market effects of in-migration on destination countries (e.g., Beerli et al. (2021), Dustmann et al. (2017), Ottaviano and Peri (2012), Borjas (2003), Card (1990)), and a somewhat smaller literature on the consequences of out-migration on origin countries (e.g., Bütikofer et al. (2020), Dustmann et al. (2015), Aydemir and Borjas (2007)), no study so far analyzes the impact of one immigration policy on both origin and destination countries simultaneously. Yet to better understand the welfare effects of migration flows, it is essential to take into account the consequences of both worker outflows and worker inflows.

This study is the first to investigate labor market effects of both out-migration and in-migration resulting from the same policy reform. For this purpose, I take advantage of an ideal case study in the context of intra-European immigration. ${ }^{2}$ In 2011, Germany opened its labor market to workers from eight Central and Eastern European countries, including its neighbouring country Czech Republic.

As a result, cross-border commuter flows from the Czech Republic to Germany substantially increased, resulting in a negative (positive) labor supply shock on the Czech (German) side of the border. As Figure 2.1 shows, the migrant share by total employment in the German border region increased from about 2\% in 2010 to about 5\% in 2017 for Czech workers. The setting is ideal to study what happens when two formerly separated labor markets, which are located in close geographic proximity, fully integrate in the long term.

\footnotetext{
${ }^{1}$ To give an example, half of Central, Eastern, and Southeastern European countries are expected to loose $5 \%$ of their population by 2030 , and $15 \%$ by 2050 (Batog et al. (2019)).

${ }^{2}$ The European Union was subject to particularly large migration flows from East to West since 2004. In 2009, 4.8 million workers from Eastern Europe were employed in the West, about three times more than in 2003 (Holland et al. (2011)). Recent studies document sharp increases in migration flows resulting from labor market openings in the course of the 2004 EU enlargement (e.g., Bratsberg et al. (2019) and Schmieder and Weber (2018)).
} 
Figure 2.1: Inflow of Czech Workers - No Controls

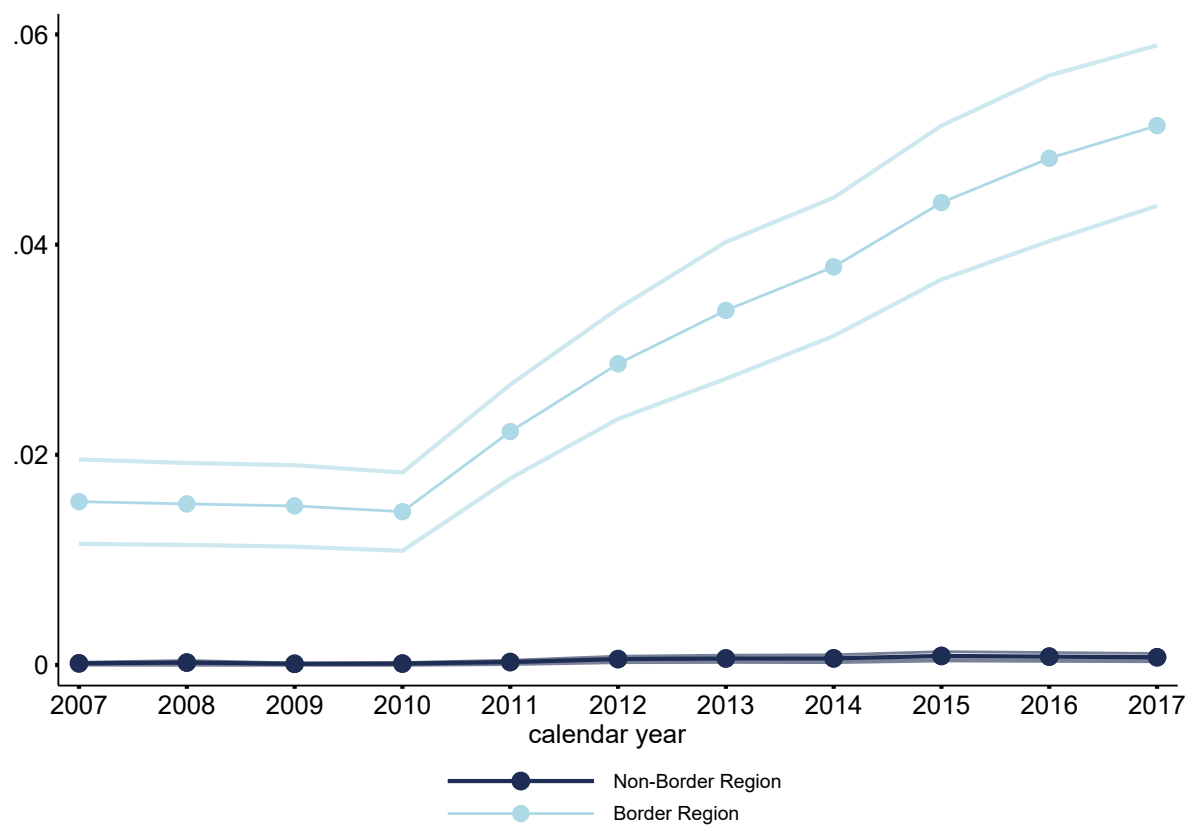

Notes: This figure shows the inflow of Czech workers to the West German border region after the opening of the German labor market in 2011. The y-axis plots the average share of Czech employment in a municipality by overall employment in the municipality (without controls) for German treated (light blue line) and control (dark blue line) municipalities, respectively. Treated municipalities are all municipalities located up to $40 \mathrm{~km}$ from the nearest road border crossing to the Czech Republic (measured by airline distance from municipality centroid). Control municipalities are matched using propensity score matching (see Section 2.5 for more details). West Germany only. Data are aggregated at the municipality level. 95-\% confidence intervals reported. Source: Integrated Employment Biographies (IEB). 
My analysis shows that the majority of Czech workers started commuting to German municipalities in close proximity to the border, suggesting that location rather than a municipality's economic prosperity played a role in Czech workers' mobility decisions. I exploit this exogenous spatial variation, in addition to the timing of the policy reform, for a difference-in-differences type of analysis. This helps me to estimate causal effects of both worker emigration and immigration on local labor markets in both countries. The fact that I explore a case of cross-border commuting means that in my setting, both supply and demand shocks are at play. For the Czech Republic, the canonical model on labor supply predicts that as a result of the worker outflow, wages - and possibly employment - of stayers in the border region will increase. At the same time, Czech commuters earning relatively higher wages in Germany will most likely raise demand for goods and services in their home country. For Germany, the standard model predicts a decrease in wages, and possibly employment, as result of the commuter inflow. Positive demand effects by Czech workers will not, or at most partly, counteract these effects.

In the first part of my study, I use a novel regional dataset with information on Czech municipalities and counties to measure the impact of out-migration on the Czech border region. I find that as a result of the policy change, unemployment rates in the border region decreased in the long term, while vacancies increased. I complement this with an analysis on regional labor market effects in Germany, where my results point to long term slower wage growth of native workers in the border region.

In the second part of my analysis, I use worker-level data for Germany to better understand margins of adjustment in response to the Czech worker inflow. Descriptive statistics on the characteristics of Czech compared to native workers show that both groups have almost identical levels of education, with Czechs being slightly more likely to have vocational training or a university degree. For a cohort of workers employed in the border region in 2010, I first document that they faced lower wage growth than workers in the control region. I then show that these workers responded by increasing employment such that their earnings remained constant.

It is important to note that throughout this paper, I focus on the Czech Republic and West Germany. Migration from Central and Eastern Europe to East Germany, which shares a border with both Czech Republic and Poland, increased after 2011, too. Regional labor market effects resulting from this worker inflow to East Germany, 
which I discuss in Section 2.7, are slightly weaker but comparable to those in the West. My decision to focus on West Germany in this paper stems from the fact that there are still structural differences between East and West Germany today, e.g. in terms of wages. This makes it a challenge to directly compare the two.

The opening of the German labor market to Czech workers in $2011^{3}$ was the result of one of the largest policy reforms in the history of the European Union: The accession of eight Central and Eastern European countries in 2004. One important pillar of European legislation is the free movement of labor within the union. When Germany granted this free movement to Czech workers in 2011, they were allowed to work in Germany without visa or work permit, and with exactly the same rights as German nationals. Given substantially lower wages in Eastern compared to Western Europe, this resulted in migration flows from East to West but very few German workers started commuting to the Czech Republic from 2011. ${ }^{4}$

My empirical strategy to estimate the effects of the free movement of labor policy is as follows: First, I define treatment and control regions. For the Czech Republic, my treatment group is defined as all counties bordering either Germany or Austria. ${ }^{5}$ For Germany, the treatment group are all municipalities located up to $40 \mathrm{~km}$ from the nearest road border crossing to the Czech Republic. In a next step, I match the border region to control regions using propensity score matching for both Czech Republic and Germany. Using the matched sample, I then estimate a regional-level eventstudy regression model. In the second part of my analysis, I make use of the high-quality German worker-level social security data at the Institute for Employment Research (IAB) and use DiNardo et al. (1996) reweighting to compare a cohort of German workers in the treated municipalities to workers in the control municipalities. ${ }^{6}$ I hereby focus on workers who were already employed in the matched municipalities in 2010, and I thus call them incumbent workers throughout this

\footnotetext{
${ }^{3}$ While Eastern European countries entered the EU already in 2004, Germany delayed access to its labor market for seven years. See Section 2.2 for a more detailed overview of the integration process.

${ }^{4}$ According to data provided by the Czech Statistical Office, the average monthly gross wage in Czech regions bordering West Germany in 2010 was about 840 EUR. The average monthly gross wage of a German worker on the other side of the border in 2010 was about twice that size.

${ }^{5}$ The Czech Republic has a long border with both Germany and Austria. Austria, which is economically comparable to Germany, also opened its labor market for Czech workers in 2011.

${ }^{6}$ To be more exact, I reweight workers in the treated municipalities to workers in the control municipalities using a set of pre-treatment individual and establishment characteristics. This serves to satisfy the key identifying assumption of no differential pre-treatment trends in the differencein-differences model. I explain this approach in more detail in Section 2.5.
} 
paper. Estimating eventstudy regression models at the individual level, I quantify effects of the commuter inflow on incumbent native workers' earnings, wages, and employment. I moreover explore heterogeneity with respect to skills, tenure, and geographic mobility.

My empirical results for the Czech Republic are in line with standard model predictions on the effects of a negative labor supply shock. For the Czech border region, I find that unemployment rates decreased by on average 0.5 percentage points in the years after the labor market opening, suggesting that not only Czech commuters but also Czech stayers benefited from the policy change. At the same time, I find that vacancies in the border region increased by on average 2.36 jobs in $2014^{7}$. Using county-level data, I moreover show that after 2011, the number of applicants per job in Czech border municipalities decreased. This evidence points to local Czech firms facing difficulties to hire new workers as a result of the commuter outflow.

In the German border region, native wages on average grew about $2 \%$ slower after 2011 than in control municipalities. Eventstudy coefficients, albeit not statistically significant, moreover suggest a short-term drop in native employment after 2011 which then gradually started to increase again. Using the rest of Bavaria as control region or using synthetic control group matching confirms this pattern, with the short-term wage drop being much more pronounced. In addition, I find that the workforce composition in the border region changed, resulting in fewer high-skilled and younger workers.

In the next step, I focus on a cohort of German workers employed in the matched municipalities in 2010. As predicted by standard theory, I find long-term negative wage effects (around 1\% lower wage growth than in control municipalities) which

\footnotetext{
${ }^{7}$ The average unemployment rate in a border municipality in 2010 was $9 \%$, and the average border municipality reported 4.3 (3.8) vacancies on December 31, 2010 (2009). Note that unfortunately, the data does not report the number of vacancies opening up in a given year, meaning that this figure includes vacancies accumulated from previous years. Most of the studies investigating the effect of out-migration on labor markets focus on wages, which makes it difficult to compare these employment effects to previous literature. Two exceptions are Elsner (2013) and Škuflić and Vučković (2018) who find no or positive effects of worker outflows on unemployment rates in the context of European immigration. These studies investigate general out-migration, and not crossborder commuting, suggesting that increased labor demand rather than decreased labor supply may play an important role in explaining my effects.
} 
were particularly pronounced for low-tenure and medium-skilled workers ${ }^{8}$. Yet contrary to what one would expect from the canonical model, my results show that workers made up for these wage losses by working slightly more, both in terms of employment probability and days worked per year. As a result, they did not face losses in yearly earnings. For a sample of workers moving out of the matched municipalities to a different commuting zone I find neither wage nor employment effects.

Reconciling the regional and worker-level results for Germany helps explain why my findings differ from standard model predictions. On the demand side, firms seemed to have temporarily hired fewer native workers. My finding that younger workers' employment shares decreased in the border region overall suggests that firms reduced demand for new native hires, and thus outsiders mainly absorbed the shock. On the supply side, incumbent workers seemed to have been willing to work for relatively lower wages to avoid losing their jobs. About two years after the policy change, they started compensating this lower wage growth by working slightly more.

My findings thus suggest that timing is important: In the longer term, firms likely updated their expectations, adjusted capital and perhaps reaped productivity gains from the commuter inflow. As a result, labor demand for native workers recovered. My findings show that particularly medium-skilled workers, for whom Czech workers were most likely substitutes, increased their employment after 2011. It is also possible that in response to the commuter inflow of mostly medium-skilled workers, firms in the border region started to shift their specialization towards industries with mainly medium-skilled workers as labor inputs.

This paper makes two contributions. First, this is the first study analyzing how an immigration policy change simultaneously affected both origin and destination countries. It thus helps to provide a more comprehensive picture of the welfare effects of migration flows. For this purpose, I exploit a novel dataset on Czech regions, provided by the Czech Statistical Office. While I show that unemployment rates in the Czech border region decreased likely benefiting Czech stayers, my findings of increased vacancies and fewer applicants per job also suggest potential skill shortages for Czech firms after the labor market opening. For Germany, my results suggest

\footnotetext{
${ }^{8}$ Czech workers commuting to Germany were mainly medium-skilled such that they were likely substitutes for medium-skilled natives. This is consistent with findings from previous literature that migrants from Eastern Europe were relatively high-skilled (Kahanec and Pytliková (2017), Zaiceva and Zimmermann (2008)).
} 
that native workers experienced lower wage growth. In turn, German firms may have benefited from the Czech worker inflow in terms of increased productivity.

Second, I show that it is informative to focus not only on regional aggregates as many previous studies do, but also on individual worker careers. For this purpose, I use German employer-employee data to follow a cohort of native workers employed in the border region in 2010 over time. My results suggest that particular groups of these workers were negatively affected by the Czech worker inflow in terms of lower wage growth, thus potentially raising worker inequality in the German border region. The two groups experiencing substantially lower wage growth are native workers with less than 1 year of tenure in 2010, and medium-skilled workers. In contrast to previous studies on the effects of immigration focusing mainly on regional aggregates, I do not find a decline in employment for this cohort of native workers. Instead, my results suggest that native workers tried to make up for lower wage growth by working slightly more in the long term. As a result, their yearly earnings did not change in the years following the Czech worker inflow.

This paper is most closely related to Dustmann et al. (2017) who assess a commuting policy in the Czech-German border region in 1991-1993, 20 years earlier. This was a policy temporarily implemented by the German government with a worker inflow of similar size. Whereas Dustmann et al. (2017) report a sharp decline in regional native employment and only a moderate decline in regional native wages, my results differ: In my baseline results, I find no effects on native employment at the regional level, but statistically significant negative effects on native wages. For the cohort of treated native workers, I find that their wages decreased by about $1 \%$ in comparison to the control group, while employment increased two years after the policy change. Similarly to Dustmann et al. (2017), my results suggest that native outsiders rather than native insiders absorbed the employment shock.

To understand why I find positive effects for native employment, it is important to keep in mind the differences in timing. Dustmann et al. (2017) analyze a temporary commuting policy and can therefore account only for short-term effects. Since it takes time for firms to adjust their expectations, shifts in labor demand may not be visible in the event of a temporary commuting policy. A recent study by Beerli et al. (2021) indeed finds that firms react to long-term commuter inflows. They exploit a commuting reform which granted European cross-border workers free access to the Swiss labor market in 2004. Their findings show that the reform led to increased 
labor demand in skill-intensive firms, which benefited in terms of size, productivity, and innovation.

Another reason for why my results differ from Dustmann et al. (2017) could be declining trade union power in Germany from 2002 onwards $^{9}$, leading to lower wage rigidity. At the same time, liberalization of the German labor market ("Hartzreforms") could have led to higher wage bargaining power on the firm side, since workers have a strong preference to stay employed (Kuhn et al., 2020).

In addition to Beerli et al. (2021) and Dustmann et al. (2017), my analysis is inspired by studies investigating the effects of negative labor supply shocks, or out-migration. Bütikofer et al. (2020) and Hafner (2020) find positive wage and employment effects for stayers resulting from out-migration in border regions. Other studies (e.g., Dustmann et al. (2015) and Aydemir and Borjas (2007)) confirm that stayers benefit from out-migration in terms of wage increases. While these studies focus on wages, I explore different outcomes, such as unemployment rates, vacancies, and applicants per job. I can thus infer not only the effects on Czech stayers, but also on Czech firms in the border region.

In a broader sense, this paper also relates to studies on the labor market effects of immigration, in particular to Card (1990), who was the first to use a natural experiment to estimate the impact of immigration on native workers. Previous literature is inconclusive on the types of effects: While some studies report negative effects of immigrant inflows on native wages and/or employment (e.g., Glitz (2012), Ottaviano and Peri (2012), Borjas (2003), Card (2001)), others find no or mildly negative effects on natives, and sometimes stronger effects on existing migrants (e.g., Signorelli (2020), Bratsberg et al. (2019), Manacorda et al. (2012), Moritz (2011), Cohen-Goldner and Paserman (2006), Altonji and Card (1991)). One explanation for these findings is that as a response to immigrant inflows, natives specialize in different types of jobs (Peri and Sparber (2009)). Some natives moreover benefit by upgrading to jobs with higher skill levels (e.g., Foged and Peri (2016)). Other studies emphasize that the labor market effects of immigration are subject to substantial heterogeneity: While workers at the lower end of the wage distribution suffer, workers at the higher end benefit (Dustmann et al. (2013)).

The remainder of this chapter is as follows. Section 2.2 describes the EU enlargement

\footnotetext{
${ }^{9}$ For insights into the German collective bargaining system, see, e.g., Hirsch and Schnabel (2014)).
} 
Figure 2.2: EU Eastern Enlargement: The Process

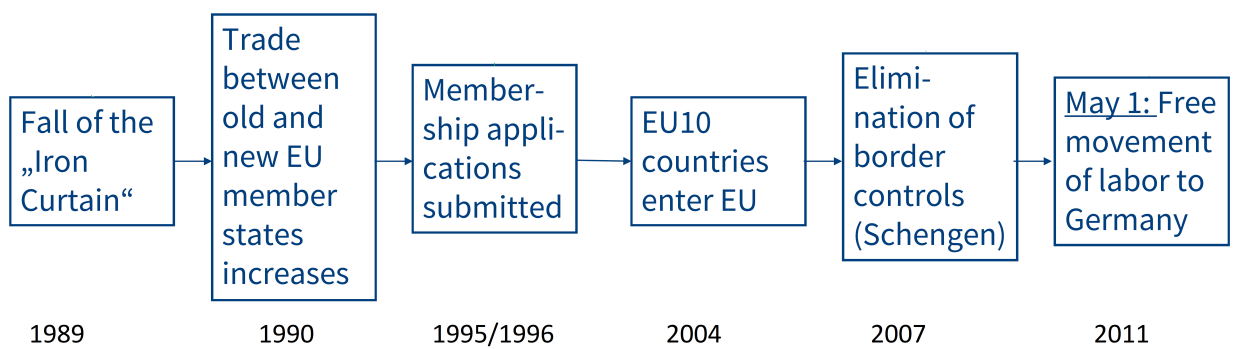

Notes: This figure gives an overview of the process of the Eastern enlargement of the EU in 2004. The process started with the fall of the iron curtain in 1989, which followed an increase in trade between Western and Eastern EU member states through the 1990s. Eastern European countries submitted their membership applications after a relatively short period of time, in 1995-1996. In 2004, 10 new countries accessed the EU, 8 of them from Eastern Europe. The 8 Eastern European countries which accessed the EU along with Cyprus and Malta are Czech Republic, Estonia, Hungary, Latvia, Lithuania, Poland, Slovakia, and Slovenia. The process of EU enlargement came along with open borders in the course of the Schengen agreement (2007) and free movement of labor (May 1, 2011, Germany). Note that while Germany and Austria delayed the opening of their labor markets until 2011, other countries such as the UK or Sweden opened them immediately in 2004 .

2004 and the resulting free movement of labor policy, followed by a simple conceptual framework in Section 2.3. Section 2.4 gives an overview of the German social security data I use for this study. Section 2.5 discusses my empirical strategy, including a detailed account of my matching method. Section 2.6 presents the results, with a discussion of robustness checks in Section 2.7. Section 2.8 concludes.

\subsection{The Policy Reform: EU Enlargement}

The focus of this paper is the EU enlargement in 2004, when eight Central and Eastern European countries (EU8) as well as Malta and Cyprus joined the EU. ${ }^{10}$ Within the EU, the "four freedoms" apply: The freedom of capital, goods, services, and labor. I focus on the freedom of labor, a regulation entailing that any EU citizen can work in another EU country without the need to apply for a visa or work permit. This means that for a worker from, e.g., Czech Republic, the same hiring conditions apply as for a German worker, and native workers are not prioritized.

\footnotetext{
${ }^{10}$ The full list of countries is Cyprus, Czech Republic, Estonia, Hungary, Latvia, Lithuania, Malta, Poland, Slovakia, and Slovenia.
} 
When the Central and Eastern European countries accessed the EU in 2004, not all Western EU countries opened their labor market immediately. Countries could delay access to their labor markets for up to seven years in what became known as the " $2+3+2$ " regulation. Whereas some countries like the UK and Sweden immediately opened their labor markets to workers from Central and Eastern Europe, other countries delayed access. Germany and Austria were the only countries delaying access for the maximum possible time span of seven years; in May 2011, they were finally obliged to open their labor markets. ${ }^{11}$

Figure 2.2 gives an overview of the process of European East-West integration, which started with the fall of the iron curtain in 1989. Trade between East and West increased already in the 1990s, which is when German firms started to invest in Czech Republic (Körner et al., 2021). Around this time, German citizens started crossing the border to Czech Republic to buy, e.g., relatively cheaper cigarettes and fuel. In 2004, Czech Republic became a member of the EU, resulting into increased political and economic exchange between the two countries. Cross-border exchange increased once more with the elimination of border controls ("Schengen Agreement") in 2007. Importantly for my empirical strategy, this means that I am not worried about spatially concentrated trade or demand shocks happening simultaneously with the labor market opening in 2011. Moreover, given that German wages were (and still are) substantially higher than Czech wages, ${ }^{12}$ worker migration from Germany to Czech Republic is not a relevant concern.

\subsection{Conceptual Framework}

The canonical model on labor supply shocks offers guidance on the potential effects of the policy reform. I base my considerations in this section on Chapter 3 in Borjas (2014).

Let's assume a world according to neoclassic theory, where labor markets are fully competitive, workers are perfect substitutes, labor and capital are the sole production inputs, and both are fully mobile. Imagine that one country in this frictionless

\footnotetext{
${ }^{11}$ For workers from Malta and Cyprus, the German labor market opened immediately in 2004. Note that in this paper, I therefore refer to EU8 countries, excluding Malta and Cyprus.

${ }^{12}$ In 2015, the minimum wage in Germany was introduced at 8.50 Euro. In Czech Republic, at that time, it was just above 2 Euro.
} 
world - Czech Republic - offers relatively low wages, whereas another country - Germany - offers high wages. This is the steady state as long as there is no exchange of workers between these two countries. If the two countries' labor markets integrate, theory predicts that workers move from Czech Republic to Germany until wages in both countries equalize. If we allow for mobility being costly, Czech workers would not move to anywhere in Germany, but prefer the border region.

For Czech Republic, this means the following: A negative labor supply shock, as induced by a worker outflow, will increase the return to labor and decrease the return to capital. The standard model predicts that in the long term, firms would adjust their stock of capital to return to the original capital/labor ratio. Yet in the case of Czech-German labor market integration, there are two aspects which may make it harder for firms to react optimally: First, the outflow of Czech workers was not sharp and sudden, but happened gradually over time. The share of Czech workers in the German border region increased slightly even in 2016-2017, the last years in my data. Firms thus faced a constant outflow of workers, and may have had to constantly update their expectations. Second, more than $80 \%$ of Czech workers employed in Germany commuted across the border. This means that Czechs would continue to consume the majority of goods and services in their home country; given their higher wages in Germany, demand for local goods was likely to increase. Firms in the border region could thus have found themselves in a situation where they needed to produce more, but faced difficulties hiring new workers.

For Germany, theory predicts the reverse pattern: A positive labor supply shock will decrease regional wages and increase the return to capital in the short term. Given cross-border commuting, the increase in labor supply will not be fully offset by an increase in demand for domestic goods in the German border region. The magnitude of the wage effect moreover depends on local labor market tightness. In a setting with a priori inelastic native labor supply, the native wage decrease will be less pronounced. This paper investigates labor market effects of immigration in a period of relative growth in Germany (both in terms of GDP and labor force). I therefore expect that relatively high labor demand may cushion potential negative labor market effects of the immigration shocks.

As one extension of this simple model, Borjas (2003) proposes a nested CES framwork which takes into account heterogeneous labor. In this model, the aggregate production function has two distinct labor inputs, e.g., high-skilled and low-skilled 
labor. The impact of the labor supply shock on native wages then depends on the degree of substitutability between the two worker groups, i.e., their elasticity of substitution. While this standard model assumes that except for labor, all other production units remain the same, this assumption has its caveats, as dicussed in Beerli et al. (2021). The inflow of Czech workers could have affected firms' productivity, thus raising their demand for a certain type of native workers.

\subsection{Czech and German Labor Market Data}

For my empirical analysis, I use two datasets on establishments and workers from the Institute for Employment Research (IAB), as well as regional-level data from the Czech Statistical Office (CSO). ${ }^{13}$ In addition, I combine my German data with spatial data from the German Federal Institute for Research on Building, Urban Affairs, and Spatial Development (BBSR).

For Czech Republic, I use county- as well as municipality-level data from the Czech Statistical Office (CSO) in 2005-2017. The county-level data has the advantage that it contains a rich set of labor market variables which I use for my matching analysis (see Section 2.5 for more details on the matching technique). Importantly, the county-level data provides information on unemployment rates and vacancies. In addition, it contains information on population size by age groups, the number of firms in given industries, and crime. I define all treatment regions as counties bordering either Germany or Austria. After matching these counties to suitable controls, I enrich the data using information on unemployment rates and vacancies, which are available at the municipality level. I assign all municipalities belonging to a treated county to my treatment group; all municipalities belonging to one of the control counties are defined as control group. The number of Czech municipalities is substantially larger than the number of Czech counties (6258 vs. 77 ), so this step helps me to estimate my regression model more precisely.

For Germany, I start with establishment level data, the Establishment History Panel

\footnotetext{
${ }^{13}$ Note that while the German data I use is at the establishment level, the Czech data reports regional-level information on the number of firms by sector. For Germany, I thus use the term "establishment" when describing the data. Conceptually, decisions are however taken at the firm level, while establishments as production units are implementing them. When I discuss the potential mechanisms at play, I will thus refer to firms instead of establishments. It is important to keep in mind, however, that the empirical results are at the establishment level.
} 
(BHP). My sample of the establishment data includes the universe of German establishments in 2004-2017 with at least one employee subject to social security contributions as of June 30 each year (Eberle and Schmucker (2017)). It covers an extensive set of establishment variables, such as the number of (native) employees, (native) wages, skill shares in an establishment, and industry. Importantly for my analysis, the data also contain information on the municipality an establishment is located in. I aggregate the data at the municipality level. ${ }^{14}$

In a next step, I combine the municipality data with spatial data provided by the German Federal Institute for Research on Building, Urban Affairs, and Spatial Development (BBSR). This data contains information on each municipality's centroid, allowing me to compute the airline distance in $\mathrm{km}$ to the nearest road border crossing to Czech Republic. I define my treatment group as all German municipalities located at most $40 \mathrm{~km}$ from the nearest border crossing. I then use propensity score matching to match the treatment municipalities to suitable control municipalities. In Section 2.5, I describe the matching process in more detail.

Figure A.2.1 gives an intuition on why I chose 40km as threshold for my definition of border region. It plots airline distance to the nearest border crossing in bins of $\mathrm{km}$. For this figure, I use the complete sample of German social security data, restricting it to all municipalities located up to $150 \mathrm{~km}$ from the nearest border crossing. In Panel (A), on the y-axis, I plot Czech workers as a share of total employment. The four lines correspond to different years before and after the policy reform. The figure shows that the closer a municipality is located to the border, the higher the share of Czech workers. Moreover, there are very few Czech workers working further than $40 \mathrm{~km}$ away from the border. In addition, the figure shows that the share of Czech workers substantially increased between 2009 and 2015. Panel (B) shows that a very similar pattern holds when looking at the share of EU8 employment.

For the second part of my paper, I follow Dauth and Eppelsheimer (2020) to prepare worker-level data from the Integrated Employment Biographies (IEB), Version 14, which comprise the universe of workers subject to social security contributions in Germany. From this dataset, I draw a 15-\% sample of workers in 2007-2017. This dataset contains a rich set of variables and comes with several advantages. Importantly for my study, it includes administrative information on workers' na-

\footnotetext{
${ }^{14}$ As of December 2018, there were 11,014 municipalities in Germany. Their size is much smaller than that of NUTS-3-regions (counties), of which Germany had 401.
} 
tionality which enables me to cleanly identify Czech workers. It moreover reports both workers' exact workplace and residence on the municipalitiy level, helping me to identify treated workers. For Czech workers, I moreover know whether they live in Germany or abroad. In addition, the data include information on workers' days worked, their dailys wage, and skill group. From the spell data, I construct a yearly panel based on observations on June 30. I correct implausible education entries following Fitzenberger et al. (2006).

Table 2.1 shows summary statistics for workers in my sample. Column (1) reports native workers' characteristics in 2010, and Column (2) reports Czech workers' characteristics in 2012, while Column (3) shows the difference. ${ }^{15}$ Perhaps not surprisingly, Czech workers' earnings are substantially lower (13,500 Euro per year vs. 21,000 Euro per year). This is mainly driven by Czechs working fewer days per year (263 vs. 330). The substantial difference in days worked per year suggests that Czech workers are partly in seasonal employment. $72 \%$ of Czech workers are male, and $84 \%$ report that they do not live in Germany. Interestingly, migrants are slightly more educated than natives: $75 \%$ of Czechs have vocational training, but only $73 \%$ of natives; the share of workers with university degree is almost identical. This positive selection with respect to skills is in line with prior literature finding that migrant workers from Central and Eastern Europe are relatively high-skilled (Kahanec and Pytliková, 2017).

Note that while vocational training systems in Czech Republic and Germany are comparable with respect to their length (2-3 years in both countries), they differ in type. In Czech Republic, vocational training is essentially integrated into the school system, and entails the last years of basic education, following primary school. The program is administered by the state, including both theoretical and practical training classes. There is moreover a common admission examination organized by the authorities. Apprentices apply to a school specialized in their occupation of interest (e.g., confectionery, gastronomy, or electronics). In Germany, apprentices apply directly to a firm which offers training in their preferred occupation. For the period of training, they are then based at this firm, where they spend the majority of their time with practical training (3-4 days a week) and receive a small salary. In addition, they spend 1-2 days per week at the respective vocational school, which

\footnotetext{
${ }^{15}$ Note that I show characteristics of Czech workers in 2012, because this is a year where a substantial number of them is already commuting across the border. In contrast, German workers' characteristics are reported in 2010 to ensure that they are not yet impacted by the inflow.
} 
Table 2.1: Native and Czech Workers in the German Border Region

\begin{tabular}{|c|c|c|}
\hline $\begin{array}{c}(1) \\
\text { Native Workers } \\
2010\end{array}$ & $\begin{array}{c}(2) \\
\text { Czech Workers } \\
2012\end{array}$ & $\begin{array}{c}(3) \\
(1)-(2)\end{array}$ \\
\hline Mean & Mean & Difference \\
\hline
\end{tabular}

Panel A: Earnings and Employment

\begin{tabular}{lcccccc} 
Total yearly earnings & 20768.0 & {$[15759.6]$} & 13508.9 & {$[10448.8]$} & $\mathbf{7 2 5 9 . 1}$ & $1.370 \mathrm{e}-52$ \\
Log daily wage & 3.707 & {$[1.046]$} & 3.659 & {$[0.808]$} & 0.04799 & 0.1302 \\
Days per year working & 329.6 & {$[81.72]$} & 262.5 & {$[123.8]$} & $\mathbf{6 7 . 0 8 3}$ & $5.734 \mathrm{e}-157$ \\
& & & & & & \\
Panel B: Demographics & & & & & & \\
Female & 0.502 & {$[0.500]$} & 0.276 & {$[0.447]$} & $\mathbf{0 . 2 2 5 6}$ & $3.195 \mathrm{e}-50$ \\
Age in years & 40.79 & {$[13.52]$} & 39.86 & {$[11.17]$} & $\mathbf{0 . 9 2 5 8}$ & 0.02342 \\
Share without vocational training & 0.218 & {$[0.413]$} & 0.193 & {$[0.395]$} & $\mathbf{0 . 0 2 4 4 0}$ & 0.09226 \\
Share with vocational training & 0.726 & {$[0.446]$} & 0.754 & {$[0.431]$} & $\mathbf{- 0 . 0 2 8 4 2}$ & 0.06958 \\
Share with university degree & 0.0563 & {$[0.231]$} & 0.0523 & {$[0.223]$} & 0.004025 & 0.6191 \\
Residency outside Germany & 0.00579 & {$[0.0759]$} & 0.835 & {$[0.371]$} & $\mathbf{- 0 . 8 2 9 2}$ & 0 \\
Manufacturing sector & 0.512 & {$[0.500]$} & 0.505 & {$[0.500]$} & 0.006676 & 0.6595 \\
Service sector & 0.471 & {$[0.499]$} & 0.466 & {$[0.499]$} & 0.004681 & 0.7570 \\
Agriculture & 0.00737 & {$[0.0855]$} & 0.00631 & {$[0.0792]$} & 0.001053 & 0.6841 \\
\hline Observations & 59605 & \multicolumn{2}{c}{1109} \\
\hline
\end{tabular}

Notes: This table presents characteristics of Czech workers (2012) and native workers (2010) in the German border region in the $15 \%$ worker sample of the German social-security data. Column (1) presents all German workers, Column (2) presents all Czech workers, and Column (3) shows the difference in means and respective p-values from a t-test for equal means. Panel A shows how Czech and German workers differ in terms of earnings, log wages, and employment. Panel B shows how Czech and German workers differ with respect to demographics such as gender, age, and education. Note that due to missing/unknown values, the industry shares do not add up to $100 \%$. Residency outside Germany is a dummy indicating whether a worker reports 'living abroad' in the administrative data. I show characteristics of Czech workers in 2012 because this is a year where a substantial number of them is already commuting across the border. In contrast, German workers' characteristics are reported in 2010, to ensure that they are not yet influenced by the inflow. West Germany only. Differences in bold signal statistical significance at the $10 \%$-level. Source: Integrated Employment Biographies (IEB). 
serves for theoretical education.

Given these differences, it is not clear that a Czech worker with, e.g., 11 years of education is a perfect substitute for a German worker with 11 years of education. In addition, previous studies have found that migrants are often downgraded upon entering the German labor market, as labor market experience is not fully transferable across countries (see, e.g., Brücker et al. (2021), Dustmann et al. (2013)).

In Table A.2.1 in the appendix, I provide more detailed evidence on the industries Czechs work in. The table shows the share of Czech/native workers in a given industry by overall Czech/native employment. Czech workers are clearly overrepresented in industries such as agriculture, food manufacturing, restaurants, investment goods, and construction. In turn, they are underrepresented in sectors such as public administration and education and - perhaps surprisingly - the health sector. As Table A.2.2 shows, Czech workers are even more concentrated in particular occupations. Their employment share is particularly large in simple and qualified manual tasks, as well as simple services.

\subsection{Empirical Strategy: Difference-in-Differences Combined With Matching}

The aim of my study is to estimate the effect of cross-border commuting of Czech workers on local labor markets in both Czech Republic and Germany, as well as native incumbent workers' labor market outcomes in Germany. To achieve this, I proceed in three steps: First, I apply propensity score matching to match border municipalities to suitable control municipalities. I match without replacement, meaning that each region is assigned one distinct control observation. ${ }^{16}$ Second, I use an eventstudy analysis to estimate the effect of the labor supply shock on labor market outcomes in regions on both sides of the border. Third, I conduct an additional analysis focusing on native incumbent workers in Germany. Here, I reweight workers in the treatment region to workers in control municipalities to match their

\footnotetext{
${ }^{16}$ For Czech Republic, the matching analysis takes place at the county level.
} 
characteristics in terms of pre-treatment individual and establishment covariates. ${ }^{17}$ Using an eventstudy analysis, I then move on to estimate effects on native workers' earnings, wages, and employment.

\subsubsection{Propensity Score Matching}

I start with propensity score matching for Czech counties. The treatment region is defined as all Czech counties bordering either Germany or Austria. I match these counties to suitable controls using a number of matching variables which are plausible predictors for how wages and employment in the Czech regions may develop in the future. These are the working age population share (2010), the share of firms in manufacturing and agriculture (2010), unemployment rates (2010), vacancies (2010), and population size (2010). The right side of Figure 2.3 shows how treatment and control counties are spatially distributed across Czech Republic. For the eventstudy regressions, I enrich this county-level data with municipality-level data on unemployment rates and vacancies.

\footnotetext{
${ }^{17}$ I hereby follow DiNardo et al. (1996). The basic idea of the reweighting approach is that it allows me to estimate treatment effects conditional on potential pre-treatment differences in covariates between workers in treated and control regions. For this purpose, I estimate probit regressions and use the respective propensity scores to construct weights. I explain the procedure in more detail in Section 2.5.3.
} 
Figure 2.3: Matched Treated and Control Regions: Germany and the Czech Republic

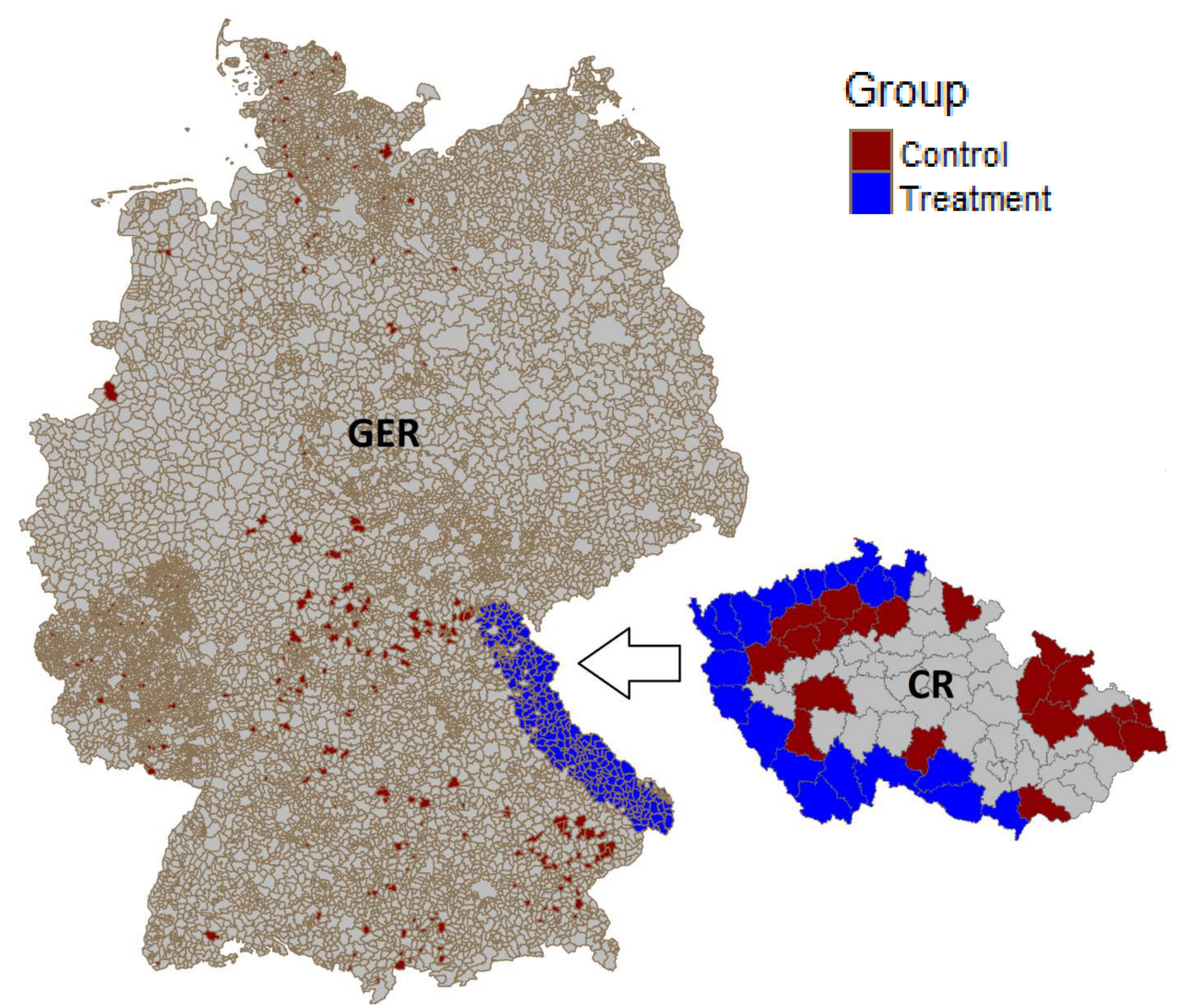

Notes: This map shows matched treated and control municipalities for Germany, as well as matched treated and control counties for the Czech Republic. For Germany, treated municipalities are all municipalities located up to $40 \mathrm{~km}$ from the nearest road border crossing to the Czech Republic (measured by airline distance from municipality centroid). For my baseline results and in this map, I consider only municipalities in West Germany. For the Czech Republic, treated municipalities are all municipalities located in a county bordering either Germany or Austria. Regions are matched using propensity score matching. The following variables enter the probit regression to compute propensity scores for the German data: Age shares (2010), skill shares (2010), share of female workers (2010), share of foreign workers (2010), share of establishments in manufacturing sector (2010), share of establishments in service sector (2010), employment in levels (2010), growth in EU8 employment 2004-2010, log wage (2008-2010). For the Czech data, the matching variables are: Working age share (2010), share of firms in manufacturing (2010), share of firms in agriculture (2010), unemployment rate (2010), vacancies (2010), population size (2010). 
Table 2.2: Summary Table of Matched Czech Counties in 2010

\begin{tabular}{|c|c|c|c|c|c|c|c|c|c|}
\hline & & \multicolumn{2}{|c|}{$(1)$} & \multicolumn{2}{|c|}{$\begin{array}{c}(2) \\
\text { Control Regions }\end{array}$} & \multicolumn{2}{|c|}{$\begin{array}{c}(3) \\
\text { Border Region }\end{array}$} & \multicolumn{2}{|c|}{$\begin{array}{c}(4) \\
(2)-(3)\end{array}$} \\
\hline & & Mean & $\mathrm{SD}$ & Mean & $\mathrm{SD}$ & Mean & $\mathrm{SD}$ & Difference & p-Value \\
\hline & \multicolumn{9}{|l|}{ Panel A: Employment } \\
\hline & Unemployment Rate & 7.840 & {$[2.070]$} & 8.597 & {$[2.177]$} & 8.945 & {$[1.916]$} & -0.3478 & 0.5948 \\
\hline & Number of Unemployed & 7292.9 & {$[4885.0]$} & 8601.1 & {$[5315.2]$} & 6970.6 & {$[2541.8]$} & 1630.5 & 0.2234 \\
\hline & Vacancies per Working Age Population & 0.00379 & {$[0.00175]$} & 0.00384 & {$[0.00192]$} & 0.00374 & {$[0.00157]$} & 0.0001047 & 0.8515 \\
\hline & Number of applicants per job & 26.13 & {$[14.50]$} & 28.23 & {$[14.65]$} & 30.17 & {$[16.61]$} & -1.9427 & 0.6971 \\
\hline & \multicolumn{9}{|l|}{ Panel B: Firms } \\
\hline & Share Firms in Agriculture in \% & 0.0511 & {$[0.0238]$} & 0.0513 & {$[0.0199]$} & 0.0563 & {$[0.0339]$} & -0.005069 & 0.5676 \\
\hline \multirow[t]{8}{*}{$t$} & Share Firms in Manufacturing in \% & 0.139 & {$[0.0229]$} & 0.132 & {$[0.0152]$} & 0.126 & {$[0.0193]$} & 0.006856 & 0.2187 \\
\hline & Share Firms in Construction in $\%$ & 0.133 & {$[0.0192]$} & 0.136 & {$[0.0220]$} & 0.131 & {$[0.0201]$} & 0.004971 & 0.4609 \\
\hline & \multicolumn{9}{|l|}{ Panel C: Population } \\
\hline & Working Age Population & 95828.6 & {$[100153.1]$} & 96953.3 & {$[51868.4]$} & 76102.8 & {$[24882.3]$} & 20850.5 & 0.1133 \\
\hline & Average age in region & 40.66 & {$[0.770]$} & 40.63 & {$[0.388]$} & 40.18 & {$[0.672]$} & 0.4488 & 0.01362 \\
\hline & Deaths & 1387.6 & {$[1396.4]$} & 1432.8 & {$[812.7]$} & 1079.3 & {$[358.9]$} & 353.55 & 0.08311 \\
\hline & Births & 1521.5 & {$[1672.4]$} & 1493.8 & {$[796.9]$} & 1180.7 & {$[427.4]$} & 313.05 & 0.1299 \\
\hline & Observations & \multicolumn{2}{|c|}{77} & \multicolumn{2}{|c|}{20} & \multicolumn{2}{|c|}{20} & & \\
\hline
\end{tabular}

Notes: Characteristics of Czech counties in year before policy change. Column (1) presents all Czech counties, Column (2) presents all matched non-border counties, Column (3) presents all matched border counties, and Column (4) shows the difference between non-border vs. border counties and respective p-values from a t-test for equal means. Regions are matched using propensity score matching. The following variables enter the probit regression to compute propensity scores (all measured in 2010): Working age share, share of firms in manufacturing, share of firms in agriculture, unemployment rate, vacancies, population size. Treated counties are all counties bordering either Germany or Austria. Standard deviations in brackets. Differences in bold signal statistical significance at the 10\%-level. Source: Czech Statistical Office. 
For Germany, I conduct a very similar matching exercise. Using data on the universe of German establishments aggregated at the municipality level, I first identify my treatment region as all West German municipalities located up to $40 \mathrm{~km}$ from the nearest Czech-German road border crossing. I then closely follow Dustmann et al. (2017) in matching these municipalities to suitable West German control municipalities, using employment in levels (2010), age shares (2010), skill shares (2010), share of female workers (2010), share of foreign workers (2010), share of firms in the manufacturing and service sectors (2010). As additional matching variables, I use log wages in 2008-2010 and the growth in EU8 employment between 2004-2010. To account for type of region, I only allow matches within five types of municipality: Large city, medium city, large town, small town, and rural municipality. ${ }^{18}$ I deliberately exclude potential control municipalities in the same commuting zone as my treatment region, since they could be subject to spillover effects. The left side of Figure 2.3 shows how treatment and control municipalities are spatially distributed across West Germany.

Table 2.2 presents summary statistics on how the Czech matched regions differ before the policy change in 2011, and how they compare to the average Czech region. Comparing all regions (Column (1)) to the matched regions (Columns (2) and (3)) shows that the matched regions are slightly negatively selected: Their unemployment rates were, on average, higher. There were no large differences with respect to firm composition or demographics. Column (4) reports the differences between Columns (2) and (3) and shows that the propensity score matching worked well in terms of balancing treatment and control group: While the Czech border region in 2010 had a slightly higher unemployment rate ( $8.94 \%$ vs. $8.6 \%)$, and slightly more applicants per job (30.2\% vs. $28.2 \%$ ), this difference was not statistically significant. As Panel B shows, Czech treated and control counties displayed a similar industry structure, with a similar share of firms in agriculture, manufacturing, and construction. Panel C reports lower levels of working age population (76,100 vs. 97,000) in the border region, which is significant at the $11 \%$ level. In comparison to both the control regions and all Czech regions, the border region was slightly younger, and reported

\footnotetext{
${ }^{18}$ For this purpose, I use a definition provided by the German Federal Institute for Research on Building, Urban Affairs, and Spatial Development (BBSR), which is based on population size and administrative function. For more information, see: https://www.bbsr.bund.de/BBSR/DE/forschung/raumbeobachtung/Raumabgrenzungen/ deutschland/gemeinden/StadtGemeindetyp/StadtGemeindetyp.html. Last access: May 30, 2021.
} 
fewer deaths.

Table 2.3 provides summary statistics for Germany. Comparing the matched regions (Columns (2) and (3)) to all German municipalities in the dataset (Column (1)) shows that the matched regions are less densely populated, they have a lower average share of foreign workers, and comparably high wages. With respect to the demographic composition, the matched regions are slightly younger and more medium-skilled. $81 \%$ of matched municipalities are rural, whereas this share is only $50 \%$ in the whole of Germany.

Comparing the matched regions, Column (4) shows that most of the pre-treatment differences are not statistically significant. The only statistically significant difference is the share of workers from the EU, which is higher in the border region already before 2011 (2.19\% vs. 1.36\%). However, as I show in Figure 2.4, the trend in the share of workers from the EU8 is similar, and constant, in both groups. Importantly, the wage structure after matching is very comparable, with (native) average wages differing only slightly between treatment and control group. The same holds for the workforce composition, with treated and control municipalities having a similar share of workers in specific age and skill groups. 
Table 2.3: Summary Table of Matched German Municipalities in 2010

\begin{tabular}{|c|c|c|c|c|c|c|c|c|}
\hline & \multicolumn{2}{|c|}{$\begin{array}{c}(1) \\
\text { All Regions }\end{array}$} & \multicolumn{2}{|c|}{$\begin{array}{c}(2) \\
\text { Control Regions }\end{array}$} & \multicolumn{2}{|c|}{$\begin{array}{c}(3) \\
\text { Border Region }\end{array}$} & \multicolumn{2}{|c|}{$\begin{array}{c}(4) \\
(2)-(3)\end{array}$} \\
\hline & Mean & $\mathrm{SD}$ & Mean & $\mathrm{SD}$ & Mean & $\mathrm{SD}$ & Difference & p-Value \\
\hline \multicolumn{9}{|l|}{ Panel A: Employment } \\
\hline Native Employment (levels)) & 2849.2 & {$[20062.7]$} & 788.2 & {$[1169.2]$} & 896.3 & {$[1061.7]$} & -108.17 & 0.2862 \\
\hline Share Foreign Workers & 0.0408 & {$[0.0494]$} & 0.0335 & {$[0.0277]$} & 0.0306 & {$[0.0258]$} & 0.002876 & 0.2368 \\
\hline Share Foreign Workers from EU & 0.0190 & {$[0.0318]$} & 0.0136 & {$[0.0121]$} & 0.0219 & {$[0.0230]$} & -0.008275 & $9.251 \mathrm{e}-07$ \\
\hline Share Full-time Workers & 0.510 & {$[0.160]$} & 0.515 & {$[0.120]$} & 0.529 & {$[0.107]$} & -0.01458 & 0.1579 \\
\hline \multicolumn{9}{|l|}{ Panel B: Wages } \\
\hline Native Average Wages & 62.37 & {$[12.32]$} & 64.54 & {$[8.742]$} & 63.90 & {$[5.864]$} & 0.6373 & 0.3458 \\
\hline Average Wages & 61.70 & {$[11.83]$} & 64.02 & {$[8.497]$} & 63.59 & {$[5.879]$} & 0.4303 & 0.5165 \\
\hline \multicolumn{9}{|c|}{ Panel C: Workforce Characteristics } \\
\hline Share Workers Aged 15-29 & 0.167 & {$[0.0652]$} & 0.194 & {$[0.0511]$} & 0.190 & {$[0.0472]$} & 0.003912 & 0.3807 \\
\hline Share Workers Aged 30-49 & 0.468 & {$[0.0838]$} & 0.487 & {$[0.0455]$} & 0.487 & {$[0.0369]$} & -0.0001997 & 0.9576 \\
\hline Share Female Workers & 0.468 & {$[0.132]$} & 0.478 & {$[0.118]$} & 0.486 & {$[0.106]$} & -0.007362 & 0.4708 \\
\hline Share High-skilled Workers & 0.0688 & {$[0.0529]$} & 0.0404 & {$[0.0195]$} & 0.0414 & {$[0.0268]$} & -0.0009734 & 0.6468 \\
\hline Share Medium-skilled Workers & 0.777 & {$[0.0884]$} & 0.804 & {$[0.0551]$} & 0.803 & {$[0.0472]$} & 0.0006790 & 0.8842 \\
\hline Share Low-skilled Workers & 0.127 & {$[0.0696]$} & 0.145 & {$[0.0542]$} & 0.144 & {$[0.0419]$} & 0.0009947 & 0.8210 \\
\hline \multicolumn{9}{|c|}{ Panel D: Regional Characteristics } \\
\hline Share Rural Regions & 0.500 & {$[0.500]$} & 0.807 & {$[0.396]$} & 0.807 & {$[0.396]$} & & \\
\hline Distance to CZ Border (km) & 265.1 & {$[129.4]$} & 242.6 & {$[119.4]$} & 22.56 & {$[10.20]$} & & \\
\hline
\end{tabular}

Notes: Characteristics of German municipalities in year before policy change. Column (1) presents all German municipalities, Column (2) presents all matched non-border municipalities, Column (3) presents all matched border municipalities, and Column (4) shows the difference between non-border vs. border municipalities and respective p-values from a t-test for equal means. Municipalities are matched using propensity score matching. The following variables enter the probit regression to compute propensity scores: Age shares (2010), skill shares (2010), share of female workers (2010), share of foreign workers (2010), share of establishments in service sector (2010), share of establishments in manufacturing sector (2010), employment in levels (2010), growth in EU8 employment 2004-2010, log wages (2008-2010). Matching occurrs within cells of region type and I exclude municipalities in the same commuting zone as potential controls. High-skilled workers have a university degree, medium-skilled workers have at least vocational training, low-skilled workers have no vocational training. Treated municipalities are all municipalities located up to $40 \mathrm{~km}$ from the nearest road border crossing to Czech Republic (measured by airline distance from municipality centroid). West Germany only. Differences in bold signal statistical significance at 10\%-level. Source: Establishment History Panel (BHP). 


\subsubsection{Eventstudy Regression Model}

After completing the matching, I estimate a standard eventstudy regression on the regional level, which - for German municipalities - takes the following form ${ }^{19}$ :

$$
y_{r, t}=\sum_{t=2007}^{2017} \beta_{t} * I(\text { year }=t) *\left[I\left(\text { Treated }_{r}\right)\right]+\alpha_{i}+\alpha_{t}+\epsilon_{r, t}
$$

where $y_{r, t}$ is the outcome variable, e.g., native wages, in region $r$ in year $t$. I interact each year $t$ with a dummy indicating whether a region is in the treatment group $\left[I\left(\right.\right.$ Treated $\left.\left._{r}\right)\right]$, i.e., whether it is located up to $40 \mathrm{~km}$ from the nearest border crossing to Czech Republic. The coefficients of interest are $\beta_{t}$, indicating the differential development of treatment municipalities compared to control municipalities by year. I estimate all coefficients relative to the base year 2010, which I omit. Municipality and year fixed effects $\alpha_{i}$ and $\alpha_{t}$ in the regression model account for time-constant municipality characteristics and year trends. I report standard errors clustered at the municipality level. The key identifying assumption of my regression model is that in absence of the labor supply shock, treatment and control regions would have evolved in the same way. I cannot test this assumption, but I can show how the two groups evolved pre-treatment. Ideally, I do not observe significant differences pre-treatment. Section 2.6 shows that this is the case for most of my regression specifications.

\subsubsection{Worker Reweighting}

In a next step, I prepare the worker-level data for Germany. First, I define treated workers as all native workers working in the border region in 2010, with the corresponding control workers defined as working in a matched control municipality in 2010. These workers have to be of working age in 2010 (18-55 years) to ensure that they are attached to the labor force. Workers who move out of the matched regions to a different commuting zone after 2010 may be a selective group; therefore, I investigate them separately in a heterogeneity analysis.

\footnotetext{
${ }^{19}$ Note that the regression model for the Czech regional-level analysis is very similar, with the exception that I observe 2005-2017, and my treatment region is defined as all municipalities located in counties with a direct border to Germany or Austria.
} 
As part of my regression analysis, I reweight workers in the treatment group to workers in the control group using DiNardo et al. (1996) reweighting. Thus, I make sure that I only compare workers with similar pre-treatment characteristics. I estimate a probit regression, where my dependent variable is a dummy for being in the control group. Explanatory variables are log wage (2010), age (2010), years of education (2010), having a full-time job (2010), tenure (2008-2010), log establishment size (2010), and 1-digit industry dummies (2010). These are variables plausibly predicting workers' future labor market success. The estimated propensity scores serve to compute the weights, which I use in my eventstudy regression. To be more exact, the weights are computed as follows:

$$
D F L_{\text {weight }}=\text { pscore } /(1-\text { pscore })
$$

where pscore refers to the estimated propensity score from the probit regression.

Table 2.4 presents summary statistics on how treated workers differ from control workers before and after reweighting. It shows that reweighting is very effective in closing the gap between treated and control workers. This holds in terms of wage differences, employment differences, and demographics. After reweighting, treated workers are very similar to control workers: they earn similar log wages (3.84 vs. 3.85 ), work similar days per year (347.4 vs. 348.6), have the same age and years of education, and very similar years of tenure (2.84 vs. 2.85). In Section 2.6, I report results both with and without reweighting; for most specifications, these are very comparable, supporting the robustness of my results. Importantly, there are no statistically significant pre-treatment trends after reweighting which is why these are my baseline results.

For the second part of my paper, I again estimate standard eventstudy regressions, this time on the worker level:

$$
\left.y_{i, t}=\sum_{t=2007}^{2017} \gamma_{t} * I(\text { year }=t) *\left[\text { I }_{\text {(reated }}\right)\right]+\theta_{i}+\theta_{t}+\epsilon_{i, t}
$$

where $y_{i, t}$ is my outcome variable, e.g., native days worked, for worker $i$ in year $t$. I interact each year $t$ with a dummy indicating whether a worker is in the treatment group $\left[I\right.$ Treated $\left.\left._{i}\right)\right]$, i.e., whether she worked in the border region in 2010. The coefficients of interest are $\gamma_{t}$, indicating the differential development of treated 
Table 2.4: Characteristics of German Control and Treated Workers in 2010

(1)

$(2)$

(3)

Control Workers Treated Workers Treated Workers

Reweighted

\begin{tabular}{|c|c|c|c|}
\hline \multicolumn{4}{|c|}{ Panel A: Earnings and Employment } \\
\hline \multirow[t]{2}{*}{ Total yearly earnings } & 22977.8 & 22121.5 & 22227.6 \\
\hline & {$[15067.9]$} & {$[14519.7]$} & {$[14415.1]$} \\
\hline \multirow[t]{2}{*}{ Log daily wage } & 3.85 & 3.82 & 3.84 \\
\hline & {$[0.926]$} & {$[0.914]$} & [0.898] \\
\hline \multirow[t]{2}{*}{ Days per year working } & 348.6 & 348.4 & 347.4 \\
\hline & {$[45.5]$} & {$[43.7]$} & {$[45.1]$} \\
\hline \multirow[t]{2}{*}{ Full-time employed on June 30} & 0.648 & 0.643 & 0.649 \\
\hline & {$[0.478]$} & {$[0.479]$} & {$[0.477]$} \\
\hline \multicolumn{4}{|l|}{ Panel B: Demographics } \\
\hline \multirow[t]{2}{*}{ Female } & 0.472 & 0.482 & 0.469 \\
\hline & {$[0.499]$} & {$[0.500]$} & {$[0.499]$} \\
\hline \multirow[t]{2}{*}{ Age in years } & 38.0 & 38.4 & 38.0 \\
\hline & {$[10.7]$} & {$[10.7]$} & {$[10.8]$} \\
\hline \multirow[t]{2}{*}{ Education in years } & 11.4 & 11.5 & 11.4 \\
\hline & {$[1.27]$} & {$[1.34]$} & {$[1.31]$} \\
\hline \multirow[t]{2}{*}{ Tenure in years } & 2.85 & 2.92 & 2.84 \\
\hline & [1.31] & {$[1.27]$} & {$[1.30]$} \\
\hline \multicolumn{4}{|c|}{ Panel C: Establishment Characteristics } \\
\hline \multirow[t]{2}{*}{ Log estab. size } & 3.99 & 3.68 & 3.91 \\
\hline & {$[1.87]$} & {$[1.79]$} & {$[1.78]$} \\
\hline \multirow[t]{2}{*}{ Share in manufacturing sector } & 0.587 & 0.558 & 0.586 \\
\hline & {$[0.492]$} & {$[0.497]$} & {$[0.493]$} \\
\hline \multirow{2}{*}{ Share in service sector } & 0.392 & 0.427 & 0.394 \\
\hline & {$[0.488]$} & {$[0.495]$} & {$[0.489]$} \\
\hline Number of workers & 24285 & 26766 & 26766 \\
\hline \multicolumn{4}{|c|}{$\begin{array}{l}\text { Notes: This table presents characteristics of treated and control native workers in the } \\
\text { German border region in } 2010 \text { in the } 15 \% \text { worker sample of the German administrative } \\
\text { social-security data. Column (1) reports characteristics of control workers, Column (2) re- } \\
\text { ports characteristics of treated workers, and Column (3) reports characteristics of treated } \\
\text { workers after reweighting them to workers in the control group. Panel A shows how con- } \\
\text { trol and (reweighted) treated workers differ in terms of earnings, log wages, and (full-time) } \\
\text { employment. Panel B shows how control and (reweighted) treated workers differ with re- } \\
\text { spect to demographics such as gender, age, and education. Panel C shows how control } \\
\text { and (reweighted) treated workers differ with respect to establishment characteristics. West } \\
\text { Germany only. Standard deviations in brackets. Source: Integrated Employment Biogra- } \\
\text { phies (IEB). }\end{array}$} \\
\hline
\end{tabular}


workers compared to control workers by year. I estimate all coefficients relative to the base year 2010. Worker and year fixed effects $\theta_{i}$ and $\theta_{t}$ in the regression model account for time-constant worker characteristics and year trends. I report standard errors clustered at the individual level. Again, the key identifying assumption of my regression model is that in absence of the labor supply shock, labor market outcomes of workers in treatment and control group would have evolved in the same way.

Before reporting regression results, I present evidence that the labor supply shock to the border region was significant in size. Panel (A) of Figure 2.4 shows raw means of the inflow of Czech/EU8 workers to treated (dark and light blue line) compared to control (dark and light red line) regions. The figure presents three key findings: First, before 2010, the share of Czech and EU8 workers was constant with little change. Second, starting in 2011, the share started to gradually, and persistently, increase in the border region. By 2017, the share of EU8 workers in the border region was about $7 \%$, corresponding to a raw increase by about 5 percentage points relative to 2010. Third, while control municipalities experienced almost no inflow of Czech workers, there is a gradual increase in the share of EU8 workers; with 2 percentage points, this increase is however much smaller than in the border region. I am aware that due to this inflow of EU8 workers to controls, my setting does not allow me to estimate the effects of a clean labor supply shock. It is likely that my results present lower-bound effects of what would have happened if the policy was restricted to the border region.

To prove that the migrant inflow to the German border region was statistically significant, I report eventstudy coefficients derived from estimating Equation 2.1 with year and municipality fixed effects. Panel (B) of Figure 2.4 shows the results for the inflow of Czech workers and the inflow of EU8 workers. For both origin groups, it is clear that the migrant worker inflow to the border region was positive and substantially different compared to the inflow to control regions. Whereas in 2012, the share of EU8 workers by total employment in the border region was only about 0.8 percentage points larger than in control municipalities, in 2017 this difference had increased to about 2.8 percentage points. 
Figure 2.4: Migrant Worker Inflow to German Municipalities

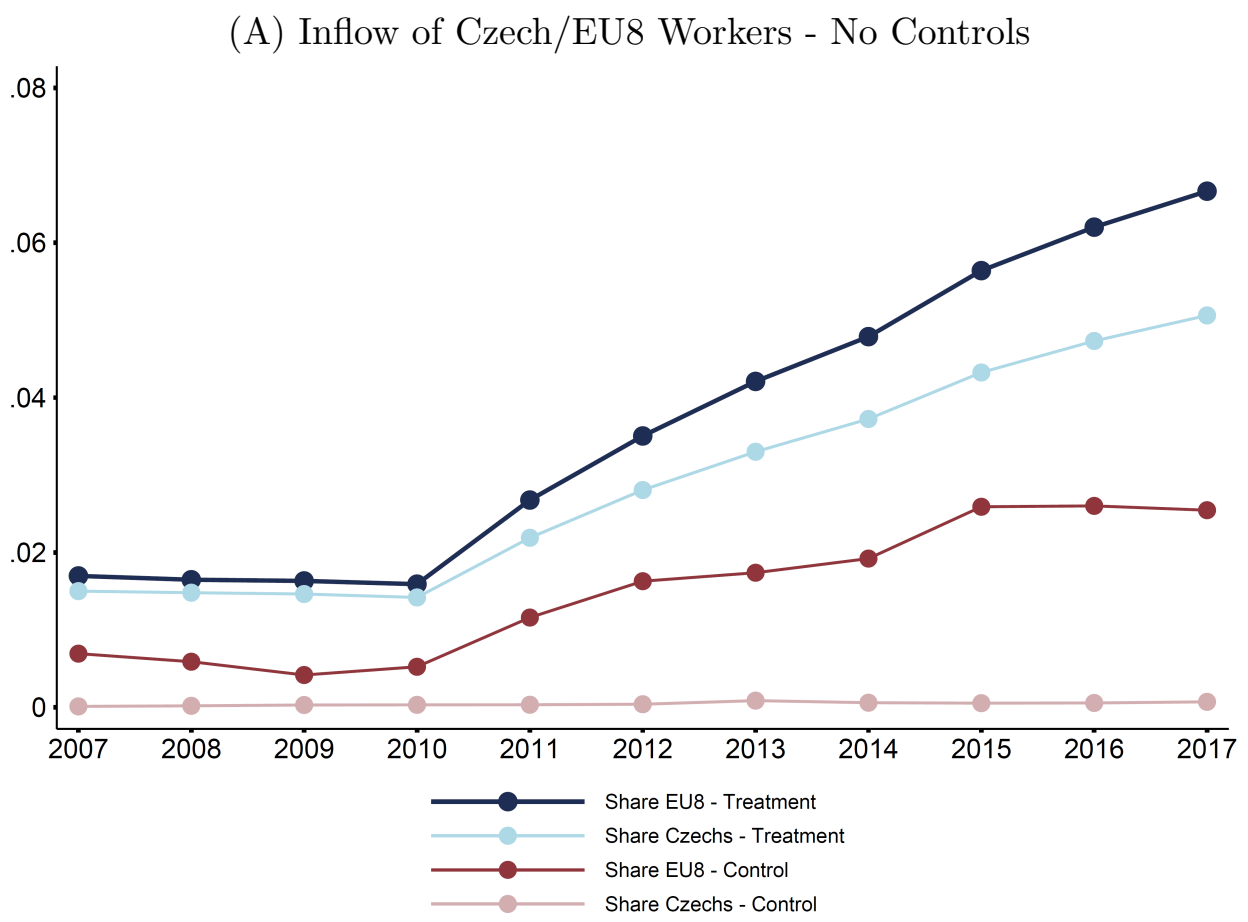

(B) Inflow of Czech/EU8 Workers - Eventstudy Coefficients

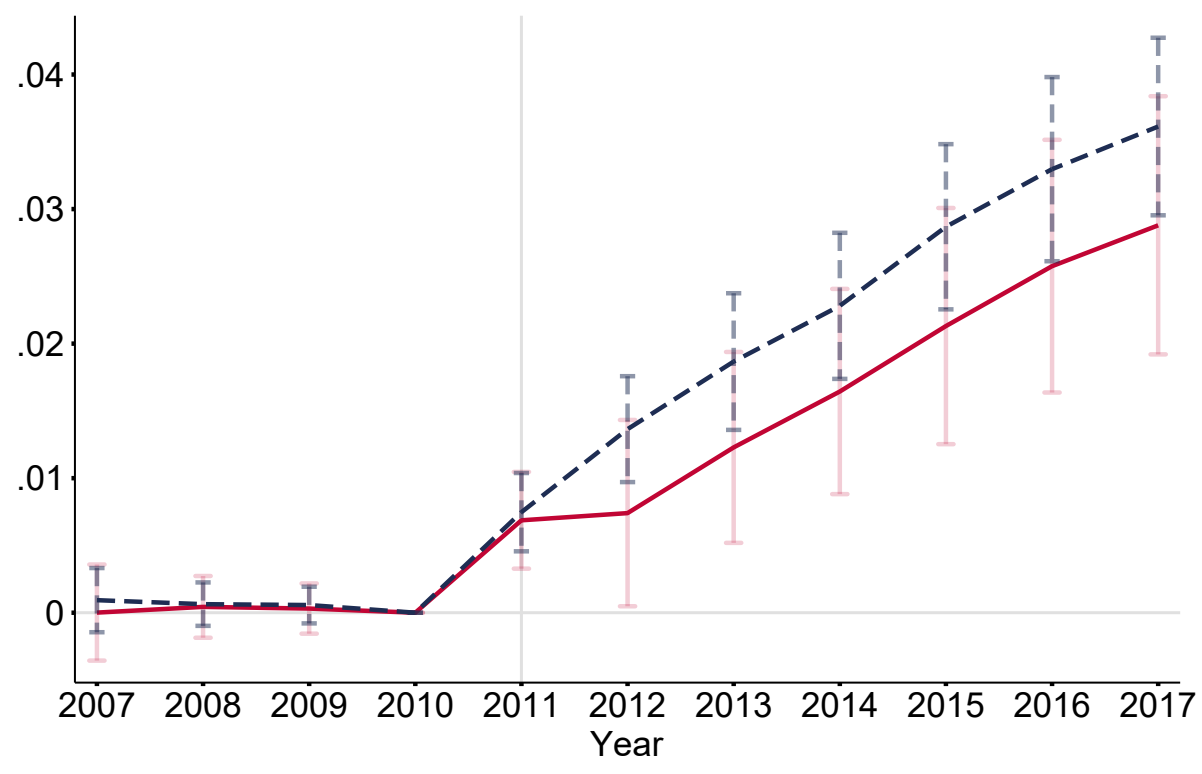

Share EU8 Workers

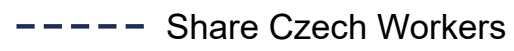

Notes: This figure shows size and nature of the inflow of Czech workers to the West German border region after the opening of the German labor market in 2011. Panel (A) shows raw means of the share of Czech/EU8 workers by total employment for German treated (blue lines) and control (red lines) municipalities, respectively. Panel (B) reports eventstudy coefficients $\beta_{t}$ from Equation 2.1 which show the differential inflow to treated vs. control municipalities. Treated municipalities are all municipalities located up to $40 \mathrm{~km}$ from the nearest road border crossing to the Czech Republic (measured by airline distance from municipality centroid). West Germany only. Data are aggregated at the municipality level. 95-\% confidence intervals reported. Source: Integrated Employment Biographies (IEB). 


\subsection{Results}

This section contains two parts: First, I report the regional-level regression results for both Czech Republic and Germany. Second, I report my worker-level results, focusing on native incumbent workers in Germany.

\subsubsection{Regional-Level Analysis}

Figure 2.5 focuses on Czech Republic, showing the evolution of unemployment rates (Panel (A)) and vacancies (Panel (B)). In line with the standard assumptions of the difference-in-differences approach, there are no statistically significant differences between treated and control municipalities in the years leading up to the policy change. Starting in 2011, there is a clear downward trend in unemployment rates in the Czech border region, amounting to a decrease of about 0.5 percentage points. To put this into context: The average border municipality reported unemployment rates of about $9 \%$ in $2010 .{ }^{20}$ This holds both for men and women.

For vacancies, we observe the reverse pattern: Vacancies started to increase in the border region relative to control municipalities after 2011. This increase is only statistically significant in the year 2014, and estimated very impresicely thereafter. In 2014, the average treated municipality had, on average, 2.36 more vacancies than the average control municipality. ${ }^{21}$ For both panels, Table A.2.6 in the appendix reports the corresponding eventstudy coefficients.

Overall, the results suggest that open positions due to the Czech commuter outflow were only partly filled by unemployed individuals or Czechs moving to the border region from other places. The policy change may thus have resulted in worker shortages and subsequently productivity constraints for Czech local firms. It is possible that the increase in vacancies did not only result from the negative labor

\footnotetext{
${ }^{20}$ Note that unfortunately, the Czech Statistical Office does not provide data for 2012 and 2013 due to a data revision. In Table 2.5, I therefore report additional difference-in-differences results for unemployment rates at the county level for which all years are available. The pattern is very similar.

${ }^{21}$ Note that in addition, I estimate the regression model on the county level to take advantage of the full set of years. The coefficient on the difference-in-differences term on the county level is much larger, amounting to on average 225 more vacancies in the average treated county after 2011. This magnitude is reasonable given the relatively larger size of Czech counties compared to municipalities.
} 
Figure 2.5: Regional Labor Market Effects in the Czech Republic

(A) Unemployment Rates in the Czech Republic - County Level
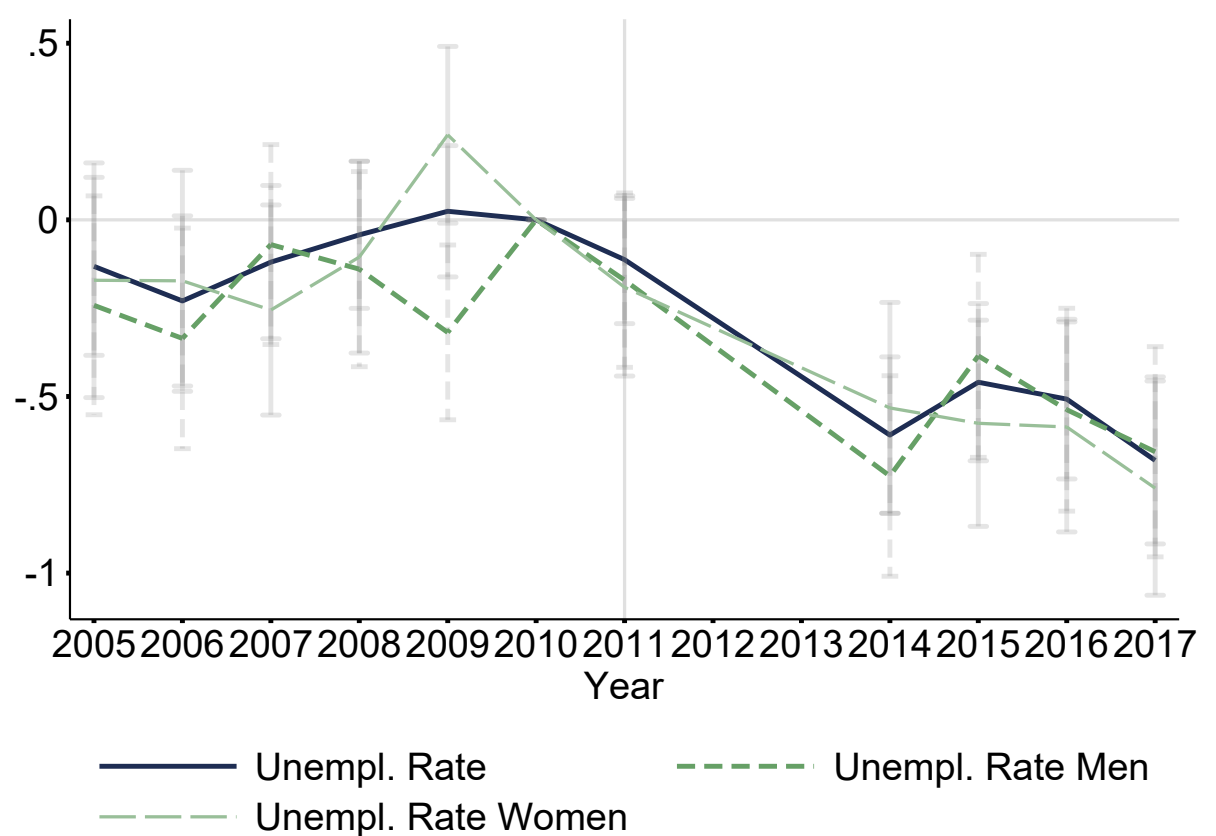

(B) Vacancies in the Czech Republic - County Level

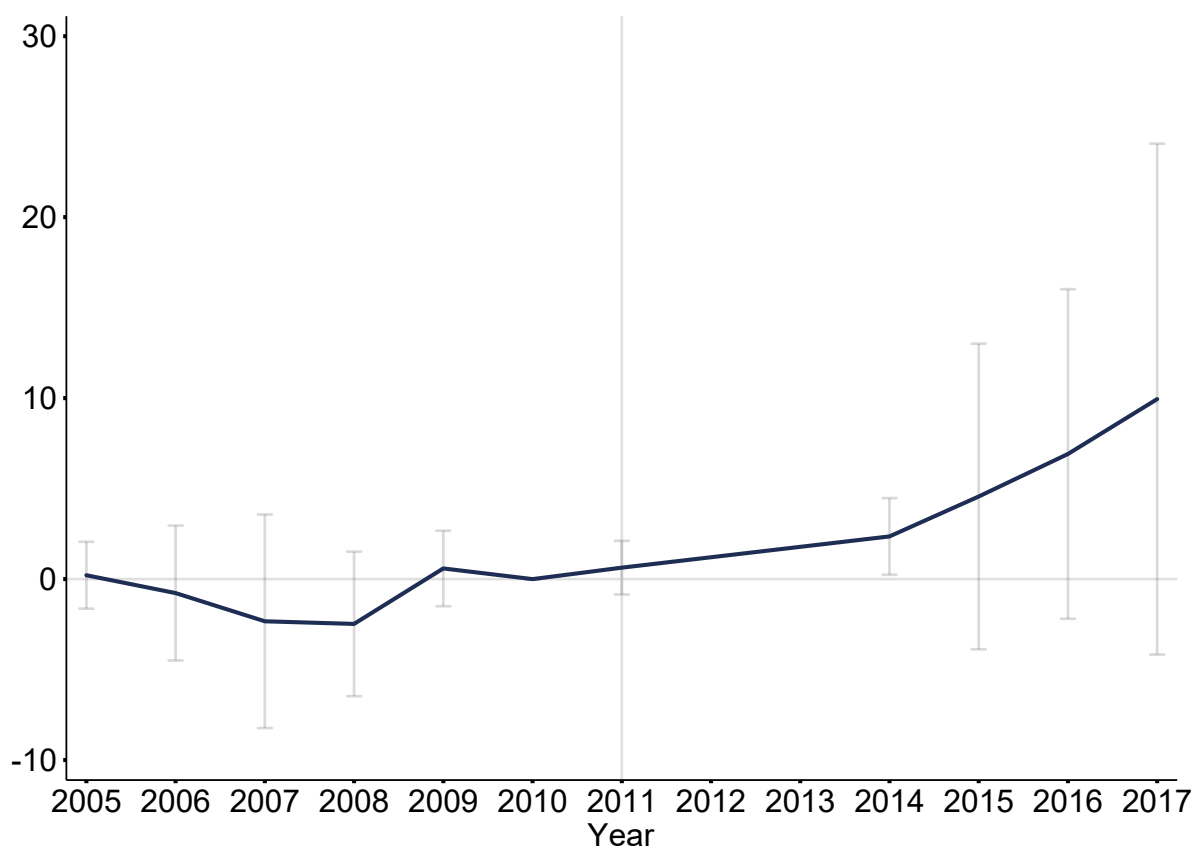

Notes: This figure shows the impact of the opening of the German labor market for Czech workers in 2011 on the labor market in the Czech border region. Panel (A) reports the impact on local unemployment rates, Panel (B) reports the impact on vacancies. The y-axis reports eventstudy coefficients $\beta_{t}$ from Equation 2.1 which measure the differential effect in treated vs. control municipalities. Treated municipalities are all municipalities located in a county bordering either Germany or Austria. Data for 2012 and 2013 are missing. 95-\% confidence intervals reported. Source: Czech Statistical Office. 
Table 2.5: Regional Characteristics - Czech Counties

\begin{tabular}{|c|c|c|c|c|}
\hline & $\begin{array}{c}\text { Unemployment } \\
\text { Rate }\end{array}$ & $\begin{array}{c}\text { Unemployment } \\
\text { Rate } \\
\text { Men }\end{array}$ & $\begin{array}{c}\text { Unemployment } \\
\text { Rate } \\
\text { Women }\end{array}$ & $\begin{array}{l}\text { Unemployed } \\
\text { (Levels) }\end{array}$ \\
\hline \multicolumn{5}{|c|}{ Panel A: Unemployment } \\
\hline Diff-in-Diff & $\begin{array}{c}-0.45 \\
(0.23)^{*}\end{array}$ & $\begin{array}{c}-0.52 \\
(0.25)^{* *}\end{array}$ & $\begin{array}{l}-0.37 \\
(0.24)\end{array}$ & $\begin{array}{l}-184.0 \\
(281.5)\end{array}$ \\
\hline Observations & 560 & 560 & 560 & 560 \\
\hline$R^{2}$ & 0.929 & 0.922 & 0.926 & 0.949 \\
\hline Mean of dep. var & 7.07 & 7.02 & 7.12 & 6362.4 \\
\hline County FE & Yes & Yes & Yes & Yes \\
\hline \multirow[t]{2}{*}{ Year FE } & Yes & Yes & Yes & Yes \\
\hline & Vacancies & Applicants per Job & Vacancies for Graduates & Inflows \\
\hline \multicolumn{5}{|c|}{ Panel B: Vacancies } \\
\hline Diff-in-Diff & $\begin{array}{c}225.2 \\
(108.9)^{* *}\end{array}$ & $\begin{array}{c}-2.90 \\
(1.63)^{*}\end{array}$ & $\begin{array}{c}28.5 \\
(47.0)\end{array}$ & $\begin{array}{c}30.9 \\
(114.0)\end{array}$ \\
\hline Observations & 560 & 560 & 556 & 560 \\
\hline$R^{2}$ & 0.760 & 0.707 & 0.712 & 0.875 \\
\hline Mean of dep. var & 929.5 & 15.2 & 216.9 & 1708.5 \\
\hline County FE & Yes & Yes & Yes & Yes \\
\hline \multirow[t]{2}{*}{ Year FE } & Yes & Yes & Yes & Yes \\
\hline & Total Population & Aged $0-14$ & Aged 15-64 & Aged 65 or older \\
\hline \multicolumn{5}{|c|}{ Panel C: Population } \\
\hline Diff-in-Diff & $\begin{array}{c}-30.6 \\
(1293.1)\end{array}$ & $\begin{array}{l}-450.6 \\
(348.8)\end{array}$ & $\begin{array}{c}863.1 \\
(1304.3)\end{array}$ & $\begin{array}{l}-443.1 \\
(480.1)\end{array}$ \\
\hline Observations & 480 & 480 & 480 & 480 \\
\hline$R^{2}$ & 0.999 & 0.995 & 0.997 & 0.993 \\
\hline Mean of dep. var & 121950.1 & 18335.5 & 83423.8 & 20190.8 \\
\hline County FE & Yes & Yes & Yes & Yes \\
\hline \multirow[t]{2}{*}{ Year FE } & Yes & Yes & Yes & Yes \\
\hline & Total Crime & Property Crime & Economic Crime & Burglary \\
\hline \multicolumn{5}{|l|}{ Panel D: Crime } \\
\hline Diff-in-Diff & $\begin{array}{c}32.2 \\
(197.4)\end{array}$ & $\begin{array}{c}75.8 \\
(154.3)\end{array}$ & $\begin{array}{l}-11.1 \\
(35.1)\end{array}$ & $\begin{array}{l}-0.64 \\
(6.14)\end{array}$ \\
\hline Observations & 560 & 560 & 560 & 560 \\
\hline$R^{2}$ & 0.952 & 0.943 & 0.894 & 0.865 \\
\hline Mean of dep. var & 3201.5 & 2390.9 & 341.2 & 341.2 \\
\hline County FE & Yes & Yes & Yes & Yes \\
\hline Year FE & Yes & Yes & Yes & Yes \\
\hline
\end{tabular}

Notes: This table shows how a number of regional characteristics in the Czech border region changed following the outflow of Czech workers. It reports difference-in-differences fixed-effects regression results on the county level for different outcome variables for the Czech Republic. "Diff-in-Diff" reports the coefficient on the interaction of a dummy for border region with a dummy for all years from 2011. Panel A reports results for different unemployment outcomes. Panel B reports results for different vacancy outcomes and worker inflows. Vacancies reports number of vacancies reported at the employment offices on December 31 in a given year. Panel C reports results for different population outcomes. Panel D reports results for different crime outcomes. Economic crime is defined as non-violent crimes with a destabilizing impact on society and economy. One example is internet crime. In all specifications, standard errors are clustered at the county level. *, ** and ${ }^{* * *}$ correspond to 10, 5 and 1 percent significance levels, respectively. County-level data for the Czech Republic, provided by the Czech Statistical Office. 
supply shock, but also from the positive demand shock due to increased consumption by Czech commuters. With the data at hand, it is difficult to assess which of the mechanisms dominated. Panel $\mathrm{B}$ in Table 2.5 gives one hint: It shows that after 2011, the number of applicants for a given job decreased by about 3 in the border region compared to controls. It thus seems that part of the increase in vacancies was indeed driven by Czech workers finding better job opportunities in Germany.

Table 2.5 moreover gives a few hints on what else happened in the border region after the policy change. Panel $\mathrm{C}$ shows how the population composition changed in terms of age, and Panel D shows a few crime outcomes. These coefficients have large standard errors and are insignificant. Overall, the sign of the coefficients suggests that after 2011, inflows to the border region and the stock of working age population increased. While there was more total crime and property crime in the border region, there was less economic crime (e.g., internet crime) and burglary.

To sum up, the policy change was clearly beneficial for local Czech workers: Given the large wage differential between German and Czech wages, Czech commuters' wages likely increased, even though I cannot directly test this. At the same time, Czech stayers were able to fill open positions, and potentially also benefited from an increase in local demand. The results for Czech Republic thus support what standard economic theory would predict for a negative labor supply shock: The clear downward trend in unemployment rates in Panel (B) of Figure 2.6 suggests that employment rates in the Czech border region increased from 2011 onward. From the standard model, one would moreover expect an increase in Czech wages in the border region; given the non-availability of data unfortunately I cannot test this. For Czech firms, on the other hand, the policy change may have resulted in skill shortages.

Figure 2.6 shows the evolution of native wages and employment in matched German municipalities. It plots eventstudy coefficients from Equation 2.1, where the outcomes are average log native wage (dark blue, dashed line), and the share of employed natives by native employment in 2010 (light blue, solid line). In line with the key identifying assumption of the difference-in-differences model, there are no statistically significant pre-trends between border and control municipalities. For the period following 2011, the graph provides two insights: First, there is a decreasing trend in regional native wages. By 2013, wage growth in the treated regions was about $2 \%$ lower than in matched controls. Wages remain on this track of lower 
Figure 2.6: Native Wages and Employment in Germany - Municipality Level

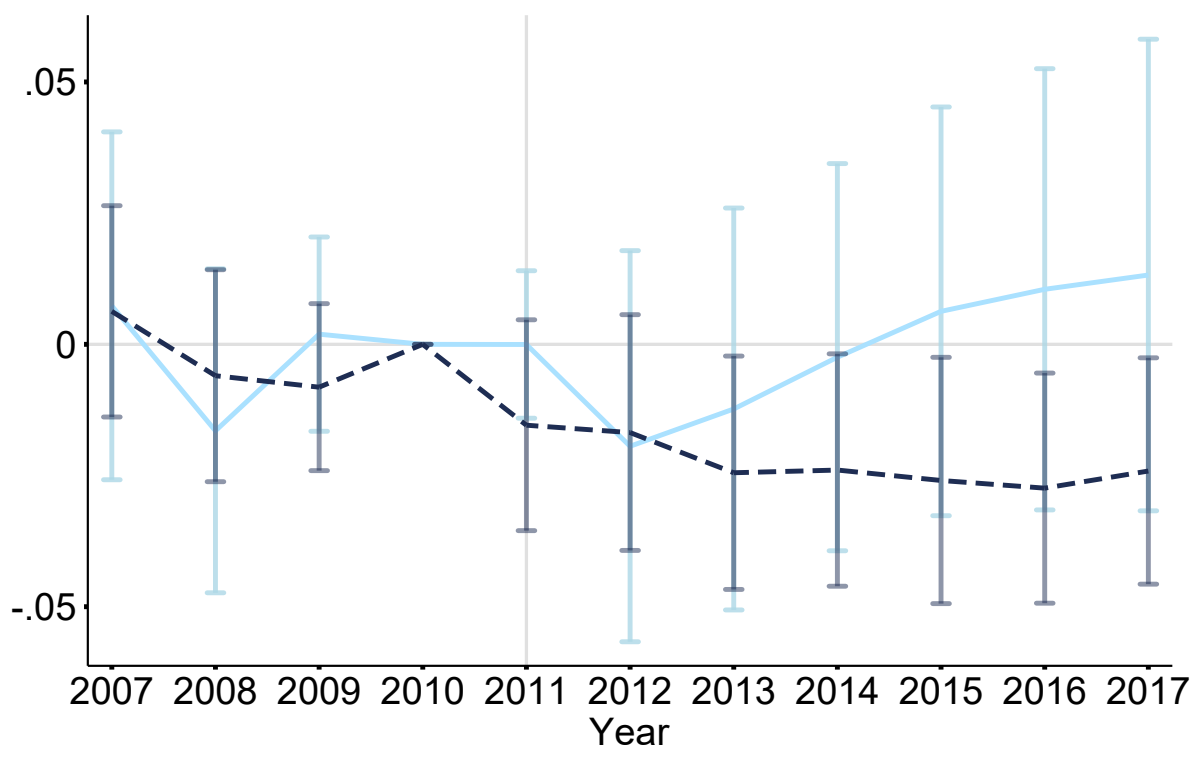

Native Employment - -----· Log Native Wage

Notes: This figure shows the impact of the opening of the German labor market for Czech workers in 2011 on native wages and employment in Germany. The y-axis reports eventstudy coefficients $\beta_{t}$ from Equation 2.1 which measure the differential effect in treated vs. control municipalities. Treated municipalities are all municipalities located up to $40 \mathrm{~km}$ from the nearest road border crossing to the Czech Republic (measured by airline distance from municipality centroid). West Germany only. Wages are measured in logs and deflated with 2010 as base year. Native employment is defined as the share of native employment by native employment in 2010. Data are aggregated at the municipality level. 95-\% confidence intervals reported. Source: Establishment History Panel (BHP). 
wage growth until 2017. To put this into context: The daily wage in the average establishment in the border region in 2010 was EUR 51. Taking this as reference point, and under the assumption of zero wage growth in the border region, the average treated worker earned about 1 EUR less per day than she could have earned, had the wages developed on the same trajectory as in the control group.

The second takeaway from Figure 2.6 is that there was no statistically significant change in the regional employment rate for natives. I define native employment as the share of native employment by native employment in 2010. While there seems to be a short-term downward trend in native employment, followed by a continuous increase from 2013 onwards, the coefficients are noisy and not statistically significant. If I use the rest of Bavaria as control group or synthetic control group matching, this pattern is confirmed and appears stronger (see Section 2.7).

Figure 2.6 only reports changes in average native employment; it may thus hide more specific underlying trends. To shed more light on how the workforce composition in the German border region changed, I estimate difference-in-differences type of regressions with different native worker group shares as outcome. Table 2.6 presents the results which show that there were no substantial changes in terms of employment composition.

Panel A reports coefficients on employment shares by native employment in 2010 for different skill groups and shows that the share of high-skilled workers in the border region slightly decreased (Column (3), coefficient significant), while the share of medium-skilled workers increased (Column (2), coefficient insignificant). This stands in contrast to the results by Beerli et al. (2021) who find that demand for high-skilled Swiss workers in the Swiss border region increased following an inflow of EU workers. One possible explanation is that to take advantage of the commuter inflow's skill composition, which was mainly medium-skilled, firms in the border region specialized in industries which required more medium-skilled workers.

Panel B reports employment shares for different age groups and shows that the age share of younger workers (aged 15-29) slightly decreased after 2011 compared to controls. This suggests that after the policy change, native outsiders faced greater difficulties to find a job in the border region. Note that in both Panels A and B, the coefficients only tell us about the change in employment in a given group relative to employment in 2010. They thus provide information about changes in the workfoce composition but one has to keep in mind that overall employment also changed 


\title{
Table 2.6: Municipality-Level Difference-in-Differences Germany
}

\author{
Share Low-Skilled Share Medium-Skilled Share High-Skilled
}

\begin{tabular}{|c|c|c|c|}
\hline \multicolumn{4}{|c|}{ Panel A: Skill Composition } \\
\hline \multirow[t]{2}{*}{ Diff-in-Diff } & -0.0034 & 0.016 & -0.0063 \\
\hline & $(0.011)$ & $(0.019)$ & $(0.0032)^{* *}$ \\
\hline Observations & 5344 & 5344 & 5344 \\
\hline$R^{2}$ & 0.598 & 0.489 & 0.658 \\
\hline Mean of dep. var & 0.25 & 0.77 & 0.041 \\
\hline County FE & Yes & Yes & Yes \\
\hline \multirow[t]{2}{*}{ Year FE } & Yes & Yes & Yes \\
\hline & Share Aged 15-29 & Share Aged 30-49 & Share Aged 50 or Older \\
\hline \multicolumn{4}{|c|}{ Panel B: Age Composition } \\
\hline \multirow[t]{2}{*}{ Diff-in-Diff } & -0.019 & 0.013 & 0.012 \\
\hline & $(0.010)^{*}$ & $(0.014)$ & $(0.011)$ \\
\hline Observations & 5344 & 5344 & 5344 \\
\hline$R^{2}$ & 0.592 & 0.462 & 0.595 \\
\hline Mean of dep. var & 0.25 & 0.46 & 0.35 \\
\hline County FE & Yes & Yes & Yes \\
\hline \multirow[t]{2}{*}{ Year FE } & Yes & Yes & Yes \\
\hline & Share Geographic Movers & Share Employed Women & Share Full-time Employed \\
\hline \multicolumn{4}{|c|}{ Panel C: Other Employment Shares } \\
\hline \multirow[t]{2}{*}{ Diff-in-Diff } & -0.013 & 0.0075 & -0.0091 \\
\hline & $(0.0028)^{* * *}$ & $(0.0065)$ & $(0.0078)$ \\
\hline Observations & 5344 & 5344 & 5344 \\
\hline$R^{2}$ & 0.392 & 0.812 & 0.773 \\
\hline Mean of dep. var & 0.060 & 0.48 & 0.50 \\
\hline County FE & Yes & Yes & Yes \\
\hline Year FE & Yes & Yes & Yes \\
\hline
\end{tabular}

Notes: This table reports how the workforce composition changed in the German border region following the inflow of Czech workers. It presents difference-in-differences fixed-effects regression results at the municipality level for different outcome variables for Germany. Outcome variables show different employment group shares by native employment in 2010. "Diff-in-Diff" reports the coefficient on the interaction of a dummy for being located in the border region with a dummy for all years from 2011. Panel A reports results for employment shares of different skill groups. Low-skilled workers have no vocational training, medium-skilled workers have vocational training, high-skilled workers have a university degree. Panel B reports results for employment share of different age groups. Panel C reports results for the share of geographic movers (Column (1)), the share of female workers (Column (2)), and the share of full-time workers (Column (3)). A geographic mover is someone who moves to a different county not in the border region. In all specifications, standard errors are clustered at the municipality level. *, ** and $* * *$ correspond to 10,5 and 1 percent significance levels, respectively. Municipality-level data for Germany. Source: Integrated Employment Biographies (IEB). 
between 2011-2017. The changes in the three coefficients in each row thus need not be symmetric.

Panel $\mathrm{C}$ shows that in contrast to workers in the control group, treated workers were less mobile: Their probability to move was around 1.3 percentage points lower following 2011. ${ }^{22}$ While previous studies have documented that immigration does not necessarily lead to native outflows (e.g., Card (2001)), it is surprising that the coefficient is negative. One explanation could be that the share of workers owning homes in the border region is higher than in controls; unfortunately I cannot test this with the data at hand. Last, Columns (2) and (3) of Panel (C) show that there was no change in the share of employed women and full-time employed workers.

For Germany, the results are overall largely in line with the canonical model predictions: If firms do not adjust their capital in the short term, native workers' wages decrease, but employment remains relatively stable. Other than predicted by the model, wages did not recover in the long-term but remained on a constantly lower growth trajectory. One potential explanation is that, as Figure 2.4 shows, the immigrant inflow was not sharp and sudden; instead, the share of Czech workers constantly increased over time. For German firms, this means that they would have to update their expectations on the capital to labor ratio constantly. The constant availability of new Czech workers may have also shifted wage bargaining power from native workers to firms in the long term.

\subsubsection{Worker-Level Analysis}

Let me now turn to the second part of this study, and provide evidence on incumbent native workers in Germany (i.e., workers who were employed in the matched municipalities in 2010). Figure 2.7 presents eventstudy coefficients from Equation 2.3. The outcome variables are native log earnings (Panel (A)), native log wages (Panel (B)), native employment (Panel $(\mathrm{C})$ ), and native days worked (Panel (D)). The solid blue line reports results with DiNardo et al. (1996) reweighting, which is my preferred specification; the dashed light blue line reports results without reweighting. Table A.2.9 in the appendix reports the corresponding eventstudy coefficients.

Panel (A) shows that native earnings before and after the policy change did not differ in treated compared to control municipalities. Once I split up earnings into

\footnotetext{
${ }^{22}$ Note that I define mobility as moves to a different county outside the border region.
} 
Figure 2.7: Labor Market Outcomes of Native Incumbents in Germany

(A) Incumbent Natives Log Earnings

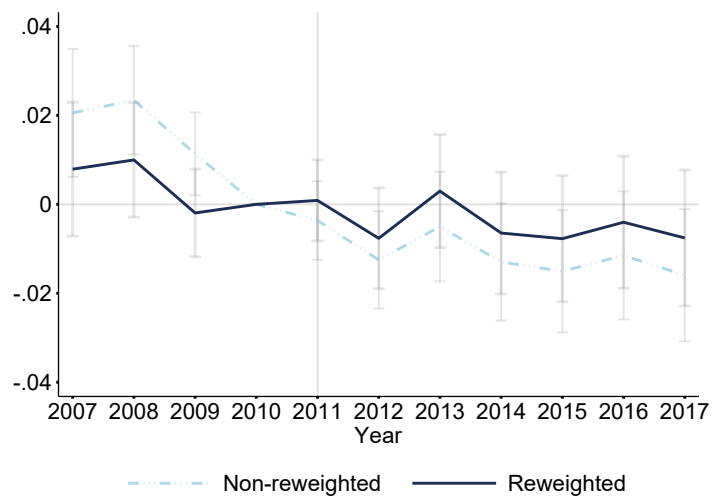

(C) Incumbent Natives Employment

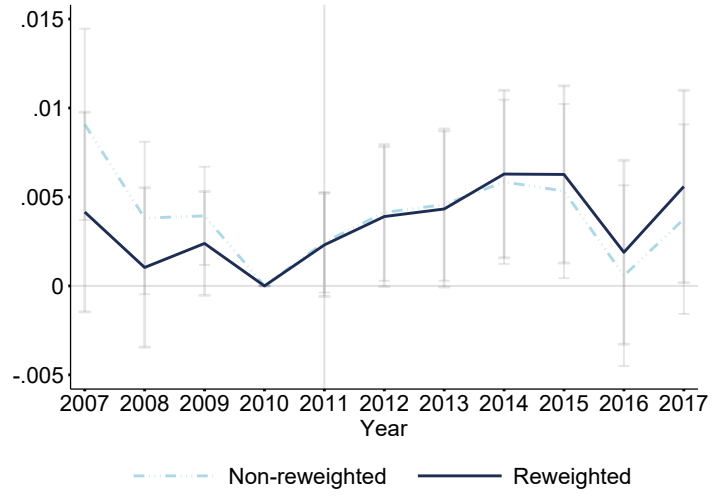

(B) Incumbent Natives Log Wages

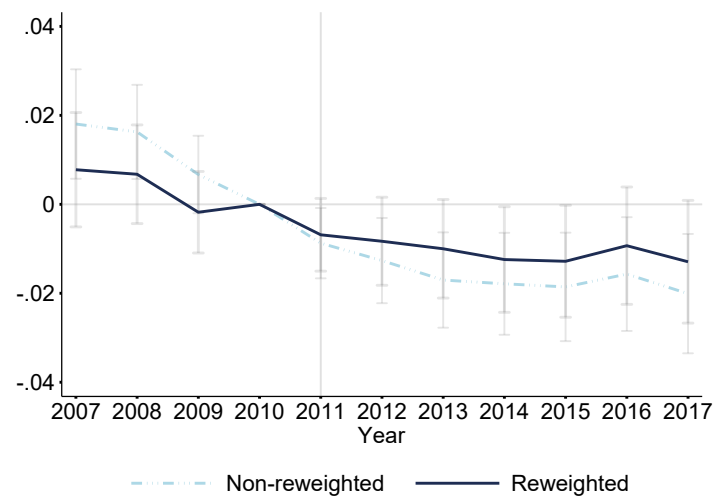

(D) Incumbent Natives Days Worked

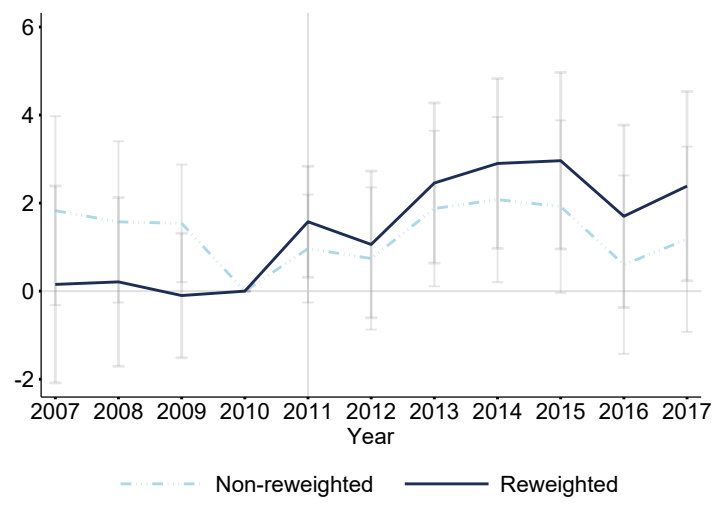

Notes: This figure shows the impact of the opening of the German labor market for Czech workers in 2011 on native incumbent workers in Germany. The sample includes workers who were employed in the matched municipalities in 2010, aged 18-55. The y-axis reports eventstudy coefficients $\beta_{t}$ from Equation 2.3 which measure the differential evolution of outcomes for treated vs. control workers. In all panels, the solid blue lines report results with worker reweighting, the dashed light blue lines report results without worker reweighting. Panel (A) reports incumbent native log earnings, Panel (B) reports incumbent native log wages, Panel (C) reports incumbent native employment, Panel (D) reports incumbent native days worked per year. West Germany only. 95-\% confidence intervals reported. Source: Integrated Employment Biographies (IEB). 
wages and employment, a clear pattern becomes visible: While there is no difference pre treatment, treated native workers' log wages grew slower than control workers' wages after 2011 (by about 1\%). At the same time, native incumbent workers in the border region slightly increased their employment starting two years after the policy change, both in terms of the probability to work (about 0.5 percentage points) and in terms of days worked per year (about 3 more days). The results thus suggest that native workers tried to make up for lower growth by working slightly more, resulting in zero earnings losses.

While I also find lower wage growth on the regional level, the result of increased employment is not in line with my regional-level evidence of no employment effects. One possible explanation is that while native insiders increased their employment, native outsiders, i.e. workers not employed in the border region before 2011, faced greater difficulties in job search after the policy change. The results in Table 2.6, which show that the share of young workers in the border region slightly decreased after 2011, are suggestive of this.

In my baseline sample, I keep both workers who moved out of their region after 2011, and who stayed in the matched regions. I do this to not condition on posttreatment outcomes (mobility) in my main specification. Yet to show that outcomes differ by mobility, Figure 2.8 presents evidence for native movers. In both treated and control municipalities, these are workers who moved to a different commuting zone outside the matched regions after 2011. For this group of workers, there were hardly any differences in labor market outcomes: Neither for log earnings (Panel (A)), nor for wages (Panel (B)) and employment (Panels (C) and (D)). The results thus suggest that native movers did not face any wage losses compared to movers in the control group. ${ }^{23}$ One has to bear in mind that native movers and stayers may be very different groups; one should thus not directly compare their outcomes. Table A.2.10 in the appendix reports the corresponding eventstudy coefficients.

In a last step, I examine whether wage losses for native workers were driven by specific worker groups. In Figure 2.9, I therefore report coefficients for the outcomes log wages and days worked, estimated separately by different tenure and skill groups. In all regressions, treated workers are reweighted to control workers. Panel (A)

\footnotetext{
${ }^{23}$ Note that in Panels (A) and (B) of Figure 2.8, a post-treatment gap opens up for the reweighted vs. non-reweighted coefficients. Yet for all of these, confidence intervals overlap, meaning that there are essentially no statistically significant differences between the two versions.
} 
Figure 2.8: Labor Market Outcomes of Native Incumbent Movers in Germany

(A) Native Movers - Log Earnings

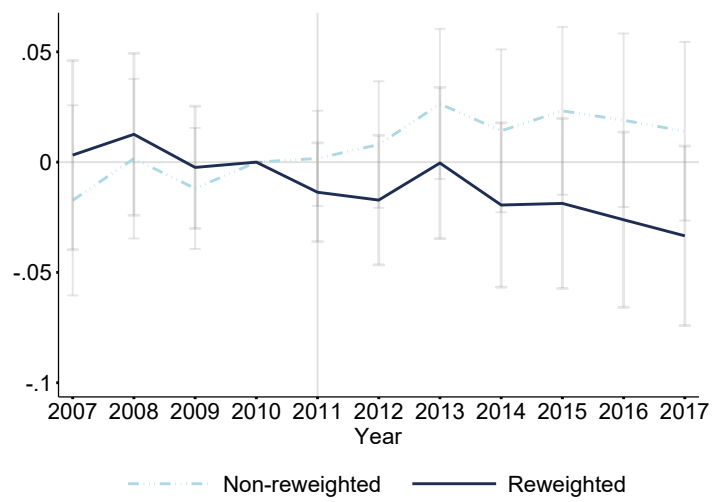

(C) Native Movers - Employment

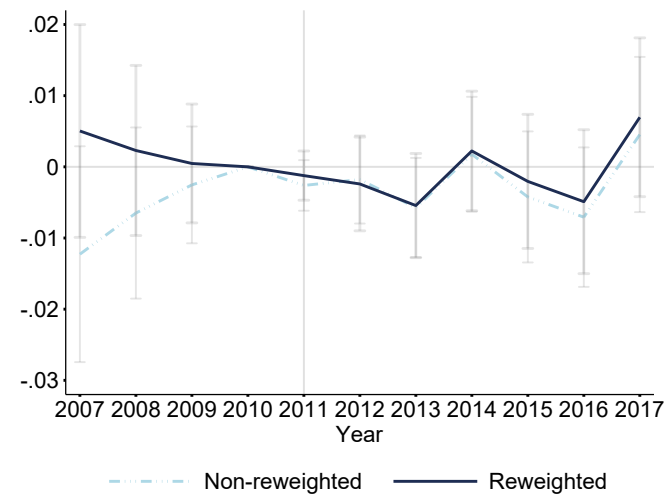

(B) Native Movers - Log Wages

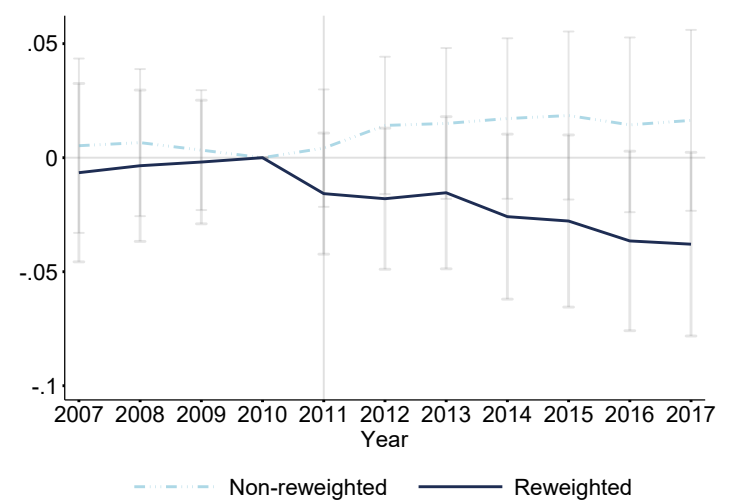

(D) Native Movers - Days Worked

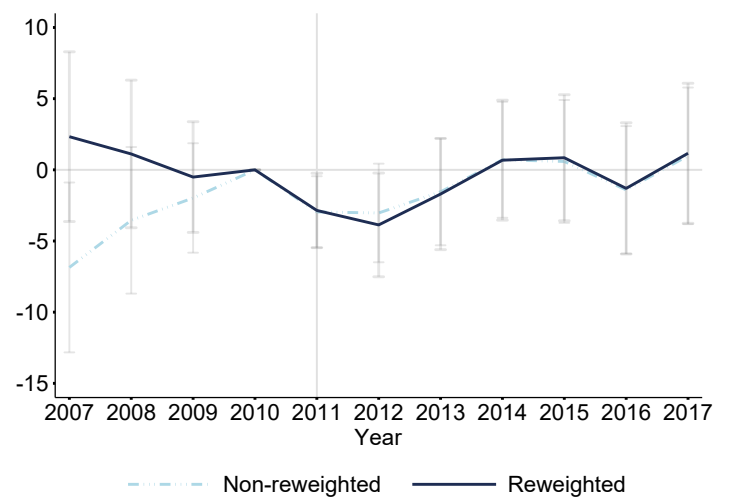

Notes: This figure shows the impact of the opening of the German labor market for Czech workers in 2011 on native incumbent movers in Germany. The sample includes workers who were employed in the matched municipalities in 2010, aged 18-55. Workers in both treated and control municipalities move away from their respective municipality after 2011; to be more precise, they move to a different commuting zone not in the matched regions. The y-axis reports eventstudy coefficients $\beta_{t}$ from Equation 2.3 which measure the differential effect for treated vs. control workers. In all panels, the solid blue lines report results with worker reweighting, the dashed light blue lines report results without worker reweighting. Panel (A) reports incumbent native log earnings, Panel (B) reports incumbent native log wages, Panel (C) reports incumbent native employment, Panel (D) reports incumbent native days worked per year. West Germany only. 95-\% confidence intervals reported. Source: Integrated Employment Biographies (IEB). 
reports native log wages by tenure. The dashed light blue line reports results for native workers with less than 1 year of tenure in 2010, the solid blue line reports results for native workers with at least 1 year of tenure in 2010, and the red dashed line reports results for native workers with at least 3 years of tenure in 2010. From the graph, it is evident that the wage losses are fully driven by workers with less than 1 year of tenure in 2010. These earned substantially lower wages than workers in the control regions: By 2015, their wages were around $10 \%$ lower than wages of control workers. It is not surprising that low-tenure workers faced the largest reduction in wages; they typically have less stable employment biographies, and, with short-term contracts, lower bargaining power in wage negotiations.

Panel (B) of Figure 2.9 shows that in turn, workers in all 3 tenure groups increased the number of days worked per year. For workers with less than 1 year of tenure, these coefficients are very noisy which makes it difficult to directly compare outcomes pre and post treatment. All in all, the coefficients do not suggest strong differential trends in employment by tenure group. Table A.2.11 in the appendix reports the corresponding eventstudy coefficients by tenure group.

Panels (C) and (D) of Figure 2.9 show native wages and days worked by skill groups. Panel (C) shows that high-skilled treated workers wages' did not decrease compared to high-skilled control workers' wages. Medium-skilled workers faced the largest wage losses and they are the only group for which the coefficients following 2011 are statistically significant (around $-1.6 \%$ ). Given that most Czech workers were medium-skilled and thus likely substitutes for medium-skilled native workers it is not surprising that their wages were most affected. Panel (D) shows that in terms of days worked, it is also medium-skilled workers who are most likely to increase employment. Following 2011, they expanded employment by 1-2 days worked per year, and the coefficient is statistically significant for 2013-2015. Table A.2.12 in the appendix reports the corresponding eventstudy coefficients by skill group.

\subsection{Robustness Checks}

\section{Synthetic Control Group Matching}

My regional-level results are robust to several robustness checks, most notably syn- 
Figure 2.9: Native Incumbent Workers by Tenure and Skill

(A) Natives Log Wages by Tenure

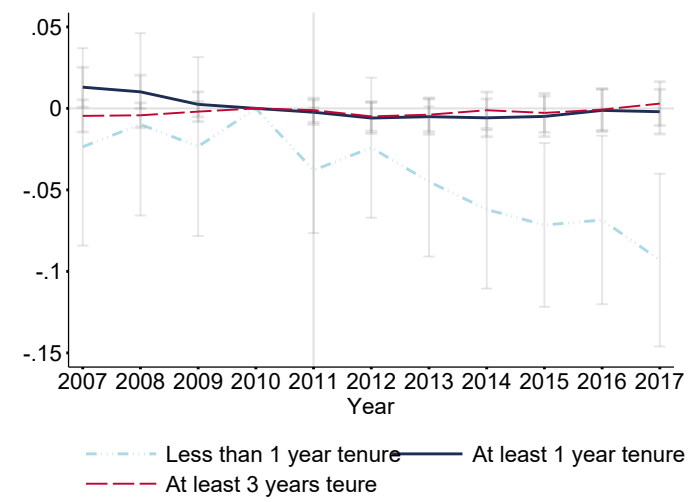

(C) Natives Log Wages by Skill

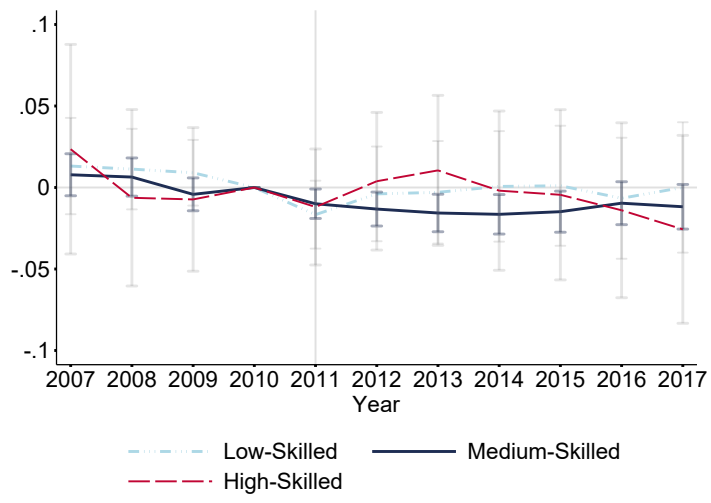

(B) Natives Days Worked by Tenure

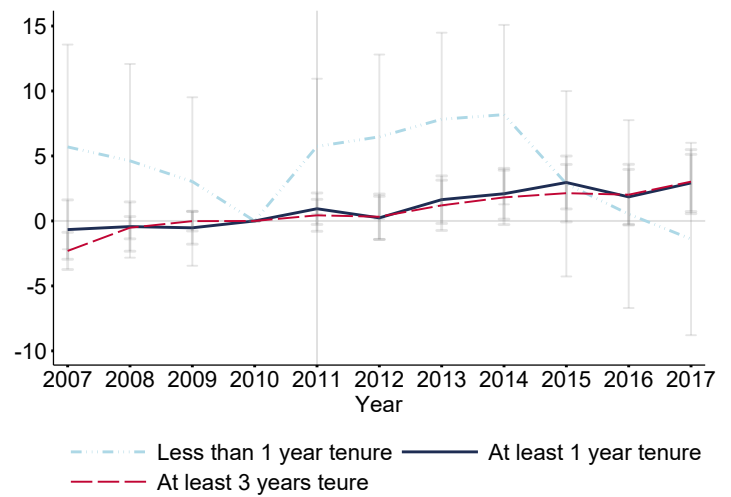

(D) Natives Days Worked by Skill

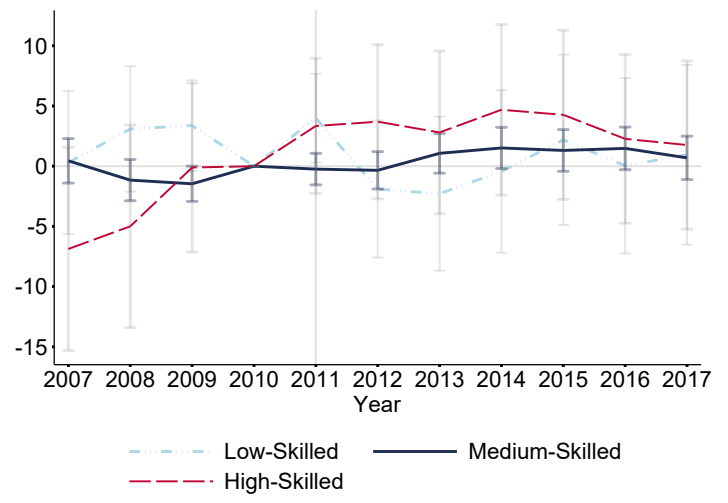

Notes: This figure shows the impact of the opening of the German labor market for Czech workers in 2011 on native incumbent workers by tenure and skill groups in Germany. The sample includes workers who were employed in the matched municipalities in 2010, aged 18-55. The y-axis reports eventstudy coefficients $\beta_{t}$ from Equation 2.3 which measure the differential effect for treated vs. control workers. Panels (A) and (B) report incumbent native log wages and employment by tenure: For workers with less than 1 year tenure in 2010 (dashed light blue line), workers with at least 1 year tenure in 2010 (solid dark blue line), and workers with at least 3 years tenure in 2010 (dashed red line). Panels (C) and (D) report incumbent native log wages and employment by skill: For high-skilled workers (dashed red line), medium-skilled workers (solid dark blue line), and low-skilled workers (dashed light blue line). West Germany only. 95-\% confidence intervals reported. Source: Integrated Employment Biographies (IEB). 
thetic control group matching in the spirit of Abadie and Gardeazabal (2003). ${ }^{24}$ synthetic control group matching ensures high balance between treatment and control group pre-treatment and it is particularly valuable if it is difficult to find a suitable control group. The main difference to propensity score matching is that with synthetic matching, the control group is a weighted average of all potential treatment regions. The pre-treatment fit is therefore usually very good by construction.

I start with Czech counties and once again define the treatment group as all counties directly bordering Germany or Austria. To generate the synthetic control group, I then match on a number of variables in 2010: Population size, the share of population aged 15-64, the share of firms in the manufacturing sector, the share of firms in agriculture, unemployment rates, and vacancies. Figure A.2.2 shows results for the main Czech outcome variables: Unemployment rate (Panel $(\mathrm{A})$ ), vacancies (Panel (B)), women's unemployment rate (Panel (C)), and men's unemployment rate (Panel (D)). Pre-treatment trends for the border region and the synthetic control group are very similar for most outcomes; they are a bit noisy for women's unemployment rate. For all four panels, post treatment trends fully support the findings from propensity score matching. Unemployment rates in the border region declined faster, and the increase in the number of vacancies was steeper.

In the next step, I use synthetic control group matching for German municipalities. I define treated municipalities as all municipalities located up to $40 \mathrm{~km}$ from the nearest road border crossing to Czech Republic. A rich set of control variables enter the synthetic control group matching regression: Share of workers in 3 skill groups (2010), share of workers in 2 age groups (2010), share of foreign workers (2010), number of workers (2010), share of rural regions (2010), share of female workers (2010), share of manufacturing establishments (2010), share of service establishments (2010), growth in EU employment in 2004-2010, and log wage (2008, 2009, 2010).

Figure A.2.3 presents results for native employment in levels (Panel (A)) and native log wage (Panel (B)). For native employment, Panel (A) shows that shortly after the policy change, there was a drop in employment in the border region. A few years later, employment caught up with the synthetic control. While this is in line with

\footnotetext{
${ }^{24}$ For my empirical estimations, I use the synth runner STATA package provided by Galiani and Quistorff (2017).
} 
the insignificant short-term drop in employment of the propensity score matching results, the employment gap after synthetic control group matching is larger. In terms of wage losses, Panel (B) shows that wages in the border region grew slightly slower from 2013 onwards, thus corroborating the propensity score matching results.

\section{Varying Definitions of Treatment and Control Group}

In addition to synthetic control group matching, I carry out several robustness checks concerning the definition of treatment and control municipalities in Germany. For this purpose, I run four different specifications whose results I report in Table A.2.13: First, I do not match, but define my control group as all other municipalities in Bavaria (Column (2)). Bavaria is the federal state where my treatment municipalities are located, and some policies in Germany are implemented at the state level (one prominent example are education policies). Second, I use a different definition of border region: Instead of all municipalities located at most $40 \mathrm{~km}$ from the nearest Czech road border crossing, I consider municipalities up to $60 \mathrm{~km}$ from the nearest Czech road border crossing (Column (3)). Third, I match excluding control municipalities located 40-100 km from the nearest border crossing, as these could potentially be subject to spillover effects (Column (4)). Last, I match allowing for control municipalities in the same commuting zone as a treatment municipality (Column (5)).

Table A.2.13 shows that my results on the inflow of EU8 and Czech workers are robust across all of these definitions, and similar in scale. Table A.2.14 then presents eventstudy coefficients for the main outcomes, native log wage and native employment shares by native employment in 2010. While in Panel A, most coefficients with log wage as outcome are negative following treatment in 2011, they are not statistically significant when I define treated municipalities as all municipalities located up to $60 \mathrm{~km}$ from the nearest border crossing, when I match without controls in the range of $40-100 \mathrm{~km}$, and when I match including municipalities in the same commuting zone as potential controls (Columns (3-5)). I am not too surprised by not finding statistically significant results when adding municipalities up to $60 \mathrm{~km}$ from the border to my treatment group; Figure A.2.1 shows that almost no Czechs work in municipalities further than $40 \mathrm{~km}$ away from the border, such that adding these municipalities must weaken the effects. When I allow for control municipalities in the same commuting zone as the border region, I might also underestimate the true effects. There could be spatial spillover effects to these control municipalities, 
e.g. if natives out-migrate from the border region to adjacent regions in response to the worker inflow. In the specification where I match without controls in the range of $40-100 \mathrm{~km}$, one of the pre-treatment years reports a highly statistically significant and positive coefficient. This suggests that excluding these potential control units adds noise to the regression model and makes it more difficult to find suitable controls.

Panel (B) of Table A.2.14 supports the finding of no statistically significant differences in native employment except for the specification in Column (2) with rest of Bavaria as control. Here, most post treatment coefficients are statistically significant and negative (in the range of 1-2 percentage points). With a closer look it becomes clear that the baseline coefficients (Column (1)) are similar in magnitude to the coefficients with Bavaria as control group in Column (2). Given the higher number of observations, the coefficients for the whole of Bavaria are however estimated much more precisely. Starting in 2015, coefficients become smaller and weaker, suggesting - as in the baseline - that employment in the border region is catching up.

\section{Dropping Health and Construction Sectors}

As an additional robustness check, I estimate the eventstudy regression model at the worker level without construction and health sectors. These are two sectors where illegal work could be of concern. E.g., some Czech workers may have already worked in these sectors illegally before 2011, and were thus not observed in the data. The increase in migrant workers from 2011 could thus simply reflect their transition from illegal to legal work. As a result, I may underestimate wage and employment losses if I include these sectors. Table A.2.15 reports the results for log native earnings, log native wages, native employment, and days worked (both nonreweighted and reweighted. The eventstudy coefficients are very similar to those in the baseline specification. Baseline patterns moreover remain the same when I estimate the regressions separately for different tenure and skill groups (Tables A.2.16 and A.2.17 in the appendix).

\section{Estimating the Regression Model for East Germany}

In another robustness check, I estimate the eventstudy regression model at the regional level for East Germany. So far, I excluded East Germany from my analysis, given that there were still structural differences between East and West Germany around 2011. The share of EU8 workers increased in East Germany, too, albeit slightly weaker, as Figure A.2.4 shows. It presents eventstudy coefficients on the 
inflow of EU8 workers in the East German border region (defined as all municipalities located up to $40 \mathrm{~km}$ from the nearest road border crossing to Czech Republic or Poland) compared to controls. From 2013-2017, the share of EU8 workers increased by about 1.5 percentage points relative to controls (2.8 percentage points for West Germany). Note that the increase in the share of Czech workers is relatively small, at less than 1 percentage points. While East Germany has a border with Czech Republic to the South, it has a much longer border with Poland to its East; thus most of EU8 migrants in East Germany were Poles.

Figure A.2.5 shows eventstudy regression results for the two main regional outcomes, native employment and native log wages. The figure suggests that in East Germany, native wages in the border region did not decrease substantially compared to controls. Coefficients for native employment point towards a decreasing trend, but are very noisy. This may reflect the fact that given a relatively larger treatment and smaller control group in East Germany, it is particularly difficult to find suitable control units.

In Figure A.2.6, I therefore present results from synthetic control group matching. Panel (A) plots native employment in the East German border region compared to synthetic controls. While the graph shows that native employment before 2011 was smaller in the border region, it substantially increased from about 2014. For log native wages, the picture is very comparable to West Germany: Wage growth in the border region is slightly lower in the border region in some of the post treatment years.

\section{Exploiting Variation by Distance from the Border}

Finally, I estimate regression equations where I explicitly exploit the variation in the share of Czech workers by distance from the West German border. For this purpose, I regress three outcomes (share of Czech workers, native employment by 2010 employment and native log wages), where I pool the post-treatment years 20112017, on 9 dummies for distance categories. Each municipality is assigned to one of these distance bins. ${ }^{25}$ I omit the last distance category "91-100 km", such that I can interpret the coefficients for the other distance bins relative to this category. Note that for this specificaton, I do not make use of propensity score matching to narrow down my sample; instead, I restrict the sample to West German municipalities

\footnotetext{
${ }^{25}$ For instance, if a municipality's centroid is located at most $10 \mathrm{~km}$ from the nearest road border crossing to Czech Republic, I assign it to the category "0-10".
} 
located up to $100 \mathrm{~km}$ from the nearest border crossing to Czech Republic.

In the regression model, I control for year FE and a set of municipality-level controls, all measured in 2010. These are: Average municipality log wage; share of establishments in manufacturing, the service sector, construction, and mining; share of high-skilled, medium-skilled, and low-skilled workers; share of workers in the age groups 15-29, 30-49, and 50 or older; and population size. I introduce these controls to capture differences in the municipality's characteristics before the policy reform.

Figures A.2.7 and A.2.8 show the corresponding eventstudy coefficients. Figure A.2.7 confirms the pattern that the closer a municipality is located to the Czech border, the higher the share of Czech workers after 2011. Figure A.2.8 shows that the effects on native labor market outcomes are strongest in the municipalities closest to the border. While the coefficients on native employment by 2010 employment (Panel (A)) are not statistically significant, it is nevertheless clear that native employment shares are somewhat lower in municipalities located up to $50 \mathrm{~km}$ from the nearest border crossing, compared to the reference category. Consistent with the baseline results, the pattern is clearer for log native wages (Panel (B)): Wages in Municipalities located up to $20 \mathrm{~km}$ from the nearest border crossing were substantially lower than those in municipalities further away. In municipalities located up to $10 \mathrm{~km}$ from Czech Republic, wages in 2011-2017 were 4 log points lower than in the reference category.

\subsection{Conclusion}

In this paper, I investigate the effects of a labor supply shock on local labor markets in the Czech-German border region, exploiting the fact that many Czech workers started commuting across the border following the opening of the German labor market in 2011. I show that integration of the two countries' labor markets led to a substantial positive labor supply shock in the German part of the border region, with a raw increase of 5 percentage points in the share of EU8 workers by 2017 compared to control regions.

I document the impact of this labor supply shock on the border regions in Czech Republic and Germany, and on incumbent native workers in Germany. Combining propensity score matching with an eventstudy analysis on the regional level, I find 
a persistent decrease in unemployment rates in Czech Republic, complemented by an increase in vacancies. For Germany, I find no statistically significant negative effects for native German employment at the regional level, and long-term negative wage effects. For a cohort of native workers employed in the German border region in 2010, I find that they experienced lower wage growth than workers in the control group. This holds particularly for workers with less than one year of tenure and medium skills. At the same time, native workers in the border region expanded their employment, both in terms of employment probability and days worked per year. As a result, they did not face earnings losses compared to workers in the control group.

Overall, my results show that in Czech Republic, workers benefited from the policy change. While Czech commuters likely benefited in terms of higher wages, Czech stayers were able to fill vacant positions left by movers. Given higher vacancies and fewer applicants per job after 2011, my findings are however also suggestive of Czech firms facing worker shortages as result of the policy change.

For Germany, the conclusion is less clear. While native incumbent workers' wages did decline after 2011, they made up for this by increasing labor supply. As a result, their earnings remained constant. For the border region overall, my results suggest that labor demand for outsiders, particularly younger workers, decreased. My regional-level results moreover point to a recovery in native employment in the long term. This suggests that firms in the border region may have benefited from the commuter inflow in terms of productivity gains.

In future research, I plan to examine more closely what happened at the firm/establishment level in Germany. Interesting firm outcomes to investigate could be firm size, firm entries and exits, shifts in firms' industry and skill specialization, and firms' productivity. One caveat of my analysis is that I cannot make clear statements about the general equilibrium effects of cross-border migration. Bringing together the effects on regions, workers, and firms on both sides of the border remains an important task for future research. 


\section{Chapter 3}

\section{The Gender Gap in Earnings Losses After Displacement}

Joint work with Johannes Schmieder and Simon Trenkle 


\subsection{Introduction}

A large literature in Economics has documented the high costs to workers who are displaced from stable jobs. Following a mass-layoff, job losers face large earnings losses that last for many years (e.g., Jacobson et al. (1993); Couch and Placzek (2010); Davis and von Wachter (2011); Lachowska et al. (2020); Schmieder et al. (2020)). A striking feature of this literature is that it has mostly focused on the experience of men, with women often not being studied at all or only as a side note. In particular, very few studies explore explicitly how the experience of women may differ from the experience of men after a job loss. This is surprising in light of the large interest among labor economists in the gender pay gap and differences in careers between men and women.

Furthermore, many papers have studied whether women respond differently than men to other "shocks" such as childbirth or marriage (recent examples include Angelov et al. (2016); Kuziemko et al. (2018); Kleven et al. (2019a); Kleven et al. (2019b)). Perhaps most strikingly, there appear to be more papers on the "added worker effect" that study how women respond to job loss of their husbands (e.g. Lundberg (1985); Bredtmann et al. (2018); Halla et al. (2020)) than papers that study how women's response to a job loss of their own differs from men (a few exceptions are Crossley et al. (1994); Kunze and Troske (2015); Meekes and Hassink (2020)). Understanding how men's and women's labor market outcomes evolve in response to job displacement is not only important given the large economic and personal costs of job loss, but can also be helpful to understand reasons for differences in labor market experiences of men and women more broadly.

In this chapter, we study labor market outcomes of displaced men and women using administrative data from Germany. ${ }^{1}$ Following the seminal eventstudy design of Jacobson et al. (1993), we document earnings losses of workers who lost their jobs during a mass-layoff or plant closing separately by gender. Men and women differ along many dimensions, such as pre-displacement earnings, occupations, or industry, which on their own affect the recovery path after job displacement. To distinguish the role of gender from these confounding job characteristics, we focus our analysis on a set of men and women who are displaced from very similar jobs (along observable

\footnotetext{
${ }^{1}$ As discussed below, our main analysis focuses on married men and women, but our results also hold when we include singles.
} 
dimensions). We show that when comparing men and women displaced from similar jobs and with similar pre-displacement earnings, women experience about 27 percent larger earnings losses than men, what we call the 'gender gap in earnings losses'. Furthermore, while there is some recovery in earnings losses for both genders relative to non-displaced workers, this recovery is markedly slower for displaced women, so that the gender gap in earnings losses between men and women grows substantially with time since job loss.

In a second step, we investigate the main drivers that underly persistent earnings losses. In particular, we show the relative importance of time spent in unemployment after a job loss, wage losses and the incidence of working part-time in shaping earnings losses. Similarly to men, the short-term earnings losses for women are to a large degree driven by losses in days worked, while in the longer term, daily wages become a more important factor, as they show no recovery as time passes. Furthermore, the gender gap is apparent both for employment and wages, with larger losses and slower recovery for women. While men's daily wages fall by around $20 \mathrm{log}$ points, women's wages fall by close to 33 log points in the post-displacement period. The different wage losses are to a large part due to the much higher propensity of women to work part-time and in marginal "mini" jobs. ${ }^{2}$ While mini-jobs and parttime work explain some of the wage loss differences, even full-time wages fall more dramatically for women than for men. For example, 5 years after job loss men's full-time wages are around $7 \mathrm{log}$ points lower relative to non-displaced men, while for similar women full-time wages are around 15 log points lower.

In a third step, we document how job characteristics after job loss, such as employer size, occupations, industry, and commuting distance can explain the large differences in wage losses between men and women. Our results show that there are relatively few differences here that do not seem to be driving the gender gap in wage losses. One factor that does turn out to be important are establishment wage premia, estimated using the two-way fixed effects model of Abowd et al. (1999) (AKM). ${ }^{3}$ We find that in the long run (5 years post displacement), women are employed at

\footnotetext{
${ }^{2}$ Mini-jobs are an unusual feature of the German labor market that are jobs that are exempt from payroll and income taxes subject to an income threshold (450 Euro per month since 2013) and thus very low income (Tazhitdinova (2020); Gudgeon and Trenkle (2019)).

${ }^{3}$ Note that based on Abowd et al. (1999), the "AKM establishment effect" is a proxy for wage differentials across establishments. This moreover builds on recent work that investigated the role of employer wage premia in explaining costs of job loss using the AKM model, such as Lachowska et al. (2020) and Schmieder et al. (2020).
} 
establishments paying lower wage premia than men (9 log point loss for women vs. 6 log point loss for men), which in turn explains about a fourth of the gender gap in wage losses. Thus while men and women fall down the job-ladder (with little sign of climbing back up), women recover more slowly. ${ }^{4}$

In a final step we turn to the household level to better understand the experience of men and women after job loss and how this is shaped by factors such as the added worker effect or the presence of children in the household. Since the household dimension is key for understanding possible mechanisms, we focus our entire analysis on married couples (though we show that all the previous results are similar when including singles). This has the advantage that we can observe the presence of children and explore the role of spousal earnings. We first show that there is no added worker effect in our context. In fact the opposite: both for men and women, a job loss is associated with small earnings declines of their partner in the following years. We then investigate how recovery paths vary by the presence of children. Here we find striking differences between men and women. While fathers of young children have substantially smaller earnings losses, mothers of young children have much larger earnings losses. Thus parenthood sharply widens the gender gap in earnings losses, as well as wage and employment losses.

The chapter makes several key empirical contributions to the existing literature. First, while some studies estimate earnings losses separately for men and women (e.g. Jacobson et al. (1993); Crossley et al. (1994); Kunze and Troske (2015)), there is usually no or very little attempt to control for the large differences in pre-displacement job and worker characteristics. This chapter is the first to systematically attempt to account for such pre-displacement differences and to focus on a set of similar men and women in the comparison. A recent example in this spirit is Meekes and Hassink (2020) which studies post-displacement labor market outcomes for men and women in the Netherlands. The paper focuses on job flexibility as an outcome, but also reports estimates for employment and wages, comparing samples of displaced men and women which look very different. Certainly, these broad comparisons of displaced men and women are interesting in their own right, and likely the right estimates for quantifying differences in the cost of job loss for example for purposes of policy advice. However, they complicate the interpretation

\footnotetext{
${ }^{4}$ This is in line with the results in Card et al. (2016) that the distribution of men and women across establishments with different wage premia plays an important role in explaining the gender wage gap.
} 
since it remains unclear whether differences are due to different characteristics of jobs that men and women hold vs. gender per se (be it due to differences in labor supply decisions or differences in labor demand, e.g. because of discrimination). By comparing men and women displaced from very similar jobs, we can zoom in on differences that are more directly tied to gender and we can show that even men and women who have had very similar labor market experiences so far and made similar choices can be very differently affected by shocks.

This chapter also differs from these previous papers on the gender gap in systematically investigating sources behind the earnings losses, such as wage vs. employment losses as well as a broad range of job characteristics (including AKM-style establishment wage premia) and their ability to explain the gender gap in earnings and wage losses. Finally, an important difference is the ability to investigate the household dimension in some detail in the same context, such as the added worker effect and the role of children.

On the methodological side, a key contribution of this chapter is to combine a matching algorithm to construct a suitable control group with a reweighting technique to make the sample of displaced women comparable to the sample of displaced men. In the first step, we use propensity score matching (as in Couch and Placzek (2010) and Schmieder et al. (2020)) to find a comparable non-displaced worker for each displaced worker. This provides for a clean counterfactual that easily passes visual inspections of the parallel trends assumption. We then use a reweighting technique in the spirit of DiNardo et al. (1996), to reweight displaced women (and their matched controls) to match characteristics of the displaced men. A major advantage of this matching-cum-reweighting method is that it allows to directly study the different post-displacement earnings losses for men and women using eventstudy figures that show outcomes for men and for comparable women.

Our analysis also combines the reweighting approach with the matched differencein-differences design proposed by Schmieder et al. (2020). This design creates an individual-level difference-in-differences type estimate of earnings losses by comparing earnings changes of an individual before and after displacement with earnings changes of the matched control worker. The advantage of this design is that it is then straightforward to regress this individual-level estimate of the earnings losses on explanatory variables such as gender, but also on possible sources of earnings losses such as changes in job characteristics. While Schmieder et al. (2020) focus 
on earnings losses over the business cycle, we use this design to estimate the gender gap in losses and we combine the design with the DiNardo et al. (1996) reweighting approach to keep other job and worker characteristics similar between displaced men and women.

A third methodological contribution is that this chapter is part of a research project at the Institute for Employment Research (IAB) to link married spouses to each other in the German social security data. ${ }^{5}$ We created a dataset of matched married couples for each year from 2001 through 2014, building on Goldschmidt et al. (2017). The linkage relies on the fact that most married couples in Germany share a last name (at least in part in the case of hyphenated names). Thus, men and women who live at the same address with the same last name and within a certain age distance have a high likelihood of being married to each other. This linkage gives us access to key variables typically not available in administrative datasets that have been used to study job loss. Most crucially, we can observe spousal income and labor market status and we can infer children and births for both partners (which otherwise would only be available for women).

This chapter is closely related to several strands in the literature exploring the reasons for differences in the labor market experience of men and women. First, it ties into the literature investigating differences in job preferences. For example, Goldin (2014) finds that a significant part of the gender wage gap is due to employers rewarding men's relatively longer working hours. Similarly, Meekes and Hassink (2020) find that women search longer for jobs after displacement and seek out jobs with shorter commuting times and more hours flexibility. In line with this, we show that after job displacement, women are more likely to take up part-time or marginal employment instead of a full-time job. This pattern is particularly striking for mothers with children below the age of 4 , suggesting that part of it is due to women trying to reconcile career and family life.

This chapter is also related to the literature on intra-household bargaining (e.g., Mincer and Polachek (1974); Chiappori et al. (2002)). For example, previous research shows that the gender pay gap is positively related to gender differences in home production (Albanesi and Olivetti (2009)). While we cannot observe home

\footnotetext{
${ }^{5}$ Apart from Johannes Schmieder and Simon Trenkle, the other researchers involved are AnnChristin Bächmann, Corinna Frodermann, Benjamin Lochner, and Michael Oberfichtner, all from the IAB.
} 
production in our data, we show that the gender gap in earnings losses is particularly high for mothers with young children. It is moreover larger for women in married couples as opposed to non-married women, suggesting that their incentives with respect to labor market re-integration differ. Similarly, we add to the added worker effect literature (e.g. Lundberg (1985) or, very recently, Halla et al. (2020)), by investigating whether partners of the displaced workers respond to the displacement by increasing their own labor supply. Finally, we contribute to the active literature looking at the effect of job loss on household decisions, such as fertility choices (Huttunen and Kellokumpu (2016)). While we cannot explore fertility directly due to data limitations, the large fall in labor force participation for women relative to men may at least in part be due to fertility choices.

We moreover contribute to the literature which analyzes how women's careers respond to shocks. For example, Kleven et al. (2019a), Kleven et al. (2019b), and Angelov et al. (2016) show that while men and women typically have similar career trajectories early on in their life, a dramatic gap opens after childbirth, suggesting that women's careers are much more negatively affected by "shocks" such as childbirth. Similarly, Gunnsteinsson and Steingrimsdottir (2019) show that women are much more likely than men to drop out of the labor force or reduce hours after the birth of a disabled child. This chapter adds to this literature by showing that women are also more adversely affected by exogenous shocks, such as job displacement. In addition, we document that having children sharply increases the gender gap in earnings losses after displacement: mothers experience much larger earnings, wage, and employment losses. This finding is also in line with Bertrand et al. (2010) who show for a sample of MBA graduates that mothers work shorter hours and face greater career disruptions.

This chapter proceeds as follows: After introducing a simple conceptual framework in Section 3.2, we describe the data sources and our methodology of combining a matched eventstudy analysis and matched Diff-in-Diff design with reweighting in Section 3.3. In Section 3.4, we document the gender gap in earnings, employment and wage losses, both for a broad sample of men and women and when comparing men and women displaced from similar jobs. In Section 3.5 we investigate gender differences in post-displacement job characteristics and analyze to what extent these differences are driving the large wage losses of women. In Section 3.6 we then turn to the household level, showing gender differences in the effects of job loss on partner's 
labor supply decisions and how the presence of young children affects labor market outcomes. Section 3.7 concludes.

\subsection{Conceptual Framework}

Conceptually, a simple framework of time allocation within households (based on Fernández et al. (2004)) helps us to think about the possible dynamics at play. Following Fernández et al. (2004), we assume that within married households, husband and wife decide how much time $t$ to allocate to market production, and how much time $1-t$ to allocate to home production. For simplicity, we abstract from leisure.

The husband optimizes his utility function which depends positively on the household consumption of the market good, the household good (e.g., the "quality" of children), and the match quality of the marriage as perceived by the husband. Similarly, the wife maximizes her utility based on the household consumption of the market good, the household good, and the match quality of the marriage as perceived by herself.

Following Fernández et al. (2004), the earnings from husband's and wife's market production add up to household consumption, where the husband's (wife's) earnings are expressed as the product of time spent in market production and wage $w_{m}\left(w_{f}\right)$. Following stylized facts from our data, we assume that $w_{m}>w_{f}$, i.e. the husband has a comparative advantage in market production. ${ }^{6}$

With respect to the cross-wage elasticity of labor supply, this implies that the husband's time spent in market production decreases with his wife's wage $w_{f}$, and increases with his wife's productivity in home production. If an exogenous shock such as job displacement affects the wife's wage between two periods $t=-1$ and $t=0$ (i.e. $w_{f, t=0}<w_{f, t=-1}$ ), then the framework predicts that this affects time allocation within the household. For example, if the wife's wage after displacement permanently decreases or if the wife drops out of the labor force completely, then the husband will increase his market production. In extreme cases, the husband may even fully specialize in market production, while the wife would specialize fully in home production.

\footnotetext{
${ }^{6}$ Note that there are several explanations for this observation, one of them being that women trade off job flexibility against wages, and thus sort into specific types of occupations.
} 
Given the assumption of this comparative advantage for women with respect to home production, the framework thus predicts that job displacement magnifies the gender gap in labor market participation: married displaced women may decide to fully shift their working time to home production, because displacement substantially reduces their opportunity costs.

\subsection{Data and Methods}

\subsubsection{German Administrative Data}

For our empirical analysis, we combine worker-level data from the social security system in Germany to a newly available couple dataset, which enables us to identify workers' spouses. Both datasets are provided by the Institute for Employment Research (IAB). The worker-level data is generated from employer-submitted employment records, and covers the universe of German workers subject to social security contributions (excluding the self-employed and civil servants). It contains day-today information on earnings and time worked in each employment spell, as well as spell information on unemployment duration and benefit receipts. In addition, the data comprises basic demographic characteristics, such as education, occupation, and industry. The couple dataset gives us information on workers' spouses; we complement it with information on mothers, using the algorithm provided by Müller et al. (2017).

From the universe of workers we select all workers in a couple, where at least one partner was displaced from a mass-layoff in 2002-2012. We combine this with a sample of couples where no partner experienced a displacement. After matching, our sample has approximately 80,655 displaced workers (48,849 men and 31,806 women). All workers in our sample are born in 1950 or later. After applying the imputation method for the education variable suggested by Fitzenberger et al. (2006), and with the help of the STATA code provided by Dauth and Eppelsheimer (2020), we construct a yearly panel spanning from 1997 through 2017. Information on couples is available from 2001 through 2014. One has to keep in mind that the couples we identify are a special group, where both partners are in the labor force. This means that partners can be in marginal employment or receive unemployment benefits, but they cannot be self-employed or civil servants. We only identify couples 
if one partner changes their name, meaning that we are more likely to identify older, more conservative couples. Our algorithm is moreover more likely to pick up couples in smaller homes (e.g. single family).

\subsubsection{Measuring Job Displacement}

In our definition of job displacement, we follow Schmieder et al. (2020). This comes with the advantage that like them, we can compare our results to state-of-the-art studies on job loss from the U.S. literature. Thus, we define a worker as displaced if she leaves her main employer in the course of a mass-layoff event. We focus on workers with at least two years tenure prior to displacement. Our focus are thus workers who most likely did not expect the mass-layoff and lost their job involuntarily.

Like Schmieder et al. (2020), we work with two definitions of a mass-layoff event. We define an establishment as a closing establishment if its workforce declines by more than 30 percent between two consecutive years. In addition, we consider permanent establishment closings. We exclude establishments with less than 30 employees in the year before the mass-layoff, and we exclude workers with large employment fluctuations prior to displacement. Our focus is on mass-layoffs occurring in 20022012; thus, we can observe each worker at least 5 years before and 5 years after displacement.

We follow Hethey-Maier and Schmieder (2013) to make sure we exclude events such as mergers, takeovers, or changes in employer identification numbers from our masslayoff data. For this purpose, we construct a complete cross-flow matrix of worker flows between establishments using the universe of the German social security data. We consider only displacements where no more than 30 percent of the laid-off workers go to a single new establishment.

\subsubsection{Constructing a Sample of Displaced and Non-Displaced Workers}

We construct our main analysis sample in two steps: First, we choose a sample of workers who fulfill our baseline restrictions. Second, we use propensity score matching to assign an appropriate control group to our displaced workers. 
To make our study comparable to the existing literature, we again follow Schmieder et al. (2020) in our baseline restrictions. One difference to the previous literature, including Schmieder et al. (2020), is that our restrictions allow for part-time employment before displacement. This makes the baseline sample more representative of women in Germany, where in recent years almost 50 percent of women work parttime (Fitzenberger and Seidlitz (2020)). We denote the year prior to displacement the baseline year c. For each baseline year c, we consider all workers that satisfy the following on June 30 for that year: the individual is aged 24 to 50 , she works in an establishment with at least 30 employees, has at least two years of tenure, and was not in marginal employment in the four years preceding displacement. ${ }^{7}$

Another important requirement for our main analysis sample is that workers have to be identified as part of a couple in at least one of the five years prior to displacement. This comes with the advantage that we can observe a large set of household variables (e.g., children and relative income) for these workers. We moreover exclude displaced workers who left the displacing establishment for reasons such as death, sick leave, parental leave, or conscription. We do this to make sure we do not falsely identify workers as displaced who in reality took up parental leave. Within this sample, a worker is displaced between year $t=c$ and $t=c+1$ if she fulfills the following two conditions: First, she leaves the establishment between $t=c$ and $t=c+1$ and is not employed at the year c establishment in any of the following 10 years. Second, the establishment she works at has a mass-layoff between year $t=c$ and $t=c+1$. We exclude potential comparison workers who move establishment between $t=c$ and $\mathrm{t}=\mathrm{c}+1$. Note, however, that control workers can be displaced in future years.

Our baseline restrictions ensure that displaced and non-displaced workers are somewhat comparable before the mass-layoff. However, they may still differ in many ways that will make it difficult for us to estimate the causal effect of displacement. For our control group for the displaced workers in our sample, we consider only workers who fulfill the baseline restrictions. Then, we use a propensity score step-matching estimator, matching within cells of 1-digit industries, gender, and location in East or West Germany. Our list of matching variables includes a worker's log wage in $t=c-2$ and $\mathrm{t}=\mathrm{c}-3$, full-time employment in $\mathrm{t}=\mathrm{c}-2$, and age, years of education, tenure, and

\footnotetext{
${ }^{7}$ We also exclude individuals working in the construction and mining sectors. Very few women work in these sectors, so that it is essentially impossible to compare displaced men from these sectors to similar women. To keep our sample constant throughout the analysis below, we impose this restriction from the beginning, though it makes little difference for the raw gender gap (before reweighting).
} 
$\log$ establishment size in $\mathrm{t}=\mathrm{c}$. Each displaced worker is assigned the non-displaced worker with the closest propensity score without replacement.

Observable characteristics of displaced and matched non-displaced workers prior to displacement are very similar as shown in Table A.3.1. Thanks to the matching, the displaced men and women are very similar to their respective controls and there are virtually no differences in individual characteristics (education, experience, tenure) as well as establishment characteristics (size, share of female/full-time workers) between displaced and non-displaced workers.

Table 3.1 shows summary statistics for the displaced women and men in our sample. As a reference point, the table includes characteristics for a random sample of all women, Column (1), and all men, Column (4) in the German administrative data during our sample period. Column (2) shows characteristics of displaced women in our sample. Compared to the overall sample of women in Column (1), displaced women are positively selected in terms of labor force attachment and earnings due to our baseline restrictions on tenure and establishment size (and ruling out workers working only in mini-jobs). For example prior to displacement, women in our sample earn about 26,600 Euro per year as opposed to only around 15,300 Euro in the overall population. Similarly, displaced men in our sample (Column (5)) are also positively selected compared to all male workers (Column (4)), and also have about 50 percent higher earnings.

While both our sample of displaced men and women is positively selected with comparatively high levels of earnings and labor force attachment, there are large differences when comparing the sample of displaced women (Column (2)) to displaced men (Column (5)). For example, displaced men have earnings or around 36,700 Euro compared to women's 26,600 Euro 2 years before displacement. Similarly, log daily wages are around $36 \log$ points higher for men. One key driver for these differences is that while men rarely work part-time in this sample (on average only 8 days per year), for women around $1 / 3$ of total time worked is part-time (on average 115 days per year). By contrast traditional measures of human capital, such as education, tenure, or experience, are quite similar for men and women. Women also work at somewhat different employers: they typically work for larger establishments that pay lower wage premia (as measured by the AKM establishment effect). Note that Column (3) shows the sample of women after reweighting it to men, making their pre-displacement characteristics much more comparable. We describe the 
Table 3.1: Summary Table of Displaced Workers in the Year Before Displacement

\begin{tabular}{|c|c|c|c|c|c|}
\hline & $\begin{array}{l}\text { (1) } \\
\text { All Workers } \\
\text { Women }\end{array}$ & $\begin{array}{c}(2) \\
\text { Baseline Sample } \\
\text { Women }\end{array}$ & $\begin{array}{c}\quad(3) \\
\text { Reweighted } \\
\text { Women }\end{array}$ & $\begin{array}{c}(4) \\
\text { All Workers } \\
\text { Men }\end{array}$ & $\begin{array}{c}(5) \\
\text { Baseline Sample } \\
\text { Men }\end{array}$ \\
\hline \multicolumn{6}{|c|}{ Panel A: Individual Characteristics } \\
\hline Log Wage in $\mathrm{t}=\mathrm{c}-2^{*}$ & $\begin{array}{c}3.54 \\
{[1.06]}\end{array}$ & $\begin{array}{c}4.18 \\
{[0.471]}\end{array}$ & $\begin{array}{c}4.60 \\
{[0.370]}\end{array}$ & $\begin{array}{c}4.11 \\
{[1.02]}\end{array}$ & $\begin{array}{c}4.54 \\
{[0.356]}\end{array}$ \\
\hline Earnings in $\mathrm{t}=\mathrm{c}-2$ & $\begin{array}{c}15320.9 \\
{[15273.2]}\end{array}$ & $\begin{array}{c}26623.3 \\
{[11881.2]}\end{array}$ & $\begin{array}{c}38498.4 \\
{[13403.6]}\end{array}$ & $\begin{array}{c}24695.4 \\
{[20570.7]}\end{array}$ & $\begin{array}{c}36677.8 \\
{[12881.5]}\end{array}$ \\
\hline Days per Year Working Full-time & $\begin{array}{c}122.0 \\
{[165.0]}\end{array}$ & $\begin{array}{c}226.9 \\
{[162.0]}\end{array}$ & $\begin{array}{l}325.0 \\
{[82.9]}\end{array}$ & $\begin{array}{c}218.8 \\
{[168.7]}\end{array}$ & $\begin{array}{l}335.5 \\
{[64.4]}\end{array}$ \\
\hline Days per Year Working Part-time & $\begin{array}{c}76.4 \\
{[142.8]}\end{array}$ & $\begin{array}{c}114.8 \\
{[160.7]}\end{array}$ & $\begin{array}{c}16.7 \\
{[69.9]}\end{array}$ & $\begin{array}{c}11.9 \\
{[60.1]}\end{array}$ & $\begin{array}{l}8.23 \\
{[50.2]}\end{array}$ \\
\hline Years of Education* & $\begin{array}{c}11.9 \\
{[1.92]}\end{array}$ & $\begin{array}{c}11.4 \\
{[1.45]}\end{array}$ & $\begin{array}{c}11.4 \\
{[1.63]}\end{array}$ & $\begin{array}{c}12.1 \\
{[2.11]}\end{array}$ & $\begin{array}{c}11.3 \\
{[1.58]}\end{array}$ \\
\hline Tenure* & $\begin{array}{c}3.25 \\
{[2.61]}\end{array}$ & $\begin{array}{c}7.54 \\
{[4.06]}\end{array}$ & $\begin{array}{c}7.32 \\
{[4.12]}\end{array}$ & $\begin{array}{c}3.35 \\
{[2.67]}\end{array}$ & $\begin{array}{c}7.74 \\
{[4.45]}\end{array}$ \\
\hline Age* & $\begin{array}{c}39.5 \\
{[13.2]}\end{array}$ & $\begin{array}{c}41.7 \\
{[5.87]}\end{array}$ & $\begin{array}{c}40.4 \\
{[6.33]}\end{array}$ & $\begin{array}{c}39.5 \\
{[13.4]}\end{array}$ & $\begin{array}{c}41.0 \\
{[5.93]}\end{array}$ \\
\hline Commuting Distance & . & $\begin{array}{c}29.4 \\
{[71.8]}\end{array}$ & $\begin{array}{c}36.3 \\
{[89.0]}\end{array}$ & . & $\begin{array}{c}39.4 \\
{[88.4]}\end{array}$ \\
\hline Has child $<7$ & . & $\begin{array}{c}0.031 \\
{[0.173]}\end{array}$ & $\begin{array}{c}0.038 \\
{[0.192]}\end{array}$ & . & $\begin{array}{c}0.119 \\
{[0.324]}\end{array}$ \\
\hline Has child $>=7$ & . & $\begin{array}{c}0.214 \\
{[0.410]}\end{array}$ & $\begin{array}{c}0.126 \\
{[0.332]}\end{array}$ & . & $\begin{array}{c}0.245 \\
{[0.430]}\end{array}$ \\
\hline Panel B: Establishment Chara & cteristics & & & & \\
\hline Log Establishment Size* & $\begin{array}{c}4.07 \\
{[2.11]}\end{array}$ & $\begin{array}{c}5.19 \\
{[1.37]}\end{array}$ & $\begin{array}{c}4.70 \\
{[1.07]}\end{array}$ & $\begin{array}{c}4.58 \\
{[2.14]}\end{array}$ & $\begin{array}{c}4.77 \\
{[1.10]}\end{array}$ \\
\hline AKM Estab FE, 2003-2010 & $\begin{array}{l}-0.331 \\
{[0.288]}\end{array}$ & $\begin{array}{l}-0.265 \\
{[0.222]}\end{array}$ & $\begin{array}{l}-0.164 \\
{[0.210]}\end{array}$ & $\begin{array}{l}-0.254 \\
{[0.264]}\end{array}$ & $\begin{array}{l}-0.193 \\
{[0.230]}\end{array}$ \\
\hline Panel C: Household Character & ristics & & & & \\
\hline Total Yearly Household Earnings & . & $\begin{array}{c}52662.4 \\
{[24048.2]}\end{array}$ & $\begin{array}{c}66600.9 \\
{[27799.8]}\end{array}$ & . & $\begin{array}{c}48557.5 \\
{[20764.6]}\end{array}$ \\
\hline Total Yearly Earnings - Partner & . & $\begin{array}{c}27063.1 \\
{[19233.8]}\end{array}$ & $\begin{array}{c}29824.6 \\
{[21146.6]}\end{array}$ & . & $\begin{array}{c}13609.9 \\
{[14335.4]}\end{array}$ \\
\hline Share of Household Income & . & $\begin{array}{c}55.5 \\
{[27.1]}\end{array}$ & $\begin{array}{c}60.7 \\
{[24.2]}\end{array}$ & . & $\begin{array}{c}76.3 \\
{[20.8]}\end{array}$ \\
\hline Same Establishment as Spouse & . & $\begin{array}{c}0.059 \\
{[0.235]}\end{array}$ & $\begin{array}{c}0.068 \\
{[0.252]}\end{array}$ & . & $\begin{array}{c}0.040 \\
{[0.197]}\end{array}$ \\
\hline Same Industry as Spouse & . & $\begin{array}{c}0.099 \\
{[0.298]}\end{array}$ & $\begin{array}{c}0.116 \\
{[0.320]}\end{array}$ & . & $\begin{array}{c}0.075 \\
{[0.263]}\end{array}$ \\
\hline Number of Individuals & 399615 & 31806 & 31806 & 418127 & 48849 \\
\hline
\end{tabular}

Notes: This table summarizes characteristics of different samples of (displaced) men and women. Columns (1) and (4) show characteristics of a random sample of workers in Germany 2003-2012. Columns (2) and (5) represent all displaced workers in the couple dataset fulfilling our baseline restrictions. We measure characteristics in $\mathrm{t}=\mathrm{c}$. We exclude individuals working in the construction and mining sectors. Column (3) presents women in the couple dataset reweighted to men. Variables with * are used in reweighting. Standard deviations in brackets. 
reweighting process in more detail in the following Section 3.3.4.

\subsubsection{Comparing Men and Women Displaced from Similar Jobs: Reweighting}

Our goal is to compare earnings losses after job displacement for men and women. If we think of the post-displacement earnings loss of a treatment effect, this means we are interested in comparing estimated treatment effects for two populations. The complication is that there may be differences in treatment effects either because of gender per se, or because of other pre-displacement characteristics that determine earnings losses. As the previous discussion showed, displaced men and women, who satisfy the same baseline restrictions, nevertheless show important differences in labor market variables prior to displacement. For example, workers displaced from high paying jobs may have relatively larger losses than workers displaced from low paying jobs. Women typically work in occupations which pay lower wages, e.g. in care work. $^{8}$

To define precisely what we are striving to estimate, consider the following potential outcomes framework (following DiNardo et al. (1996) and Hotz et al. (2005)). Let earnings in the case of job loss be denoted by $Y_{1}$ and in the absence of job loss be denoted by $Y_{0}$. The earnings loss on the individual-level is then simply the difference between these two potential outcomes: $\Delta \equiv Y_{1}-Y_{0}$. Let gender be denoted by $D \in\{m, f\}$. We can then define the unconditional gender gap in earnings losses as:

$$
y \operatorname{Gap}_{\text {unc }} \equiv E[\Delta \mid D=f]-E[\Delta \mid D=m]
$$

where $E[\Delta \mid D=f]$ refers to the expected value of earnings losses for women, and $E[\Delta \mid D=m]$ refers to the expected value of earnings losses for men. Note that while this unconditional gender gap is interesting in itself, it may be driven by differences in characteristics between the two groups.

In order to account for these differences, we next consider a vector of covariates $X \in \mathcal{X}$ for each individual, which are potentially determinants of individual earnings losses, i.e. $Y_{1}$ and $Y_{0}$ are functions of X. Earnings losses for women $E[\Delta \mid D=f]$

\footnotetext{
${ }^{8}$ Note that the choice of occupation is endogenous and may, for example, reflect women's objective to reconcile career and family life.
} 
may then differ from the earnings losses for men $E[\Delta \mid D=m]$ either because of differences in the Xs or because of gender itself. We can write the earnings loss conditional on gender and the covariates as: $E[\Delta \mid D, X]$ and express the expected earnings loss for women adjusted to the male characteristics as:

$$
E[E[\Delta \mid D=f, X] \mid D=m]=\int_{\mathcal{X}} E[\Delta \mid D=f, X] d F_{X}^{m}(x)
$$

where $F_{X}^{m}(x)$ denotes the distribution of covariates for men. What Equation 3.2 tells us is that ideally, we would like to observe the distribution of earnings losses for women with the distribution of individual characteristics of men. Since this is not possible in reality, we apply an econometric method first used by DiNardo et al. (1996): we use a reweighting function $\phi_{X}(x)$ to map the distribution of women's individual characteristics before displacement to the distribution of men's individual characteristics before displacement. Formally, we express this as follows:

$$
E[E[\Delta \mid D=f, X] \mid D=m]=\int_{\mathcal{X}} E[\Delta \mid D=f, X] d F_{X}^{f}(x) \phi_{X}(x)
$$

Intuitively, this means that women who are more similar to men before the job displacement (e.g., in terms of working hours), receive a higher weight in the regression estimation. We can implement this strategy as long as $\mathcal{X}^{m} \subseteq \mathcal{X}^{f}$, that is as long as there is sufficient overlap in the observables between the two groups. We can then define the composition adjusted gender gap:

$$
\operatorname{Gap}_{a d j} \equiv \int_{\mathcal{X}} E[\Delta \mid D=f, X] d F_{X}^{f}(x) \phi_{X}(x)-E[\Delta \mid D=m]
$$

The composition adjusted gender gap thus amounts to a test for the hypothesis that earnings losses are independent of gender, conditioning on the covariates: $\Delta \perp D \mid X$. This means that after netting out the part of the gap driven by differences in predisplacement characteristics, we can attribute the remaining adjusted gap to the effect of gender per se (e.g., labor supply vs. labor demand mechanisms).

In order to empirically calculate the composition adjusted gender gap, we follow the non-parameteric approach in DiNardo et al. (1996) and use a weighting procedure to reweight displaced women to displaced men. To do this, we estimate a probit regression, where the dependent variable is a dummy for being male. We include 
the same individual and establishment characteristics as controls which we used in the propensity score matching. These are: log wage in $\mathrm{t}=\mathrm{c}-2$ and $\mathrm{t}=\mathrm{c}-3$, full-time employment in $\mathrm{t}=\mathrm{c}-2$, and age, years of education, tenure, log establishment size, 1 digit industry dummies, and location in East or West Germany in $t=c .{ }^{9}$ We obtain the predicted propensity score $\hat{p}$ from this regression and use $\omega=\frac{\hat{p}}{1-\hat{p}}$ to reweight women in our sample to match their male counterparts. ${ }^{10}$

Table 3.1, Column (3), shows the sample of displaced women reweighted using the weights described above. After reweighting, displaced women look very similar to displaced men along most dimensions, even along characteristics that we did not match on such as earnings. Not shown here is that there are also substantial industry differences between men and women and now we are upweighting women in the industries where they are underrepresented (Table A.3.2). Compared to the overall sample of displaced women, the reweighted women have much higher earnings, work mostly full-time, commute longer and work in smaller establishments that pay higher wage premia.

\subsubsection{Estimation Strategies: Eventstudy and Matched Diff- in-Diff Design}

\section{Eventstudy}

In order to estimate the dynamic impact of displacement effects for men and women, we use an eventstudy analysis for a variety of outcome variables. Let $y_{i t c}$ be the outcome of interest for a worker i, with baseline year c, observed in year t. Furthermore, let $\operatorname{Disp}_{i}$ be a dummy variable for whether worker $\mathrm{i}$ is a displaced worker. In order to obtain causal estimates of the displacement effects, we estimate the following regression model where we include control variables. Note that we estimate the model separately by gender:

\footnotetext{
${ }^{9}$ In our baseline specification, we do not reweight women to men with respect to occupations. In a robustness check in Section 3.5.3, we show that the adjusted gender gap slightly increases if we add occupations to our reweighting algorithm.

${ }^{10}$ As robustness checks we also reweight men to women (that is weight all male observations by $\left.\frac{1-\hat{p}}{\hat{p}}\right)$. We show the results in Table 3.4 .
} 
$y_{i t c}=\sum_{k=-5}^{5} \delta_{k} \times I(t=c+1+k) \times \operatorname{Disp}_{i}+\sum_{k=-5}^{5} \gamma_{k} \times I(t=c+1+k)+\pi_{t}+\alpha_{i}+X_{i t} \beta+\varepsilon_{i t c}$

where y denotes the outcome (e.g., log earnings) for worker i at time $t$, in "cohort" (baseline year) c. The main coefficients of interest are $\delta_{k}$, which measure the change in earnings of displaced workers relative to the evolution of earnings of non-displaced workers (with $\delta_{0}$ being the first year post-displacement). ${ }^{11}$ To avoid perfect collinearity, we omit k=c-2 from the regression. Like Schmieder et al. (2020), we control for "year relative to baseline year" fixed effects (coefficients $\gamma_{k}$ ). The reason for this is that due to our baseline restrictions (e.g., 2 years tenure), workers in both treatment and control group are on an upward earnings profile before treatment. This means that even in the control group, which does not experience job loss, earnings may decrease once we lift these restrictions. In addition, we include year fixed effects $\pi_{t}$, worker fixed effects $\alpha_{i}$, and time-varying control variables $X_{i t} \beta$ (age polynomials). Standard errors are clustered at the worker level. We estimate this model unweighted both for our sample of men and women. We also estimate the model reweighting women to match the baseline characteristics of displaced men, as discussed above.

\section{Matched Diff-in-Diff Design}

The reweighted eventstudy design traces out the time path of labor market effects of job displacement and the reweighting makes it straightforward to compare men and women with similar characteristics. We complement this analysis with a matched difference-in-differences design that allows us to obtain an individual-level estimate of the displacement effect, which in turn makes it straightforward to investigate heterogeneity in the displacement effect and to what extent various factors (such as changing job characteristics) can explain the direct displacement effects and gender differences in these effects.

To do so, we use the fact that for each job loser we have a matched control worker. ${ }^{12}$ We then calculate an individual-level estimate of the earnings loss after displacement.

\footnotetext{
${ }^{11}$ Note that the letter $I$ in this equation refers to an indicator function, meaning that it takes the value 1 if $t=c+1+k$ is true.

${ }^{12}$ Note that the reason for this is that we use 1:1 nearest neighbor propensity score matching, as described in Section 3.3.3.
} 


$$
\Delta_{d d} y_{i c}=\Delta_{d} y_{i c}-\Delta_{n d} y_{i c}
$$

where $\Delta_{d} y_{i c}$ is the individual change in earnings from before (-5 to -2 years) to after (0 to 3 years) job displacement for a displaced worker i with baseline year $\mathrm{c}$, while $\Delta_{n d} y_{i c}$ is the earnings change for the matched non-displaced worker. The difference between the two, $\Delta_{d d} y_{i c}$, is an estimate of the individual treatment effect from job displacement.

Based on the individual-level estimate of the treatment effect it is now straightforward to estimate the unconditional gender gap in the cost of job loss Gapunc as: $E\left[\Delta_{d d} y_{i c} \mid D=f\right]-E\left[\Delta_{d d} y_{i c} \mid D=m\right]$, which we can obtain by running the simple univariate regression:

$$
\Delta_{d d} y_{i c}=\beta_{0} \text { Female }+\varepsilon_{i c}
$$

The coefficient estimate $\hat{\beta}_{0}$ will be an estimate of Gap unc. In order to estimate the composition adjusted gender gap $G a p_{a d j}$, we estimate Equation 3.7 using the $\omega$ weights to reweight women to the sample of men.

As an alternative to the reweighting approach, we can also estimate Equation 3.7 but including controls for the covariates. This assumes that the unconditional gap can be modeled as the sum of the unadjusted gap and the effect of the covariates: $G a p_{u n c}=G_{a p} p_{a d j}+X \theta+u$. In this case we can estimate:

$$
\Delta_{d d} y_{i c}=\beta_{1} \text { Female }+X \theta+\varepsilon_{i c}
$$

and the coefficient estimate $\hat{\beta}_{1}$ will again be an estimate of $G a p_{u n c}$. In practice this parametric approach to estimating Gap unc provides similar estimates as the non-parametric reweighting approach and we will provide both for comparison. One advantage of the parametric approach is that it is straightforward to include interaction terms between the Female dummy and other covariates and the interpretation is straightforward.

With the matched Diff-in-Diff approach, it is also straightforward to investigate whether changes in job characteristics $Z_{i c}$ explain the earnings and wage losses. For this we compute Diff-in-Diff estimates of changes in these characteristics on the 
individual level, e.g. establishment size or the establishment wage premium. We then estimate regressions of the form:

$$
\Delta_{d d} y_{i c}=\beta_{2} \text { Female }+\gamma \Delta_{d d} Z_{i c}+\varepsilon_{i c}
$$

If women have large wage losses because they are more likely to move to low paying establishments or change industry or occupations, adding these controls for changes in job characteristics should reduce the magnitude of the coefficient $\hat{\beta}_{2}$ relative to $\hat{\beta}_{1}$.

\subsection{Earnings and Employment Losses after Dis- placement of Men and Women}

\subsubsection{Comparing Raw Earnings Losses for Men and Women}

Figure 3.1 presents first evidence on how earnings losses between female and male workers differ. Panels (A) and (B) show the averages of total annual earnings (without controls) from 5 years before to 5 years after job loss for the displaced workers as well as their matched control workers. Pre-trends for the treatment and control groups line up very well up to $\mathrm{t}=\mathrm{c}$, the baseline year, which is not surprising given the matching algorithm. In year $\mathrm{t}=\mathrm{c}$ a small gap opens up driven by the fact that displacement occurs at some point between June of $t=c$ and $t=c+1$. In the displacement year $t=c+1$, earnings drop sharply for men and women, and only recover slowly in subsequent years. Comparing Panels (A) and (B) highlights that while the overall pattern is very similar for men and women, women have much lower pre-displacement earnings.

Panel (C) plots the eventstudy dummies from regression 3.5 for annual earnings in levels. Note that here, the difference between the red and blue lines is the unconditional gender gap in earnings losses, i.e. the gap without accounting for differences in observable characteristics between men and women. While this unconditional gender gap is interesting in itself, one has to be aware that it may simply reflect differences in individual characteristics of the two groups. 
Figure 3.1: The Gender Gap in Earnings Losses after Displacement without Controlling for Pre-Displacement Characteristics

(A) Total Earnings in Year - Men

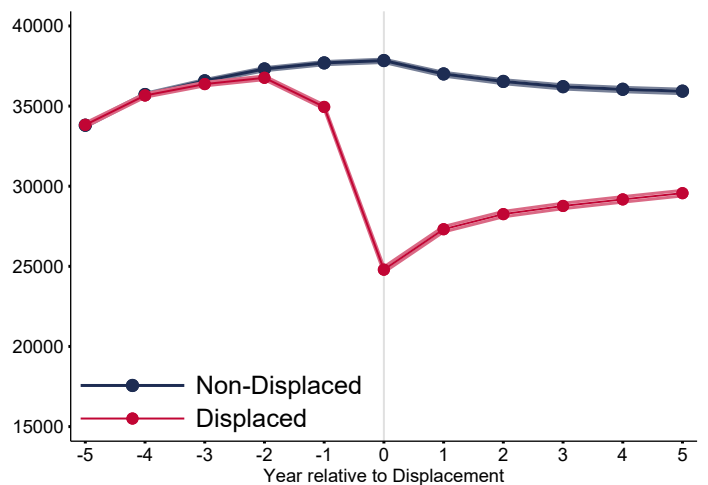

(C) Total Earnings in Year

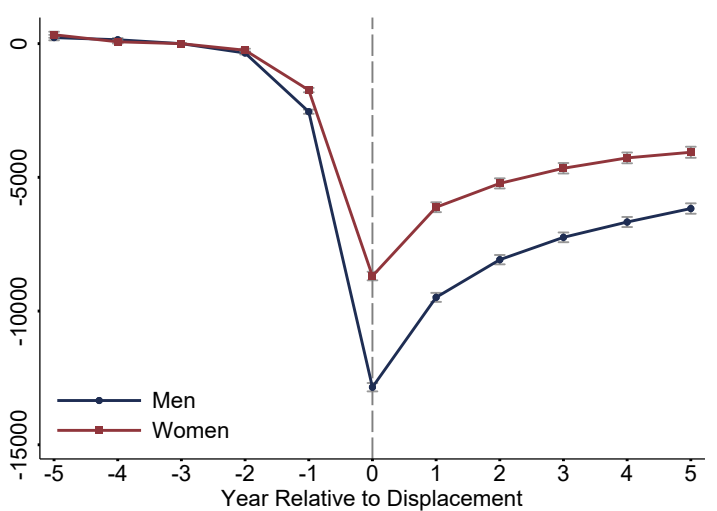

(B) Total Earnings in Year - Women

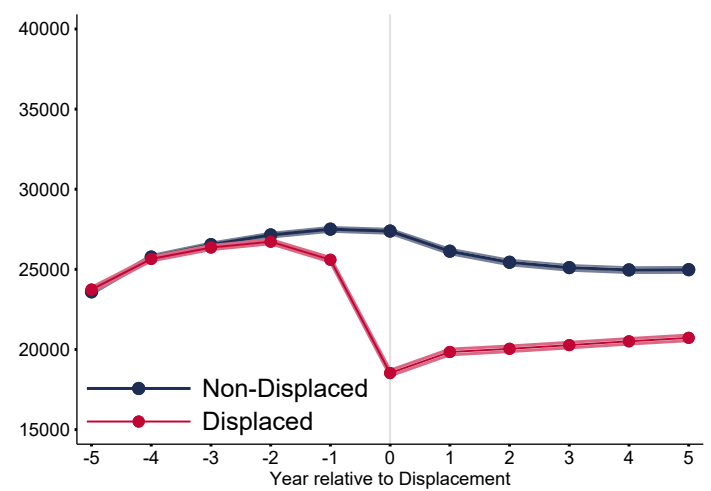

(D) Earnings Relative to $\mathrm{t}=\mathrm{c}-1$

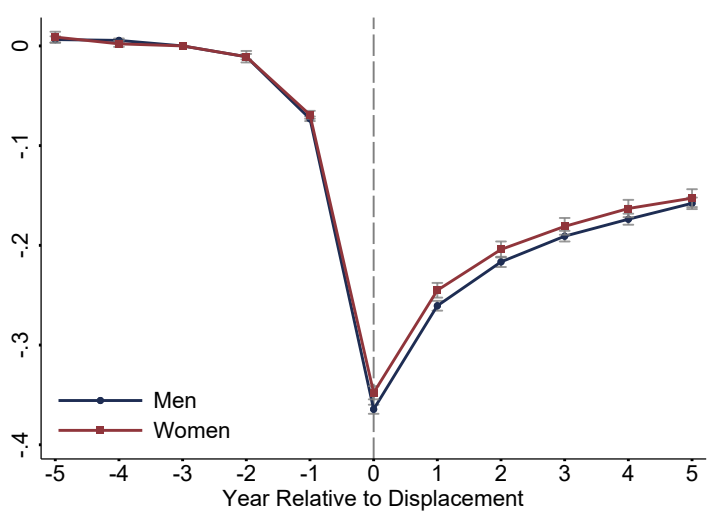

Notes: This figure shows earnings losses for displaced and non-displaced workers. Panels (A) and (B) show total yearly earnings for displaced and non-displaced men (A) and women (B). The red line corresponds to workers who are displaced from year $t=c$ to $t=c+1$, while the blue line corresponds to the matched control group that is constructed of non-displaced workers via propensity score matching. Each point represents the average value in the respective worker group. Panels (C) and (D) show eventstudy coefficients, controlling for person FE, year FE, years since separation, and age polynomials. Panel (C) shows eventstudy coefficients for total yearly earnings as outcome. Panel (D) shows eventstudy coefficients for earnings relative to $\mathrm{t}=\mathrm{c}-1$ as outcome. The red line corresponds to women, the blue line corresponds to men. Workers are displaced in 2002-2012, and they are observed from 1997-2017. 
Table 3.2: The Gender Gap in Earnings Losses and Other Characteristics

\begin{tabular}{|c|c|c|c|c|c|c|c|c|c|}
\hline & \multicolumn{2}{|c|}{$\begin{array}{c}(1) \\
\text { Mean Change } \\
\text { in Outcome Variable } \\
\text { for Men }\end{array}$} & \multicolumn{2}{|c|}{$\begin{array}{c}(2) \\
\text { Unadjusted } \\
\text { Gender Gap }\end{array}$} & \multicolumn{2}{|c|}{$\begin{array}{c}(3) \\
\text { Composition } \\
\text { Adjusted } \\
\text { Gender Gap } \\
\text { Regression-Adj. }\end{array}$} & \multicolumn{2}{|c|}{$\begin{array}{c}(4) \\
\text { Composition } \\
\text { Adjusted } \\
\text { Gender Gap } \\
\text { Reweighted }\end{array}$} & \multirow[t]{2}{*}{$\begin{array}{c}(5) \\
\text { Number of } \\
\text { Observations }\end{array}$} \\
\hline & Change & Std. Err. & Gap & Std. Err. & Gap & Std. Err. & Gap & Std. Err. & \\
\hline \multicolumn{10}{|c|}{ Panel A: Earnings, Wages, and Employment } \\
\hline Total Yearly Earnings & -9418.0 & {$[313.8]$} & 3214.6 & {$[371.2]$} & -1115.8 & {$[239.0]$} & -2491.1 & {$[339.6]$} & 80,655 \\
\hline Earnings r.t. t-2 & -0.258 & {$[0.0066]$} & 0.014 & {$[0.012]$} & -0.077 & {$[0.0072]$} & -0.092 & {$[0.012]$} & 80,655 \\
\hline Log Earnings & -0.405 & {$[0.0077]$} & -0.030 & {$[0.020]$} & -0.155 & {$[0.012]$} & -0.128 & {$[0.017]$} & 76,321 \\
\hline Sinh(Earnings) & -1.55 & {$[0.064]$} & 0.165 & {$[0.079]$} & -0.193 & {$[0.050]$} & -0.294 & {$[0.060]$} & 80,655 \\
\hline Log Wage Loss & -0.201 & {$[0.0053]$} & -0.066 & {$[0.013]$} & -0.166 & {$[0.0098]$} & -0.133 & {$[0.013]$} & 73,598 \\
\hline Full-time Log Wage & -0.094 & {$[0.0029]$} & 0.013 & {$[0.0085]$} & -0.045 & {$[0.0052]$} & -0.039 & {$[0.0084]$} & 52,996 \\
\hline Days Worked & -67.7 & {$[2.01]$} & 9.04 & {$[2.97]$} & -2.97 & {$[1.73]$} & -7.05 & {$[2.13]$} & 80,655 \\
\hline Days Worked Full-time & -75.5 & {$[2.11]$} & 31.4 & {$[3.24]$} & -24.9 & {$[2.51]$} & -23.1 & {$[2.84]$} & 80,655 \\
\hline Days Worked Part-time & -0.154 & {$[0.380]$} & -33.8 & {$[1.72]$} & 12.6 & {$[1.49]$} & 11.3 & {$[1.66]$} & 80,655 \\
\hline Days Worked in Mini-job & 1.09 & {$[0.516]$} & 14.3 & {$[1.10]$} & 10.6 & {$[1.08]$} & 4.88 & {$[1.51]$} & 80,655 \\
\hline \multicolumn{10}{|c|}{ Panel B: Job Characteristics } \\
\hline Commuting Distance & 2.59 & {$[1.54]$} & -8.76 & {$[1.62]$} & -0.505 & {$[1.46]$} & -0.321 & {$[2.11]$} & 73,027 \\
\hline Log Establishment Size & -0.740 & {$[0.029]$} & -0.571 & {$[0.077]$} & -0.066 & {$[0.023]$} & -0.041 & {$[0.036]$} & 72,811 \\
\hline Industry Change & 0.536 & {$[0.0066]$} & -0.061 & {$[0.020]$} & 0.034 & {$[0.0086]$} & 0.046 & {$[0.011]$} & 73,564 \\
\hline Occ. Change & 0.417 & {$[0.0067]$} & -0.105 & {$[0.015]$} & -0.017 & {$[0.0076]$} & -0.043 & {$[0.012]$} & 73,598 \\
\hline Estab. Share Women & 0.019 & {$[0.0024]$} & 0.019 & {$[0.0032]$} & 0.043 & {$[0.0035]$} & 0.042 & {$[0.0049]$} & 72,370 \\
\hline Temp Work & 0.034 & {$[0.0014]$} & -0.012 & {$[0.0018]$} & -0.0099 & {$[0.0021]$} & -0.0087 & {$[0.0026]$} & 72,811 \\
\hline Business Service Estab. & 0.064 & {$[0.0023]$} & -0.019 & {$[0.0032]$} & -0.024 & {$[0.0033]$} & -0.028 & {$[0.0040]$} & 72,811 \\
\hline New Estab. & 0.195 & {$[0.0067]$} & 0.085 & {$[0.018]$} & 0.0086 & {$[0.0075]$} & 0.0063 & {$[0.0087]$} & 72,811 \\
\hline AKM Estab FE & -0.086 & {$[0.0063]$} & 0.011 & {$[0.0066]$} & -0.024 & [0.0043] & -0.0097 & {$[0.0054]$} & 63,452 \\
\hline
\end{tabular}

Notes: Each row represents a separate regression of the mean change in the outcome variable over a five year period after job loss on a constant and a dummy for female. The first column shows the constant, representing the mean effect for men. The second column presents the coefficient on a female dummy without any controls. The third column presents the coefficient on the female dummy controlling for all covariates. The fourth column uses reweighting. We cluster standard errors at displacement establishment level (constant within matched worker pairs). Sinh(Earnings) refers to the inverse hyperbolic sine transformation of earnings. "Temp Work", "Business Service Estab.", and "New Estab." are variables indicating whether workers changed their job to temporary work, to a business service establishment, or to a new establishment (5 years old or younger), respectively. Workers in our sample are displaced in 2002-2012, and they are observed from 1996-2017. Coefficients in bold are statistically significant at the $5 \%$-level. 
Given the matching design, the additional controls make virtually no difference and the eventstudy coefficients are very close to the simple difference in the means of the two lines in Panels (A) and (B). This figure shows that in levels, women have substantially smaller losses of around 9,000 Euro in the first post-displacement year, while men lose around 13,000 Euro. The recovery path looks similar but even 5 years out women's losses are smaller. Of course the higher losses in levels stem largely from the fact that men have more to lose given their higher baseline earnings. Panel (D) thus shows the earnings losses using as an outcome earnings in the respective year divided by each individual's earnings in year $t=c-1$, that is the year before the baseline year. We denote this as $\tilde{y}_{i, t} \equiv \frac{y_{i, t}}{y_{i,-2}}$. This outcome variable is similar to the main outcome variable in Blien et al. (2020) and has the distinct advantage that it allows for expressing the effect in percentage terms and is thus easily interpretable.

Using $\tilde{y}_{i, t}$ also provides for a very natural way of including observations with 0 earnings, as in that case we simply have: $\tilde{y}_{i, t}=0$. More commonly, studies use $\log$ (earnings) or inverse hyperbolic sine earnings as an outcome. The former has the disadvantage that zero earnings observations are excluded and that for many individuals, earnings fall by very large values (e.g. some workers go to mini-jobs where annual earnings are just a few thousand Euro), so that the typical percentage interpretation of log-earnings becomes a bad approximation. Similarly, while inverse hyperbolic sine earnings allows for including zeros, the magnitudes are very difficult to interpret (e.g. in our case the mean change in inverse hyperbolic sine earnings for men is -1.55 , but obviously this is not a decline of 155 percent). Using $\tilde{y}_{i, t}$ as an outcome in Figure 3.1 (D) reveals that in percentage terms men and women in this unweighted sample experience virtually identical losses and recovery paths. Furthermore the magnitudes are very large: in the first year, earnings decline by almost 40 percent relative to pre-displacement earnings. In the following years there is some recovery, but 5 years out earnings are still about 20 percent lower relative to the pre-displacement year.

Table 3.2 shows the corresponding estimates from our matched Diff-in-Diff design, that is estimates of Equation 3.7. The unit of observation in this regression is the number of displaced workers, where for each displaced worker we calculated $\Delta_{d d} y_{i c}$ for various outcomes. Each row corresponds to a different outcome variable. Column (1) shows the mean change in the outcome variable for men, Column (2) shows the unadjusted gender gap, from estimating Equation 3.7. 
The results in Columns (1) and (2) confirm the impression from from Figure 3.1. Men experience large earnings losses both in levels (around 9,400 Euro per year) and relative to the baseline (around 26 percent). For women the earnings losses are smaller in levels (a loss of about 6,200 Euro per year), but very similar in relative earnings or when using log earnings. Using the inverse hyperbolic sign transformation of earnings allows for including 0 s but the mean value of the variable $(-1.55)$ shows why the interpretation is not very intuitive.

Overall, there are clearly large earnings losses which are comparable to those found by, for example, Schmieder et al. (2020) for Germany or various studies for the U.S. using administrative data (e.g., Jacobson et al. (1993), Couch and Placzek (2010) or Lachowska et al. (2020)).

\subsubsection{The Gender Gap in Earnings Losses for Men and Women Displaced from Comparable Jobs}

We now turn to estimating the gender gap in earnings losses where we compare women who are displaced from comparable jobs as men using the reweighting technique by DiNardo et al. (1996) described in Section 3.3.4. The main idea of the reweighting approach is that it allows us to compare earnings losses in the hypothetical case where women's observable characteristics were distributed in the same way as men's.

To illustrate this intuitively, assume that women in our sample had, on average, more years of education than men. Table 3.1, Column (2) vs. (5), shows that this is a plausible assumption. ${ }^{13}$ Since labor market re-integration after job displacement is potentially easier for high-skilled workers, we may then observe women displaying lower earnings losses than men. Yet this would not allow us to draw conclusions on the effect of gender per se: we could merely infer from this that the group of workers with a higher average skill level suffers less from job displacement. Since education is only one of the characteristics in which men and women differ, and which might play a role for the gender gap in earnings losses, we reweight women to men on a number of additional pre-displacement individual and establishment characteris-

\footnotetext{
${ }^{13}$ Referring back to the conceptual framework in Section 3.2, higher educated or "positively selected" women may have a particularly high incentive to stay in the workforce. This is because for them, foregone earnings when focusing fully on home production will be much higher.
} 
tics (for details, see Section 3.3.4). Note that for transparency, the graphs show eventstudy coefficients for both the sample of unweighted and reweighted women.

Figure 3.2 presents eventstudy graphs for the main earnings outcomes. Each panel shows four lines: the eventstudy estimates for men (solid blue line), for women without reweighting (red blue line), for women reweighting using individual characteristics such as education, age and pre-displacement tenure and wages (dashed pink line), and for women reweighting using both individual characteristics and establishment characteristics, such as industry and establishment size (dashed orange line). Figure 3.2, Panel (A), shows a striking result: while wage losses for our broad sample of women were smaller than for men, once we reweight women to closely match the men, their earnings losses become substantially larger. For example, in the first year after displacement, losses are around 1,000 Euro higher for women than for men. Strikingly, this gap grows as time passes and 5 years post displacement, earnings are around 4,000 Euro lower for displaced women than for men.

Note that the more relevant measure of earnings to compare men and women is log earnings in Panel (B), because in constrast to Panel (A), it shows the relative earnings losses. Here, a similar pattern emerges: women lose about 5 percentage points more earnings immediately after job loss and the gap grows over time to around 10 percentage points 5 years after job loss. Panels (C) and (D) of Figure 3.2 show earnings relative to pre-displacement and the inverse hyperbolic sine of earnings, respectively. ${ }^{14}$ The pattern is similar for these two outcomes and both show a large gender gap in earnings losses once we compare similar women and men, although there is somewhat more convergence for inverse hyperbolic sine earnings.

Columns (3) and (4) in Table 3.2 show regression estimates of the gender gap when accounting for differences in job characteristics between women and men. In Column (3), we estimate our matched Diff-in-Diff specification but including the same predisplacement characteristics of individual- and establishment-level variables as linear controls. The second row shows that the gender gap grows sharply to 7.7 percentage points, closely in line with the reweighted eventstudy results from Figure 3.2, Panel (B). We find similarly large gender gaps when looking at log earnings and inverse hyperbolic sine earnings. Column (4) uses DiNardo et al. (1996) reweighting instead of the linear controls, applying the reweighting weights $\omega$ discussed in Section 3.3.4

\footnotetext{
${ }^{14}$ Note that the inverse hyperbolic sine transformation helps us to include observations with values of 0 . Formally, the inverse hyperbolic sine is defined as $\operatorname{ar} \sinh x=\ln \left(x+\sqrt{x^{2}+1}\right)$.
} 
Figure 3.2: The Gender Gap in Earnings Losses after Displacement, Controlling for Pre- Displacement Job and Worker Characteristics

(A) Total Earnings

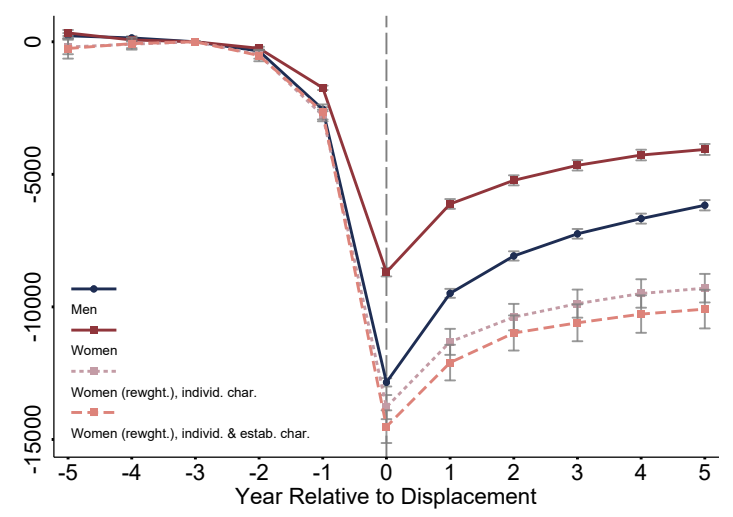

(C) Earnings Relative to $\mathrm{t}=\mathrm{c}-1$

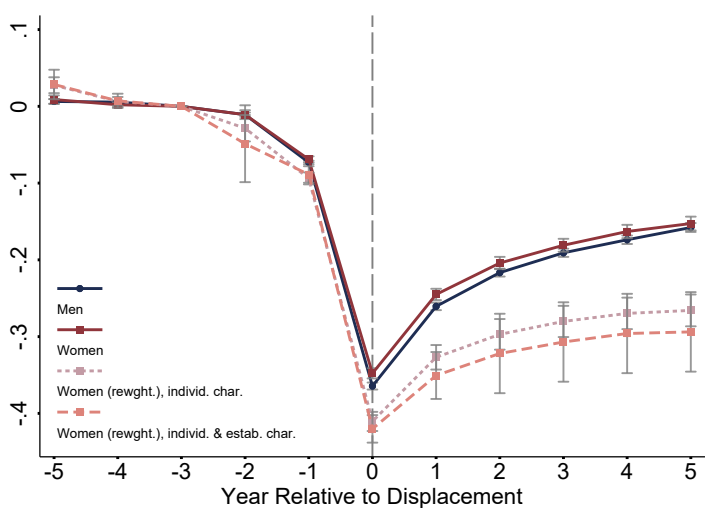

(B) Log Earnings

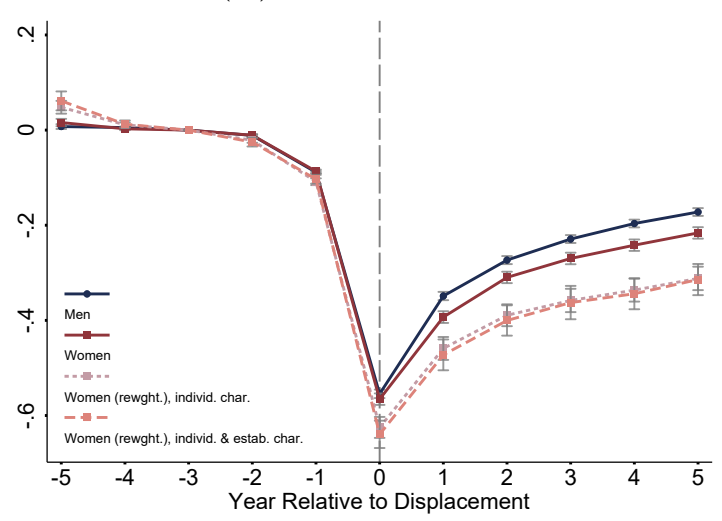

(D) Inverse Hyperbolic Sine Earnings

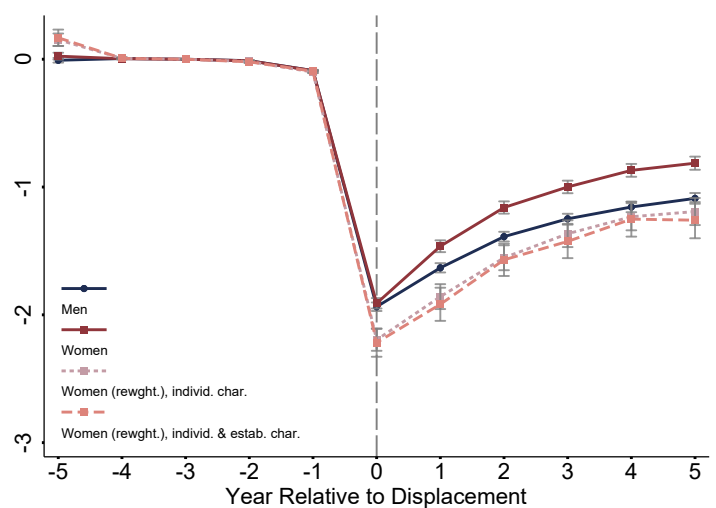

Notes: This figure shows how earnings losses from displacement differ for men and women. Panels (A)-(D) show eventstudy coefficients for total yearly earnings, log earnings, earnings relative to $t=c-$ 1, and inverse hyperbolic sine earnings. The four lines correspond to four eventstudy regressions: Men only, women only, women reweighted with individual characteristics, and women reweighted with individual characteristics and establishment characteristics. Individual characteristics are a worker's $\log$ wage in $\mathrm{t}=\mathrm{c}-2$ and $\mathrm{t}=\mathrm{c}-3$, full-time employment in $\mathrm{t}=\mathrm{c}-2$, and age, years of education, tenure, and location in East or West Germany in $\mathrm{t}=\mathrm{c}$. Establishment characteristics are 1-digit industry dummies and $\log$ establishment size in $\mathrm{t}=\mathrm{c}$. All regressions include controls for person FE, year FE, years since separation, and age polynomials. Vertical bars indicate the estimated $95 \%$ confidence interval based on standard errors clustered at the individual level. Workers are displaced in 2002-2012, and they are observed from 1997-2017. 
and used in Figure 3.2. This specification is more general than the linear controls and provides a consistent estimator for the gender gap even if the other controls have a non-linear effect on earnings losses. The results are broadly similar, though the gender gap is slightly larger (e.g. 9.2 percentage points for earnings relative to pre-displacement).

\subsubsection{The Role of Wage and Employment Losses after Dis- placement}

Earnings losses after job displacement occur partly due to workers being unemployed or leaving the labor force and partly due to losses in wages and hours worked. While the German social security data does not contain information on hours worked, it has detailed information on days worked (for each employment spell the exact start- and end-date is reported) and it provides an indicator for whether workers are working full-time, part-time or in a mini-job. There is also no information on hourly wages, but we can compute daily wages and daily wages conditional on working in a full-time job. Distinguishing between wages and different types of employment losses helps us to better understand the underlying mechanisms of the gender gap in earnings losses. For example, we can infer whether women are more likely than men to completely drop out of the labor force, or whether they sort into more flexible types of employment such as mini-jobs.

Figure 3.3 presents a number of wage and employment outcomes. Panel (A) shows that $\log$ daily wages decline dramatically after job loss for both men and women. Even unweighted, women have larger losses in daily wages but this gap becomes much larger when reweighting women to their male counterparts. Women lose around an extra 8 log points immediately after displacement, a gap that grows to around $20 \log$ points 5 years out. Turning to full-time log wages in Panel (B), we find that men and women experience similar losses without weighting, but there is again a very substantial gender gap once we reweight women to match the men. Overall, women lose about an extra 5 log points conditional on working full-time.

Panels (C) and (D) show that after reweighting, men and women have only slightly larger employment losses when measured as any employment in a given year or annual days worked. This however masks a large gap in days worked full-time (Panel (E)) when comparing similar men and women, where women work around 
Figure 3.3: The Gender Gap in Wage and Employment Losses after Displacement

(A) Log Daily Wage

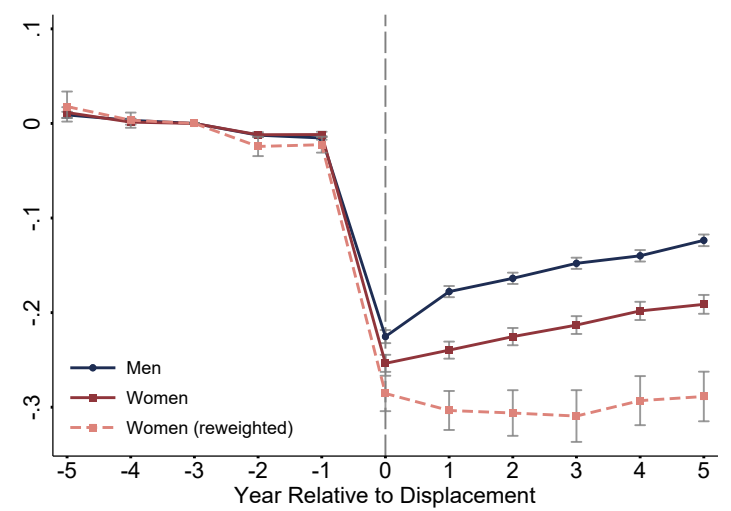

(C) Any Employment in Year

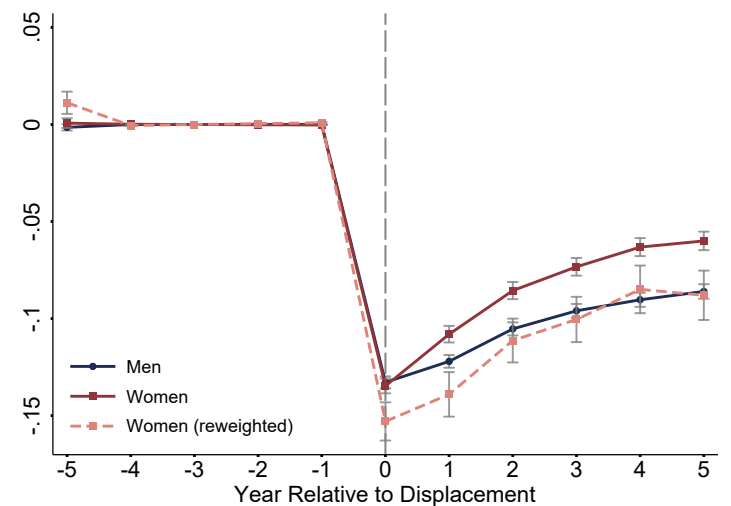

(E) Full-time Days Worked per Year

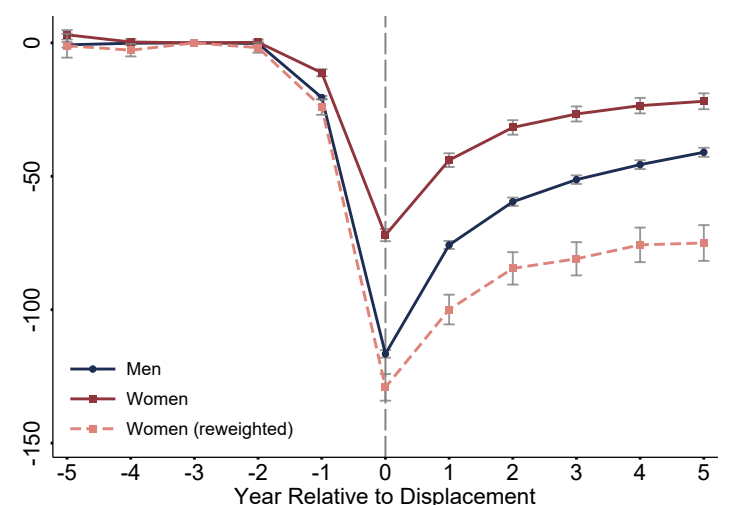

(B) Log Daily Wage - Full-time Jobs Only

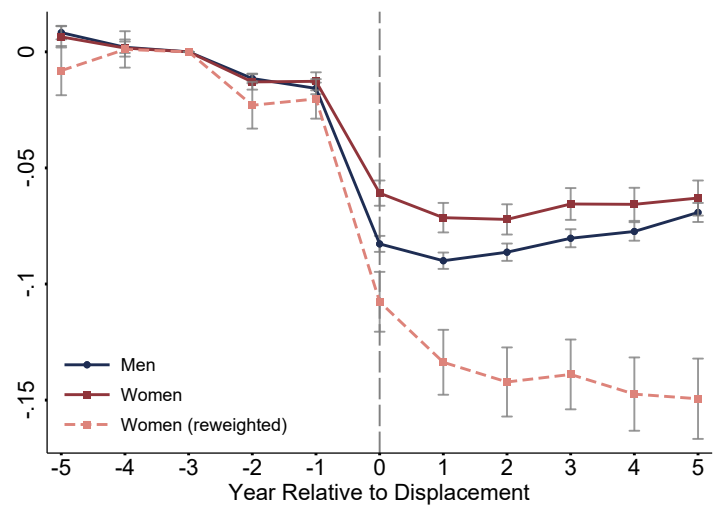

(D) Days Worked per Year

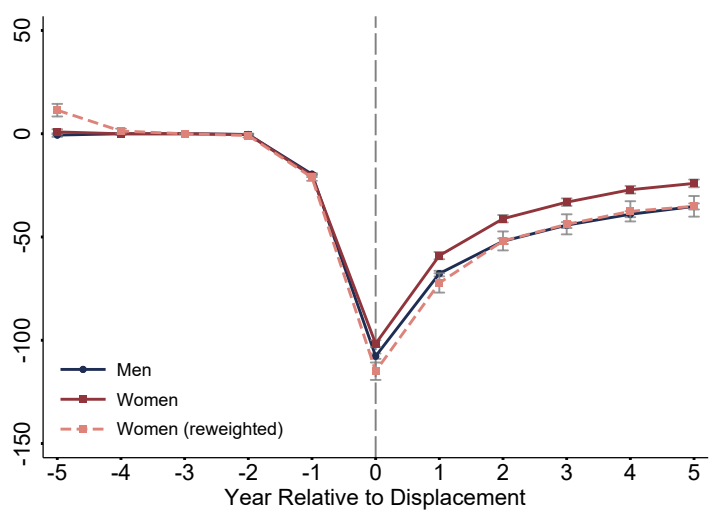

(F) Days Worked in Mini-job per Year

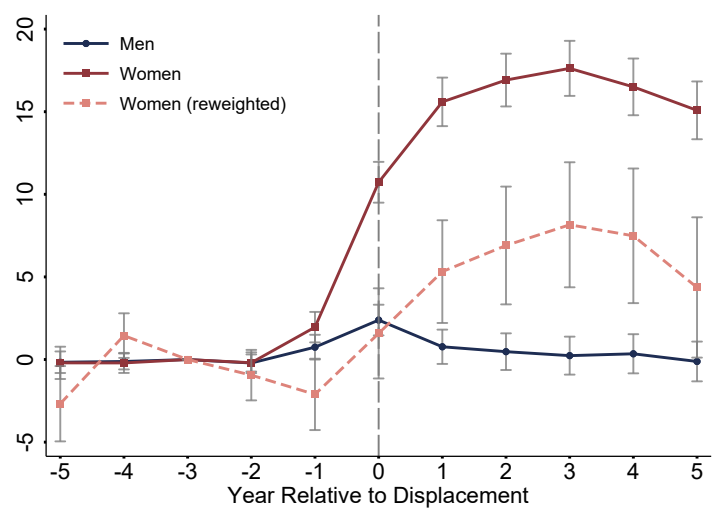

Notes: This figure shows how labor market characteristics before and after displacement differ for men and women. Panels (A)-(F) show eventstudy coefficients for log wage, log wage from fulltime job, employment, days worked, days worked in full-time job, and days worked in mini-job. The three lines correspond to three eventstudy regressions: Men only, women only, and women reweighted with individual and establishment characteristics. All regressions include controls for person $\mathrm{FE}$, year FE, years since separation, and age polynomials. Vertical bars indicate the estimated $95 \%$ confidence interval based on standard errors clustered at the individual level. Workers are displaced in 2002-2012, and they are observed from 1997-2017. 
30 days less full-time per year. ${ }^{15}$ This implies that women are much more likely to take on part-time jobs than men. Indeed, even women who worked full-time before displacement often switch to working part-time afterwards, something rarely observed for men.

This is also supported by Panel (F), which shows the number of days worked in a mini-job. Mini-jobs are a special type of marginal employment in the German labor market. For most of our observation period, mini-jobs define an employment contract with remuneration not exceeding 400 Euros per month. ${ }^{16}$ They are exempt from social security contributions and are particularly common among female workers, partly because they make it easy to combine work and family life. Note that given our baseline restrictions, we exclude workers working only in mini-jobs, though they can work a mini-job on the side. Following job loss, there is essentially no uptake of mini-jobs for men, however there is a big increase for the broad sample of women of around 15 days, and about an 8 day increase after reweighting. In fact, the large increase in part-time and mini-jobs for women after job loss is an important factor behind the large daily wage losses for women in Panel (A) compared to men.

The visual results from Figure 3.3 are also confirmed in Table 3.2, rows 5 to 10 . Overall, holding pre-displacement characteristics constant, women experience larger employment losses than men, are more likely to switch to part-time work or minijobs, and have much larger wage losses, even when conditioning on working fulltime. All factors together produce the large and lasting earnings losses that we documented in Section 3.4.1. The empirical results thus support the predictions of our conceptual framework in Section 3.2: displacement makes women shift their time allocation towards home production. Note however that we cannot say whether this is driven by labor demand or labor supply, or a mix of both.

\footnotetext{
${ }^{15}$ The unweighted gap for days full-time goes in the other direction, but this is mainly because women work so much less full-time to begin with and thus have less to lose.

${ }^{16}$ Prior to 2003, the threshold on monthly earnings was 325 Euros, with an additional limit of 15 working hours per week. Since 2013, the income threshold is 450 Euro per month (Tazhitdinova (2020); Gudgeon and Trenkle (2019)).
} 


\subsection{Understanding the Gender Gap in Wage Losses}

\subsubsection{Changes in Job and Establishment Characteristics af- ter Displacement}

The previous section showed that there is a large gender gap in earnings losses, which is driven by both employment and wage losses for displaced women compared to men. We next study whether differences in the nature of jobs after displacement contribute to this gap. For example, if women moved to establishments with lower average wage premia, then this would explain part of their higher wage losses. Similarly, if women were more likely to switch industries and/or occupations after job displacement (thus losing human capital), then this would be another explanation for the wage gap.

In Figure 3.4, we show the types of establishments men and women move to after displacement. A number of recent papers have shown that job losers tend to move to lower paying firms after job loss. As one measure of the type of employer quality, we show log establishment size (a measure which is positively associated with establishment wage premia) in Figure 3.4, Panel (A). Recall from Table 3.1 that women tend to work at larger establishments before reweighting. In the unweighted sample, women move to much smaller establishments post job loss. However after reweighting, the difference disappears and women displaced from comparable jobs as men also do not move to smaller employers.

As another measure of establishment characteristics, we show the share of women working in an establishment as an outcome variable in Panel (B). The figure shows that while the share of female coworkers remains similar for men after displacement, women move to establishments with much more female coworkers. Unweighted, women move to establishments with a female share that is 4 percentage points higher, while after weighting this increases to around 6 percentage points. This complements the evidence on the establishment wage premia, and is consistent with the evidence from Card et al. (2016) that women tend to be concentrated in low paying establishments. ${ }^{17}$ Strikingly, this suggests that even women with similar careers as men fall back to more typical female employers.

\footnotetext{
${ }^{17}$ Figure A.3.1 shows that the share of women in an establishment is strongly negatively correlated with the establishment wage premium. In turn, an establishment's size is positively correlated with the establishment wage premium.
} 
Panels (C) and (D) of Figure 3.4 show the probability of switching industry or occupation. Both are an important channel for wage losses after job loss, since they are usually correlated with losses in human capital. Approximately 40 percent of job losers switch industry and 40-50 percent switch occupation immediately after job loss. Gender differences here are pretty modest, especially after reweighting, and if anything women are slightly less likely to switch occupation. Thus at least along this measure it does not seem that the gender gap in earnings losses is due to larger human capital losses of women.

A more direct measure of employer quality are estimated establishment fixed effects from an AKM model (Abowd et al. (1999)). A recent version of the AKM model for our time period was estimated by Bellmann et al. (2020) ${ }^{18}$ who generously made them available to us. Panel (E) of Figure 3.4 shows the evolution of the estimated establishment effect after job loss. The estimated establishment effect, or establishment wage premium, drops by around $8 \log$ points for men. This corresponds almost exactly to the drop in log full-time wages for men, confirming the result in Schmieder et al. (2020) that the change in the establishment effects fully accounts for the change in log wages for displaced men for a slightly earlier time period. For women the unweighted loss in the establishment effect is slightly smaller than for men, with around 6 log points losses, while after reweighting the loss is larger, around $9 \log$ points in year 5 . These establishment effect losses mirror the losses in log full-time wages for women in Figure 3.3, Panel (B), and suggest that at least part of the gender gap in log full-time wages (and thus earnings) is due to women moving to worse paying establishments relative to men after job loss.

Finally, Panel (F) of Figure 3.4 shows how commuting distances are affected by job loss. Our measure of commuting distance (in $\mathrm{km}$ ) is the straight line distance between the geographic center of the municipality of residence and the municipality of work. This is relatively granular since many German towns and villages are geographically small, but it is obviously a noisy measure when it comes to large urban areas. The result on the broad sample of women is in line with Le Barbanchon et al. (2020), showing that women substantially reduce commuting distance after job loss, by almost $8 \mathrm{~km}$ (relative to a $30 \mathrm{~km}$ commute prior to displacement), while men's commuting distance is essentially unchanged. However, when we reweight women to match men, the gap in commuting disappears completely and women's

\footnotetext{
${ }^{18}$ In turn closely following Card et al. (2013).
} 
Figure 3.4: Changes in Job Characteristics after Displacement

(A) Log Size of Establishment

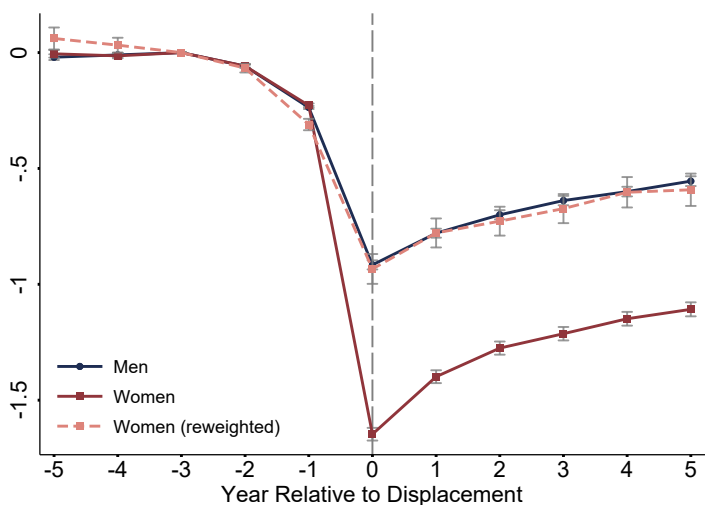

(C) Industry Changed Since $\mathrm{t}=\mathrm{c}$

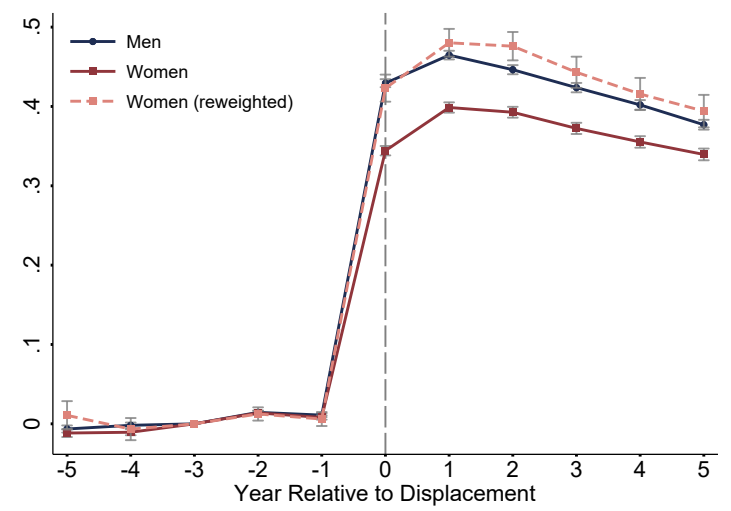

(E) AKM Wage Premia

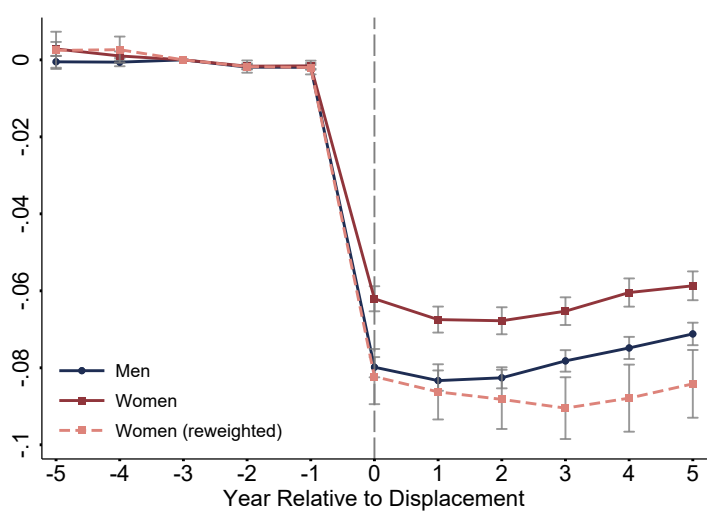

(B) Share of Women in Establishment

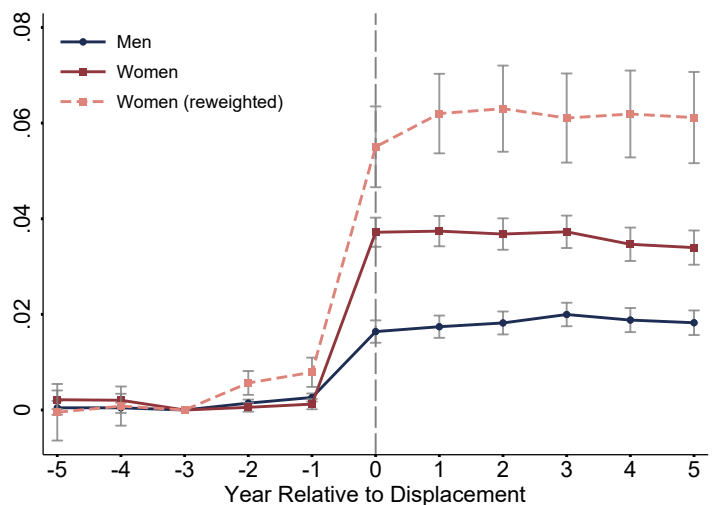

(D) Occupation Changed Since $t=c$

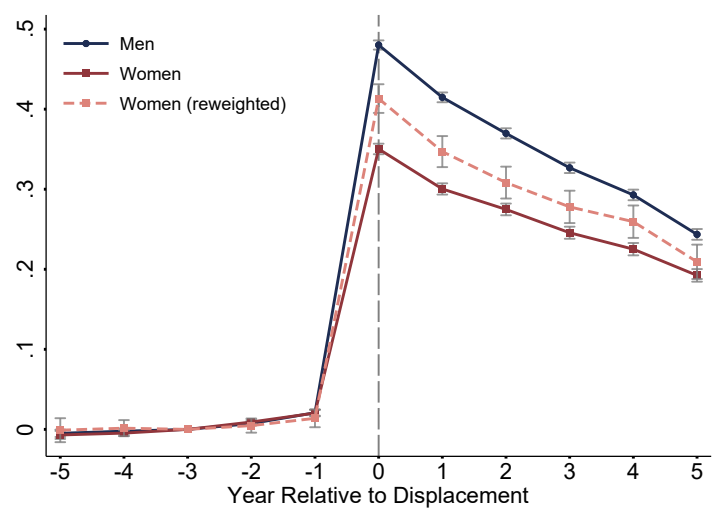

(F) Commuting Distance in $\mathrm{km}$

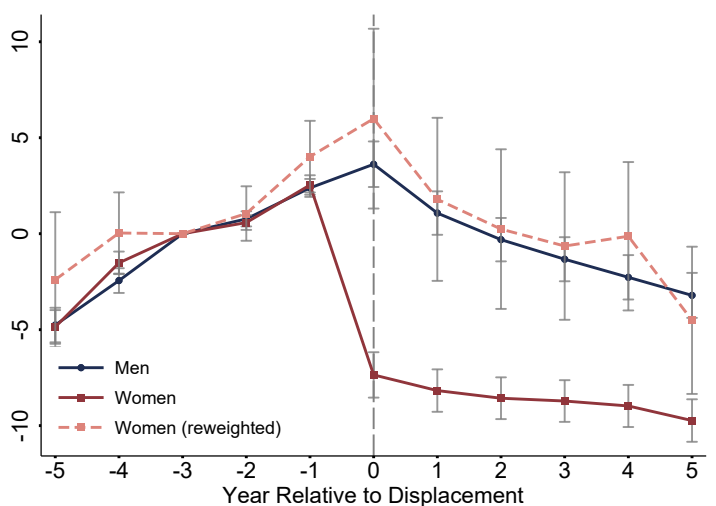

Notes: This figure shows how job characteristics for men and women evolve before and after displacement. Panels (A)-(F) show eventstudy coefficients for log establishment size, share of female workers in establishment (leave-one-out mean), industry switches (2-digits), occupation switches (3-digits), AKM establishment effects, and commuting distance (in km). The three lines correspond to three eventstudy regressions: Men only, women only, and women reweighted with individual and establishment characteristics. All regressions include controls for person FE, year FE, years since separation, and age polynomials. Vertical bars indicate the estimated $95 \%$ confidence interval based on standard errors clustered at the individual level. Commuting distance is measured on the municipality level, and is recorded on December 31 each year. Workers are displaced in 2002-2012, and they are observed from 1997-2017. 
commutes remain essentially unchanged relative to their pre-displacement job.

\subsubsection{Sources Underlying the Gender Gap in Wage Losses}

Given the changes in job characteristics shown above, we can now turn to whether these observable post-displacement job characteristics can explain the losses in wages, and the gender gap in particular. For this we estimate Equation 3.9, including changes in job characteristics $\Delta_{d d} Z_{i c}$ as explanatory variables. Table 3.3 shows these estimates both for overall daily wages (Panel (A)) and full-time wages (Panel (B)). All regressions are weighted so that women match their male counterparts. Column (1) reproduces the benchmark results from Table 3.2, Column (4), for the two outcomes. We first include indicators for changing industry and occupation in Column (2). While both are associated with large drops in log daily wages and full-time wages, the coefficient on female remains unchanged, which is not surprising given that the incidence of occupation change and industry change is so similar for both groups (Figure 3.4). Column (3) includes the change in log establishment size and shows that larger establishments pay higher wages (elasticity of 0.06 or 0.03 for full-time workers). We also include the share of women working in an establishment as an explanatory variable, since women are often concentrated in low wage establishments. While this is strongly negatively correlated with overall log wages and full-time wages, only a small share of the gender gap is explained by size and gender composition of the post-displacement establishment.

Based on Le Barbanchon et al. (2020), we might expect that women trade off a higher wage for a shorter commute after job loss and that this would explain some of the gender gap, but we see no evidence for this in Column (4). Commuting distance is not clearly related to wages and the gender gap is unchanged when controlling for it.

In Columns (5) and (6), we turn to the establishment wage premium (or AKM establishment effect). The wage premium does explain a substantial part of the gender gap in wage losses, especially for full-time workers, where the gap is reduced from 3.9 to $3.2 \mathrm{log}$ points (or around 20 percent) in Column (5). The coefficient on the establishment effect is 0.74 in Column (5). If the AKM model is not misspecified, the true coefficient should in principle be 1, but due to measurement error in the estimates of the AKM model we would expect the coefficient to be downward biased 
Table 3.3: Explaining the Gender Gap in Wage Losses After Displacement

\begin{tabular}{|c|c|c|c|c|c|c|c|c|}
\hline & $(1)$ & $(2)$ & $(3)$ & (4) & $(5)$ & $(6)$ & (7) & $(8)$ \\
\hline \multicolumn{9}{|c|}{ Panel A: All Workers: Log Wage } \\
\hline Female & \multirow{9}{*}{$\begin{array}{c}-0.13 \\
(0.013)^{* *}\end{array}$} & \multirow{9}{*}{$\begin{array}{c}-0.13 \\
(0.013)^{* *} \\
-0.14 \\
(0.011)^{* *} \\
-0.13 \\
(0.0096)^{* *}\end{array}$} & \multirow{5}{*}{$\begin{array}{c}-0.11 \\
(0.013)^{* *}\end{array}$} & \multirow{9}{*}{$\begin{array}{c}-0.13 \\
(0.013)^{* *}\end{array}$} & \multirow{8}{*}{${ }^{-0.12}(0.012)^{* *}$} & \multirow{8}{*}{$(0.011)^{* *}$} & -0.11 & -0.097 \\
\hline & & & & & & & $(0.012)^{* *}$ & $(0.011)^{* *}$ \\
\hline Industry Change & & & & & & & $\begin{array}{c}-0.10 \\
(0.011)^{* *}\end{array}$ & $\begin{array}{l}-0.081 \\
(0.010)^{* *}\end{array}$ \\
\hline Occ. Change & & & & & & & -0.095 & -0.071 \\
\hline & & & & & & & $(0.0089)^{* *}$ & $(0.0090)^{* *}$ \\
\hline Log Estab Size & & & \multirow{4}{*}{$\begin{array}{c}0.059 \\
(0.0040)^{* *} \\
-0.41 \\
(0.034)^{* *}\end{array}$} & & & & $\begin{array}{l}0.042 \\
(0.0035)^{* *}\end{array}$ & $\begin{array}{c}0.026 \\
(0.0037)^{* *}\end{array}$ \\
\hline Estab Share Women & & & & & & & -0.28 & -0.23 \\
\hline Commuting Distance & & & & & & & $\begin{array}{l}(0.030) \\
-0.000052\end{array}$ & $\begin{array}{l}(0.031) \\
-0.000045\end{array}$ \\
\hline AKM Estab FE & & & & & $\begin{array}{c}1.06 \\
(0.064)^{* *} \\
\end{array}$ & 1 & $\begin{array}{c}(0.000064) \\
0.90 \\
(0.061)^{* *}\end{array}$ & $\begin{array}{c}(0.000065) \\
1\end{array}$ \\
\hline Observations & 73598 & 73598 & 73598 & 73598 & 73598 & 63452 & 73598 & 63452 \\
\hline & 0.010 & 0.043 & 0.083 & 0.034 & 0.157 & 0.009 & 0.227 & 0.059 \\
\hline Mean Dep. Var Men & -.201 & -.201 & -.201 & -.201 & -.201 & -.201 & -.201 & -.201 \\
\hline & $(.003)$ & $(.003)$ & $(.003)$ & $(.003)$ & $(.003)$ & $(.003)$ & $(.003)$ & $(.003)$ \\
\hline \multicolumn{9}{|c|}{ Panel B: Full-time Workers: Full-time Log Wage } \\
\hline \multirow{2}{*}{ Female } & -0.039 & -0.038 & -0.035 & -0.039 & -0.032 & -0.028 & -0.030 & -0.027 \\
\hline & $(0.0084)^{* *}$ & $(0.0084)^{* *}$ & $(0.0085)^{* *}$ & $(0.0084)^{* *}$ & $(0.0075)^{* *}$ & $(0.0076)^{* *}$ & $(0.0076)^{* *}$ & $(0.0077)^{* *}$ \\
\hline Industry Change & & $(0.0068)^{* *}$ & & & & & $(0.0067)^{* *}$ & $\begin{array}{c}-0.021 \\
(0.0062)^{* *}\end{array}$ \\
\hline \multirow[t]{2}{*}{ Occ. Change } & & -0.022 & & & & & -0.0096 & -0.0027 \\
\hline & & $(0.0059)^{* *}$ & & & & & $(0.0054)$ & $(0.0051)$ \\
\hline Log Estab Size & & & 0.025 & & & & 0.012 & 0.0059 \\
\hline \multirow{2}{*}{ Estab Share Women } & & & $\begin{array}{c}(0.0023) \\
-0.14\end{array}$ & & & & $(0.0018)^{* *}$ & $(0.0027)^{*}$ \\
\hline & & & $(0.018)^{* *}$ & & & & $(0.016)^{* *}$ & $(0.015)$ \\
\hline \multicolumn{2}{|l|}{ Commuting Distance } & & & 0.000066 & & & 0.000054 & 0.000062 \\
\hline AKM Estab FE & & & & $(0.000043)$ & $\begin{array}{c}0.74 \\
(0.055)^{* *}\end{array}$ & 1 & $\begin{array}{c}(0.000040) \\
0.70 \\
(0.055)^{* *}\end{array}$ & $\begin{array}{c}(0.000042) \\
1\end{array}$ \\
\hline \multirow{4}{*}{$\begin{array}{l}\text { Observations } \\
R^{2} \\
\text { Mean Dep. Var Men }\end{array}$} & 52996 & 52996 & 52996 & 52996 & 52996 & 52996 & 52996 & 52996 \\
\hline & 0.003 & 0.014 & 0.030 & 0.004 & 0.220 & 0.002 & 0.228 & 0.006 \\
\hline & -.094 & -.094 & -.094 & -.094 & -.094 & -.094 & -.094 & -.094 \\
\hline & $(.002)$ & $(.002)$ & $(.002)$ & $(.002)$ & $(.002)$ & $(.002)$ & $(.002)$ & $(.002)$ \\
\hline \multicolumn{9}{|c|}{$\begin{array}{l}\text { Notes: This table shows to what extent changes in industry, occupation, and establishment characteristics can explain the } \\
\text { effect of being female on wages after displacement. All outcome variables are based on the individual difference-in-differences } \\
\text { estimate. We reweight women to men using individual and establishment characteristics pre displacement. In Panel A, the } \\
\text { outcome variable is log wages. In Panel } \mathrm{B} \text {, the outcome variable is full-time log wages. In both panels, we control for the same } \\
\text { set of difference-in-differences estimates as depicted in the table. These represent the individual change in earnings from before } \\
\text { (-5 to }-2 \text { years) to after ( } 0 \text { to } 3 \text { years) job displacement for treated vs. control workers. Columns (2)- }(6) \text { control for various } \\
\text { difference-in-differences terms. Column ( } 7 \text { ) controls for all difference-in-differences terms at once. In Columns }(6) \text { and (8), the } \\
\text { coefficient on the establishment effect is forced to be equal to } 1 \text {. We cluster standard errors at displacement establishment } \\
\text { level (constant within matched worker pairs). Workers in our sample are displaced in } 2002-2012 \text {, and they are observed from } \\
1996-2017 . * \text { and } * * \text { correspond to } 5 \text { and } 1 \text { percent signficance levels, respectively. }\end{array}$} \\
\hline
\end{tabular}


(Kline et al. (2020)). Indeed, Schmieder et al. (2020) show that using a two sample IV leads to a coefficient close to 1 in this type of regression. If we simply impose that the establishment effect has a coefficient of 1 , we find that about a quarter of the gender gap is explained by changes in the establishment effects (Column 6).

Finally, we put in all job characteristics jointly in Columns (7) and (8). For overall wages, job characteristics explain roughly one quarter of the gender gap, while for full-time wages they explain about 30 percent.

\subsubsection{Robustness of Main Results}

Table 3.4 provides a range of robustness checks for our main results on the gender gap after job loss. For comparison, Column (1) replicates the baseline estimates for the composition adjusted gender gap in the costs of job loss using the reweighting method from Table 3.2, Column (4), for our key outcomes: earnings relative to predisplacement, $\log$ wages (all and full-time), and days worked. Additional outcomes are shown in Table A.3.5. 
Table 3.4: The Gender Gap in Earnings Losses - Robustness Checks

\begin{tabular}{|c|c|c|c|c|c|c|c|c|c|c|}
\hline & $\begin{array}{c}(1) \\
\text { Baseline }\end{array}$ & $\begin{array}{c}(2) \\
10 \text { Years } \\
\text { Post Displ. }\end{array}$ & $\begin{array}{l}(3) \\
\text { Shorter } \\
\text { Tenure } \\
\text { Restr. }\end{array}$ & $\begin{array}{c}(4) \\
\text { Mahalanobis } \\
\text { And Exact } \\
\text { Matching }\end{array}$ & $\begin{array}{c}(5) \\
\text { Reweight. } \\
\text { With } \\
\text { Occupations }\end{array}$ & $\begin{array}{l}(6) \\
\text { Displ. } \\
\text { Estab. } \\
\text { FE }\end{array}$ & $\begin{array}{l}(7) \\
\text { Matching } \\
\text { Without } \\
\text { Wages }\end{array}$ & $\begin{array}{l}(8) \\
\text { Reweight. } \\
\text { Men to } \\
\text { Women }\end{array}$ & $\begin{array}{c}(9) \\
\text { Non } \\
\text { Couples }\end{array}$ & $\begin{array}{c}(10) \\
\text { Couples } \\
+ \\
\text { Non-Couples }\end{array}$ \\
\hline \multicolumn{11}{|c|}{ Panel A: Earnings Rel. to Year -2} \\
\hline $\begin{array}{l}\text { Observations } \\
R^{2} \\
\text { Mean Dep. Var Men }\end{array}$ & $\begin{array}{c}-0.092 \\
(0.012)^{* *} \\
80655 \\
0.007 \\
-.258 \\
(.002)\end{array}$ & $\begin{array}{c}-0.093 \\
(0.018)^{* *} \\
55107 \\
0.006 \\
-.203 \\
(.003)\end{array}$ & $\begin{array}{c}-0.11 \\
(0.014)^{* *} \\
93755 \\
0.008 \\
-.268 \\
(.002)\end{array}$ & $\begin{array}{c}-0.093 \\
(0.012)^{* *} \\
80707 \\
0.007 \\
-.245 \\
(.002)\end{array}$ & $\begin{array}{c}-0.12 \\
(0.025)^{* *} \\
80423 \\
0.013 \\
-.258 \\
(.002)\end{array}$ & $\begin{array}{c}-0.086 \\
(0.0089)^{* *} \\
77144 \\
0.352 \\
-.258 \\
(.002)\end{array}$ & $\begin{array}{c}-0.087 \\
(0.012)^{* *} \\
80706 \\
0.006 \\
-.258 \\
(.002)\end{array}$ & $\begin{array}{c}-0.068 \\
(0.020)^{* *} \\
78695 \\
0.003 \\
-.259 \\
(.002)\end{array}$ & $\begin{array}{l}-0.017 \\
(0.013) \\
16422 \\
0.000 \\
-.297 \\
(.006)\end{array}$ & $\begin{array}{c}-0.048 \\
(0.013)^{* *} \\
96158 \\
0.002 \\
-.287 \\
(.002)\end{array}$ \\
\hline \multicolumn{11}{|l|}{ Panel B: Log Wages } \\
\hline $\begin{array}{l}\text { Female } \\
\text { Observations } \\
R^{2} \\
\text { Mean Dep. Var Men }\end{array}$ & $\begin{array}{c}-0.13 \\
(0.013)^{* *} \\
73598 \\
0.010 \\
-.201 \\
(.003)\end{array}$ & $\begin{array}{c}-0.14 \\
(0.017)^{* *} \\
51670 \\
0.009 \\
-.187 \\
(.004)\end{array}$ & $\begin{array}{c}-0.16 \\
(0.013)^{* *} \\
85092 \\
0.013 \\
-.205 \\
(.003)\end{array}$ & $\begin{array}{c}-0.15 \\
(0.013)^{* *} \\
73626 \\
0.013 \\
-.188 \\
(.003)\end{array}$ & $\begin{array}{c}-0.22 \\
(0.036)^{* *} \\
73369 \\
0.025 \\
-.201 \\
(.003)\end{array}$ & $\begin{array}{c}-0.16 \\
(0.013)^{* *} \\
70058 \\
0.347 \\
-.201 \\
(.003)\end{array}$ & $\begin{array}{c}-0.13 \\
(0.013)^{* *} \\
73634 \\
0.009 \\
-.201 \\
(.003)\end{array}$ & $\begin{array}{c}-0.16 \\
(0.017)^{* *} \\
71758 \\
0.014 \\
-.202 \\
(.003)\end{array}$ & $\begin{array}{c}-0.079 \\
(0.016)^{* *} \\
14551 \\
0.004 \\
-.201 \\
(.007)\end{array}$ & $\begin{array}{c}-0.075 \\
(0.015)^{* *} \\
87342 \\
0.003 \\
-.203 \\
(.003)\end{array}$ \\
\hline \multicolumn{11}{|c|}{ Panel C: Log Full-time Wages } \\
\hline $\begin{array}{l}\text { Observations } \\
R^{2} \\
\text { Mean Dep. Var Men }\end{array}$ & $\begin{array}{c}-0.039 \\
(0.0084)^{* *} \\
52996 \\
0.003 \\
-.094 \\
(.002)\end{array}$ & $\begin{array}{c}-0.046 \\
(0.012)^{* *} \\
39002 \\
0.003 \\
-.091 \\
(.002)\end{array}$ & $\begin{array}{c}-0.052 \\
(0.0079)^{* *} \\
60891 \\
0.005 \\
-.094 \\
(.002)\end{array}$ & $\begin{array}{c}-0.067 \\
(0.0077)^{* *} \\
56077 \\
0.009 \\
-.084 \\
(.002)\end{array}$ & $\begin{array}{c}-0.090 \\
(0.027)^{* *} \\
52939 \\
0.015 \\
-.094 \\
(.002)\end{array}$ & $\begin{array}{c}-0.061 \\
(0.0074)^{* *} \\
49526 \\
0.360 \\
-.094 \\
(.002)\end{array}$ & $\begin{array}{c}-0.051 \\
(0.0086)^{* *} \\
53169 \\
0.005 \\
(.002)\end{array}$ & $\begin{array}{c}-0.045 \\
(0.0099)^{* *} \\
52938 \\
0.004 \\
-.094 \\
(.002)\end{array}$ & $\begin{array}{c}-0.039 \\
(0.011)^{* *} \\
10944 \\
0.003 \\
-.086 \\
(.004)\end{array}$ & $\begin{array}{c}-0.044 \\
(0.012)^{* *} \\
63191 \\
0.003 \\
-.09 \\
(.002)\end{array}$ \\
\hline \multicolumn{11}{|c|}{ Panel D: Days Worked Full-time } \\
\hline $\begin{array}{l}\text { Observations } \\
R^{2} \\
\text { Mean Dep. Var Men }\end{array}$ & $\begin{array}{c}-23.1 \\
(2.84)^{* *} \\
80655 \\
0.005 \\
-75.47 \\
(.766)\end{array}$ & $\begin{array}{c}-32.5 \\
(3.73)^{* *} \\
55107 \\
0.009 \\
-56.298 \\
(.976)\end{array}$ & $\begin{array}{c}-30.4 \\
(2.73)^{* *} \\
93755 \\
0.008 \\
-77.46 \\
(.717)\end{array}$ & $\begin{array}{c}-10.1 \\
(2.74)^{* *} \\
80707 \\
0.001 \\
-74.628 \\
(.727)\end{array}$ & $\begin{array}{c}-31.9 \\
(6.66)^{* *} \\
80423 \\
0.009 \\
-75.471 \\
(.766)\end{array}$ & $\begin{array}{c}-22.3 \\
(2.87)^{* *} \\
77144 \\
0.335 \\
-75.47 \\
(.766)\end{array}$ & $\begin{array}{c}-17.4 \\
(2.86)^{* *} \\
80706 \\
0.003 \\
-75.8 \\
(.763)\end{array}$ & $\begin{array}{c}-25.4 \\
(4.64)^{* *} \\
78695 \\
0.004 \\
-75.664 \\
(.765)\end{array}$ & $\begin{array}{c}-6.68 \\
(4.20) \\
16422 \\
0.000 \\
-88.476 \\
(1.706)\end{array}$ & $\begin{array}{c}-14.4 \\
(4.07)^{* *} \\
96158 \\
0.002 \\
-84.705 \\
(.716)\end{array}$ \\
\hline \multicolumn{11}{|c|}{ 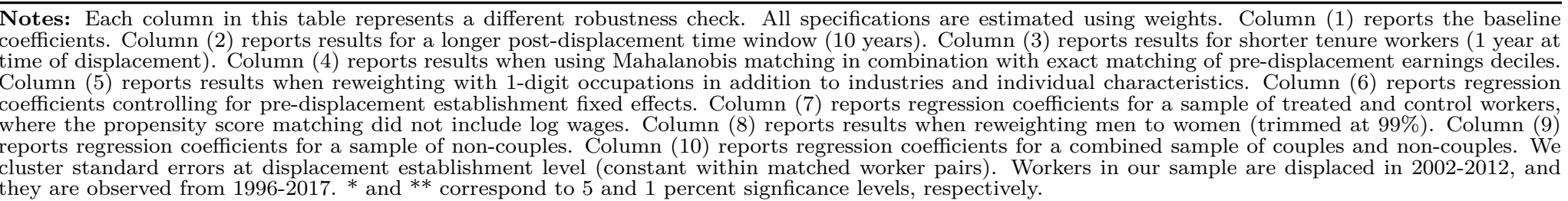 } \\
\hline
\end{tabular}




\section{Sample Construction}

We first turn to alternative ways of measuring the cost of job loss and creating a suitable control group. While our baseline specification estimates the cost of job loss over a 5 year horizon after displacement, Table 3.4, Column (2), presents a result for a 10 year post-displacement horizon. Since we have to drop displacement events after 2007 to observe the full time horizon, we lose about $30 \%$ of our observations. Strikingly, even over this longer time horizon results are very similar as before, suggesting that wage and earnings losses are highly persistent. This is also shown in Figure A.3.2, Panels (A) and (B), where earnings and full-time log wages show virtually no recovery after 10 years.

Our main estimates impose a 2 year tenure restriction in the baseline year. Column (3) shows that relaxing this restriction to only 1 year does not substantially alter the result and in fact leads to an even larger gender gap. ${ }^{19}$ Similarly, we show in Table A.3.6, Column (6), that imposing the stricter restrictions (3 years tenure, baseline establishment size larger than 50) from Schmieder et al. (2020) leads to similar results and again a somewhat larger gender gap.

One downside of propensity score matching is that while on average, displaced and non-displaced workers have very similar characteristics, this does not have to be the case on the individual level. As an alternative, Column (4) in Table 3.4 and Panels (E) and (F) in Figure A.3.2 show estimates based on Mahalanobis distance matching using the same covariates, which leads to close covariates within each pair. In this specification, we also force the treatment and control worker to be in the same predisplacement earnings decile. The results are fairly similar and the wage losses even slightly larger.

A key contribution of our approach is to hold pre-displacement characteristics constant when comparing men and women. Table A.3.3 shows that occupations of displaced workers are also quite different between men and women. For example, before the layoff displaced men often have blue collar jobs, such as Trucker, Warehouseman or Bricklayer, and the broad white collar occupation "Qualified Office Employee" only accounts for about 7.3 percent of job losers. Women on the other hand are much more likely to be in white collar jobs with almost $30 \%$ being "Qualified Office Employees" or Salesperson. These numbers are similar post displacement, as shown in Table A.3.4. Table 3.4, Column (5), shows that when we also reweight

\footnotetext{
${ }^{19}$ See also Panels (C) and (D) in Figure A.3.2.
} 
on 1-digit occupations, the gender gap becomes substantially larger, especially for wages. Panels (A) and (B) of Figure A.3.2 confirm this pattern.

\section{Controlling for Displacing Establishment}

Table 3.1 showed that women tend to work at different establishments than men (larger, lower paying, different industries). While these differences become substantially smaller after reweighting (Table 3.1, Columns (3) vs. (5)), this may not capture all the relevant differences. It could be for example that women are still on average laid off during mass lay-off events that are more destructive, e.g. particularly large, or in particularly depressed regions. To account for this we estimate the gender gap by comparing men and women displaced from the same establishment by adding pre-displacement establishment fixed effects to the regression. The results are shown in Table 3.4, Column (6). ${ }^{20}$ Earnings losses in this specification are still substantially larger for women (8.6 percentage points) and the gender gap in wage losses is increased relative to the baseline.

\section{Alternative Matching and Reweighting Algorithms}

One might be concerned that in the propensity score matching algorithm, we match on pre-displacement outcomes, namely wages. To show that our results are robust to excluding wages from the probit regression, we re-run the matching algorithm without conditioning on wages. Table 3.1, Column (7) shows that when we implement the reweighting algorithm without matching on pre-displacement wages, we get almost the same results as in the baseline specification. Again, Panels (E) and (F) in Figure A.3.2 confirm this pattern.

So far we compared men and women displaced from similar jobs by reweighting women to the characteristics of displaced men. An obvious alternative is to reweight men to the characteristics of women. One practical issue is that there are very few men working part-time in our sample (and in general), so that in some cells we have almost no men to reweight leading to very large standard errors (since some individuals get a huge weight). To deal with this we drop observations with a propensity score of greater than 0.99 (that is, observations that based on observables have a more than 99 percent probability of being women). The resulting estimates in Table 3.4, Column (8), and Panels (A) and (B) in Figure A.3.3 show a similar pattern as the baseline results. While the gender gap in relative earnings losses is slightly smaller, it is larger for wage losses and days worked full-time.

\footnotetext{
${ }^{20}$ See also Panels (C) and (D) in Figure A.3.2.
} 


\section{Evidence on Non-Couples}

Our main analysis focuses on individiuals who we identified as married as described above. While this is clearly an important sample in itself (and the relevant sample when looking at job displacement in the household context as in the next section), it is also somewhat restrictive. Therefore we replicate our baseline analysis for a random sample of individuals who are not identified as couples (Table 3.4, Column (9)) and a combined sample of couples and non-couples (corresponding to a random sample of the overall population of workers in Germany, Table 3.4, Column (10)). Panels (C)-(F) in Figure A.3.3 report the corresponding eventstudy graphs.

Table 3.4, Column (9), shows that the gender gap is somewhat smaller for noncouples, though the basic pattern is still very similar. It is noteworthy that just because we do not observe someone in the data as a married couple does not mean that they are not married (the partner could be self-employed, for example). Finally, Column (10) shows that a representative sample of couples and non-couples again displays similar patterns as the baseline, with just slightly smaller gender gaps. ${ }^{21}$

\section{East vs. West}

One might expect that the results differ between East and West Germany, given that culture may influence women's labor supply (Boelmann et al. (2020)). Table A.3.6, Columns (2) and (3), shows that costs of job loss indeed slightly differ between women working in East compared to West Germany in $t=c$ : Earnings losses are about 50\% larger for West German women. Interestingly, East German women lose more in terms of full-time wages and employment. This is partly because - along with East German men - they have a much higher propensity to switch to mini-job employment after job displacement (see Figure A.3.5).

Complete Closure vs. Mass-Layoff Finally, one worry could be that the gender gap differs between workers displaced from a complete establishment closure versus a mass-layoff. Workers displaced from a mass-layoff could constitute a negative selection, because firms may lay-off low productivity workers first (Gibbons and Katz (1991)). As Columns (4) and (5) of Table A.3.6 show, the gender gap is however remarkably stable for these two groups of workers. The gender gap in earnings losses is identical, and the gender gap in wage losses is somewhat lower for workers displaced from a mass-layoff.

\footnotetext{
${ }^{21}$ Note that for practical reasons, we use a random sample of non-couples and the universe of displaced workers in couples in Column (10) but then reweight both groups to correspond to a random sample of the overall population.
} 


\subsection{Displacement in the Household Context}

\subsubsection{The Added Worker Effect}

A long-standing hypothesis in Labor Economics is that married women increase their labor supply in response to their husbands' unemployment (e.g. Lundberg (1985), Halla et al. (2020)). Our newly created link of married couples allows us for the first time to study this effect in German administrative data. As a departure from the long-standing focus of this literature on the labor force participation of wives only, we look at labor supply responses of both husbands and wives of displaced workers. This allows us to examine whether there are gender differences in spousal labor supply which could either mitigate or amplify the individual-level gender gap in the costs of job loss.

Our main results are shown in Figure 3.5. Panels (A) and (B) report the impact of job loss on the partner's earnings and log wages by gender of the displaced worker. The blue line shows that if a man loses his job there is virtually no change in the partner's log earnings and wages and the confidence intervals encompass 0 . There does however seem to be a negative effect on the days worked of displaced men's partners (Panel (C)), which fall by around 18 days. The fact that wages do not fall suggests that this employment loss is driven by people not working at all and as a result log earnings and wages are missing for that group. Together this suggests that there is a small negative added worker effect. For women the pattern is somewhat different in that it appears that husbands of displaced women do have a negative earnings shock in the subsequent years of around 2-3 percent, though the estimate is only significant for the unweighted sample of women and very noisy after reweighting. Similarly, in the unweighted sample both days worked and log wages decline for the partners of displaced women, while weighting makes these estimates too noisy to be distinguishable from 0 .

Finally in Figure 3.5 (Panel (D)), we show the effect of job loss on total household income. Given that partner's earnings barely respond to job displacement, the picture on the household level is very similar to the individual level. Women's job loss lead to smaller (absolute) household earnings losses in the overall sample than when men lose their job. However, once we reweight the sample so that we compare similar men and women, the losses are significantly larger if women lose their job. 
Figure 3.5: Job Loss at the Household Level - The Added Worker Effect

(A) Partner's Log Earnings

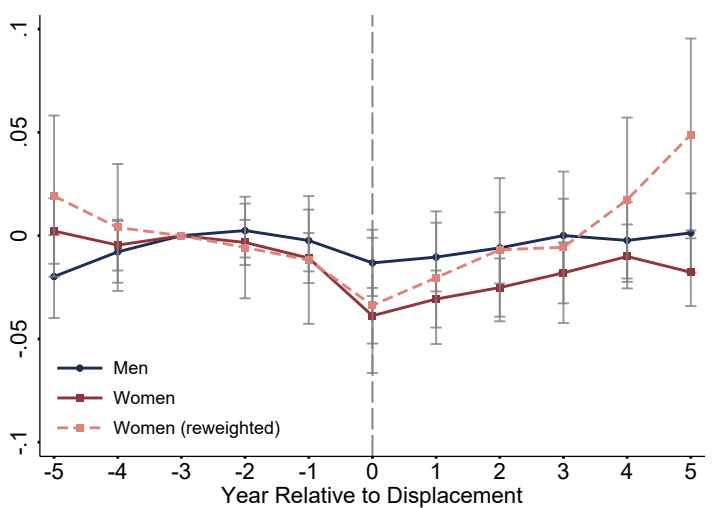

(C) Partner's Days Worked per Year

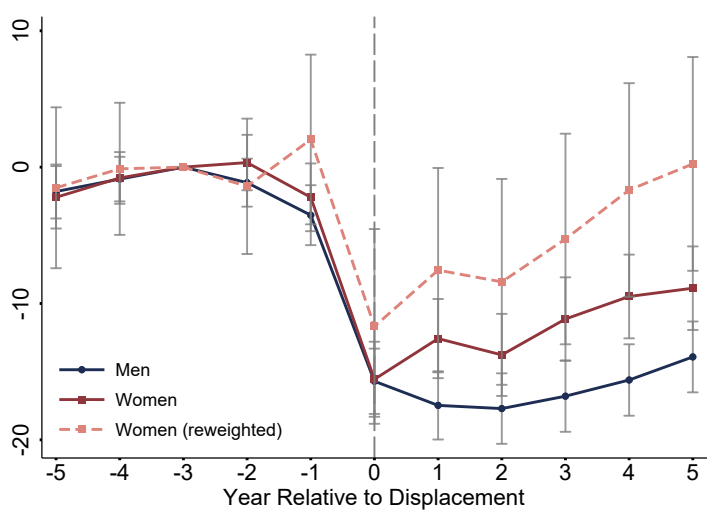

(B) Partner's Log Wage

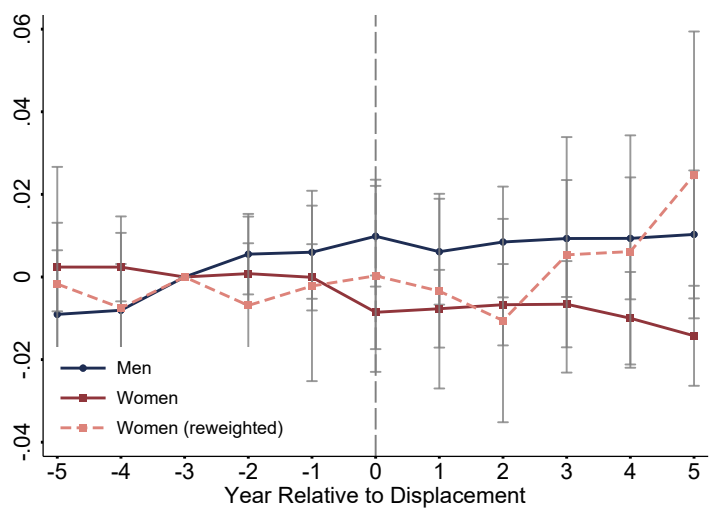

(D) Total Yearly Household Earnings

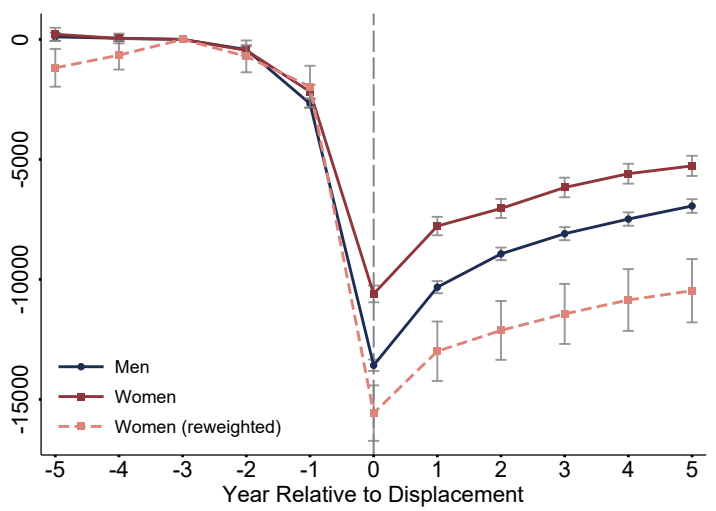

Notes: This figure shows how partner and household outcomes evolve differently for non-displaced workers compared to displaced workers. Panels (A)-(D) show eventstudy coefficients for partner's log earnings, partner's log wage, partner's days worked, and household earnings (in Euros). The three lines correspond to three eventstudy regressions: Men only, women only, and women reweighted with individual and establishment characteristics. All regressions include controls for person $\mathrm{FE}$, year FE, years since separation, and age polynomials. Vertical bars indicate the estimated $95 \%$ confidence interval based on standard errors clustered at the individual level. Workers are displaced in 2002-2012, and they are observed from 1997-2017. 
Overall, the small and negative added worker effect may come at a surprise. One caveat is that we can only identify married couples where both partners are in the social security data, either by working a social security liable job or by receiving UI benefits. In particular, we miss all couples where one spouse is not in the labor force at all or is self-employed. It may well be the case that spouses who are not working or working self-employed are the most likely to respond by increasing their labor supply, which would lead us to underestimate the added worker effect in the overall population.

The reason for a negative added worker effect is likely that there are correlated shocks on the household level (for an analysis of risk sharing mechanisms within households, see also Huber and Winkler (2019)). Many spouses work in similar jobs and industries (sometimes even the same employer), so that if one spouse is displaced, the other spouse might also face a negative labor demand shock in the form of job loss or cuts in hours. Our finding that spousal labor supply responses are negative and not able to mitigate the costs of job-loss is somewhat in contrast to Halla et al. (2020) who study the added worker effect in the Austrian context. Halla et al. (2020) find a slightly positive employment response of married women to the job loss of their husband. A key data difference is that they have access to the marriage and divorce register and thus can include couples where the wife is not working prior to the displacement event of the husband. In fact, when they restrict the sample to women who were employed at baseline they also find a clear negative added worker effect (see Halla et al. (2020), Table 3).

\subsubsection{The Role of Children}

We now turn to whether the earnings losses after job loss are affected by whether young children are in the household. Ex ante one can imagine different channels for why children may matter. On the one hand, holding income constant the presence of children may increase the marginal value of consumption, since household income is spread thinner. This may increase search effort during spells of unemployment following job loss, or increase hours worked once a job is found. On the other hand, the presence of children may increase the opportunity cost of working. Especially if there is a permanent loss in wage prospect for job losers, as we showed in Section 3.4 , this may make it relatively more attractive to focus on childcare instead of labor market participation. 
Figure 3.6: The Gender Gap and Children

(A) Earnings Relative to $\mathrm{t}=\mathrm{c}-1$

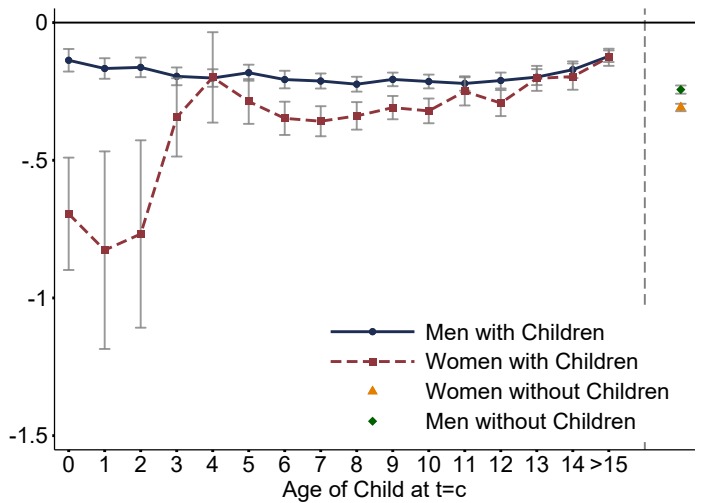

(C) Full-time Days Worked per Year

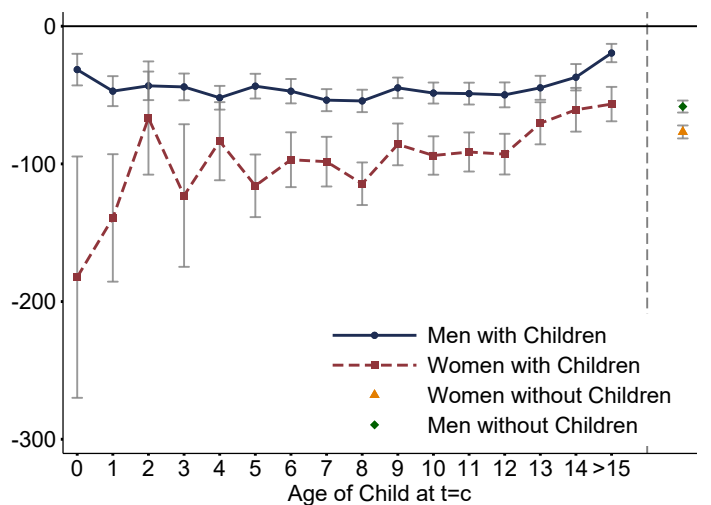

(B) Log Daily Wage

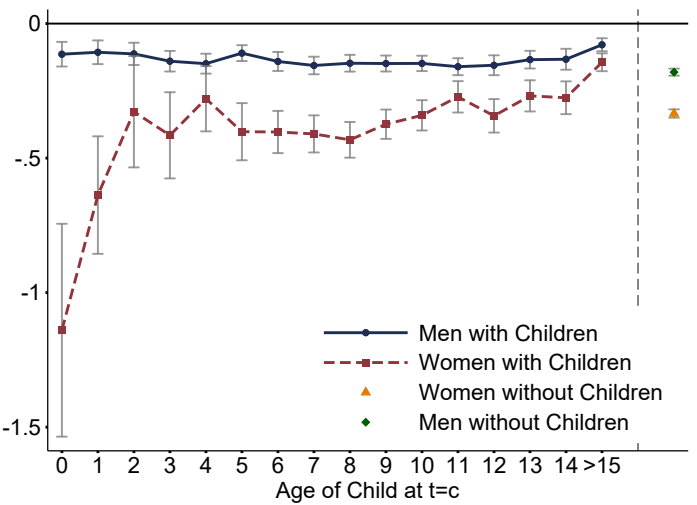

(D) Part-time Days Worked per Year

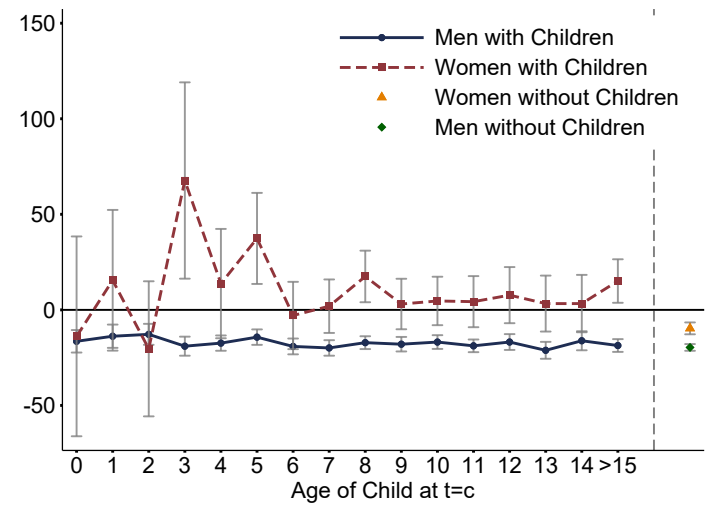

Notes: This figure shows how labor market outcomes before and after displacement differ for men and women by age of first child at time of displacement. The outcome variables correspond to $\Delta_{d d} y_{i c}$, where we compute the difference in the individual change in earnings from before $(-5$ to -2 years) to after (0 to 3 years) job displacement for treated vs. control workers. Panels (A)-(D) show eventstudy coefficients for earnings relative to $t=c-1, \log$ wage, days worked in full-time job per year, and days worked in part-time job per year. The dark blue line corresponds to men with children, the dashed red line corresponds to women with children. The green diamond and orange triangle report coefficients for men without children and women without children, correspondingly. All regressions control for individual and establishment characteristics. Individual characteristics are a worker's log wage in $\mathrm{t}=\mathrm{c}-2$ and $\mathrm{t}=\mathrm{c}-3$, full-time employment in $\mathrm{t}=\mathrm{c}-2$, and age, years of education, tenure, and location in East or West Germany in $t=c$. Establishment characteristics are 1-digit industry dummies and log establishment size in $\mathrm{t}=\mathrm{c}$. Vertical bars indicate the estimated 95\% confidence interval based on standard errors clustered at the displacement establishment level. Workers are displaced in 2002-2012, and they are observed from 1997-2017. 
In order to estimate the effect of job displacement separately by the age of the first child in the household, we extend the model in Equation 3.8:

$$
\Delta_{d d} y_{i c}=\sum_{a}\left(\alpha_{a}+\beta_{a} \text { Female }_{i}\right) I_{\text {KidAge }_{i}=a}+X_{i} \theta+\varepsilon_{i c}
$$

where $\mathrm{KidAge}_{i}$ is the age of the first child of the displaced worker (or an indicator if there is no child) and $a$ indicates the possible age of the first child. All the covariates $X_{i}$ are demeaned, so that the estimated $\alpha_{a}$ provide estimates of the cost of job loss for men with a child aged $a$ (or no child), while the estimated $\beta_{a}$ provide the respective gender wage gap. ${ }^{22}$

Figure 3.6 plots the estimated effects for men $\alpha_{a}$ and for women $\left(\alpha_{a}+\beta_{a}\right)$. Note that we plot the estimates for men and women without children on the far right of the graph. Panel (A) shows our main estimate: earnings relative to c-1. For men and women without young children, the results are similar as the results in Section 3.4: women have significantly larger earnings losses than men when holding pre-displacement characteristics constant. A striking result emerges, however, when comparing these to parents: displaced men who have a child at home have smaller earnings losses than men without young children. In stark contrast, mothers of very young children have much larger earnings losses in the order of 80 percent of predisplacement earnings. Mothers with older children (around 3 years and older) have comparatively much smaller earnings losses, albeit still larger than men. A plausible explanation for the trend break at age 3 might be that this is when children typically join kindergarten and then elementary school, in effect reducing the opportunity cost of working.

Panels (C) and (D) show that women with very young children also have huge losses in days working full-time without a parallel increase in working part-time. However, once children are aged 3 or older there appears to be more a substititon effect from full-time to part-time rather than dropping out of the labor force.

Interstingly, for mothers with teenage children the gap seems to largely disappear. It is noteworthy that we can only observe children who are born while the mother is employed, so that the "without children" group likely also contains some mothers who we misclassify. Thus one possibility might be that the gender gap for childless

\footnotetext{
${ }^{22} \mathrm{We}$ use regression adjustment here rather than reweighting as this is intuitively easier to understand in the presence of many interaction terms. In practice this makes little difference.
} 
joblosers is in fact 0 (as the figure suggests for parents with children older than 15) and that the gender gap is entirely driven by children.

We also explored whether these large losses for mothers of young children are transitory by replicating our baseline evenstudy analysis. Figure A.3.6 shows that at least over a 5 year horizon, the larger losses for mothers of young children are very persistent. Similarly, the smaller losses for fathers of young children compared to other men also seem to be persistent and are still apparent 5 years after job loss.

Table 3.5 shows comparable results from a regression model, where we estimate Equation 3.8 but include dummies for children under 7 and over 6 years of age, both interacted with gender. The omitted category is men without children. The results in Column (1) suggest that for job losers without children there is still a small gender gap of only 6.7 percentage points. The coefficient on the dummy for young child (0.064) and its interaction with a female dummy (-0.13) show that the presence of young children substantially reduces the earnings losses for men, but sharply increase earnings losses for women. Older children seem to have a slight positive effect on earnings losses (i.e. reducing the losses) both for men and women. The remaining columns of Table 3.5 complete the story: The presence of children has a positive effect on men's post-displacement trajectories: they work more, have lower wage losses, show a smaller probability of working part-time. For women, these effects are reversed with much larger losses in days worked and wages, and a higher propensity to work part-time or in mini-jobs. Women also move to smaller and lower paying employers if they have young children. Interestingly, mothers of young children also have a pretty large (though statistically insignificant) decline in commuting distances after job loss, potentially to be able to better reconcile childcare with work. 
Table 3.5: Labor Market Outcomes for Couples with Children

\begin{tabular}{|c|c|c|c|c|c|c|c|c|c|c|c|}
\hline & $\begin{array}{c}(1) \\
\text { Earnings } \\
\text { Rel. To } \\
\text { t=-2 }\end{array}$ & $\begin{array}{c}(2) \\
\text { Log } \\
\text { Wage }\end{array}$ & $\begin{array}{c}(3) \\
\text { Log } \\
\text { Wage } \\
\text { Full-time }\end{array}$ & $\begin{array}{c}(4) \\
\text { Days } \\
\text { Worked }\end{array}$ & $\begin{array}{c}(5) \\
\text { Days } \\
\text { Worked } \\
\text { Full-time }\end{array}$ & $\begin{array}{c}(6) \\
\text { Days } \\
\text { Worked } \\
\text { Part-time }\end{array}$ & $\begin{array}{c}(7) \\
\text { Days } \\
\text { Worked } \\
\text { In Minijob }\end{array}$ & $\begin{array}{c}(8) \\
\text { Comm- } \\
\text { uting } \\
\text { Distance }\end{array}$ & $\begin{array}{c}(9) \\
\text { Log } \\
\text { Estab } \\
\text { Size }\end{array}$ & $\begin{array}{c}(10) \\
\text { AKM } \\
\text { Estab } \\
\text { FE }\end{array}$ & $\begin{array}{c}(11) \\
\text { Partner's } \\
\text { Earn. Rel. to } \\
\text { Job Loser's }\end{array}$ \\
\hline \multicolumn{12}{|c|}{ Regression Adjusted Gender Wage Gap - Adding Family Controls } \\
\hline Female & $\begin{array}{c}-0.067 \\
(0.0082)^{* *}\end{array}$ & $\begin{array}{c}-0.15 \\
(0.011)^{* *}\end{array}$ & $\begin{array}{c}-0.041 \\
(0.0056)^{* *}\end{array}$ & $\begin{array}{c}0.48 \\
(1.93)\end{array}$ & $\begin{array}{c}-18.6 \\
(2.78)^{* *}\end{array}$ & $\begin{array}{c}9.92 \\
(1.58)^{* *}\end{array}$ & $\begin{array}{c}10.2 \\
(1.18)^{* *}\end{array}$ & $\begin{array}{l}-1.02 \\
(1.54)\end{array}$ & $\begin{array}{l}-0.039 \\
(0.025)\end{array}$ & $\begin{array}{c}-0.015 \\
(0.0048)^{* *}\end{array}$ & $\begin{array}{c}-0.029 \\
(0.011)^{* *}\end{array}$ \\
\hline Child $<=6$ yrs & $\begin{array}{c}0.064 \\
(0.0078)^{* *}\end{array}$ & $\begin{array}{c}0.058 \\
(0.0086)^{* *}\end{array}$ & $\begin{array}{c}0.031 \\
(0.0050)^{* *}\end{array}$ & $\begin{array}{c}16.0 \\
(2.10)^{* *}\end{array}$ & $\begin{array}{c}14.5 \\
(2.26)^{* *}\end{array}$ & $\begin{array}{c}3.33 \\
(1.04)^{* *}\end{array}$ & $\begin{array}{l}-2.58 \\
(1.33)\end{array}$ & $\begin{array}{l}-0.62 \\
(1.58)\end{array}$ & $\begin{array}{c}0.092 \\
(0.026)^{* *}\end{array}$ & $\begin{array}{c}0.025 \\
(0.0040)^{* *}\end{array}$ & $\begin{array}{c}0.020 \\
(0.0085)^{*}\end{array}$ \\
\hline Female*Young Child & $\begin{array}{c}-0.13 \\
(0.028)^{* *}\end{array}$ & $\begin{array}{c}-0.13 \\
(0.028)^{* *}\end{array}$ & $\begin{array}{c}-0.067 \\
(0.024)^{* *}\end{array}$ & $\begin{array}{c}-14.9 \\
(5.58)^{* *}\end{array}$ & $\begin{array}{c}-39.5 \\
(6.33)^{* *}\end{array}$ & $\begin{array}{c}19.1 \\
(6.08)^{* *}\end{array}$ & $\begin{array}{c}3.82 \\
(3.43)\end{array}$ & $\begin{array}{l}-6.25 \\
(3.34)\end{array}$ & $\begin{array}{c}-0.21 \\
(0.069)^{* *}\end{array}$ & $\begin{array}{c}-0.058 \\
(0.010)^{* *}\end{array}$ & $\begin{array}{c}0.063 \\
(0.050)\end{array}$ \\
\hline Child $>6$ yrs & $\begin{array}{c}0.049 \\
(0.0059)^{* *}\end{array}$ & $\begin{array}{c}0.044 \\
(0.0068)^{* *}\end{array}$ & $\begin{array}{c}0.016 \\
(0.0037)^{* *}\end{array}$ & $\begin{array}{c}15.9 \\
(1.59)^{* *}\end{array}$ & $\begin{array}{c}15.0 \\
(1.80)^{* *}\end{array}$ & $\begin{array}{c}1.47 \\
(0.76)\end{array}$ & $\begin{array}{l}-0.38 \\
(1.07)\end{array}$ & $\begin{array}{l}-2.27 \\
(1.25)\end{array}$ & $\begin{array}{c}0.035 \\
(0.020)\end{array}$ & $\begin{array}{c}0.022 \\
(0.0034)^{* *}\end{array}$ & $\begin{array}{c}0.056 \\
(0.0054)^{* *}\end{array}$ \\
\hline Female*Old Child & $\begin{array}{c}0.014 \\
(0.011)\end{array}$ & $\begin{array}{l}0.0024 \\
(0.013)\end{array}$ & $\begin{array}{c}0.013 \\
(0.012)\end{array}$ & $\begin{array}{l}-4.03 \\
(2.82)\end{array}$ & $\begin{array}{c}-19.1 \\
(3.73)^{* *}\end{array}$ & $\begin{array}{c}16.2 \\
(3.07)^{* *}\end{array}$ & $\begin{array}{l}-0.12 \\
(1.97)\end{array}$ & $\begin{array}{c}3.12 \\
(1.87)\end{array}$ & $\begin{array}{l}-0.068 \\
(0.035)\end{array}$ & $\begin{array}{c}-0.021 \\
(0.0058)^{* *}\end{array}$ & $\begin{array}{c}-0.098 \\
(0.021)^{* *}\end{array}$ \\
\hline Observations & 80655 & 73598 & 52996 & 80655 & 80655 & 80655 & 80655 & 73027 & 72811 & 63452 & 80655 \\
\hline$R^{2}$ & 0.056 & 0.059 & 0.069 & 0.032 & 0.151 & 0.211 & 0.012 & 0.038 & 0.218 & 0.072 & 0.002 \\
\hline Mean Dep. Var Men & $\begin{array}{l}-.258 \\
(.002)\end{array}$ & $\begin{array}{l}-.201 \\
(.003)\end{array}$ & $\begin{array}{l}-.094 \\
(.002)\end{array}$ & $\begin{array}{l}-67.66 \\
(.585)\end{array}$ & $\begin{array}{c}-75.471 \\
(.766)\end{array}$ & $\begin{array}{l}-.154 \\
(.56)\end{array}$ & $\begin{array}{l}1.086 \\
(.448)\end{array}$ & $\begin{array}{c}2.59 \\
(.442)\end{array}$ & $\begin{array}{c}-.74 \\
(.009)\end{array}$ & $\begin{array}{l}-.086 \\
(.001)\end{array}$ & $\begin{array}{c}-.02 \\
(.004)\end{array}$ \\
\hline
\end{tabular}

Notes: This table shows the role of children in explaining gender-specific labor market outcomes after displacement. All outcome variables are based on the individual difference-in-differences estimate. All columns in the panel show the regression adjusted gender gap for several outcome variables, controlling for having younger (under 7 years) or older (above 6 years) children. In Germany, children enter school aged 6-7. We cluster standard errors at displacement establishment level (constant within matched worker pairs). Workers in our sample are displaced in 2002-2012, and they are observed from 1996-2017. * and ** correspond to 5 and 1 percent signficance levels, respectively. 


\subsection{Conclusion}

In this chapter, we used administrative employer-employee data from Germany to investigate how the costs of job loss differ between men and women. Whereas existing research from both the U.S. and Germany has shown that displaced men suffer large and persistent earnings losses, evidence for women is scarce. A key contribution of this chapter is to compare men and women who are displaced from comparable jobs with similar pre-displacement careers. This distinction is crucial for understanding the impact of job loss, since the costs of job loss are heterogeneous along many dimensions that would otherwise confound the gender differences. With the help of detailed and high-quality administrative labor market from the IAB, we can compare men and women in terms of individual (e.g., age, education, and tenure) and establishment (e.g., establishment size and 1-digit industries) characteristics.

We showed that when taking these differences in pre-displacement characteristics into account through a reweighting approach, women's earnings losses are much higher than men's, with the difference persisting and, in fact growing, five years after job displacement. This difference is due to a gender gap in both wage and employment losses. One important reason for women's higher earnings losses is their much higher propensity to take up part-time or mini-job employment after displacement. Another explanation for the large gender gap in earnings losses is the presence of children in a household: women with young children at time of displacement face the largest earnings, wage, and employment losses. In contrast, men with young children have the smallest losses. We do not find evidence for an added worker effect.

An obvious and important question is whether the gender gap is due to men and women facing different labor demand or whether it is due to differences in labor supply. Disentangling the role of demand from supply in this context is very difficult and beyond the scope of this chapter. The fact that mothers of young children have by far the largest earnings losses and are often moving to part-time employment may seem consistent with a labor supply effect where women decide to stay at home to look after children. However, another possible explanation is that mothers of young children face discimination in the labor market, making it much harder for them to find any or at least a full-time job. Fully disentangling the role of demand and supply will surely be an important area for future research. 


\section{Chapter 4}

\section{Who Suffers the Greatest Loss? \\ Costs of Job Displacement for Migrants and Natives}

Joint work with Theresa Koch 


\subsection{Introduction}

A large body of literature has investigated workers' long-term costs of job loss (e.g., Jacobson et al. (1993), Couch and Placzek (2010), von Wachter et al. (2011), Schmieder et al. (2020)). Most of these studies pay little attention to heterogeneities in costs of job loss, with almost no evidence on migrant workers. However, for several reasons, the experience of losing one's job may differ dramatically between migrant and native workers: Migrants are at high risk of losing their job during recessions, including the recession caused by the Covid-19 Pandemic (e.g., Freeman et al. (1973), Borjas and Cassidy (2020), Couch et al. (2020), Montenovo et al. (2020)), migrants may face discrimination (Bertrand and Mullainathan (2004)), migrants' entry wages when changing employers are typically lower than natives' (Borjas (1995)), and their networks may be worse (Glitz (2017), Gërxhani and Kosyakova (2020)). To better understand whether job loss reinforces inequalities between migrants and natives, it is crucial to investigate differences in their response to job displacement in more detail.

Understanding these differences is of high economic and political relevance, in particular because immigration in many OECD countries has increased substantially in recent decades. One prominent example is Germany: While in 2005, $18 \%$ of the German population reported that they or at least one of their parents were born without German citizenship (and thus had "migration background"), this share had increased to $26 \%$ by 2019 (Destatis (2020)). ${ }^{1}$ Given that Germany, along with many other OECD countries, is facing skilled worker shortages as a result of demographic change, there is increased attention towards migrants' labor market integration. Successful labor market integration is crucial for migrants to contribute to the fiscal system (Dustmann and Frattini (2014)) and - due to path dependence - for the next generations' labor market outcomes ${ }^{2}$. It is therefore surprising that no study to date has analyzed how quickly migrants, compared to natives, reintegrate into the labor market after displacement.

\footnotetext{
${ }^{1}$ Note that in our sample, which spans the years 1996-2017, approximately $12 \%$ of the workers are migrants. We identify migrant workers via their citizenship, meaning that the share of workers with "migration background" is bound to be much higher.

${ }^{2}$ See, e.g., Solon (1999) for a survey. Furthermore, there exists a large body of literature comparing the economic outcomes of migrants, migrants' children, and natives. See, for instance, Dustmann et al. (2012), Algan et al. (2010), Dustmann (2008), Casey and Dustmann (2008), Casey (2010), Gang and Zimmermann (2000), or Riphahn (2003).
} 
From a theoretical point of view, it is ex ante unclear whether job displacement affects migrants or natives more. On the one hand, migrants may be disadvantaged in their destination country's labor market: for example, they may possess less destination country-specific human capital, which might harm them during the job search process (Friedberg (2000)). On the other hand, previous research has shown that migrants experience similar occupational upgrading as natives (Abramitzky et al. (2014)), and some migrant groups are even less likely to apply for social benefits such as unemployment insurance (Dustmann et al. (2010)). In this chapter, we present empirical evidence to better understand which of the potential mechanisms prevails in the context of displacement.

In particular, we use rich administrative employer-employee data from Germany provided by the Institute for Employment Research (IAB), which span more than 20 years (1996-2017), to compare the labor market outcomes of displaced migrants (individuals with non-German citizenship) and natives. These data cover the universe of employees covered by social security in Germany, and they are directly filed by employers, making them both representative and highly reliable. We use the rich set of individual characteristics recorded in the data to follow the growing literature on heterogeneity in the costs of job loss by worker type (see, e.g., Blien et al. (2020) for differences by occupational routine intensity, and Chapter 3 of this thesis and Meekes and Hassink (2020) for differences by gender).

Our main empirical approach builds on the seminal paper by Jacobson et al. (1993), who compare the labor market outcomes of displaced to nondisplaced workers before and after job loss. The intuition behind this approach is that job loss is unexpected for long-tenured workers, and these are therefore highly comparable to workers with similar characteristics who are not displaced in the same year.

The key challenge of our study is to make migrants comparable to natives. For example, since many of the migrant workers in our sample were not born in Germany, they possess less destination country-specific human capital. We can directly observe these differences in our data: migrants in our sample are, e.g., less educated (11.2 vs. 12.3 years), younger (37.9 vs. 39.4 years), and earn lower wages (89.2 EUR vs. 102.3 EUR) than native workers in the year before displacement. All of these characteristics may impact their wage losses or their unemployment duration after job displacement.

In this study, we first present the "raw migrant-native gap" in earnings losses after 
displacement, meaning that we compare migrants and natives without controlling for observables. While this raw gap is interesting per se, it is unclear to what extent it is driven by differences in observable characteristics. In a second step, to isolate the role of observable characteristics in explaining the gap, we use a reweighting scheme first proposed by DiNardo et al. (1996) and first applied to the context of job loss in Chapter 3 of this thesis, to control for migrants' and natives' different individual characteristics and differential sorting across industries and occupations before displacement. This helps us to investigate whether a migrant-native gap in earnings losses remains even after controlling for observable differences between migrants and natives, such as differential pre-displacement sorting across industries or occupations.

With respect to the raw gap, we first show descriptively that both migrants and natives face large average earnings losses after displacement, with substantially larger losses for migrants (12,000 EUR vs. 16,000 EUR in the year after losing their job, compared to earnings two years earlier). The results from our event study regression model, where we control for worker and year fixed effects, confirm that the decline in migrants' earnings in the year of the layoff is 35 percentage points larger than that of natives ${ }^{3}$. This is what we call the "raw migrant-native gap", where we do not take into account differences in individual and establishment characteristics. Our results moreover show that migrants do not catch up with natives even five years after displacement.

Once we reweight migrants to natives using an extensive set of controls such as individual characteristics, industry, and occupation, this gap in earnings immediately after displacement shrinks to 14 percentage points but remains significant. This suggests that observable characteristics explain only part of the migrant-native gap in earnings losses. There are several potential explanations for the remaining difference, one of them being unobservable characteristics such as language skills which we do not observe in our data.

In order to nevertheless get closer to understanding what is driving the gap, we first

\footnotetext{
${ }^{3}$ If we include spells with zero earnings (and thus account for workers in unemployment or workers temporarily unobserved due to, e.g., self-employment), this difference increases to 80 percentage points, meaning that the effects on migrants are 1.8 times the effects on natives. To account for potential differential selection into informal employment, we construct a panel where we keep workers in the sample if they disappear from the social security data in a given year and appear again in a future year. If they fully disappear from the data, we only include them up to the last year they are observed in the data.
} 
decompose earnings losses into wage and employment losses. In terms of the "raw gap", migrants face both substantially larger wage and employment losses. While observable characteristics fully explain the gap in wage losses (conditional on finding a job), the gap in employment losses persists even after reweighting. Differences in age, education, or occupational distribution can thus explain why migrants earn lower wages after job loss, but they cannot explain why migrants are less likely to take up new employment. In particular, we find that even after controlling for observables, migrants are approximately 5 percentage points less likely to be employed in the year after job loss. This gap shrinks to approximately 2 percentage points five years later. We observe a similar pattern for days worked per year: migrants work approximately 25 fewer days per year in the year after displacement; five years later, the difference is still statistically significant but reduced to approximately 10 days.

Finally, we explore three channels to better understand the potential causes behind the migrant-native gap in earnings losses. First, we investigate whether, conditional on employment, migrants sort into different types of establishments. We show that after displacement, migrants work in establishments with lower average wages, lower establishment fixed effects ${ }^{4}$ (Abowd et al. (1999)), and a higher share of marginally employed workers. Consistent with our findings on wage losses, these differences are much weaker once we reweight migrants to natives. Nevertheless, they suggest that we can attribute part of migrants' worse labor market outcomes after layoff to differences in establishment sorting.

Second, we analyze whether migrants' and natives' mobility patterns (conditional on finding a new job) differ. In line with Huttunen et al. (2018), we find that both migrants and natives expand their regional mobility - both in terms of changing workplace location and commuting - after job loss. Our results suggest that migrants are slightly more likely to commute after job loss (a 2 percentage point difference compared to natives) and slightly less likely to move workplaces to a new federal state (a 3 percentage point difference). Migrants may thus face higher mobility constraints than natives (e.g., because of housing market tightness), and their lower geographic mobility may partly explain their larger earnings losses.

Third, we explore the importance of local labor market concentration, proxied by

\footnotetext{
${ }^{4}$ Based on Abowd et al. (1999), a large literature finds that persistent wage differentials exist across firms within the same labor market (e.g., Card et al. (2013), Song et al. (2019), Bonhomme et al. (2019)).
} 
three measures: i) the change in local unemployment rates around time of displacement, ii) city residency, and iii) the share of same-nationality working age population in a worker's workplace county. We expect that these three proxies are relevant because prior literature has shown that i) migrants' wage assimilation is particularly slow in periods of high unemployment (Bratsberg et al. (2006)), ii) displaced workers' unemployment duration is particularly high if they live in cities (Haller and Heuermann (2019)), and iii) within-network competition may be harmful to migrants (e.g., Albert et al. (2020), Beaman (2012)).

To assess the importance of local labor market concentration, we follow Schmieder et al. (2020) and conduct a matched difference-in-differences analysis. We thus construct an individual-level variable measuring the difference in earnings before and after job loss between each displaced and nondisplaced worker pair. For our sample of displaced workers, we then regress this measure on the three concentration proxies and a number of worker- and establishment-level controls. Our results suggest that displaced workers, irrespective of nationality, face greater earnings losses if local unemployment rates at the time of displacement increase more. Moreover, earnings losses are greater if displaced workers live in a city at the time of displacement, and this effect is approximately twice as high for migrants. In addition, migrants working in counties with a higher share of the same-nationality population in the year before displacement face substantially higher costs of job loss. These findings suggest, in line with Caldwell and Danieli (2021), that a greater concentration of similar workers at the time of displacement is a crucial factor driving displaced workers' earnings losses. Migrants in particular seem to compete with workers of the same origin for the same types of jobs.

This chapter contributes to the literature on the individual costs of job loss by adding evidence on migrant workers. Many studies have documented large and persistent earnings losses for displaced workers (see, e.g., Jacobson et al. (1993), Couch and Placzek (2010), von Wachter et al. (2011), Schmieder et al. (2020)) but without differentiating between specific groups. While there is an emerging literature on the costs of job loss by worker type (e.g., Blien et al. (2020), Meekes and Hassink (2020), Helm et al. (2021), and Chapter 3 of this thesis), no study to date focuses 
on migrant workers. ${ }^{5}$ Against the backdrop of increasing immigration flows and interest in migrants' labor market integration, we are the first to shed more light on this issue. We establish that displaced migrants face larger earnings losses than natives and that this is mainly driven by differences in re-employment probability. While we estimate our main results for a sample of men, we show that the same patterns hold when focusing on women.

We moreover contribute to the literature investigating how sensitive migrants are to adverse economic shocks. A recent paper by Borjas and Cassidy (2020) finds that migrants particularly suffered from displacement during the Covid-19 Pandemic, partly because they are less likely to work in jobs that can be performed remotely. In the same spirit, other studies have shown that migrants' entry wages during recessions are lower than natives' (see, e.g., Kondo (2015), Kahn (2010), Speer (2016)) and that migrants' or blacks' unemployment rate is particularly sensitive to business cycle conditions and local unemployment rates (e.g., Altonji and Blank (1999), Bratsberg et al. (2006), Hoynes et al. (2012)). The main difference to our study is that whereas most of these papers analyze aggregate outcomes, we follow individual workers' careers before and after job loss. The high-quality administrative employer-employee data from Germany thus allow us to focus on the worker level and show how each worker's earnings, wage, and employment trajectory evolved up to five years before and after job loss. We can thus directly compare how involuntary displacement affects migrants relative to native workers at the individual level.

The remainder of this chapter proceeds as follows. Section 4.2 provides an overview of our data, including insights into our definition of job displacement, sample selection, and the propensity score matching algorithm. Section 4.3 describes our empirical strategy and reports descriptive evidence and our event study results. In Sections 4.4 and 4.5, we explore the extent to which sorting into particular establishments after displacement, differences in geographic mobility, and local labor market concentration explain our results. Section 4.6 presents our robustness checks, and Section 4.7 concludes the chapter.

\footnotetext{
${ }^{5}$ A notable exception is the study by Hardoy and Schøne (2014) who focus on displacement effects from plant closings over the business cycle. In comparison to this study, they, however, study only two outcomes: employment probability and employment duration. Moreover, they are not clear on the extent to which differences in observable characteristics drive differences in employment outcomes between migrants and natives.
} 


\subsection{Data and Sample Construction}

In this section, we proceed as follows: First, we describe the German linked employeremployee data that we use for our analysis. Second, we discuss how we define mass layoffs and displaced workers. Third, we explain our propensity score matching algorithm, which we use to find a unique control worker for each displaced worker.

\subsubsection{German Administrative Employer-Employee Data}

For our empirical analysis, we use high-quality social security data provided by the Institute for Employment Research (IAB). Our primary data source is a random 12.5 percent sample of the universe of workers subject to social security contributions in 1996-2017, which stems from the Integrated Employment Biographies (IEB), version 14. ${ }^{6}$ Importantly, the IEB includes information on both workers' employment and unemployment spells with daily precision. We thus have access to a detailed set of labor market characteristics for each worker, including wage, employment status, and days worked. Moreover, the data contain highly reliable individual characteristics, such as nationality, age, education, industry, occupation, and workplace at the municipality level.

We use a unique establishment identifier to combine our worker-level sample with establishment data from the Establishment History Panel (BHP), which provides access to information such as establishment size, average establishment wage, number of migrant workers in the establishment, and number of marginally employed workers in the establishment.

Based on the code provided by Dauth and Eppelsheimer (2020), we use these data to construct a worker-level panel as of June 30 each year. If workers leave the data

\footnotetext{
${ }^{6}$ These data stem from administrative sources and are therefore highly reliable. Note, however, that these data do not include the self-employed, civil servants, or the informal sector. One limitation of our study is that we cannot observe whether more migrants than natives sort into self-employment or into the informal sector after displacement.
} 
and do not return until 2017, they drop out of our sample upon exit. ${ }^{7}$ If workers only temporarily leave the data, we assign them zero earnings and missing wages for the missing spells. To ensure the validity of the data, we further conduct two imputation procedures. First, we correct implausible education entries following Fitzenberger et al. (2006). Second, we impute wages censored at the contribution assessment ceiling in Germany following Gartner (2005) and Dustmann et al. (2009).

\subsubsection{Identifying Mass Layoff Events}

Next, we use the universe of German workers to identify mass layoff events in 20012011. To ensure that our results are comparable with state-of-the-art studies from the U.S. and other countries, we follow Hethey-Maier and Schmieder (2013) in their identification of mass layoffs in the German data. In our definition, a layoff occurs between June 30 in $\mathrm{t}=-1$ and June 30 in $\mathrm{t}=0$ if an establishment (i) completely closes down or (ii) reduces its workforce by at least 30 percent. To identify genuine mass layoffs, we restrict our sample to establishments with a minimum of 50 employees in the year before the layoff ${ }^{8}$ and without major employment fluctuations in the years before. This definition follows common approaches in the U.S. literature and thus ensures the comparability of our study.

One threat to the identification of mass layoffs in administrative data are mergers, takeovers, spinoffs, and id changes. To eliminate such events from our data and thus avoid measurement error, we construct a matrix of worker flows between establishments by year following Hethey-Maier and Schmieder (2013). If more than 30 percent of displaced workers move to the same successor establishment, we exclude this establishment from our sample.

\footnotetext{
${ }^{7}$ We drop these workers because they could potentially include migrants who have moved abroad (e.g., returned to their native country) or selected into self-employment or informal sector employment. If more migrants than natives left social security employment for these reasons, we would otherwise overestimate our results. Note that in the data, we observe both workers' employment and unemployment spells; workers who drop out of the data are not registered with the employment agency at all. If we nevertheless keep these workers in the sample and assign them zero earnings and missing wages for all missing spells, our results do not change substantially. Regression tables are available upon request.

${ }^{8}$ We introduce this size restriction because in a small establishment, the employees can directly affect its profits and because the share of employment fluctuations is larger in small companies.
} 


\subsubsection{Sample of Displaced Workers}

In the next step, we identify displaced workers from our random sample of workers. Closely following Schmieder et al. (2020), we only consider workers subject to the following baseline restrictions at time of displacement: male workers with at least 3 years of tenure who are full-time employed in an establishment with at least 50 employees and aged 25-50. ${ }^{9}$ These baseline restrictions allow us to compare our results to prior literature from the U.S. However, they come at the expense of the representativity of our sample. For example, Chapter 3 of this thesis shows that the costs of job loss differ substantially between men and women, and throughout this study, we focus on men. ${ }^{10}$ Reassuringly, however, existing literature from the U.S. (e.g., von Wachter et al. (2011), Hildreth et al. (2009)) shows that their results are robust to variations in establishment size, the size of the mass layoff, and restrictions on workers' tenure.

We define a worker in our sample as displaced between June 30 in $t=-1$ and $t=0$ if (i) the establishment lays off at least 30 percent of its workforce between $t=-1$ and $t=0$ and (ii) the worker leaves the establishment between $t=-1$ and $t=0$ and is not employed in the displacement establishment in the following ten years. Workers in our sample are displaced in 2001-2011. Restricting our observation period to 1996-2017 thus ensures that we can follow workers for at least five years prior to and five years after displacement.

\subsubsection{Propensity Score Matching}

We cannot simply compare displaced to nondisplaced workers in our sample, since they may differ in terms of individual characteristics, which could bias our regression coefficients. We thus follow the job loss literature, in particular Schmieder et al. (2020), and apply propensity score matching to assign each displaced worker a suitable nondisplaced control worker match. We consider only displaced workers

\footnotetext{
${ }^{9}$ The focus on workers with high tenure and full-time employment ensures that if workers switch jobs, they likely do so involuntarily. For high-tenure workers, job-to-job mobility in Germany is very low, as German law offers employees a high level of protection. We moreover focus on primeage workers to ensure that workers have already fully entered the labor market and do not yet have access to partial retirement programs. Furthermore, the outside options after job loss may differ by sex (e.g., fertility for women), which is why we exclude women from our baseline sample. All of these restrictions enable a clearer interpretation of our results.

${ }^{10}$ Table A.4.17 reports our main results for a sample of women.
} 
and potential controls who satisfy our baseline restrictions in a given baseline year. We then estimate a probit regression, where the outcome variable is a dummy for being displaced. In this regression, we include the following controls: establishment size in $t=-1$, log wage in $t=-3$ and $t=-4$, years of education in $t=-1$, tenure in $t=-1$, and age in $t=-1$. We only allow exact matches within cells of baseline year, 1-digit industries, and migration status. This means that we only match displaced migrants to non-displaced migrants, and displaced natives to non-displaced natives. We assign each worker a control worker with the closest propensity score (without replacement). ${ }^{11}$

This matching algorithm leaves us with a highly comparable control group of nondisplaced workers for migrants and natives. Table 4.1 presents summary statistics on the individual characteristics of displaced compared to nondisplaced workers in the year before displacement. While Columns (1) and (2) show migrant workers' characteristics, Columns (4) and (5) report native workers' characteristics.

Panel A of Table 4.1 shows that the matched workers exhibit very similar predisplacement means in individual characteristics such as years of education and tenure. In contrast, displaced workers' wages, earnings, and days worked are lower than those of matched controls. The main reason for this is our definition of displacement: As workers are displaced between June 30 in $t=-1$ and $t=0$, the average wages of the displaced worker sample are already lower in $t=-1$ by construction. Another explanation are anticipation effects (Ashenfelter (1978)). Note that for this reason, we use log wages in $t=-3$ and $t=-4$ for our propensity score matching algorithm. As Figures 4.1 and 4.2 show, both levels and trends in log earnings are, however, remarkably similar for displaced workers and nondisplaced workers in all periods leading up to $t=-1$.

Panel B of Table 4.1 focuses on regional characteristics. It shows that displaced workers are slightly more likely to live in cities, and in East Germany. The change in local (municipality) unemployment rates between $t=-1$ and $t=0$ is substantially larger for displaced workers, suggesting that some of the layoffs disrupt local labor markets.

\footnotetext{
${ }^{11}$ Schmieder et al. (2020) show that their results are robust to different matching specifications. In particular, they are robust to matching within counties, as well as variations in the set of matching variables.
} 
Table 4.1: Worker Characteristics of Displaced Workers and Matched Nondisplaced Workers One Year Prior to Displacement $(t=-1)$

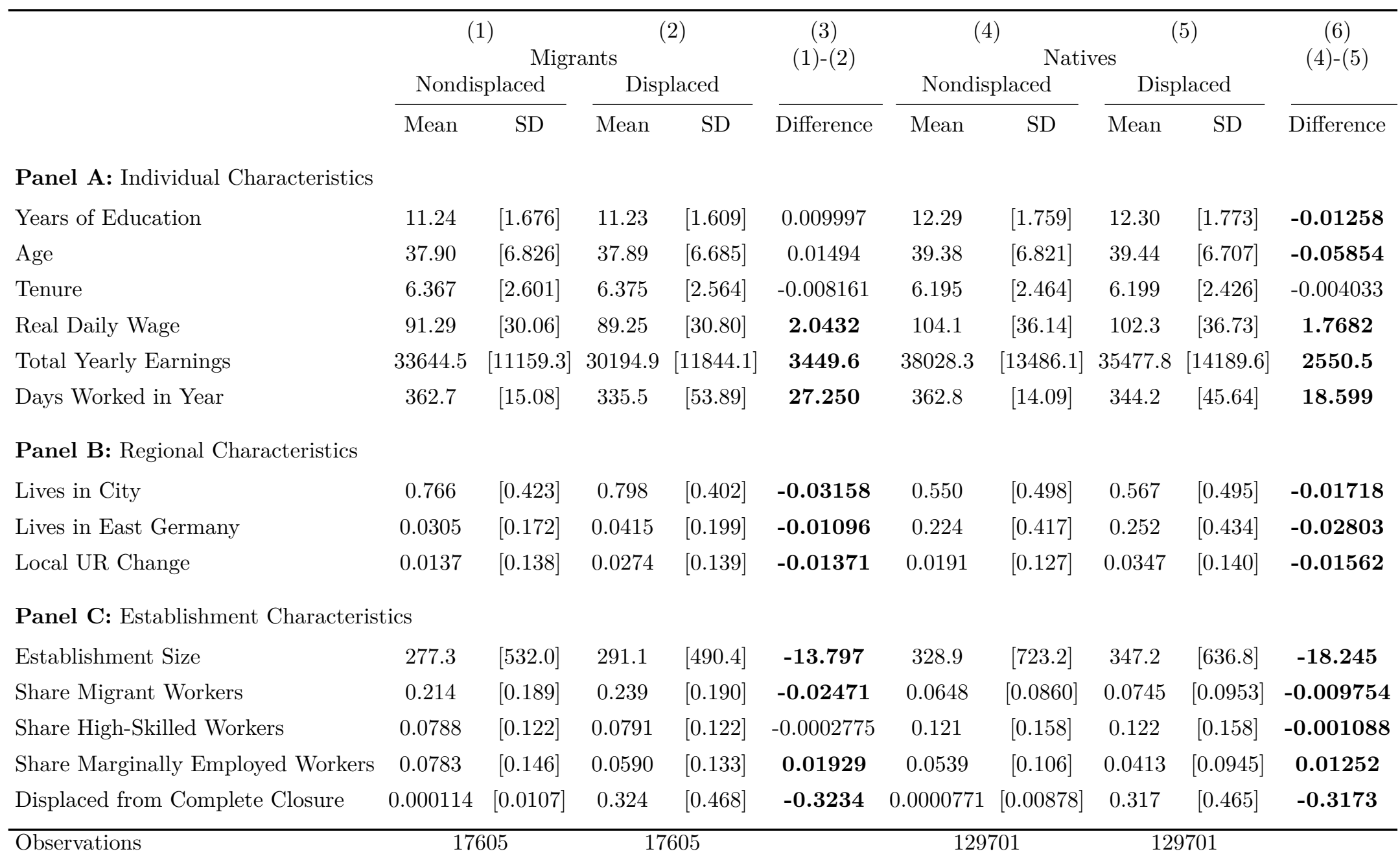

17605

17605

129701

129701

Notes: Characteristics of displaced and nondisplaced workers in the year prior to the displacement year. Column (1) presents nondispalced migrant workers, Column (2) presents displaced migrant workers, and Column (3) shows the difference in means and respective p-values from a t-test for equal means. Column (4) presents nondispalced native workers, Column (5) presents displaced native workers, and Column (6) shows the difference in means and respective p-values from a t-test for equal means. Workers satisfy the following baseline restrictions: Aged 24 to 50, working full-time, at least 3 years of tenure, and establishment has at least 50 employees. Nondisplaced workers are matched to displaced workers using propensity score matching within year and industry cells. The nondisplaced sample of workers is a random sample of workers (one per displaced worker) who satisfy the same baseline restrictions. Differences in bold signal statistical significance at the $10 \%$-level. Standard deviations in brackets. Sources: IEB, BHP. 
Panel C of Table 4.1 shows that matched workers work for establishments that are similar in terms of worker composition. One difference is that displaced workers tend to work in slightly larger establishments. Approximately one third of workers are displaced from a complete establishment closure (100 percent layoff rate). We moreover see that a tiny fraction of nondisplaced workers are laid off in complete closures. This is because we do not impose any restrictions with respect to employment on this control group after (pseudo-)treatment following Schmieder et al. (2020). Some of the control workers are thus also laid-off in future years.

While there are a number of statistically significant differences in characteristics between displaced and nondisplaced workers before treatment, the difference is mostly very small in economic terms. Importantly, our event study figures in Sections 4.3.2 and 4.3.3 show that there are virtually no pre treatment trends for a large set of outcome variables.

In constrast, when comparing displaced migrants to natives, a few differences stand out: migrants have substantially lower daily wages (90 EUR vs. 102 EUR) and consequently lower yearly earnings (30,000 EUR vs. 35,000 EUR). They report fewer years in formal education (11.2 vs. 12.3 years of education).

Note that surprisingly, migrants have slightly higher tenure than native workers (6.4 vs. 6.2 years). This stands in sharp contrast to the random sample of migrant workers with an average of 2.4 years of tenure (see Table A.4.1). The high tenure of migrant workers in our baseline sample stems from our baseline restrictions (e.g., at least 3 years tenure in the year before displacement) and helps us to compare similar migrants to native workers. We are, however, aware that the migrants in our sample are not fully representative of the average migrant worker in Germany. As Table A.4.1 shows, migrants in our baseline sample are a positive selection, meaning that we likely underestimate displacement costs for the average migrant worker in Germany.

Turning to Panel B of Table 4.1, we see that the vast majority of migrants live in cities (80 percent), compared to only 57 percent of natives. Migrants also work in different types of establishments: These are, on average, smaller, have a substantially higher average share of migrant workers (24 percent vs. 7.5 percent) and a lower share of high-skilled workers (7.9 percent vs. 12 percent).

Tables A.4.2 and A.4.3 in the Appendix report the predisplacement distributions of migrants and natives (and their respective matched control group) across industries 
and occupations. In groups of migration status and due to our exact matching within industry cells, the distribution of displaced and nondisplaced workers across industries is the same. However, there are differences between migrants and natives; e.g., migrants are more likely to work in food manufacturing, in the hospitality sector, and in the production goods sector. Natives, in turn, are more likely to work in education, the nonprofit sector, and public administration. With respect to occupations, migrants are more likely to work in occupations with simple, manual tasks. Natives more often work in high-skilled occupations such as engineering, qualified services, and qualified administrative tasks.

These differences show that directly comparing migrant to native workers is a challenge. For example, if we found that migrants' earnings losses after job displacement are greater, then this could simply be due to the fact that they on average work in occupations with fewer vacancies. While this raw gap is interesting per se, we aim to understand whether a migrant-native gap remains even net of observable characteristics between both groups. For our regression analysis, we will therefore reweight migrants to natives with respect to individual characteristics, industries, and occupations, using the reweighting scheme first proposed by DiNardo et al. (1996) and first applied in the context of job displacement in Chapter 3 of this thesis.

\subsection{The Effect of Job Loss on Migrants and Na- tives}

Section 4.3 presents our main results. As a benchmark without controls, we first present descriptive statistics (Section 4.3.1). We proceed with the results of both the event study regression model and the reweighting scheme (Sections 4.3.2 and 4.3.3).

\subsubsection{The Evolution of Earnings without Controls}

We first present descriptive statistics on how average yearly earnings develop before and after job loss. Panel (A) of Figure 4.1 shows how earnings (without controls) evolve differently for displaced (green line) and nondisplaced (blue line) natives in the five years before and after job loss. While trends and levels in pretreatment 
earnings are remarkably similar between displaced workers and matched controls, displaced workers' earnings start decreasing from $t=-1$ onwards. Between $t=-2$ and $t=0$, displaced workers' earnings decrease from approximately EUR 37,000 to EUR 25,000. While they recover slightly in the years following job loss, they do not catch up with average earnings in the control group even five years after displacement. Panel (B) of Figure 4.1 shows earnings losses for migrant workers. Displaced migrants' average earnings are already lower than natives' pre displacement, and they lose more, both in absolute and relative terms: Their earnings drop from roughly EUR 33,000 in $t=-2$ to EUR 17,000 in $t=0 .{ }^{12}$ Again, these earnings losses are persistent for up to five years.

Figure 4.1 moreover shows that for the control groups of nondisplaced workers, log earnings slightly fall from $t=1$ onwards. Recall that in the year before (pseudo-) displacement, both displaced and nondisplaced workers have to be employed with three years of tenure. This ensures that both groups display relatively stable employment careers before job loss. Starting with period $t=0$, we, however, allow nondisplaced workers to leave social security records for reasons such as unemployment, self-employment, or parental leave; their average earnings thus naturally decrease. This does not present a threat to the validity of our analysis, as we think of our control group as a random sample of worker biographies, which we do not want to artificially restrict to being employed. Given the decreasing trends in the control group, even if there was bias, we would under- rather than overestimate our effects.

Our motivation for this study is to empirically investigate whether migrants or natives face greater difficulties from job displacement. These descriptive results offer a first hint: migrants face substantially greater earnings losses. From a theoretical point of view, different factors could drive this result. For example, migrants may possess less destination country-specific human capital and therefore face greater difficulties to re-integrate into the labor market (Friedberg (2000)). In the next section, we will try to better understand to what extent such differences in observables can explain the gap.

\footnotetext{
${ }^{12}$ Note that migrants who have contributed to social security in Germany for at least one year are entitled to receive unemployment benefits according to the same rules as German workers. Due to our baseline restrictions, all displaced workers in our sample have at least three years of experience in the German labor market upon displacement.
} 
Figure 4.1: Migrant and Native Workers' Earnings - No Controls

(A) Total Yearly Earnings in EUR, Natives

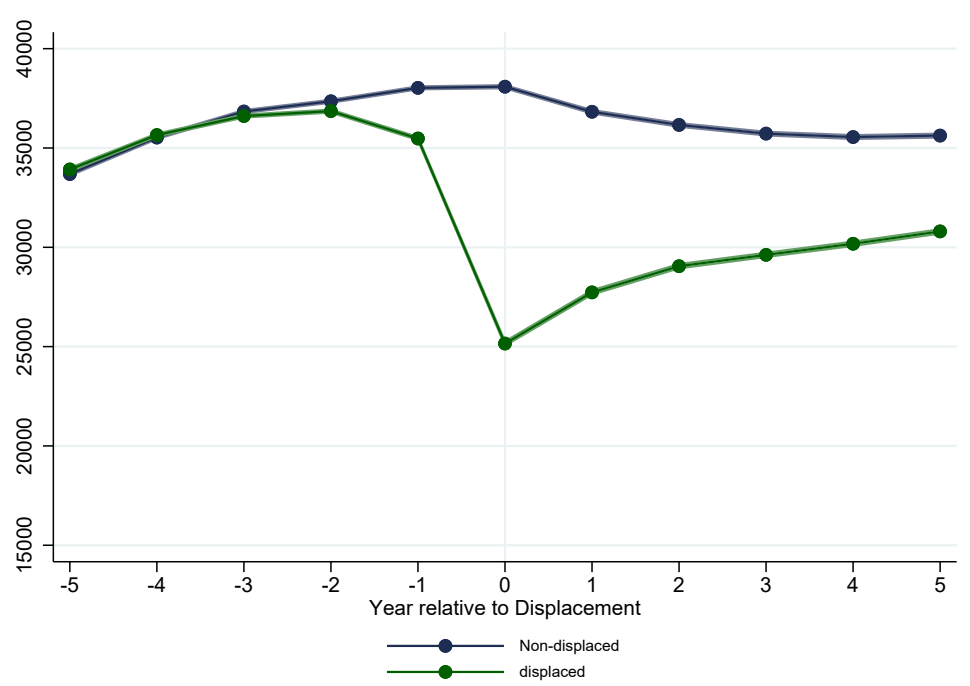

(B) Total Yearly Earnings in EUR, Migrants

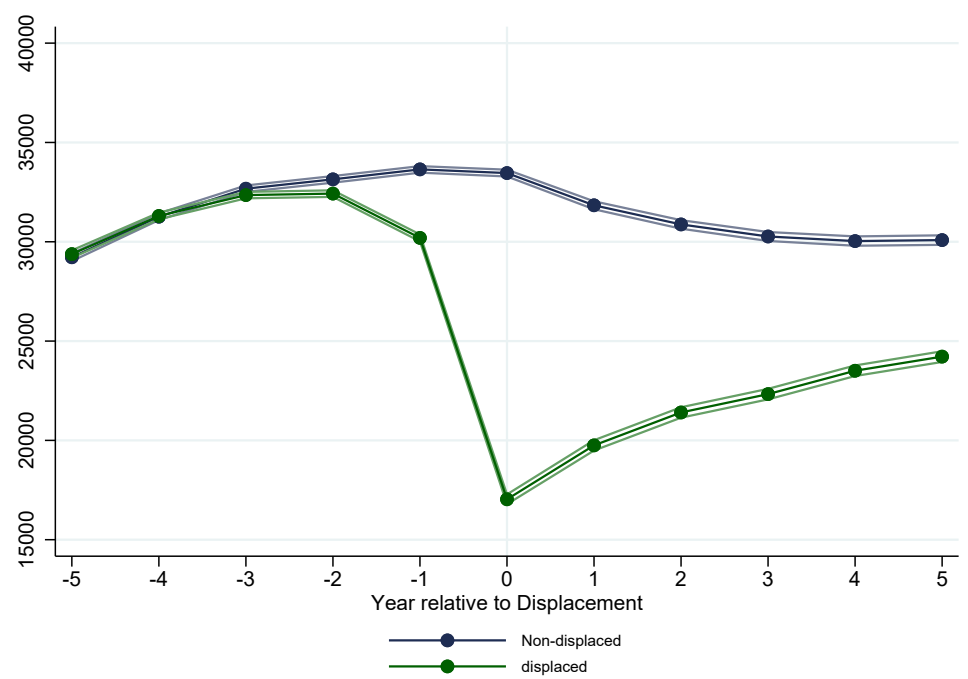

Notes: This figure plots raw earnings losses for displaced compared to nondisplaced workers, and natives (Panel (A)) compared to migrants (Panel (B)). The blue line shows earnings trajectories for nondisplaced workers, and the green line shows earnings trajectories for workers displaced between $t=-1$ and $t=0$. Displaced workers are matched to nondisplaced workers using propensity score matching. Workers in our sample are displaced in the period 2001-2011, and they are observed from 1996 to 2017. In $t=-1$, we observe 17,605 displaced migrants and 129,701 displaced natives. Source: IEB. 


\subsubsection{Event Study Regression Model}

When analyzing the effects of job loss on migrants' and natives' labor market outcomes, we follow the seminal study by Jacobson et al. (1993) and apply an event study regression model with worker and time fixed effects. Specifically, we estimate the following regression specification separately for migrants and natives:

$Y_{i t c}=\sum_{j=-5, j \neq-3}^{5} \alpha_{j} * I(t=c+1+j) * D i s p_{i}+\sum_{j=-5, j \neq-3}^{5} \gamma_{j} * I(t=c+1+j)+\theta_{t}+\gamma_{i}+X_{i t} \beta+\epsilon_{i t c}$

where the dependent variable $Y_{\text {itc }}$ denotes average labor market outcomes (e.g., log yearly earnings, log daily wages, employment, number of days worked) of individual $i$, belonging to cohort $c$ in year $t .{ }^{13} \operatorname{Disp}_{i}$ is a dummy indicating whether a worker is displaced, which is interacted with dummies $I(t=c+1+j)$ for years -5 to 5 since job loss. We omit period $t=-3$ as the reference category, as it should not be affected by Ashenfelter (1978) anticipation effects. The coefficients of interest are $\alpha_{j}$, which present the change in labor market outcomes of displaced workers relative to the trends of the nondisplaced control group. Following Schmieder et al. (2020), we include dummies for years since displacement in the regression equation. In addition, $\theta_{t}$ adds year fixed effects, $\gamma_{i}$ captures individual fixed effects, and $X_{i t}$ is a vector of age polynomials. We cluster standard errors at the worker level.

Panel (A) of Figure 4.2 presents the event study coefficients for yearly earnings losses, both for migrants (dashed blue line) and natives (solid green line). The results underscore the descriptive results from Figure 4.1. Yearly log earnings decline significantly both for native (56 log points) and migrant (91 log points) displaced workers between $t-1$ and $t=0$. Note that migrants' earnings losses are exceptionally high and substantially exceed earnings losses typically found in other displacement studies for an average sample of workers in the German labor market. ${ }^{14}$ Neither

\footnotetext{
${ }^{13}$ For all workers laid off in year $t$, the baseline year is $t-1$, which is also their cohort, $c$.

${ }^{14}$ Note that also the earnings losses for native workers are somewhat larger than those reported in other studies for Germany (e.g., Blien et al. (2020), Helm et al. (2021)), which is mainly due to us finding larger losses in daily wages. Note that our baseline restrictions slightly differ, e.g. with respect to gender, length of the full-time employment restriction, time frame, and inclusion of East vs. West Germany. Moreover, we include wages from marginal employment in our analysis. If we define wages only for full-time or part-time workers, our estimates are comparable to previous studies.
} 
Figure 4.2: The Difference in Earnings Losses for Migrants vs. Natives

(A) Yearly Log(Earnings)

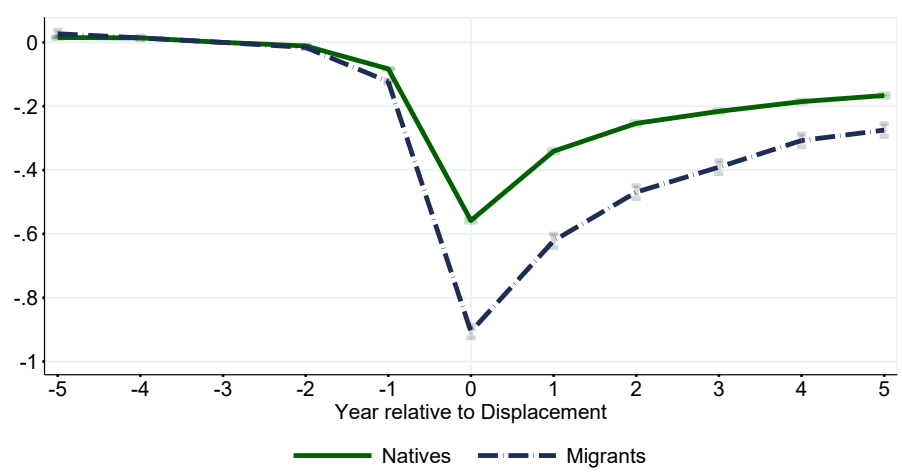

(B) Yearly $\log ($ Earnings +1$)$

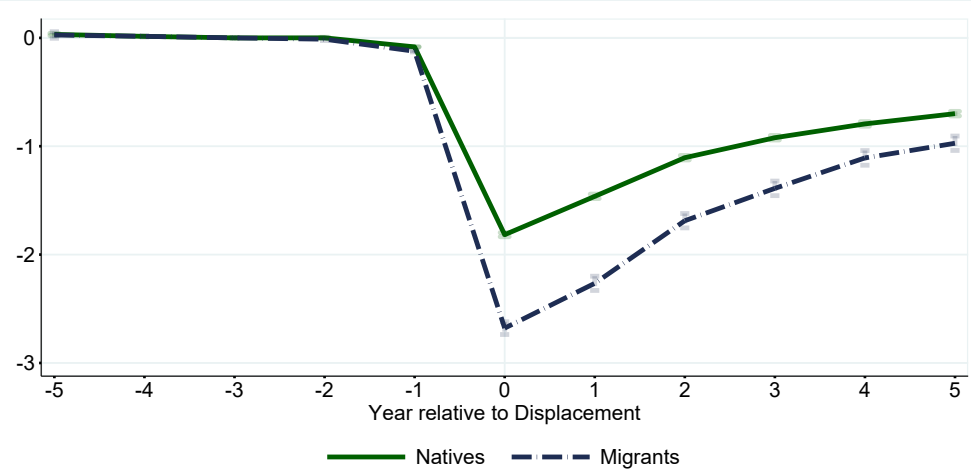

(C) Total Yearly Earnings in EUR

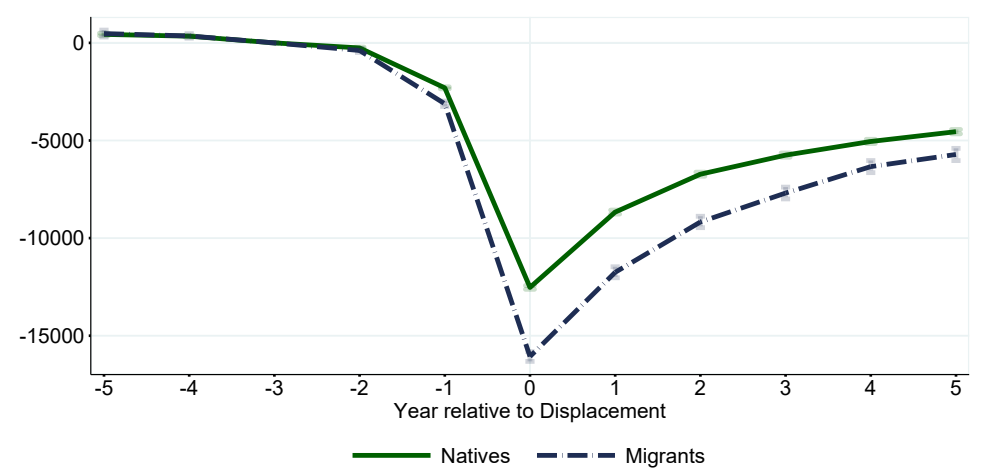

Notes: This figure shows losses in yearly $\log ($ earnings) (Panel (A)), yearly log(earnings +1$)$ (Panel (B)), and yearly earnings in EUR (Panel (C)) for displaced and nondisplaced workers. The solid green line reports the results for our sample of native workers, and the dashed blue line reports the results for our sample of migrant workers. Vertical bars indicate the estimated $95 \%$ confidence interval based on standard errors clustered at the individual level. Our regression controls for year fixed effects, year since displacement fixed effects, age polynomials, and worker fixed effects. We omit $t=-3$ as the reference category. Displaced workers are matched to nondisplaced workers using propensity score matching. Workers in our sample are displaced in the period 2001-2011, and they are observed from 1996 to 2017. Tables A.4.4 and A.4.5 report the corresponding coefficients. Source: IEB. 
displaced migrants nor displaced natives have fully caught up with the control group 5 years after job loss. From $t=1$ onwards, migrants' average recovery rate is faster, but their earnings losses are still higher than those of natives five years after job loss. ${ }^{15}$

Note that for Panel (B) of Figure 4.2, we report $\log ($ earnings +1$)$ and thus include non-employment spells in our measure of earnings losses. While including workers with zero earnings substantially increases the size of our coefficients, Panel (B) of Figure 4.2 shows that the overall pattern holds: both migrant and native displaced workers face large earnings losses, with a substantial gap between migrant and native displaced workers. We observe the same pattern in Panel (C), which shows total yearly earnings (in EUR).

\subsubsection{Making Migrants and Natives Comparable: Reweight- ing}

Thus far, we have compared migrant and native workers without accounting for the fact that they display differences in individual characteristics and sort into different industries and occupations. This is what we call the "raw migrant-native gap" in earnings losses. To better understand whether pre-displacement differences in observable characteristics are driving the results, we follow Chapter 3 of this thesis and use a reweighting scheme first proposed by DiNardo et al. (1996). We thereby reweight migrants to native workers in terms of observable characteristics before job loss, thus artificially making the two samples very comparable in terms of pre-treatment characteristics. Migrants who are more similar to natives on characteristics such as years of education and tenure receive a higher weight. The intuition is that after reweighting migrants to natives, we can attribute the differences in their outcomes after job loss to how they respond to displacement or to the difficulties they face, rather than to their characteristics.

Econometrically, we approach this as follows: First, we estimate a probit regression model, where the dependent variable is a dummy that takes value 1 for all native

\footnotetext{
${ }^{15}$ Table A.4.16 in the Appendix shows earnings losses separately for migrants from different origin groups as defined by Battisti et al. (2021). The table shows that differences in earnings losses from natives are less pronounced for specific origin groups, such as European migrants and migrants from Western countries, the former USSR, and Central and South America. In contrast, losses for migrants from Turkey, Asia and the Middle East and Africa are particularly high. See Table A.4.19 for an overview of the origin group definition.
} 
workers. We regress this dummy on a set of individual and establishment characteristics. These are log wage $(t=-3, t=-4)$, age $(t=-1)$, years of education $(t=-1)$, tenure $(t=-1)$, and city resident $(t=-1)$. In addition, we control for establishment size $(t=-1)$, 1-digit industry $(t=-1)$ and occupations $(t=-1)$ following the definition of Blossfeld (1987). For each displaced migrant worker, we then use the estimated propensity score $\hat{p s}$ to assign an individual weight $=\frac{\hat{p s}}{1-\hat{p s}}$. Following Chapter 3 of this thesis, we compute these weights only for displaced migrants and then ensure that the weights are constant within matched worker pairs. In a robustness check in Section 4.6, we show that our results do not change if we reweight natives to migrants, instead.

Table A.4.1 presents summary statistics of displaced workers in our sample in $t=-1$. Column (1) shows the characteristics of a random 2-percent sample of migrants in Germany, which we compare to our baseline sample of migrants (Column (2)), and migrants after reweighting (Column (3)). Migrants in our sample have substantially higher tenure, wages, and earnings than the random sample of migrants. A similar pattern holds for a random sample of native workers (Column (4)) compared to native workers in our sample (Column (5)). This reflects our baseline restrictions, which ensure that we focus on a sample of high-tenured workers with strong attachment to the labor market. Comparing our reweighted sample of migrants (Column (3)) to baseline native workers (Column (5)) shows that they are very similar in terms of characteristics. Due to the reweighting, hardly any differences between migrants and natives remain in terms of characteristics such as years of education, age, earnings, and establishment types.

Figure 4.3 presents the results from our event study regression model, where the solid green line shows the trajectory for natives, the dashed blue line shows the trajectory for migrants, and the dashed light blue line shows the trajectory for reweighted migrants. Panel (A) presents our results for log(earnings). The light blue line shows that controlling for individual and establishment characteristics as well as occupations halves the original migrant-native gap in earnings. Nevertheless, a significant gap remains, showing that differences in observable characteristics cannot fully explain the differences in earnings losses.

To better understand what drives the difference, we next decompose earnings losses into wage and employment losses. Panel (B) of Figure 4.3 shows that migrants face substantially higher wage losses than natives (40 vs. $20 \log$ points in $t=0$ ), but 
Figure 4.3: Differences in Labor Market Outcomes after Displacement for Migrants vs. Natives

(A) Yearly $\log ($ Earnings $)$

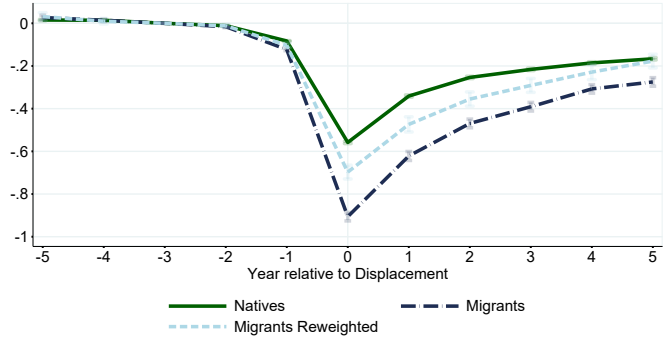

(C) Employment

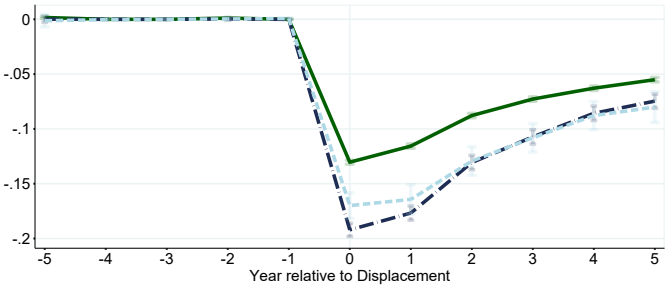

- Natives $--\cdot$ Migrants
(B) Log Wage

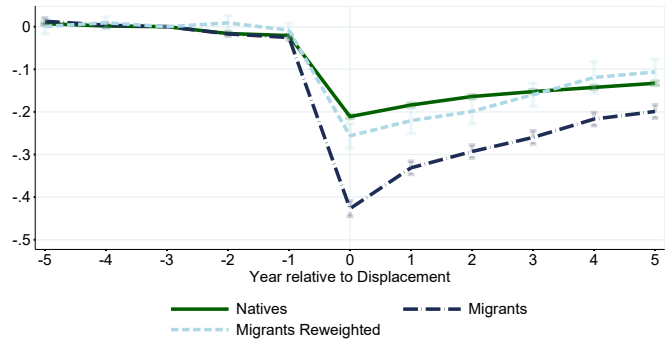

(D) Days Worked per Year

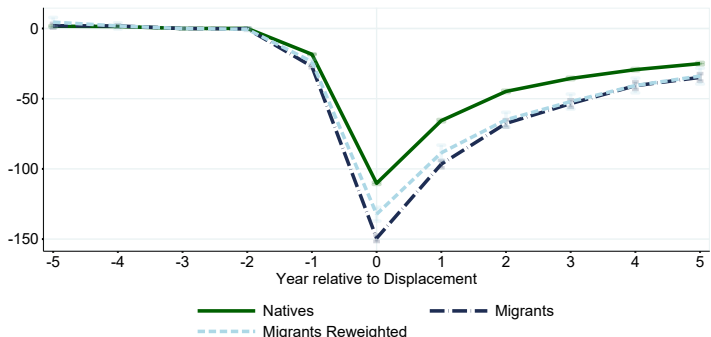

(E) Days Worked in Part-Time Employment (F) Days Worked in Full-Time Employment
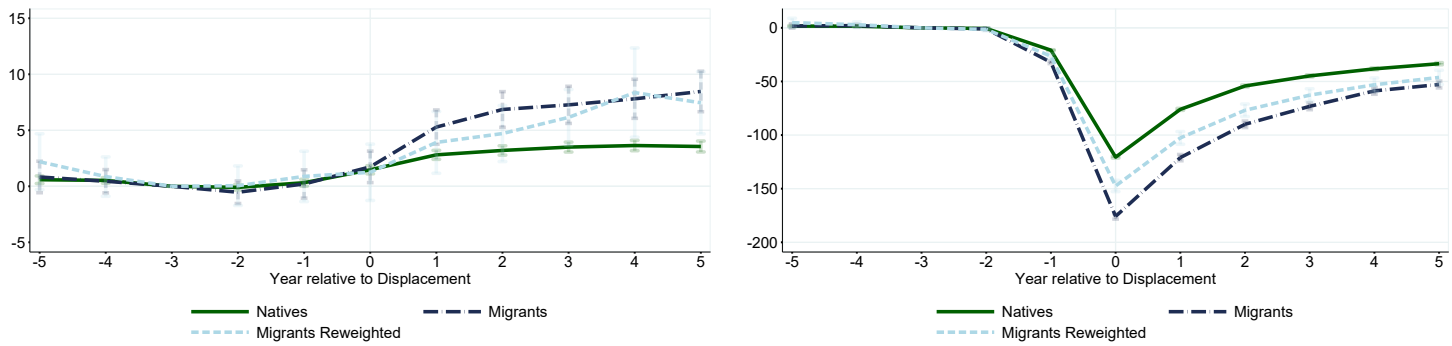

Notes: This figure shows losses in log (earnings+1) (Panel (A)), log wages (Panel (B)), employment probability (Panel $(\mathrm{C})$ ), yearly days worked (Panel (D)), days worked in part-time employment (Panel (E)), and days worked in full-time employment (Panel (F)) for displaced and nondisplaced workers. The solid green line reports the results for our sample of native workers, the dashed blue line reports the results for our sample of migrant workers, and the light blue line reports the results for our sample of reweighted migrant workers. Reweighting characteristics are log wage $(t=-3, t=-4)$, age $(t=-1)$, years of education $(t=-1)$, tenure $(t=-1)$, city resident $(t=-1)$, establishment size $(t=-1)$, 1 -digit industry $(t=-1)$, and 1-digit occupation $(t=-1)$. Vertical bars indicate the estimated $95 \%$ confidence interval based on standard errors clustered at the individual level. Our regression controls for year fixed effects, year since displacement fixed effects, age polynomials, and worker fixed effects. We omit $t=-3$ as the reference category. Displaced workers are matched to nondisplaced workers using propensity score matching. Workers in our sample are displaced in the period 2001-2011, and they are observed from 1996 to 2017. Tables A.4.4, A.4.5 and A.4.6 report the corresponding coefficients. Source: IEB. 
observable characteristics can almost fully explain these losses. In contrast, as Panels (C) and (D) show, observable characteristics cannot explain the migrant-native gap in employment losses.

Panel (C) shows that migrants and natives are both less likely to be employed in the years following their job loss. Here, the outcome variable is a dummy for being employed at least once in a given year (this includes full-time, part-time, and marginal employment). Migrants' employment decreases substantially and more than natives' (20 vs. 13 percentage points), and observable characteristics cannot explain the differences. Even five years after displacement, migrants have not fully caught up with natives. ${ }^{16}$

Panel (D) presents a very similar pattern with respect to days worked per year. Again, the reduction is larger for migrants (approximately 150 days) than natives (approximately 100 days). The gap hardly closes if we reweight migrants to natives based on observable characteristics (light blue line). Strikingly, migrants never fully catch up with natives, even though the gap substantially shrinks from $t=3$ onwards; after five years, neither group has fully recovered from displacement in terms of days worked. Finally, Panels (E) and (F) show that migrants are more likely to take up part-time rather than full-time employment after layoff. This is another explanation for migrants' higher earnings losses and suggests that they are offered worse employment contracts.

Overall, Figure 4.3 offers two key takeaways. First, if migrants find a new job after displacement, their wage losses are slightly higher but observable characteristics explain this gap. Second, migrants experience greater difficulty finding a new job than natives after displacement. Neither individual characteristics nor differential sorting across industries and occupations can explain this employment gap. This means that differences in, for example, years of education cannot fully explain why migrants suffer greater losses from job displacement. Ultimately, we would like to better understand whether labor supply or labor demand mechanisms drive this remaining gap. While this is a challenge with the data at hand, we try to get closer to these mechanisms with the following channel analysis.

\footnotetext{
${ }^{16}$ Our findings are in line with recent work on the Dutch labor market by Meekes and Hassink (2020). While the focus of their paper is gender differences in job flexibility outcomes after job loss, they also show in their online appendix that relative to individuals born in the Netherlands, the foreign born (non-natives) are less likely to become re-employed (10 percentage points) after job loss. Conditional on employment, they find no differential effect on hourly wages.
} 


\subsection{The Role of Establishment Sorting and Geo- graphic Mobility}

We first explore the types of establishments migrants and natives work for after job loss. If displaced migrants sorted into establishments with lower average wages, then this would explain part of their higher wage losses. Note that both labor supply and labor demand factors can drive this: migrants may prefer to work in specific types of establishments, or specific types of establishments may hire them.

We next assess whether differences in mobility patterns can partly explain differences in labor market outcomes. Workers who are willing to move geographically will potentially face lower wage losses and will find a new job more quickly. Geographic mobility may be seen as an rather imperfect proxy for labor supply. However, differences in geographic mobility may not necessarily reflect labor supply but labor demand if establishments offer particular workers jobs in a particular geographical range only.

\subsubsection{Establishment Characteristics}

From theory we know that given seniority wages (e.g., Lazear (1979) and Lazear (1981)) and firm-specific human capital accumulation (e.g., Becker (1962)), wage losses for displaced workers who are forced to change establishment come as no surprise. In our study, we focus on a sample of high-tenured workers at time of displacement; their wages thus partly reflect their experience at the displacement establishment. However, wages also mirror the overall productivity of an establishment (Abowd et al. (1999)). We therefore investigate the types of establishments workers reallocate to after displacement. We assume these establishments to be, on average, a negative selection compared to pre-displacement establishments for two reasons: First, displacement is a negative signal. If labor supply is elastic enough, high-quality establishments may thus be reluctant to hire displaced workers. Second, we think of displacement as an exogenous shock to workers' careers, which came as surprise. If workers face high pressure to find a new job, they will be more willing to accept bad offers.

If displacement had similar effects on migrant and native workers, then we would expect them to, on average, sort into similar establishments. Yet as we have shown, 
migrant and native workers differ in observable characteristics, and workers with particular characteristics may sort into specific types of establishments. In the following analysis, we therefore estimate Equation 4.1 with establishment-specific outcome variables, including a specification where we reweight migrant to native workers on individual characteristics, industries, and occupations.

The solid green and dashed dark blue lines in Panels (A)-(C) of Figure 4.4 show that both displaced migrants and natives sort into worse establishments after displacement. These establishments pay lower average wages (Panel (A)), have lower wage premia (Panel (B)), and have higher shares of marginally employed workers (Panel (C)). Looking at the raw migrant-native gap only, our results suggest that migrants sort into substantially worse establishments, with an even larger reduction in wage premia, and a higher increase in the share of marginally employed coworkers. However, once we control for observable characteristics, these differences largely disappear (dashed light blue lines in Panels (A), (B), and (C)), suggesting that observables can largely explain the differential sorting of migrants and natives. Note that while the migrant-native gap with respect to establishment fixed effects (Panel (B)) slightly closes after reweighting, it remains significant even thereafter, suggesting that losses in establishment wage premia can explain a greater share in migrants' wage losses.

Panel (D) of Figure 4.4 shows that after job loss, both migrants and natives sort into establishments with a lower share of migrant workers compared to control workers. ${ }^{17}$ Initially, this share is particularly low for migrants but they catch up with natives as time passes. For the re-weighted sample, the difference in establishments' migrant share disappears starting from the second year after displacement. It is surprising that migrants do not sort into establishments with a higher share of migrant coworkers; this suggests that ethnic networks do not play a prominent role in job search after displacement.

\subsubsection{Geographic Mobility}

While the type of establishment seems important in explaining differential wage losses after displacement, the channel underlying different unemployment durations

\footnotetext{
${ }^{17}$ Note that for the share of migrant workers in an establishment, we compute the "leave-one-out mean", as otherwise the share mechanically increases if displaced migrants start working at a new establishment.
} 
Figure 4.4: Sorting into Establishments after Displacement for Migrants vs. Natives

(A) Average Establishment Wage

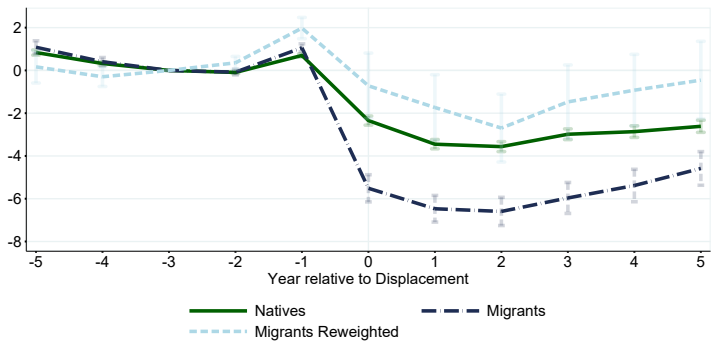

(C) Share of Marginally Employed Workers

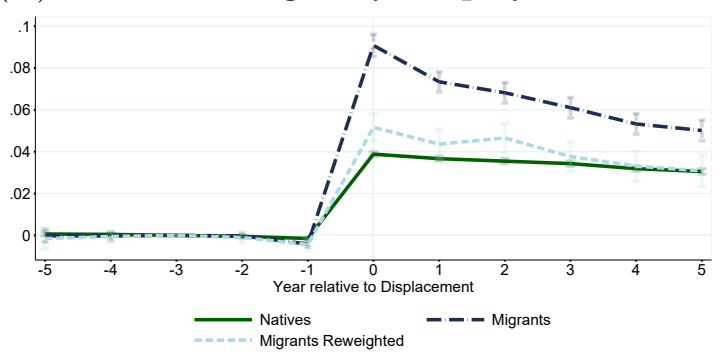

(B) AKM Establishment Effect

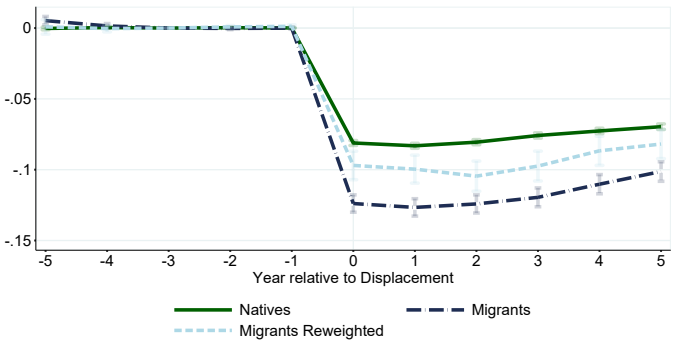

(D) Share of Migrant Workers

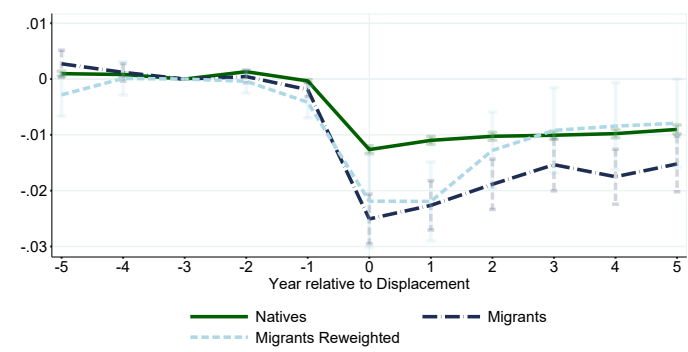

Notes: This figure shows average establishment wages (Panel (A)), AKM-style establishment fixed effects (Panel (B)) (the AKM effect is a proxy for wage differentials across firms, based on Abowd et al. (1999)), the share of marginally employed workers in an establishment (Panel (C)), and the share of migrant workers in an establishment (Panel (D), leave-one-out mean) for displaced and nondisplaced workers. The solid green line reports the results for our sample of native workers, the dashed blue line reports the results for our sample of migrant workers, and the light blue line reports the results for our sample of reweighted migrant workers. Reweighting characteristics are log wage $(t=-3, t=-4)$, age $(t=-1)$, years of education $(t=-1)$, tenure $(t=-1)$, city resident $(t=-1)$, establishment size $(t=-1)$, 1-digit industry $(t=-1)$, and 1-digit occupation $(t=-1)$. Vertical bars indicate the estimated $95 \%$ confidence interval based on standard errors clustered at the individual level. Our regression controls for year fixed effects, year since displacement fixed effects, age polynomials, and worker fixed effects. We omit $t=-3$ as the reference category. Displaced workers are matched to nondisplaced workers using propensity score matching. Workers in our sample are displaced in the period 2001-2011, and they are observed from 1996 to 2017. Tables A.4.9 and A.4.10 report the corresponding coefficients. Source: IEB, BHP. 
is still unclear. In this section, we discuss one characteristic that could explain differences in the success of finding a new job: geographic mobility. Within-country geographic mobility is an important tool to adjust regional labor market imbalances and, hence, raise local labor market efficiency (Blanchard and Katz, 1992). Displaced workers who move geographically may be rewarded with higher job search success. Nudges for displaced workers to relocate are particularly high if they work in highly concentrated labor markets with fewer outside options (Haller and Heuermann, 2019). While previous literature has shown that migrants tend to be more geographically mobile than natives (e.g., Borjas (2001), Cadena and Kovak (2016)), this pattern may reverse in regions with tight housing markets (Clark and Drever (2000)).

For this section, we make use of the geographic information recorded in the IAB data. We know the municipality, county, and federal state in which a worker lives and works. ${ }^{18}$ It is important to keep in mind that we only observe this information for employed natives and migrants. To draw conclusions on all displaced workers, we have to assume that employed workers' mobility patterns reflect mobility patterns in the overall population of migrants and natives.

Panel (A) of Figure 4.5 reports event study coefficients for workplace changes as the outcome variable. Specifically, we create a dummy variable indicating whether the workplace municipality differs from the workplace municipality in $t=-1$. In line with our expectation, displaced workers' likelihood of moving workplaces substantially increases following job loss. In $t=0$, displaced natives were approximately 58 percent more likely to change workplaces than nondisplaced controls. For migrants, this number is slightly lower (approximately 50 percent). Once we control for observable characteristics, hardly any differences between migrants and natives remain. ${ }^{19}$

Note that given German municipalities' small size, mobility across municipalities is not a good proxy for geographical relocation. Our preferred mobility outcome

\footnotetext{
${ }^{18}$ Germany exhibits widespread federalism. Therefore, there exist different administrative units (according to size): (i) federal states and city states, (ii) administrative districts, (iii) counties and cities, and (iv) municipalities. In 2010, there were a total of 11,993 municipalities and 401 counties in Germany. According to data provided by Statistisches Bundesamt (Destatis), the median population size in 2010 in a municipality was 1,652 ; the range was $8-522,686$. For counties, the median population size was $139,010.5$; the range was $33,944-1,353,186$. Note that this is just an approximation, because some municipalities and counties are missing from the data.

${ }^{19}$ This result is robust to adapting the mobility definition to include only workplace moves over a distance of more than $50 \mathrm{~km}$.
} 
Figure 4.5: Differences in Geographic Mobility after Displacement for Migrants vs. Natives

(A) Changed Workplace Municipality since $t=-1$

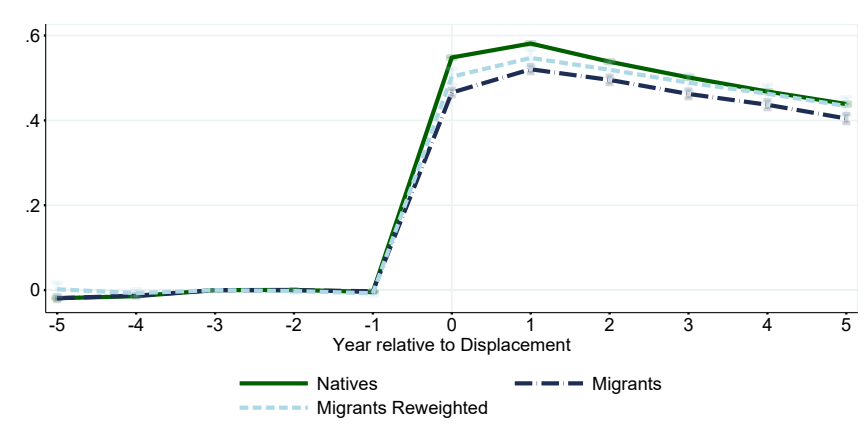

(B) Changed Workplace Federal State since $t=-1$

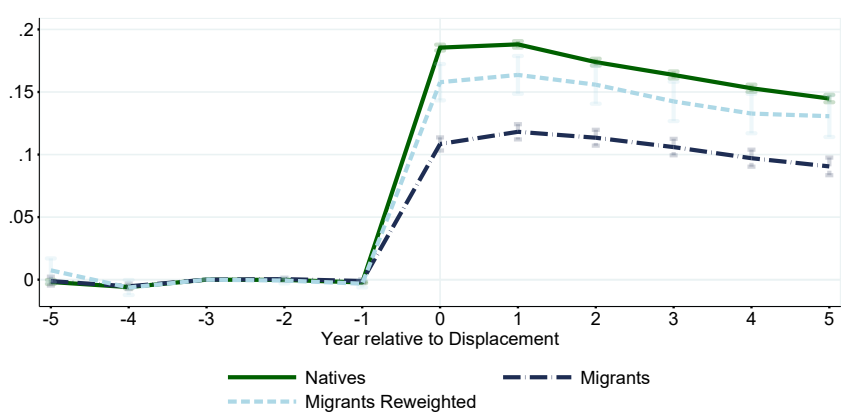

(C) Commutes

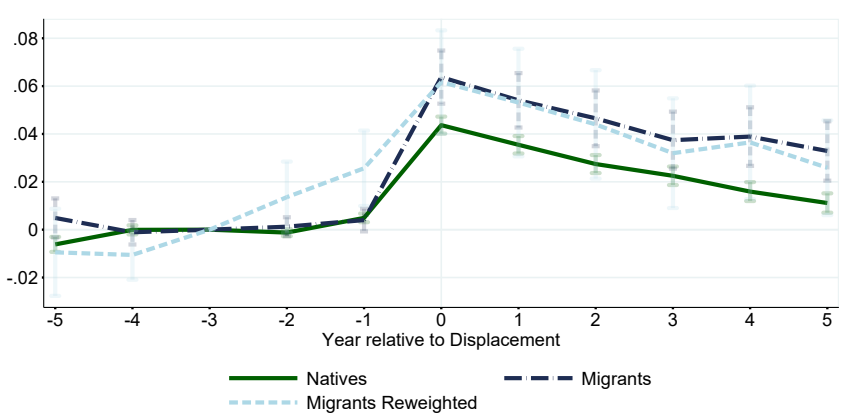

Notes: This figure shows the propensity to change one's workplace to a different municipality from $t=-1$ (Panel (A)), the propensity to change one's workplace to a different federal state (Panel (B)), and the propensity to commute (Panel (C)). The propensity to commute is defined as working and living in different municipalities. The solid green line reports the results for our sample of native workers, the dashed blue line reports the results for our sample of migrant workers, and the light blue line reports the results for our sample of reweighted migrant workers. Reweighting characteristics are $\log$ wage $(t=-3, t=-4)$, age $(t=-1)$, years of education $(t=-1)$, tenure $(t=-1)$, city resident $(t=-1)$, establishment size $(t=-1)$, 1-digit industry $(t=-1)$, and 1 -digit occupation $(t=-1)$. Vertical bars indicate the estimated $95 \%$ confidence interval based on standard errors clustered at the individual level. Our regression controls for year fixed effects, year since displacement fixed effects, age polynomials, and worker fixed effects. We omit $t=-3$ as the reference category. Displaced workers are matched to nondisplaced workers using propensity score matching. Workers in our sample are displaced in the period 2001-2011, and they are observed from 1996 to 2017. Tables A.4.7 and A.4.8 report the corresponding coefficients. Source: IEB. 
is thus Panel (B) of Figure 4.5, which presents mobility across federal states. Not surprisingly, the share of movers is now much lower, but the pattern is comparable. Approximately 19 percent of displaced natives changed their workplace to a different federal state from $t=-1$ to $t=0$. In contrast, only 12 percent of migrants moved to a different federal state after displacement. After reweighting migrants to natives, this difference reduces from 7 to 3 percentage points but remains significant. Under the assumption that employment is exogenous to mobility, lower geographic mobility may thus partly explain why migrants experience greater difficulty reintegrating into the labor market after displacement.

Finally, Panel (C) of Figure 4.5 shows how commuting patterns evolve after displacement, where commuting is defined as working and living in different municipalities. It shows that following displacement, the likelihood of commuting increases substantially. Slightly more migrants (6 percent) than natives (4 percent) start commuting following displacement. ${ }^{20}$

The observed pattern that migrants are less likely to permanently relocate to a difference workplace state may seem surprising. There are various possible explanations for this. For example, migrants may be more reliant on local networks in job search, or they may face discrimination on the housing market which makes moving harder for them. The results could moreover simply reflect the fact that migrants receive fewer job offers at a geographical distance. Overall, our results do point to potentially higher mobility constraints for migrants. While they attempt to compensate for this by commuting slightly more, this may not be enough to catch up in terms of job search success.

\subsection{Location at Time of Displacement: Difference- in-Differences Analysis}

In the previous sections, we discussed whether sorting into different establishments after displacement and differences in geographic mobility can explain the migrantnative earnings gap after job loss. Our results showed that after displacement, migrants tend to sort into low-paying establishments with a higher share of migrants and that they tend to be slightly less likely to relocate geographically. However, it is

\footnotetext{
${ }^{20}$ This result is robust to defining commuting at the county rather than municipality level.
} 
still unclear what really drives the remaining migrant-native gap in earnings losses after displacement.

In this section, we explore one more channel: How concentrated is the local environment at the time of displacement? We believe that concentration matters in two ways which are connected to labor demand. First, if displaced workers live and work in labor markets with a high concentration of similar workers, then finding a new job will be particularly challenging for them (e.g., Haller and Heuermann (2019), Caldwell and Danieli (2021)), and this may hold in particular for migrants (Bratsberg et al. (2006)). On the one hand, prospective employers may find it difficult to judge migrants' skill portfolio, especially if they did not receive their qualifications in Germany (Brücker et al. (2021)). They may thus perceive asymmetric information to be a more severe issue when hiring migrants and prefer to hire native workers instead. On the other hand, establishments may display taste-based or statistical discrimination against migrants. If labor supply is very elastic and employers can choose between a migrant and native candidate, they may thus opt for the native worker.

Second, migrants may compete for jobs among each other. While previous studies show that migrants benefit from better social networks (e.g., Edin et al. (2003), Munshi (2003)), migrants may also suffer from within-network competition (e.g., Albert et al. (2020), Beaman (2012), Calvo-Armengol and Jackson (2004)). Migrants living in counties with a particularly high share of same-nationality population may compete for a limited number of jobs ${ }^{21}$.

For our empirical approach, we follow Schmieder et al. (2020) and estimate a difference-in-differences type of regression model, where we proceed in two steps. In the first step, within each matched worker pair, we construct an individual-level measure of earnings losses (and other outcomes), which we call the difference-indifferences outcome. For this purpose, we calculate the mean difference in earnings before and after job loss within each displaced and nondisplaced worker match:

$$
\Delta y_{i c}^{D I D}=\Delta y_{i c}^{D P}-\Delta y_{i c}^{N D P}
$$

where $\Delta y_{i c}^{D P}$ reports the difference in average earnings for displaced worker $i$ in

\footnotetext{
${ }^{21}$ It is plausible to assume that migrants with the same nationality are similar in terms of characteristics, e.g., because of similar education systems in their countries of origin, and therefore substitutes.
} 
cohort $c$ before $(t=-5$ to $t=-2)$ and after $(t=0$ to $t=3)$ job loss. $\Delta y_{i c}^{N D P}$ reports the measure for the corresponding nondisplaced worker. $\Delta y_{i c}^{D I D}$ then indicates the extent to which these differences in means vary within matched worker pairs. We can interpret this difference as the individual treatment effect from job loss.

In the second step, we estimate three OLS regression models for displaced workers only, where we use $\Delta y_{i c}^{D I D}$ as the outcome variable and consecutively include three regressors as proxy measures for local labor market concentration:

$$
\begin{gathered}
\Delta y_{i c}^{D I D}=\alpha M i g+\beta_{1} U R_{i c}+\beta_{2} U R_{i c} * M i g+\phi X_{i c}+\epsilon_{i c} \\
\Delta y_{i c}^{D I D}=\alpha M i g+\gamma_{1} \text { City }_{i c}+\gamma_{2} \text { City }_{i c} * M i g+\phi X_{i c}+\epsilon_{i c} \\
\Delta y_{i c}^{D I D}=\alpha M i g+\delta_{1} \text { EthnicShare }_{i c}+\delta_{2} \text { EthnicShare }_{i c} * \text { Mig }_{i c}+\phi X_{i c}+\epsilon_{i c}
\end{gathered}
$$

Our first proxy measure for concentration is $U R_{i c}$, which measures the percentage change in the unemployment rate in the workplace municipality between $t=-1$ and $t=0$ for displaced worker $i$ in cohort $c$. Our second concentration proxy, City $y_{i c}$, is a dummy indicating whether a worker lives in a city at the time of displacement. ${ }^{22}$

Last, EthnicShare ${ }_{i c}$ reports the share of the working age population of a worker's nationality by the total working age population in his workplace county at $t=-1$. We use data on working age population by nationality and county from the German Federal Statistical Office (Destatis). ${ }^{23}$ In addition to these variables of interest, we include a vector $X_{i c}$ with individual, industry, and occupation controls measured in the year before displacement. We cluster standard errors at the baseline county level.

\footnotetext{
${ }^{22}$ To define cities, we use a municipality classification proposed by the German Federal Institute for Research on Building, Urban Affairs and Spatial Development (BBSR), which is based on population size and administrative function. For more information, see: https://www. bbsr.bund.de/BBSR/DE/forschung/raumbeobachtung/Raumabgrenzungen/ deutschland/gemeinden/StadtGemeindetyp/StadtGemeindetyp.html. Last access: May 30, 2021.

${ }^{23}$ For our analysis, we use the dataset Population and Employment, Foreign Population, Results of the Central Register of Foreigners, Destatis, 2019. This dataset reports the population in Germany on December 31 by county, nationality, and age for each year in the period 1998-2017. It is based on records from the German foreigners' registration office. For the majority of foreigners' registration offices, the jurisdictions coincide with German counties. However, in Saarland, Hesse, and Brandenburg, a county-specific assignment of data is not always possible. Therefore, it is not possible to determine the percentage of the working-age population of a certain nationality for all German counties over the whole period. This is only a minor issue for our analysis, as the vast majority of counties (especially the five largest metropolitan areas (Berlin, Cologne, Frankfurt, Hamburg, and Munich) are included in the sample.
} 
Table 4.2 reports the results from Equation 4.3, where we consecutively include controls. The outcome variable is $\log$ (earnings). In Column (1), we control for a set of individual characteristics ${ }^{24}$, 1-digit industries (in $t=-1$ ), and occupations according to Blossfeld (1987) (in $t=-1$ ). The average loss of earnings is $36 \mathrm{log}$ points for native workers (see the mean of the dependent variable), and for migrants, this loss increases by an additional $19 \log$ points $^{25}$ (Column (1)). This confirms that even after controlling for observable characteristics, migrants face larger earnings losses.

\footnotetext{
${ }^{24}$ These are age, age squared, years of education, tenure, experience, full-time employment, log establishment size (all measured in $t=-1$ ), and log wage in $t=-3$.

${ }^{25}$ This corresponds to an increase of 20.92 percent $\left(100 *\left(e^{0.19}-1\right)=20.92 \%\right)$.
} 
Table 4.2: Explaining Earnings Losses by Local Labor Market Concentration

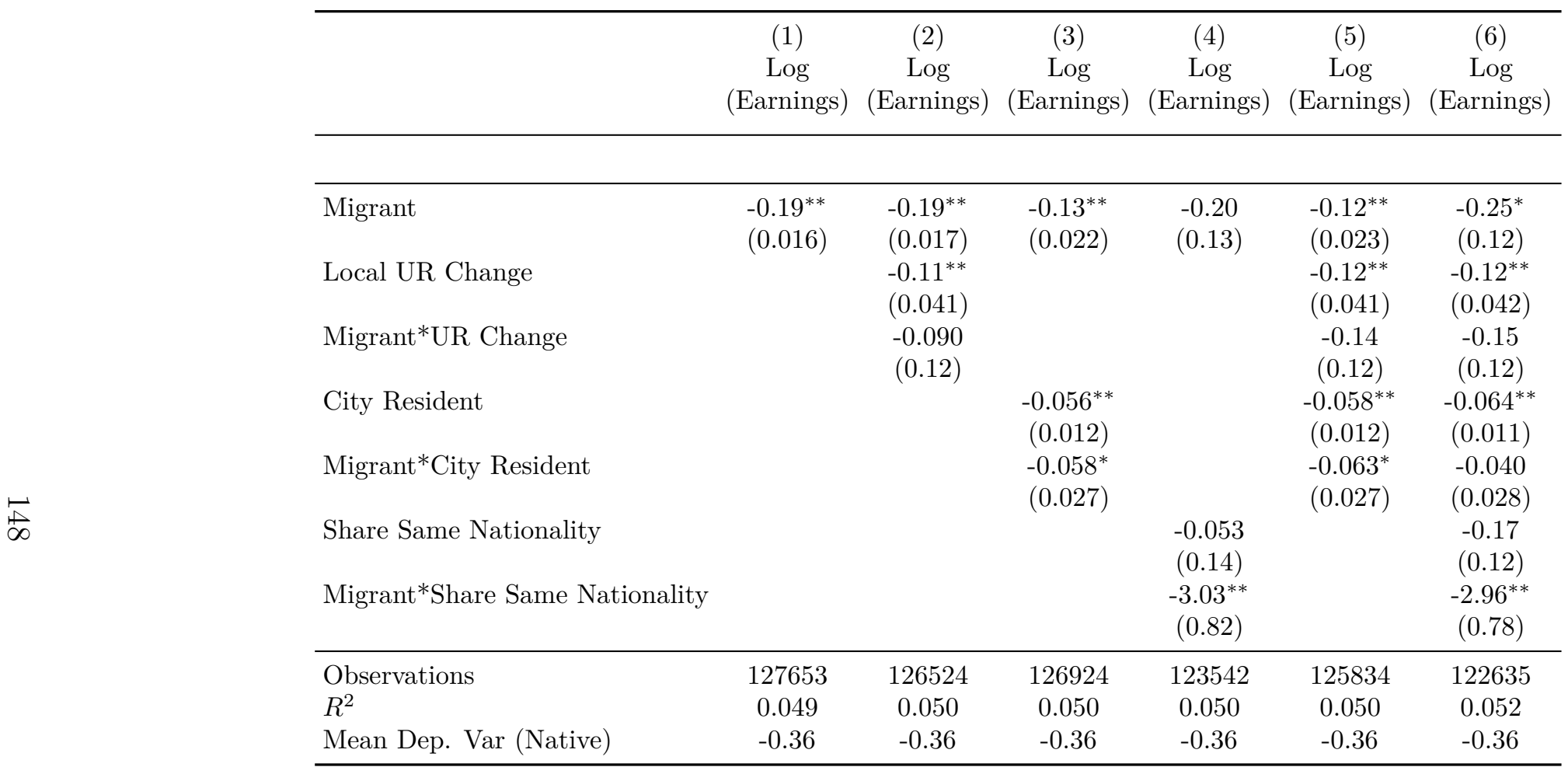

Notes: The table shows the effect of being a migrant on $\log ($ earnings) losses. All outcome variables are based on the individual difference-in-differences estimate derived from Equation 4.2. In Column (1), we control for individual characteristics (age, age squared, years of education, tenure, experience, fulltime work, log wage in $\mathrm{t}=-3$, and log establishment size), 1-digit industries and occupations according to Blossfeld (1987) in the year before displacement. We then successively add controls for local unemployment rate changes reported at the municipality level (Column (2)), city residency (Column (3)), and the share of co-ethnic working age population in a county (Column (4)), all measured in the year before displacement. Columns (5) and (6) show the coefficients when all controls are included simultaneously. We cluster standard errors at the baseline county level. ** and * refer to statistical significance at the 1 and 5 percent level, respectively. Workers in our sample are displaced in 2001-2011, and they are observed from 1996 to 2017. Source: IEB, BBSR, Destatis. 
We then add our first proxy for local labor market concentration and local unemployment rate changes in Column (2). The result implies that a $1 \%$ increase in the municipality unemployment rate from $t=-1$ to $t=0$ increases earnings losses regardless of migration status - by $11 \%$. This supports our hypothesis that higher local unemployment rates reduce workers' outside options and thus increase displaced workers' earnings losses. The coefficient on the interaction of local unemployment rate changes and the migrant dummy is negative but estimated very imprecisely. In Column (3), we include city residency as another proxy for concentration. The coefficients confirm the negative relationship between living in a city at the time of displacement and earnings losses, as documented by Haller and Heuermann (2019). Earnings losses of displaced workers who live in cities at time of displacement are $5.6 \%$ larger. This effect is approximately twice the size for migrant workers.

Column (4) reveals that the concentration of similar workers, proxied by the share of the working-age population of a worker's nationality by the total working-age population in his workplace county before job loss, substantially increases migrants' earnings losses. Note that if we simultaneously control for all concentration proxies (Column (6)), the interaction of the migrant dummy with city residency becomes insignificant. This suggests that a large part of the city effect for migrants can be explained by a higher share of the same-nationality working-age population in cities.

We do not want to interpret the magnitude of the coefficient on the interaction between migrants and shares of the same nationality since the effect may vary substantially depending on a migrant's position in the share distribution. To show this, we regress the individual DID term for $\log$ (earnings) on 18 categories for the share of same-nationality working age population in $t=-1$. We plot the respective marginal effects in Figure 4.6, where the x-axis reports the 18 categories. While earnings losses for natives (Panel (A), solid green line) are constant and do not vary substantially by the percentage share of same-nationality working age population, there is a clear pattern for migrants (dashed blue line): Earnings losses are particularly high for migrants working in counties with a share of same-nationality working age population of $8-10 \%$. 
Figure 4.6: Costs of Job Loss and Share of Same-Nationality Working Age Population in $\mathrm{t}=-1$

(A) Losses in Log Earnings per Year

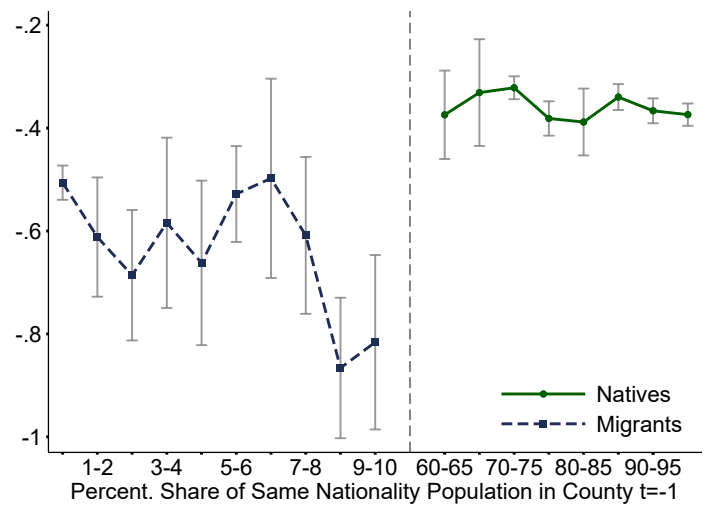

(C) Losses in Employment

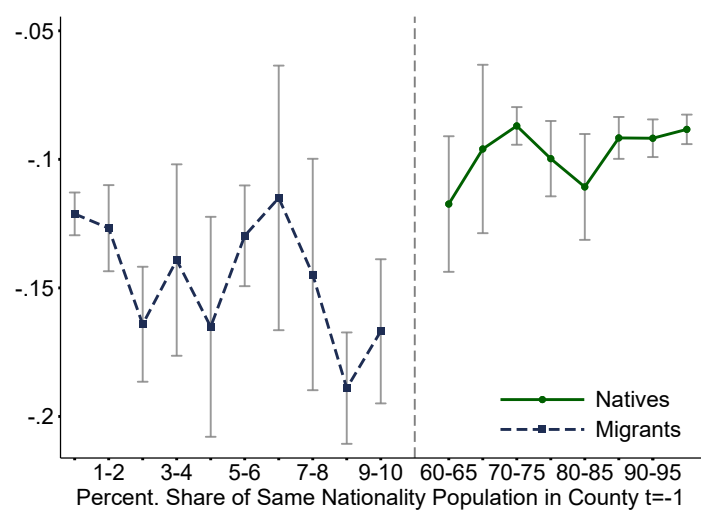

(B) Losses in Daily Log Wage

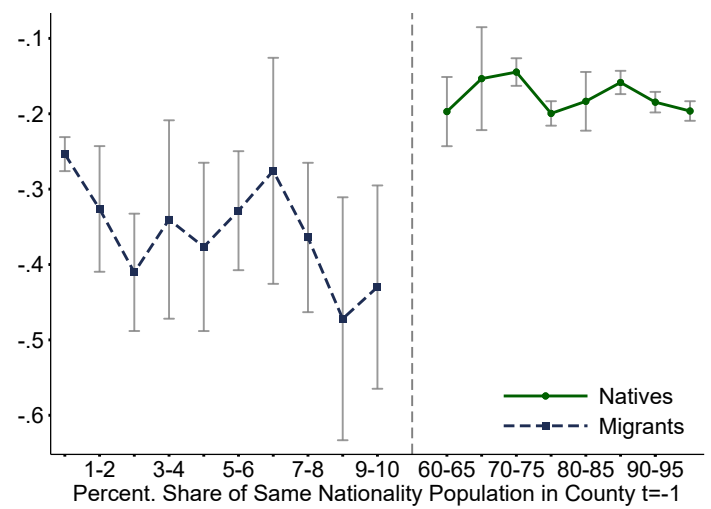

(D) Losses in Days Worked per Year

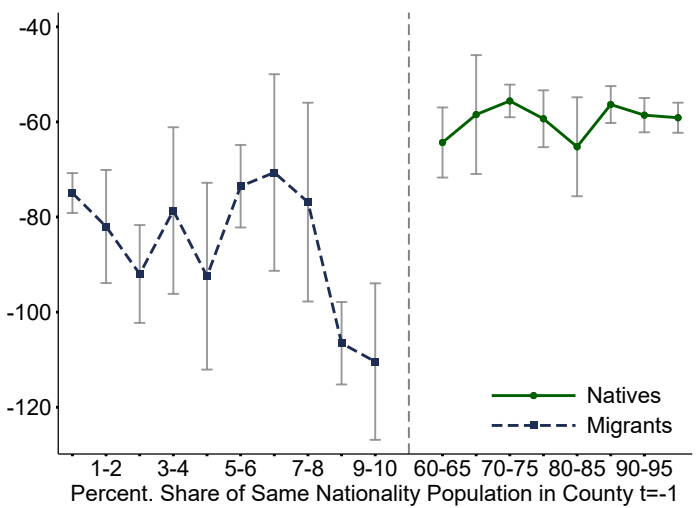

Notes: This figure shows how costs of job loss differ by the share of the same-nationality working-age population in a worker's workplace county in $t=-1$. This share ranges from 0 to $10 \%$ for migrants and from 60 to $100 \%$ for natives. For the distribution of the share, see Figure A.4.1. Panel (A) reports $\log$ (earnings), Panel (B) reports log(wage), Panel (C) reports employment probability, and Panel (D) reports number of days worked per year. We regress workers' individual difference-indifferences outcomes on the categories of same-nationality share reported on the x-axis, as well as individual, industry, and occupation controls. The solid green line reports the results for our sample of native workers, and the dashed blue line reports the results for our sample of migrant workers. Vertical bars indicate the estimated $95 \%$ confidence interval based on standard errors clustered at the displacement establishment level. Our regression controls for individual characteristics (age, age squared, years of education, tenure, experience, full-time work, log wage in $t=-3$, and log firm size), 1-digit industries, and occupations according to Blossfeld (1987) in the year before displacement. Source: IEB and Destatis. 
This pattern is driven by larger log wage losses (Panel (B)) and larger employment losses, both on the extensive and intensive margins (Panels (C) and (D)). Note that due to the nature of the difference-in-differences analysis, which we estimate based on the sample of displaced workers in $t=-1$ only, some of the categories have quite a low number of observations. This contributes to the imprecision of the coefficients. For example, there are only 181 workers in the category "percentage share of same nationality population of $9-10 \% "$. It is thus possible that a few outliers drive the effects and one has to interpret the results with caution.

To complete the picture, we estimate versions of Equation 4.3 for additional outcome variables. Panel A of Table 4.3 reports coefficients on the migrant dummy for regressions with individual, industry, and occupation controls. The table confirms the overall pattern from the event study regression model: Migrants' employment (Columns (1) and (2)) and wage (Column (3)) losses after displacement are substantially larger than natives'. This can partly be explained by migrants selecting into establishments with lower wage premia (Column (5)) and a higher share of marginally employed workers (Column (7)).

We next add our concentration proxy controls in Panel (B). The respective coefficients broadly confirm the pattern that we already observed in Table 4.2: 1) A larger increase in the local unemployment rate change from $t=-1$ to $t=0$ leads to greater losses in terms of days worked per year. 2) Workers living in cities at the time of displacement face larger employment and wage losses; for migrants, this "city penalty" on wage losses is particularly high. 3) Migrants living in counties with a higher share of the same-nationality population face particularly large wages and employment losses. Overall, our results suggest that labor demand mechanisms do play a role in explaining the higher costs of job loss for migrants. 
Table 4.3: Explaining Costs of Job Loss by Local Labor Market Concentration

\begin{tabular}{|c|c|c|c|c|c|c|c|}
\hline & $\begin{array}{c}(1) \\
\text { Employed }\end{array}$ & $\begin{array}{c}(2) \\
\text { Days Worked }\end{array}$ & $\begin{array}{c}(3) \\
\text { Log Wage }\end{array}$ & $\begin{array}{c}(4) \\
\text { Commutes }\end{array}$ & $\begin{array}{c}(5) \\
\text { AKM Effect }\end{array}$ & $\begin{array}{c}(6) \\
\text { Share } \\
\text { Migrants }\end{array}$ & $\begin{array}{l}(7) \\
\text { Share Marginally } \\
\text { Employed }\end{array}$ \\
\hline \multicolumn{8}{|c|}{ Panel A: Controlling for Individual Characteristics, Industry, and Occupation } \\
\hline Migrant & $\begin{array}{l}-0.040^{* *} \\
(0.0044)\end{array}$ & $\begin{array}{c}-21.1^{* *} \\
(2.10)\end{array}$ & $\begin{array}{l}-0.11^{* *} \\
(0.011)\end{array}$ & $\begin{array}{l}-0.0070 \\
(0.0096)\end{array}$ & $\begin{array}{l}-0.030^{* *} \\
(0.0066)\end{array}$ & $\begin{array}{c}0.0014 \\
(0.0035)\end{array}$ & $\begin{array}{l}0.028^{* *} \\
(0.0031)\end{array}$ \\
\hline $\begin{array}{l}\text { Observations } \\
R^{2} \\
\text { Mean Dep. Var (Native) }\end{array}$ & $\begin{array}{c}133338 \\
0.020 \\
-0.094\end{array}$ & $\begin{array}{c}133338 \\
0.034 \\
-58.7\end{array}$ & $\begin{array}{c}121866 \\
0.047 \\
-0.17\end{array}$ & $\begin{array}{c}121676 \\
0.018 \\
0.027\end{array}$ & $\begin{array}{c}94866 \\
0.093 \\
-0.072\end{array}$ & $\begin{array}{c}119631 \\
0.007 \\
-0.0098\end{array}$ & $\begin{array}{c}119291 \\
0.021 \\
0.034\end{array}$ \\
\hline \multicolumn{8}{|c|}{ Panel B: Adding Controls for Local Unemployment Rate Change, City Resident and Share of Coethnic Neighbors } \\
\hline Migrant & $\begin{array}{c}0.012 \\
(0.031)\end{array}$ & $\begin{array}{l}-26.5 \\
(16.2)\end{array}$ & $\begin{array}{l}-0.15^{*} \\
(0.070)\end{array}$ & $\begin{array}{c}-0.016 \\
(0.069)\end{array}$ & $\begin{array}{l}0.0096 \\
(0.046)\end{array}$ & $\begin{array}{c}0.17^{* *} \\
(0.016)\end{array}$ & $\begin{array}{c}-0.027 \\
(0.016)\end{array}$ \\
\hline Local UR Change & $\begin{array}{l}-0.014 \\
(0.011)\end{array}$ & $\begin{array}{l}-15.8^{*} \\
(6.21)\end{array}$ & $\begin{array}{l}-0.020 \\
(0.023)\end{array}$ & $\begin{array}{c}0.017 \\
(0.017)\end{array}$ & $\begin{array}{l}-0.039 \\
(0.044)\end{array}$ & $\begin{array}{c}0.0071 \\
(0.0065)\end{array}$ & $\begin{array}{c}0.0069 \\
(0.0070)\end{array}$ \\
\hline Migrant*UR Change & $\begin{array}{c}-0.0100 \\
(0.027)\end{array}$ & $\begin{array}{l}-6.46 \\
(14.8)\end{array}$ & $\begin{array}{l}-0.087 \\
(0.076)\end{array}$ & $\begin{array}{l}-0.064 \\
(0.053)\end{array}$ & $\begin{array}{c}0.053 \\
(0.044)\end{array}$ & $\begin{array}{l}-0.011 \\
(0.032)\end{array}$ & $\begin{array}{c}0.0089 \\
(0.025)\end{array}$ \\
\hline City Resident & $\begin{array}{l}-0.018^{* *} \\
(0.0035)\end{array}$ & $\begin{array}{c}-9.72^{* *} \\
(1.61)\end{array}$ & $\begin{array}{l}-0.022^{* *} \\
(0.0062)\end{array}$ & $\begin{array}{c}0.059^{* *} \\
(0.0099)\end{array}$ & $\begin{array}{c}0.0024 \\
(0.0063)\end{array}$ & $\begin{array}{c}0.00026 \\
(0.0012)\end{array}$ & $\begin{array}{l}0.0037^{* *} \\
(0.0014)\end{array}$ \\
\hline Migrant*City Resident & $\begin{array}{c}0.0047 \\
(0.0066)\end{array}$ & $\begin{array}{c}3.63 \\
(3.10)\end{array}$ & $\begin{array}{c}-0.073^{* *} \\
(0.019)\end{array}$ & $\begin{array}{l}-0.024 \\
(0.019)\end{array}$ & $\begin{array}{l}-0.033^{* *} \\
(0.0079)\end{array}$ & $\begin{array}{c}-0.00053 \\
(0.0062)\end{array}$ & $\begin{array}{l}0.018^{* *} \\
(0.0061)\end{array}$ \\
\hline Share Same Nationality & $\begin{array}{c}0.045 \\
(0.033)\end{array}$ & $\begin{array}{l}-12.1 \\
(17.1)\end{array}$ & $\begin{array}{c}-0.13 \\
(0.073)\end{array}$ & $\begin{array}{c}-0.0063 \\
(0.073)\end{array}$ & $\begin{array}{c}0.013 \\
(0.050)\end{array}$ & $\begin{array}{l}0.18^{* *} \\
(0.017)\end{array}$ & $\begin{array}{l}-0.039^{*} \\
(0.016)\end{array}$ \\
\hline Migrant*Share Same Nationality & $\begin{array}{c}-0.76^{* *} \\
(0.18)\end{array}$ & $\begin{array}{c}-329.3^{* *} \\
(86.2)\end{array}$ & $\begin{array}{c}-2.06^{* *} \\
(0.57)\end{array}$ & $\begin{array}{c}0.66 \\
(0.47)\end{array}$ & $\begin{array}{l}-0.70 \\
(0.44)\end{array}$ & $\begin{array}{c}0.13 \\
(0.20)\end{array}$ & $\begin{array}{c}0.38^{*} \\
(0.15)\end{array}$ \\
\hline Observations & 128092 & 128092 & 117075 & 116885 & 91178 & 115078 & 114745 \\
\hline$R^{2}$ & 0.021 & 0.035 & 0.049 & 0.021 & 0.095 & 0.015 & 0.022 \\
\hline Mean Dep. Var (Native) & -0.094 & -58.7 & -0.17 & 0.027 & -0.072 & -0.0098 & 0.034 \\
\hline
\end{tabular}

Notes: The table shows the effect of being a migrant on labor market outcomes. All outcome variables are based on the individual difference-in-differences estimate derived from Equation 4.2. Panel A shows the results when controlling for individual characteristics, and sorting across industries and occupations in the year before displacement. Panel B adds controls for local unemployment rate changes reported at the municipality level, city residency, and the share of coethnic working age population in a county, all measured in the year before displacement. The AKM effect is a proxy for wage differentials across firms, based on Abowd et al. (1999). We cluster standard errors at the baseline county level. ** and ${ }^{*}$ refer to statistical significance at the 1 and 5 percent level, respectively. Workers in our sample are displaced in the period 2001-2011, and they are observed from 1996 to 2017. Source: IEB, BBSR, Destatis. 


\subsection{Robustness Checks}

\subsubsection{Robustness of Main Results}

In the following, we perform three robustness checks to show that our main results from Sections 4.3.2 and 4.3.3 do not change substantially if we i) exclude the financial crisis years from our sample, ii) exclude East Germany from our sample, and iii) change our reweighting algorithm to reweight natives to migrants.

For the first robustness check, we estimate Equation 4.1 only for baseline years up to 2007. Thus, we ensure that none of the workers in our analysis sample lose their jobs during the financial crisis. This may matter because, as discussed, migrants particularly suffer during recessions (e.g., Borjas and Cassidy (2020), Freeman et al. (1973), Couch et al. (2020), Montenovo et al. (2020))). The financial crisis years may thus bias our results in the direction of particularly large earnings losses for migrants. As Table A.4.11 shows, this is not the case: Our results are remarkably robust to excluding the financial crisis years. Migrants displaced in 2001-2007 face substantially larger earnings losses (Columns (1) and (2)), wage losses (Columns (3) and (4)), employment losses (Columns (5) and (6)), and losses in yearly days worked (Columns (7) and (8)) than native workers. ${ }^{26}$ We thus conclude that the financial crisis does not drive our results.

For our second robustness check, we exclude workers displaced in East Germany from our sample. We do this because our observation period ranges from 1996-2017. Thus, it starts only six years after German reunification and covers a time when East Germany underwent major economic transitions. This could lead to different displacement effects for workers in East Germany. For migrants in East Germany, reintegration into the labor market may be particularly difficult. In Table A.4.12, however, we see that our results are robust to estimating our regression based on a sample for workers displaced in West Germany only. Again, migrants displaced in West Germany face higher earnings losses (Columns (1) and (2)), wage losses

\footnotetext{
${ }^{26}$ Since our post-job-loss period spans five years, restricting the observation period to 2007 , the year before the financial crisis, could not suffice - the crisis could also have reduced job search success in $t=1$ up to $t=5$. We therefore run an additional robustness check, where we only include matched worker pairs with baseline years up to 2003 in our sample (see Table A.4.18). The resulting patterns are very similar to our main results: Migrants face larger earnings, wage, and employment losses.
} 
(Columns (3) and (4)), employment losses (Columns (5) and (6)), and losses in yearly days worked (Columns (7) and (8)) than native workers.

Finally, we show that our reweighting scheme is robust to the direction of reweighting. For our main regression results, we reweighted migrants to natives following DiNardo et al. (1996). However, if only a few migrants are comparable to native workers, these workers may receive very high weights and drive our results. We therefore check whether our results differ if we instead reweight natives to migrants. We use the same reweighting algorithm as described in Section 4.3.3. The only difference is that instead of a dummy for native workers as an outcome variable in our probit regression, we now regress a dummy for migrant workers on a set of predisplacement individual characteristics, 1-digit industries, and occupations as defined by Blossfeld (1987). Table A.4.13 reports the regression results, confirming that the migrant-native gap in costs of job loss is robust to changing the reweighting scheme. Some of the coefficients slightly increase in size, and the gap between migrants and natives increases for all labor market outcomes.

\subsubsection{Layoffs vs. Complete Closures}

Throughout this study, our aim is to make the migrants and natives in our sample as comparable as possible. We undertake a number of steps to achieve this: We reweight migrants to natives based on individual characteristics, industries, and occupations, and we control for regional labor market characteristics. However, thus far, our sample includes both workers displaced from complete establishment closures and from layoffs where only part of the workforce is laid off. In this section, we first estimate our event study regression model only for workers laid off in complete closures. We then proceed to control for the establishment from which workers are displaced.

In the spirit of Gibbons and Katz (1991), we assume that workers displaced in mass layoffs are different from workers laid off during complete establishment closures: If establishments decide whom to lay off, they are more likely to first fire workers of low ability, without family obligations, or bad matches. Being laid off could thus be a negative signal to future employers. ${ }^{27}$ Imagine, for example, that some migrants

\footnotetext{
${ }^{27}$ Gibbons and Katz (1991) show that workers displaced from mass layoffs have larger wage losses and higher unemployment durations than workers laid off in complete closures.
} 
have worse language skills than their coworkers, and are thus more likely to be laid off during a mass layoff. These differences in language skills (which we do not observe and thus cannot control for) moreover negatively affect their re-employment probability. If displaced migrants in our sample constituted a negative selection in terms of language skills compared to the average migrant population, then we would overestimate their costs of job displacement.

To solve this, we restrict the sample to workers laid off in a complete establishment closure only, where we assume that neither migrants nor natives will constitute a negative selection. We expect that migrants and natives laid off in complete closures are particularly comparable.

Table A.4.14 shows that for most labor market outcomes, our difference-in-differences results for complete closures are very similar to the results from the full sample. The coefficients on earnings, employment, and wage losses are comparable to Panel A in Table 4.3. The coefficients on the local concentration proxies in Panel B confirm the pattern for the full sample: Displaced workers living in municipalities with a higher change in unemployment rates from $t=-1$ to $t=0$ lose more; the same holds for city residents. Migrants living in counties with a high share of the same-nationality working-age population have particularly large losses.

In a second robustness check, we add fixed effects for the establishment from which workers are displaced to our regression model. We do this because workers may sort into specific establishments prior to displacement. By including establishment fixed effects, we account for this potential sorting and make our worker sample even more comparable. Again, our difference-in-differences results, as reported in Table A.4.15, are remarkably stable.

\subsection{Conclusion}

In this chapter, we investigated differences in the costs of job loss for migrants compared to native workers. While recent research has emphasized the importance of investigating displacement costs for different worker groups (see, e.g., Chapter 3 of this thesis, Blien et al. (2020), Meekes and Hassink (2020)), no study to date has focused explicitly on migrant workers. For our empirical analysis, we use rich administrative employer-employee data from Germany. We show that migrants face 
larger costs of job loss than natives, with substantial gaps in earnings losses (40 percentage points) and re-employment probability ( 5 percentage points) in the year after displacement. While migrants start catching up as time passes, differences still exist even five years after displacement. Observable individual and establishment characteristics can explain the difference in wage losses, but they cannot explain why migrants experience longer unemployment durations after displacement.

In terms of channels, we show that one explanation for migrants' higher wage losses is that they sort into establishments with lower wage premia and a higher share of marginally employed workers after displacement. We moreover find that while migrants are slightly more likely to commute (2 percentage points), they are less likely to permanently relocate to a new federal state (3 percentage points) following job loss, pointing to mobility contraints. Finally, we show that local labor market concentration upon displacement is an important contributor to displaced workers' costs of job loss. Displaced workers living in municipalities with a higher increase in local unemployment rates or in cities face greater losses. One important factor driving the migrant-native gap in earnings losses is competition by same-nationality workers: The higher the share of the working-age population of the same nationality in their workplace county, the larger migrants' earnings losses are.

Policymakers interested in improving migrants' labor market outcomes should pay attention to our finding that migrants face substantial difficulties in job search after displacement. When searching for a job, migrants may therefore need a different type of training than natives (e.g., language courses or training targeted at learning how the job application process in their destination country works). For authorities, it may be worthwhile to invest in different types of trainings for unemployed individuals, depending on their migration status. 


\section{Concluding Remarks}

In this thesis, I investigated the impact of economic shocks on workers' labor market outcomes with the help of two case studies: First, an immigration policy reform which led to a substantial increase in the share of Czech cross-border workers in Germany, and second, job displacement as a consequence of mass layoffs. For all of my empirical analyses, I used German administrative employer-employee data from the IAB. Overall, my research shows that economic shocks can have a lasting impact on workers' careers.

Following the introductory chapter, the second chapter showed that a labor supply shock in the form of increased immigration impacts both regions and workers. The opening of the German labor market to Czech workers affected local labor markets on both sides of the border. For Czech Republic, I find that workers benefited, whereas in Germany, native workers' wages decreased. My results moreover suggest that firms in Czech Republic suffered from skill shortages as a result of the worker outflow. In contrast, German workers expanded their employment, suggesting that German firms benefited in the form of productivity gains. When drawing policy conclusions on the reform, it is thus important to take into account all involved agents.

With ageing societies in Europe, and potential out-migration waves due to climate change in the future, immigration remains a topic of high relevance. Future research can advance in three directions: First, while the response of regions to immigration shocks is well-studied, there is not so much evidence on how workers, and firms, react to migration flows (Kerr et al. (2015)). Yet to fully understand the general equilibrium effects of immigration, it is important to take all sides into account. Exploring the firm-side response to labor market shocks in more detail is on my agenda for future research. Second, labor market institutions may be key to understanding how easily countries absorb immigration shocks (Foged et al. (2021)). 
If ageing societies will be more and more reliant on immigration, it is important to know how labor markets should be designed to optimally integrate migrants at low costs to native workers. Third, there is little evidence on how immigration and technological progress interact (for an exception, see Lafortune et al. (2019)). For instance, it could be that immigrants prevent firms to invest into new technologies, because they reduce the price of labor as a production unit. At the same time, the relationship could also be reversed: Technological change may impact the selection of workers who move to a given country. If a country undergoes technological change, migrating may only pay off for workers with the relevant skill set. Within the next years, more research will be needed to shed more light on these issues.

Let me now turn to the second part of my thesis, where I explore the costs of job displacement for different types of workers. In the third chapter, together with Johannes Schmieder and Simon Trenkle, we analyzed to what extent men and women are differently affected by losing their job as part of a mass layoff event. We found that women face substantially higher earnings losses than men, and that women with young children have particularly large losses. Women are also much more likely than men to take up marginal employment after job loss. These differences remain even after controlling for pre-displacement differences in individual characteristics, and differential sorting into industries, and they are stable to an extensive set of robustness checks.

In the fourth chapter, which is joint work with Theresa Koch, we investigated a different type of heterogeneity with respect to job displacement: Migrants compared to native workers. Our results show that migrant workers have larger earnings, wage, and employment losses. While differences in individual characteristics, sorting into industries, and sorting into occupations can explain the difference in wage losses, they cannot explain migrants' longer unemployment duration. We also found that migrants' earnings losses are particularly high if they live in counties with a high share of same-nationality working age population.

For many decades, the displacement literature has focused almost exclusively on men. Yet paying more attention to how subgroups, such as women and migrants, are affected from job displacement is a relevant undertaking both for researchers and for policy-makers. Equal opportunities are an important precondition for efficient labor markets; they benefit firms, the government, and workers alike. For instance, if women lack the incentives to stay in the labor force after displacement 
- e.g., because of wrong incentives due to income tax splitting or missing child care options - then this reduces the pool of job candidates for firms. If the government can tackle the reasons for migrants' longer unemployment duration, then it may save with respect to unemployment benefits and collect more taxes. For displaced workers, a longer unemployment duration after job loss entails a number of costs: Decreased consumption, bad signals to future employers, and mental health issues. Understanding which groups of workers are particularly affected from job loss and subsequently developing tools to facilitate re-integration for them, is thus a crucial task for policy-makers.

Job displacement is a particularly pressing issue in light of the Covid-19 Pandemic, which has substantially reinforced inequalities (Adams-Prassl et al. (2020)). For instance, in many countries both women and migrants were more likely to be affected from job loss as a result of the Covid-19 Pandemic, for various reasons (see, e.g., Alon et al. (2020) and Borjas and Cassidy (2020)). In my view, future research on job displacement has two important tasks: First, foster a better understanding on the extent to which recent job displacements during the Covid-19 Pandemic affected different types of workers and on the underlying implications for society as a whole. For instance, did the division of tasks such as child care change within households? Did the reputation of female-dominated occupations such as care work improve as a result of the Covid-19 Pandemic? Did layoffs and short-time work increase the gap between rich and poor? Second, to understand better who is particularly affected from job displacement in recessions, it is crucial to understand how firms decide which workers to lay off first. While previous literature suggests that bad matches are laid-off first (e.g., Gibbons and Katz (1991)), there is so far little evidence on systematic differences by worker type. In follow-up projects connected to this thesis, I am already exploring some of these questions, applying similar empirical methods.

This thesis has contributed to the knowledge on labor market shocks and their economic consequences for workers and regions. Labor markets are dynamic, and shocks - such as the Covid-19 Pandemic - can happen quickly and without prior warning. With this thesis, I have filled research gaps both with respect to the effects of a labor market shock in the form of immigration, and with respect to heterogeneities in the costs of job displacement. While my results are interesting from the perspective of economic research per se, I hope that they can also help policy-makers in designing optimal responses to labor market shocks. 


\section{Bibliography}

Abadie, Alberto and Javier Gardeazabal, "The economic costs of conflict: A case study of the Basque Country," American Economic Review, 93 (1), (2003), 113132 .

Abowd, John M, Francis Kramarz, and David N Margolis, "High wage workers and high wage firms," Econometrica, 67 (2), (1999), 251-333.

Abramitzky, Ran, Leah Platt Boustan, and Katherine Eriksson, "A nation of immigrants: Assimilation and economic outcomes in the age of mass migration," Journal of Political Economy, 122 (3), (2014), 467-506.

Adams-Prassl, Abi, Teodora Boneva, Marta Golin, and Christopher Rauh, "Inequality in the impact of the coronavirus shock: Evidence from real time surveys," Journal of Public Economics, 189 (2020), 104-245.

Albanesi, Stefania and Claudia Olivetti, "Home production, market production and the gender wage gap: Incentives and expectations," Review of Economic dynamics, 12 (1), (2009), 80-107.

Albert, Christoph, Albrecht Glitz, and Joan Llull, "Labor Market Competition and the Assimilation of Immigrants," Technical Report, Universitat Autonoma de Barcelona: Mimeo (2020).

Albrecht, James, Mary Ann Bronson, Peter Skogman Thoursie, and Susan Vroman, "The career dynamics of high-skilled women and men: Evidence from Sweden," European Economic Review, 105 (2018), 83-102. 
Algan, Yann, Christian Dustmann, Albrecht Glitz, and Alan Manning, "The economic situation of first and second-generation immigrants in France, Germany and the United Kingdom," Economic Journal, 542 (120), (2010), F4-F30.

Alon, Titan, Matthias Doepke, Jane Olmstead-Rumsey, and Michèle Tertilt, "This time it's different: the role of women's employment in a pandemic recession," Working Paper No. w26947, NBER (2020).

Altonji, Joseph and Rebecca Blank, Race and gender in the labor market., Vol. 3.C, Handbook of Labor Economics, (1999).

Altonji, Joseph G and David Card, "The effects of immigration on the labor market outcomes of less-skilled natives," in "Immigration, trade, and the labor market," University of Chicago Press, (1991), pp. 201-234.

Angelov, Nikolay, Per Johansson, and Erica Lindahl, "Parenthood and the gender gap in pay," Journal of Labor Economics, 34 (3), (2016), 545-579.

Angrist, Joshua D and Adriana D Kugler, "Protective or counter-productive? Labour market institutions and the effect of immigration on natives," The Economic Journal, 113 (488), (2003), F302-F331.

Ashenfelter, Orley, "Estimating the effect of training programs on earnings," The Review of Economics and Statistics, 60 (1), (1978), 47-57.

Aydemir, Abdurrahman and George J Borjas, "Cross-country variation in the impact of international migration: Canada, Mexico, and the United States," Journal of the European Economic Association, 5 (4), (2007), 663-708.

Bachmann, Ronald, Daniel Baumgarten, and Joel Stiebale, "Foreign direct investment, heterogeneous workers and employment security: Evidence from Germany," Canadian Journal of Economics/Revue canadienne d'économique, 47 (3), (2014), 720-757.

Barbanchon, Thomas Le, Roland Rathelot, and Alexandra Roulet, "Gender Differences in Job Search: Trading off Commute Against Wage," The Quarterly Journal of Economics, 10 (2020). qjaa033. 
Batog, Cristina, Ernesto Crivelli, Ms Anna Ilyina, Zoltan Jakab, Mr Jaewoo Lee, Anvar Musayev, Iva Petrova, Mr Alasdair Scott, and Ms Anna Shabunina, Demographic Headwinds in Central and Eastern Europe, International Monetary Fund, (2019).

Battisti, Michele, Agnese Romiti, and Giovanni Peri, "Dynamic Effects of Co-Ethnic Networks on Immigrants' Economic Success," The Economic Journal, (forthcoming), (2021).

Beaman, L., "Social networks and the dynamics of labor market outcomes: Evidence from refugees resettled in the U.S.," Review of Economic Studies, 79 (1), (2012), $128-161$.

Becker, Gary S, "Investment in Human Capital: A Theoretical Analysis," Journal of Political Economy, 70 (5, Part 2), (1962), 9-49.

Beerli, Andreas, Jan Ruffner, Michael Siegenthaler, and Giovanni Peri, "The abolition of immigration restrictions and the performance of firms and workers: evidence from Switzerland," American Economic Review, 111 (3), (2021), 976-1012.

Bellmann, Lisa, Benjamin Lochner, Stefan Seth, and Stefanie Wolter, "AKM effects for German labour market data," Technical Report, Institut für Arbeitsmarktund Berufsforschung (IAB) (2020).

Bertrand, Marianne and Sendhil Mullainathan, "Are Emily and Greg more employable than Lakisha and Jamal? A field experiment on labor market discrimination," American Economic Review, 94 (4), (2004), 991-1013.

_ , Claudia Goldin, and Lawrence F Katz, "Dynamics of the gender gap for young professionals in the financial and corporate sectors," American economic journal: applied economics, 2 (3), (2010), 228-55.

Blanchard, Olivier Jean and Lawrence F Katz, "Regional Evolutions," Brookings Papers on Economic Activity, 23 (1), (1992), 1-61.

Blau, Francine D and Lawrence M Kahn, "Understanding international differences in the gender pay gap," Journal of Labor economics, 21 (1), (2003), 106-144. 
Blien, Uwe, Wolfgang Dauth, and Duncan Roth, "Occupational Routine Intensity and the Adjustment to Job Loss: Evidence from Mass Layoffs," Labour Economics, 68 (2020).

Blossfeld, Hans-Peter, "Labor-market entry and the sexual segregation of careers in the Federal Republic of Germany," American Journal of Sociology, 93 (1), (1987), 89-118.

Boelmann, Barbara, Anna Raute et al., "Wind of Change? Cultural Determinants of Maternal Labor Supply," Technical Report, Centre for Research and Analysis of Migration (CReAM) (2020).

Bonhomme, Stéphane, Thibaut Lamadon, and Elena Manresa, "A distributional framework for matched employer employee data," Econometrica, 87 (3), (2019), 699-739.

Borjas, George J, "Self-Selection and the Earnings of Immigrants," The American Economic Review, 77 (4), (1987), 531-553.

_, "Assimilation and changes in cohort quality revisited: what happened to immigrant earnings in the 1980s?," Journal of Labor Economics, 13 (2), (1995), 201-245.

_, "Does immigration grease the wheels of the labor market?," Brookings papers on economic activity, 2001 (1), (2001), 69-133.

_, "The labor demand curve is downward sloping: Reexamining the impact of immigration on the labor market," The Quarterly Journal of Economics, 118 (4), (2003), 1335-1374.

_, Immigration Economics, Harvard University Press, (2014).

_ , "The wage impact of the Marielitos: Additional evidence," Working Paper No. w21850, National Bureau of Economic Research (2016).

_ , "The wage impact of the Marielitos: A reappraisal," ILR Review, 70 (5), (2017), 1077-1110.

- and Hugh Cassidy, "The Adverse Effect of the COVID-19 Labor Market Shock on Immigrant Employment," Working Paper 27243, National Bureau of Economic Research (2020). 
Borrs, Linda and Johann Eppelsheimer, "The effects of foreign direct investment on job stability: Upgrades, downgrades, and separations," Working Paper No. 202024, Institut für Arbeitsmarkt-und Berufsforschung (IAB), Nürnberg (2020).

Bratsberg, Bernt, Andreas Moxnes, Oddbjørn Raaum, and Ulltveit-Moe KarenHelene, "Opening the Floodgates: Industry and Occupation Adjustments to Labor Immigration," Discussion Paper 13670, Centre for economic policy research (2019).

_ , Erling Barth, and OddbjÅrn Raaum, "Local Unemployment And The Relative Wages Of Immigrants: Evidence From The Current Population Surveys," The Review of Economics and Statistics, 88 (2), (2006), 243-263.

Bredtmann, Julia, Sebastian Otten, and Christian Rulff, "Husband's unemployment and wife's labor supply: the added worker effect across Europe," ILR Review, 71 (5), (2018), 1201-1231.

Brücker, Herbert, Albrecht Glitz, Adrian Lerche, and Agnese Romiti, "Occupational recognition and immigrant labor market outcomes," Journal of Labor Economics, 39 (2), (2021).

Bütikofer, Aline, Katrine V Løken, and Alexander Willén, "Building Bridges and Widening Gaps: Wage Gains and Equity Concerns of Labor Market Expansions," Technical Report, Norwegian School of Economics: Mimeo (2020).

Cadena, Brian and Brian Kovak, "Immigrants equilibrate local labor markets: Evidence from the Great Recession," American Economic Journal: Applied Economics, 8 (1), (2016), 257-290.

Caldwell, Syndee and Oren Danieli, "Outside options in the labor market," Technical Report, Unpublished manuscript (2021).

Calvo-Armengol, Antoni and Matthew Jackson, "The effects of social networks on employment and inequality," American Economic Review, 94 (3), (2004), 426-454.

Card, David, "The impact of the Mariel boatlift on the Miami labor market," ILR Review, 43 (2), (1990), 245-257.

_ , "Immigrant inflows, native outflows, and the local labor market impacts of higher immigration," Journal of Labor Economics, 19 (1), (2001), 22-64. 
_, Ana Rute Cardoso, and Patrick Kline, "Bargaining, sorting, and the gender wage gap: Quantifying the impact of firms on the relative pay of women," The Quarterly Journal of Economics, 131 (2), (2016), 633-686.

_ , Joerg Heining, and Patrick Kline, "Workplace heterogeneity and the rise of West German wage inequality," The Quarterly Journal of Economics, 128 (3), (2013), 967-1015.

Casey, Teresa, "Immigrants' identity, economic outcomes, and the transmission of identity across generations," Economic Journal, 120 (542), (2010), F31-F51.

- and Christian Dustmann, "Intergenerational transmission of language capital and economic outcomes," Journal of Human Resources, 43 (3), (2008), 299-324.

Chiappori, Pierre-Andre, Bernard Fortin, and Guy Lacroix, "Marriage market, divorce legislation, and household labor supply," Journal of political Economy, 110 (1), (2002), 37-72.

Clark, William AV and Anita I Drever, "Residential mobility in a constrained housing market: Implications for ethnic populations in Germany," Environment and Planning A, 32 (5), (2000), 833-846.

Clemens, Michael A and Jennifer Hunt, "The labor market effects of refugee waves: reconciling conflicting results," ILR Review, 72 (4), (2019), 818-857.

Cohen-Goldner, Sarit and M Daniele Paserman, "Mass migration to Israel and natives' employment transitions," ILR Review, 59 (4), (2006), 630-652.

_ and _ , "The dynamic impact of immigration on natives' labor market outcomes: Evidence from Israel," European Economic Review, 55 (8), (2011), 1027-1045.

Couch, Kenneth A and Dana W Placzek, "Earnings losses of displaced workers revisited," American Economic Review, 100 (1), (2010), 572-89.

_, Robert W Fairlie, and Huanan Xu, "Early evidence of the impacts of COVID-19 on minority unemployment," Journal of Public Economics, 192 (2020), 104-287.

Crossley, Thomas F, Stephen RG Jones, and Peter Kuhn, "Gender differences in displacement cost: evidence and implications," Journal of Human Resources, (1994), $461-480$. 
Dauth, Wolfgang and Johann Eppelsheimer, "Preparing the Sample of Integrated Labour Market Biographies (SIAB) for Scientific Analysis: A Guide," Journal for Labour Market Research, 54 (1), (2020), 1-14.

Davis, Steven and Till von Wachter, "Recessions and the Costs of Job Loss.," Brookings papers on economic activity, 2011 (2), (2011), 1-72.

Destatis, "Population with a migrant background up 2.1 percent in 2019," Technical Report, German Federal Statistical Office (2020).

DiNardo, John, Nicole Fortin, and Thomas Lemieux, "Labor Market Institutions and the Distribution of Wages, 1973-1992: A Semiparametric Approach," Econometrica, 64 (5), (1996), 1001-1044.

Dustmann, Christian, "Return migration, investment in children, and intergenerational mobility: Comparing sons of foreign- and native-born fathers," Journal of Human Resources, 2 (43), (2008), 299-324.

- and Tommaso Frattini, "The fiscal effects of immigration to the UK," The Economic Journal, 124 (580), (2014), F593-F643.

_, Johannes Ludsteck, and Uta Schönberg, "Revisiting the German wage structure," The Quarterly Journal of Economics, 124 (2), (2009), 843-881.

_ , Tommaso Frattini, and Anna Rosso, "The effect of emigration from Poland on Polish wages," The Scandinavian Journal of Economics, 117 (2), (2015), 522-564.

_ , _ , and Caroline Halls, "Assessing the Fiscal Costs and Benefits of A8 Migration to the UK," Fiscal Studies, 31 (1), (2010), 1-41.

_ , _, and Gianandrea Lanzara, "Educational achievement of second-generation immigrants: An international comparison," Economic Policy, 27 (69), (2012), 143-185.

_, _, and Ian P Preston, "The effect of immigration along the distribution of wages," Review of Economic Studies, 80 (1), (2013), 145-173.

_, Uta Schönberg, and Jan Stuhler, "Labor supply shocks, native wages, and the adjustment of local employment," The Quarterly Journal of Economics, 132 (1), (2017), 435-483. 
Eberle, Johanna and Alexandra Schmucker, "The Establishment History PanelRedesign and Update 2016," Jahrbücher für Nationalökonomie und Statistik, 237 (6), (2017), 535-547.

Edin, Per-Anders, Peter Fredriksson, and Olof Åslund, "Ethnic enclaves and the economic success of immigrants -Evidence from a natural experiment," The Quarterly Journal of Economics, 118 (1), (2003), 329-357.

Edo, Anthony, "The impact of immigration on the labor market," Journal of Economic Surveys, 33 (3), (2019), 922-948.

_ , Lionel Ragot, Hillel Rapoport, Sulin Sardoschau, Andreas Steinmayr, and Arthur Sweetman, "An introduction to the economics of immigration in OECD countries," Canadian Journal of Economics/Revue canadienne d'économique, 53 (4), (2020), 1365-1403.

Elsner, Benjamin, "Does emigration benefit the stayers? Evidence from EU enlargement," Journal of Population Economics, 26 (2), (2013), 531-553.

Fernández, Raquel, Alessandra Fogli, and Claudia Olivetti, "Mothers and sons: Preference formation and female labor force dynamics," The Quarterly Journal of Economics, 119 (4), (2004), 1249-1299.

Fitzenberger, Bernd, Aderonke Osikominu, Robert Völter et al., "Imputation Rules to Improve the Education Variable in the IAB Employment Subsample," Schmollers Jahrbuch: Journal of Applied Social Science Studies/Zeitschrift für Wirtschafts-und Sozialwissenschaften, 126 (3), (2006), 405-436.

_ and Arnim Seidlitz, "The 2011 break in the part-time indicator and the evolution of wage inequality in Germany," Journal for Labour Market Research, 54 (1), January (2020).

Foged, Mette and Giovanni Peri, "Immigrants' effect on native workers: New analysis on longitudinal data," American Economic Journal: Applied Economics, 8 (2), (2016), 1-34.

_ , Linea Hasager, and Vasil I Yasenov, "The Role of Labor Market Institutions in the Impact of Immigration on Wages and Employment," Scandinavian Journal of Economics, (2021). 
Freeman, R. B., R. A. Gordon, D. Bell, and R. E. Hall, "Changes in the labor market for black Americans, 1948-72," Brookings Papers on Economic Activity, (1), (1973), 67-131.

Friedberg, Rachel M, "You can't take it with you? Immigrant assimilation and the portability of human capital," Journal of Labor Economics, 18 (2), (2000), $221-251$.

_ , "The impact of mass migration on the Israeli labor market," The Quarterly Journal of Economics, 116 (4), (2001), 1373-1408.

Galiani, Sebastian and Brian Quistorff, "The synth_runner package: Utilities to automate synthetic control estimation using synth," The Stata Journal, 17 (4), (2017), 834-849.

Gang, Ira and Klaus Zimmermann, "Is child like parent? Educational attainment and ethnic origin," Journal of Human Resources, 35 (3), (2000), 550-569.

Gartner, Hermann, "The imputation of wages above the contribution limit with the German IAB employment sample," FDZ Methodenreport, 2 (2005), (2005).

Gërxhani, Klarita and Yuliya Kosyakova, "The Effect of Social Networks on Migrants' Labor Market Integration: A Natural Experiment," Working Paper No. 3/2020, Institute for Employment Research (IAB) (2020).

Gibbons, Robert and Lawrence F Katz, "Layoffs and lemons," Journal of Labor Economics, 9 (4), (1991), 351-380.

Glitz, Albrecht, "The labor market impact of immigration: A quasi-experiment exploiting immigrant location rules in Germany," Journal of Labor Economics, 30 (1), (2012), 175-213.

_ , "Coworker networks in the labour market," Labour Economics, 44 (2017), 218230 .

Goldin, Claudia, "A grand gender convergence: Its last chapter," American Economic Review, 104 (4), (2014), 1091-1119.

_ , Sari Pekkala Kerr, Claudia Olivetti, and Erling Barth, "The expanding gender earnings gap: Evidence from the LEHD-2000 Census," American Economic Review, 107 (5), (2017), 110-14. 
Goldschmidt, Deborah, Wolfram Klosterhuber, and Johannes F Schmieder, "Identifying couples in administrative data," Journal for Labour Market Research, 50 (1), (2017), 29-43.

Gudgeon, Matthew and Simon Trenkle, "The Speed of Earnings Responses to Taxation and the Role of Firm Labor Demand," Mimeo, (2019).

Gunnsteinsson, Snaebjorn and Herdis Steingrimsdottir, "The Long-Term Impact of Children's Disabilities on Families," Technical Report, Working paper (2019).

Hafner, Flavio, "Labor Market Competition, Wages and Worker Mobility," Technical Report, Aalto University School of Business: Mimeo (2020).

Halla, Martin, Julia Schmieder, and Andrea Weber, "Job Displacement, Family Dynamics, and Spousal Labor Supply," American Economic Journal: Applied Economics, 12 (4), October (2020), 253-87.

Haller, Peter and Daniel F Heuermann, "Opportunities and Competition in Thick Labor Markets: Evidence from Plant Closures," Regional Science, 60 (2), (2019), 273-295.

Hardoy, Inés and Pål Schøne, "Does the impact of plant closure on labour market attachment differ between immigrants and native workers across the business cycle?," Empirical Economics, 46 (1), (2014), 229-252.

Helm, Ines, Alice Kügler, and Uta Schönberg, "Displacement Effects in Manufacturing," Technical Report, University College London: Mimeo (2021).

Hethey-Maier, Tanja and Johannes F Schmieder, "Does the Use of Worker Flows Improve the Analysis of Establishment Turnover? Evidence from German Administrative Data," Schmollers Jahrbuch, 133 (4), (2013), 477-510.

Hildreth, Andrew, Elizabeth Weber-Handwerker, and Till von Wachter, "Estimating the 'True' Cost of Job Loss: Evidence Using Matched Data from California 19912000," Working Paper CES-WP-09-14, US Census Bureau Center for Economic Studies (2009).

Hirsch, Boris and Claus Schnabel, "What can we Learn from Bargaining Models about Union Power? The Decline in Union Power in G ermany, 1992-2009," The Manchester School, 82 (3), (2014), 347-362. 
Holland, Dawn, Tatiana Fic, Ana Rincon-Aznar, Lucy Stokes, and Paweł Paluchowski, "Labour mobility within the EU-The impact of enlargement and the functioning of the transitional arrangements," National Institute of Economic and Social Research, 2978 (2011).

Hotz, V Joseph, Guido W Imbens, and Julie H Mortimer, "Predicting the efficacy of future training programs using past experiences at other locations," Journal of Econometrics, 125 (1-2), (2005), 241-270.

Hoynes, Hilary, Douglas Miller, and Jessamyn Schaller, "Who suffers during recessions?," Journal of Economic Perspectives, 3 (26), (2012), 27-48.

Huber, Katrin and Erwin Winkler, "All you need is love? Trade shocks, inequality, and risk sharing between partners," European Economic Review, 111 (2019), 305335.

Huttunen, Kristiina and Jenni Kellokumpu, "The effect of job displacement on couples' fertility decisions," Journal of Labor Economics, 34 (2), (2016), 403-442.

_ , Jarle Møen, and Kjell G Salvanes, "Job loss and regional mobility," Journal of Labor Economics, 36 (2), (2018), 479-509.

Jacobson, Louis S, Robert J LaLonde, and Daniel G Sullivan, "Earnings losses of displaced workers," The American Economic Review, 83 (4), (1993), 685-709.

Jovanovic, Boyan, "Job matching and the theory of turnover," Journal of Political Economy, 87 (5, Part 1), (1979), 972-990.

Kahanec, Martin and Mariola Pytliková, "The economic impact of east-west migration on the European Union," Empirica, 44 (3), (2017), 407-434.

Kahn, Lisa, "The long-term labor market consequences of graduating from college in a bad economy.," Labour Economics, 17 (2), (2010), 303-316.

Kerr, Sari Pekkala, William R Kerr, and William F Lincoln, "Skilled immigration and the employment structures of US firms," Journal of Labor Economics, 33 (S1), (2015), S147-S186.

Kleven, Henrik, Camille Landais, and Jakob Egholt Søgaard, "Children and gender inequality: Evidence from Denmark," American Economic Journal: Applied Economics, 11 (4), (2019), 181-209. 
_ , _ , Johanna Posch, Andreas Steinhauer, and Josef Zweimüller, "Child penalties across countries: Evidence and explanations," AEA Papers and Proceedings, 109 (2019), 122-26.

Kline, Patrick, Raffaele Saggio, and Mikkel Sølvsten, "Leave-out estimation of variance components," Econometrica, 88 (5), (2020), 1859-1898.

Kondo, Ayako, "Differential effects of graduating during a recession across gender and race.," Journal of Labor Economics, 4 (1), (2015), 1-24.

Körner, Konstantin, Michael Moritz, and Johannes Schäffler, "FDI and Onshore Employment Dynamics: Evidence from German Firms with Affiliates in the Czech Republic," Working Paper No. 9/2021, Institut für Arbeitsmarkt-und Berufsforschung (IAB), Nürnberg (2021).

Kuhn, Moritz, Benjamin Hartung, and Philip Jung, "What hides behind the German labor market miracle? Unemployment insurance reforms and labor market dynamics," Technical Report, University of Bonn: Mimeo (2020).

Kunze, Astrid and Kenneth R Troske, "Gender differences in job search among young workers: a study using displaced workers in the United States," Southern Economic Journal, 82 (1), (2015), 185-207.

Kuziemko, Ilyana, Jessica Pan, Jenny Shen, and Ebonya Washington, "The Mommy Effect: Do Women Anticipate the Employment Effects of Motherhood?," Technical Report, National Bureau of Economic Research (2018).

Lachowska, Marta, Alexandre Mas, and Stephen A Woodbury, "Sources of displaced workers' long-term earnings losses," American Economic Review, 110 (10), (2020), $3231-66$.

Lafortune, Jeanna, Ethan Lewis, and Jose Tassada, "People and Machines: A Look at The Evolving Relationship between Capital and Skill in Manufacturing, 18601930, Using Immigration Shocks," Review of Economics and Statistics, 101 (1), (2019), 30-43.

Lazear, Edward, "Why is there mandatory retirement?," Journal of Political Economy, 87 (6), (1979), 1261-1284. 
Lazear, Edward P, "Agency, earnings profiles, productivity, and hours restrictions," The American Economic Review, 71 (4), (1981), 606-620.

Lundberg, Shelly, "The added worker effect," Journal of Labor Economics, 3 (1, Part 1), (1985), 11-37.

Manacorda, Marco, Alan Manning, and Jonathan Wadsworth, "The impact of immigration on the structure of wages: theory and evidence from Britain," Journal of the European Economic Association, 10 (1), (2012), 120-151.

Meekes, Jordy and Wolter HJ Hassink, "Fired and pregnant: Gender Differences in Job Flexibility Outcomes after Job Loss," Working Paper 13779, Institute of Labor Economics (IZA) (2020).

Mincer, Jacob, "On-the-job training: Costs, returns, and some implications," Journal of Political Economy, 70 (5, Part 2), (1962), 50-79.

_ and Solomon Polachek, "Family investments in human capital: Earnings of women," Journal of political Economy, 82 (2, Part 2), (1974), S76-S108.

Montenovo, L., X. Jiang, F. L. Rojas, I. M. Schmutte, K. I. Simon, B. A. Weinberg, and C. Wing, "Determinants of disparities in COVID-19 job losses," Working Paper 27132, National Bureau of Economic Research (2020).

Moritz, Michael, "The Impact of Czech Commuters on the German Labour Market," Prague Economic Papers, 2011 (1), (2011), 40-58.

Müller, Dana, Katharina Strauch et al., "Identifying mothers in administrative data," FDZ-Methodenreport, 13 (2017), 2017.

Munshi, K., "Networks in the modern economy: Mexican migrants in the U.S. labor market," The Quarterly Journal of Economics, 118 (2), (2003), 549-599.

Olivetti, Claudia and Barbara Petrongolo, "Unequal pay or unequal employment? A cross-country analysis of gender gaps," Journal of Labor Economics, 26 (4), (2008), 621-654.

Ottaviano, Gianmarco IP and Giovanni Peri, "Rethinking the effect of immigration on wages," Journal of the European Economic Association, 10 (1), (2012), 152197. 
Peri, Giovanni and Chad Sparber, "Task specialization, immigration, and wages," American Economic Journal: Applied Economics, 1 (3), (2009), 135-69.

- and Vasil Yasenov, "The labor market effects of a refugee wave synthetic control method meets the mariel boatlift," Journal of Human Resources, 54 (2), (2019), 267-309.

Riphahn, Regina, "Cohort effects in the educational attainment of second generation immigrants in Germany: An analysis of census data," Journal of Population Economics, 16 (4), (2003), 711-37.

Schaller, Jessamyn and Ann Huff Stevens, "Short-run effects of job loss on health conditions, health insurance, and health care utilization," Journal of Health Economics, 43 (2015), 190-203.

Schmieder, Johannes, Till von Wachter, and Joerg Heining, "The costs of job displacement over the business cycle and its sources: evidence from Germany," Technical Report, Boston University: Mimeo (2020).

Schmieder, Julia and Andrea Weber, "How did EU Eastern enlargement affect migrant labor supply in Austria?," Focus on European Economic Integration, 3 (2018), 113-121.

Signorelli, Sara, "Do Skilled Migrants Compete with Native Workers? Analysis of a Selective Immigration Policy," Technical Report, Paris School of Economics (2020).

Škuflić, Lorena and Valentina Vučković, "The effect of emigration on unemployment rates: the case of EU emigrant countries," Economic research-Ekonomska istraživanja, 31 (1), (2018), 1826-1836.

Solon, Gary, "Intergenerational Mobility in the Labor Market.," Handbook of Labor Economics,, 3 A (1999), 1761-1800.

Song, Jae, David Price, Fatih Guvenen, Nicholas Bloom, and Till von Wachter, "Firming Up Inequality," The Quarterly Journal of Economics, 134 (1), (2019), $1-50$. 
Speer, Jamin, "Wages, hours, and the school-to-work transition: The consequences of leaving school in a recession for less-educated men.," The BE Journal of Economic Analysis and Policy, 16 (1), (2016), 97-124.

Statistisches Bundesamt (Destatis), "Genesis-Online," (2020). Datenlizenz by-2-0, https://www.govdata.de/dl-de/by-2-0.

Sullivan, Daniel and Till Von Wachter, "Job displacement and mortality: an analysis using administrative data," The Quarterly Journal of Economics, 124 (3), (2009), $1265-1306$.

Tazhitdinova, Alisa, "Do only tax incentives matter? Labor supply and demand responses to an unusually large and salient tax break," Journal of Public Economics, 184 (2020), 104162.

von Wachter, Till, Jae Song, and Joyce Manchester, "Long-term earnings losses due to mass layoffs during the 1982 recession: An analysis using US administrative data from 1974 to 2004," Unpublished paper, Columbia University (2011).

Woodcock, Simon D, "Match effects," Research in Economics, 69 (1), (2015), 100121.

Zaiceva, Anzelika and Klaus F Zimmermann, "Scale, diversity, and determinants of labour migration in Europe," Oxford Review of Economic Policy, 24 (3), (2008), $427-451$. 


\section{Appendix: Chapter 2}

Appendix Chapter 2: Figures 
Figure A.2.1: Migrant Worker Inflow to German Municipalities by Distance

(A) Inflow of Czech Workers by Distance to the Border

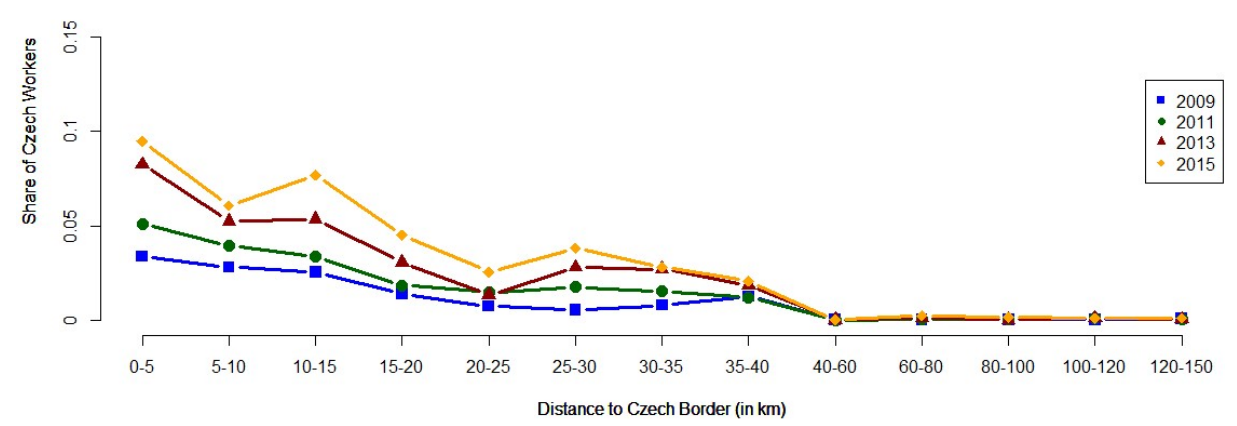

(B) Inflow of EU8 Workers by Distance to the Border

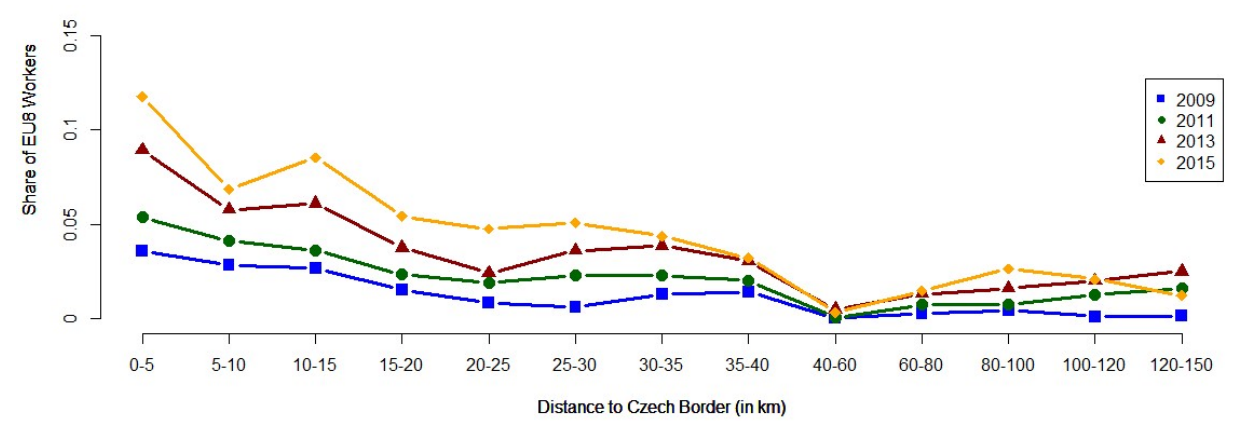

Notes: This figure shows how the inflow of Czech/EU8 workers changed with airline distance in $\mathrm{km}$ from the nearest road border crossing to the Czech Republic. Different colors/symbols present different years before and after the policy change. The closer a municipality is located to the border region, the higher is the increase in the share of Czech/EU8 workers in 2009-2015. 15\% sample of German social security data, not restricted to matched municipalities but to all municipalities located up to $150 \mathrm{~km}$ from the nearest border crossing. West Germany only. Source: Integrated Employment Biographies (IEB), aggregated on municipality level. 
Figure A.2.2: Synthetic Control Group Matching as Robustness Check for the Czech Republic

(A) Unemployment Rate

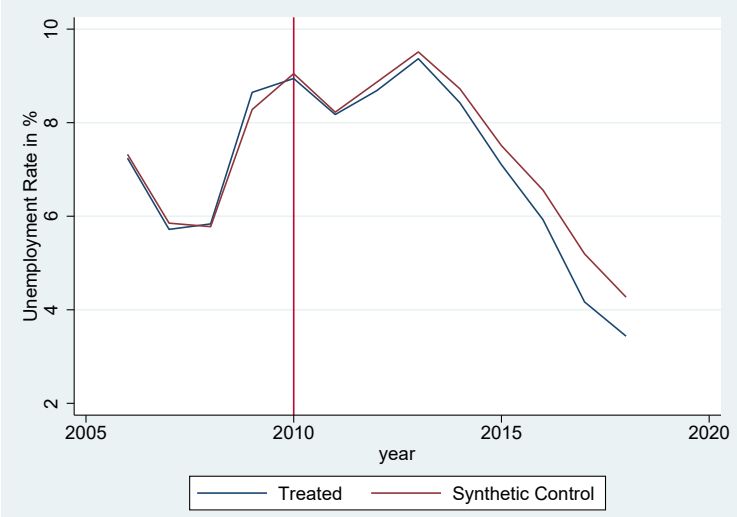

(C) Unemployment Rate - Women

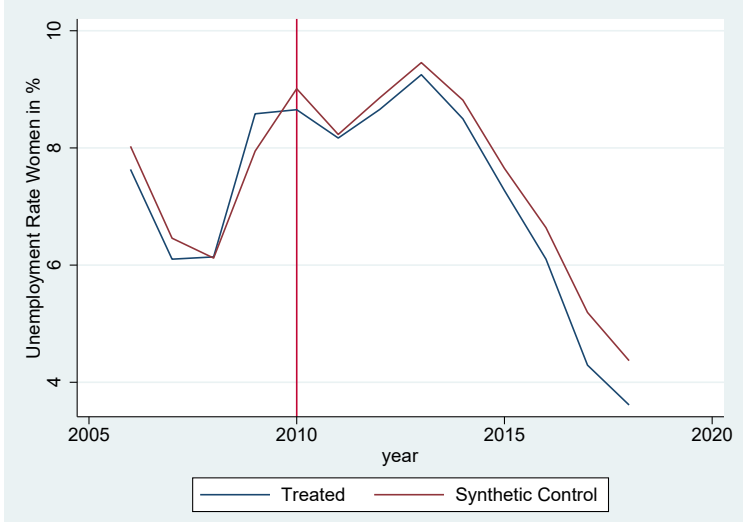

(B) Vacancies

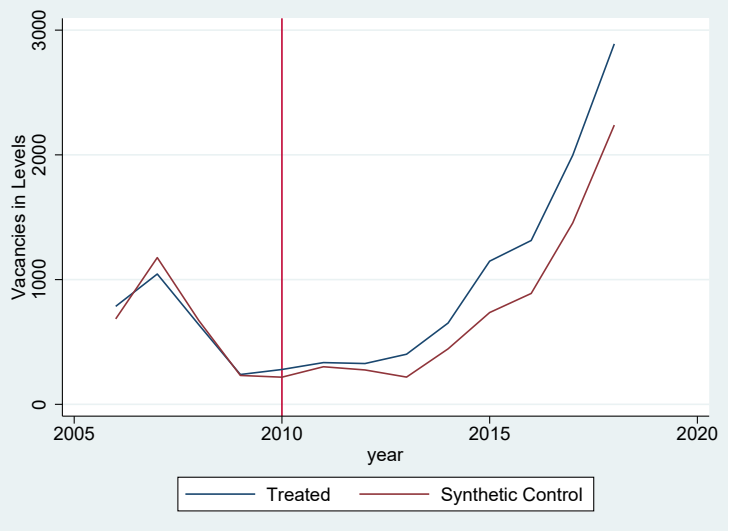

(D) Unemployment Rate - Men

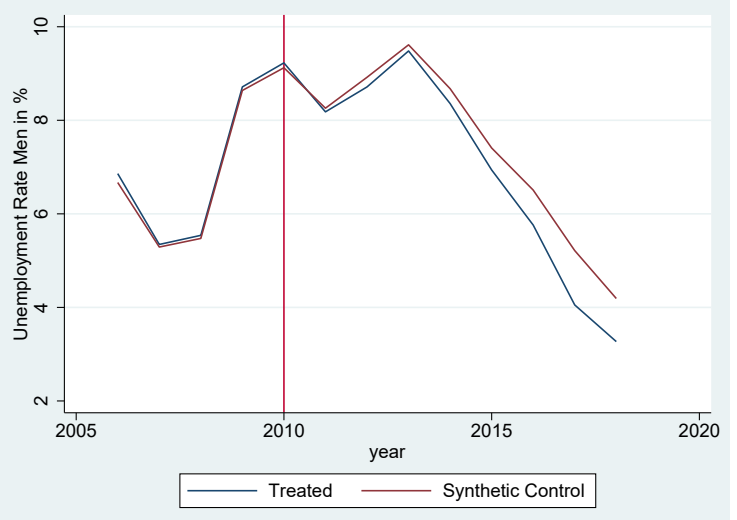

Notes: This figure uses synthetic control group matching to show how unemployment rate and vacancies differ between Czech border counties and the synthetic control group. Panel (A) reports results for the unemployment rate, Panel (B) reports results for vacancies, Panel (C) reports results for women's unemployment rate, Panel (D) reports results for men's unemployment rate. Vacancies reports number of vacancies reported at the employment offices on December 31 in a given year. Treated counties are all counties bordering either Germany or Austria. Control variables (all measured in 2010) are: Population size, the share of population aged 15-64, the share of firms in the manufacturing sector, the share of firms in agriculture, unemployment rates, vacancies. Source: Czech Statistical Office. 
Figure A.2.3: Synthetic Control Group Matching as Robustness Check for Germany

(A) Native Employment in German Municipalities

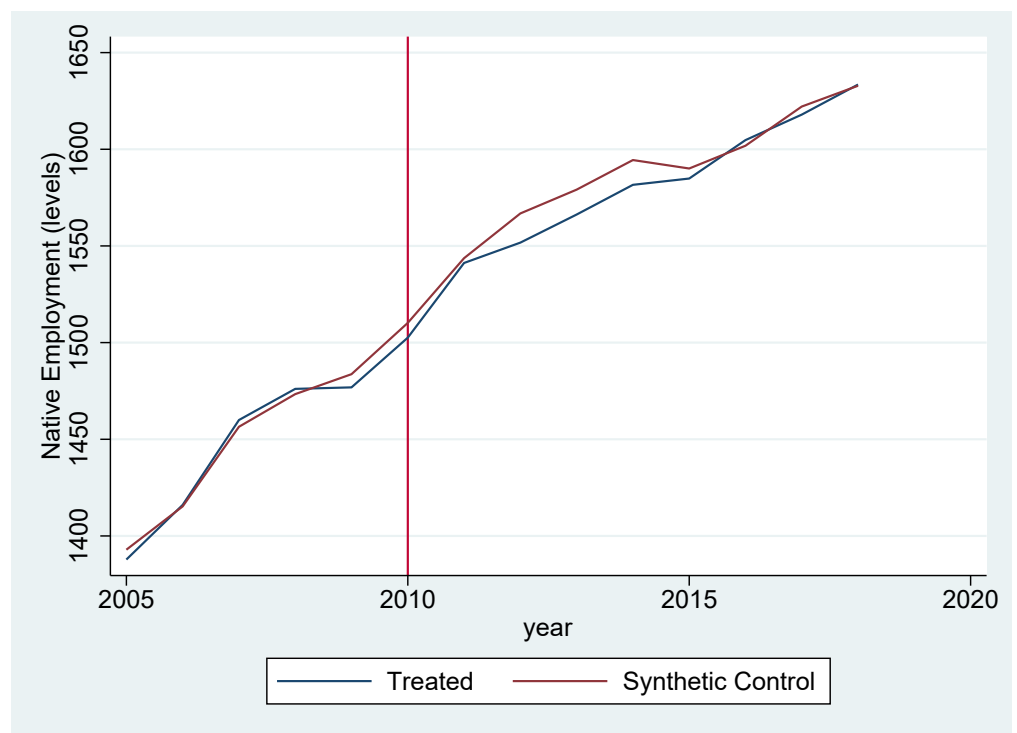

(B) Native Log Wage in German Municipalities

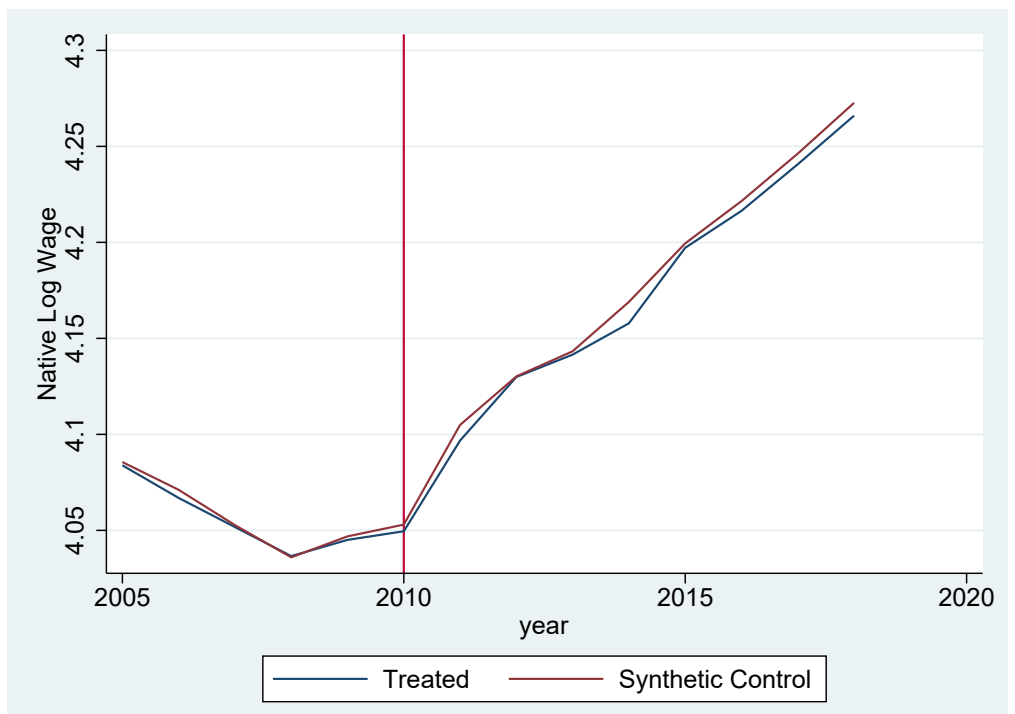

Notes: This figure uses synthetic control group matching to show how native employment and native $\log$ wages differ between German border municipalities and the synthetic control group. Panel (A) reports the share of native employment by 2010 employment, Panel (B) reports log native wages. Treated municipalities are all municipalities located up to $40 \mathrm{~km}$ from the nearest road border crossing to the Czech Republic. Control variables are: Share of workers in 3 skill groups (2010), share of foreign workers (2010), number of workers (2010), rural regions (2010), share of workers in two age groups (2010), share of female workers (2010), share of manufacturing firms (2010), share of service firms (2010), growth in EU employment in 2004-2010, log wage (2008, 2009, 2010). West Germany only. Source: Establishment History Panel (BHP). 
Figure A.2.4: Migrant Worker Inflow to East German Municipalities - Eventstudy Coefficients

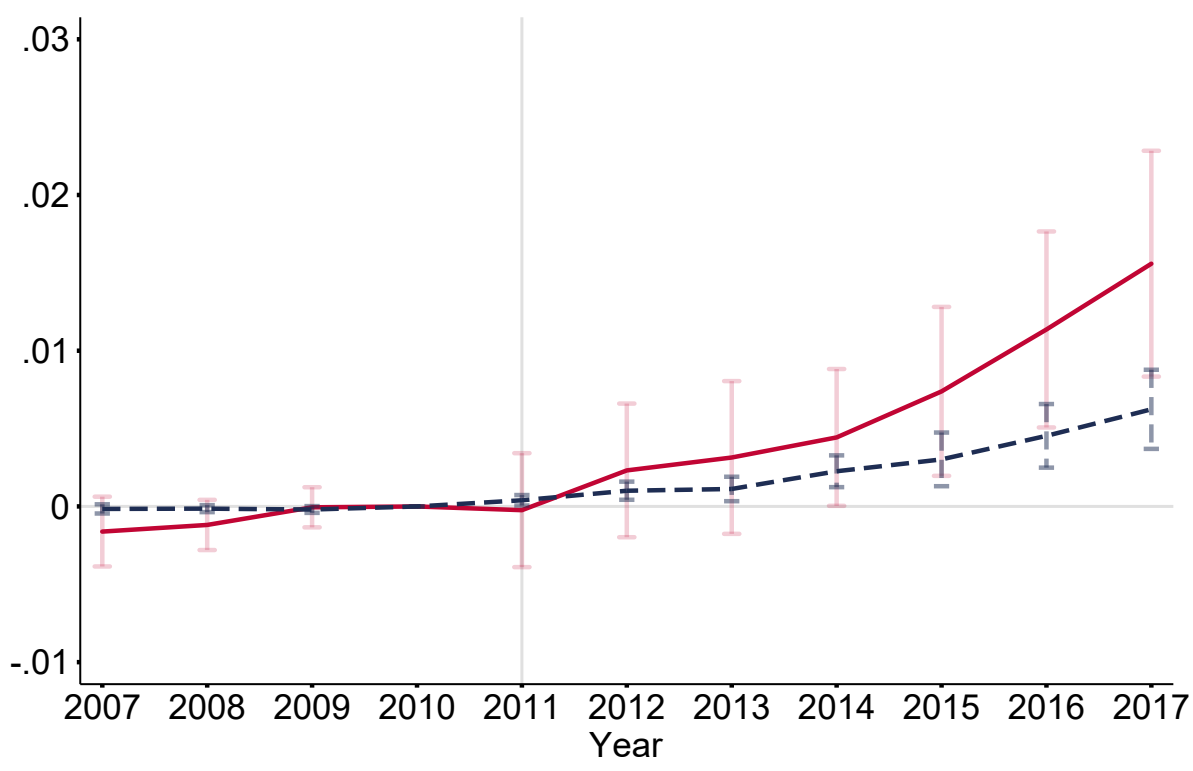

Share EU8 Workers

Share Czech Workers

Notes: This figure shows size and nature of the inflow of Czech workers to the East German border region induced by the opening of the German labor market in 2011. Panel (A) shows the raw means in the share of Czech/EU8 workers by total employment for German treated (blue lines) and control (red lines) municipalities, respectively. Panel (B) reports event study coefficients $\beta_{t}$ from Equation 2.1 which measure the differential effect in treated vs. control municipalities. Treated municipalities are all municipalities located up to $40 \mathrm{~km}$ from the nearest road border crossing to the Czech Republic or Poland (measured by airline distance from municipality centroid). East Germany only. Data are aggregated at the municipality level. 95-\% confidence intervals reported. Source: Integrated Employment Biographies (IEB). 
Figure A.2.5: Native Wages and Employment in East Germany - Municipality Level

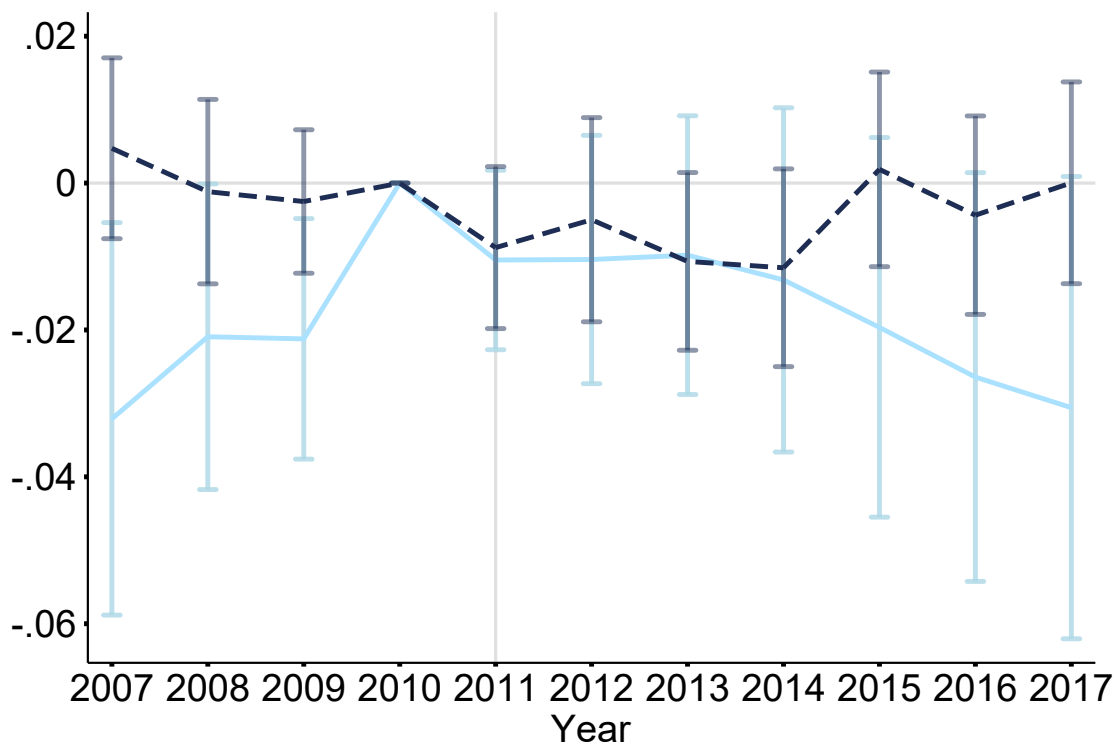

\section{Native Employment ----- Log Native Wage}

Notes: This figure shows the impact of the opening of the German labor market for EU8 workers in 2011 on native wages and employment in East Germany. The y-axis reports event study coefficients $\beta_{t}$ from Equation 2.1 which measure the differential effect in treated vs. control municipalities. Treated municipalities are all municipalities located up to $40 \mathrm{~km}$ from the nearest road border crossing to the Czech Republic or Poland (measured by airline distance from municipality centroid). Wages are measured in logs and deflated with 2010 as base year. Native employment is defined as the share of native employment by native employment in 2010. Data are aggregated at the municipality level. 95-\% confidence intervals reported. East Germany only. Source: Establishment History Panel (BHP). 
Figure A.2.6: Synthetic Control Group Matching as Robustness Check for East Germany

(A) Native Employment in German Municipalities

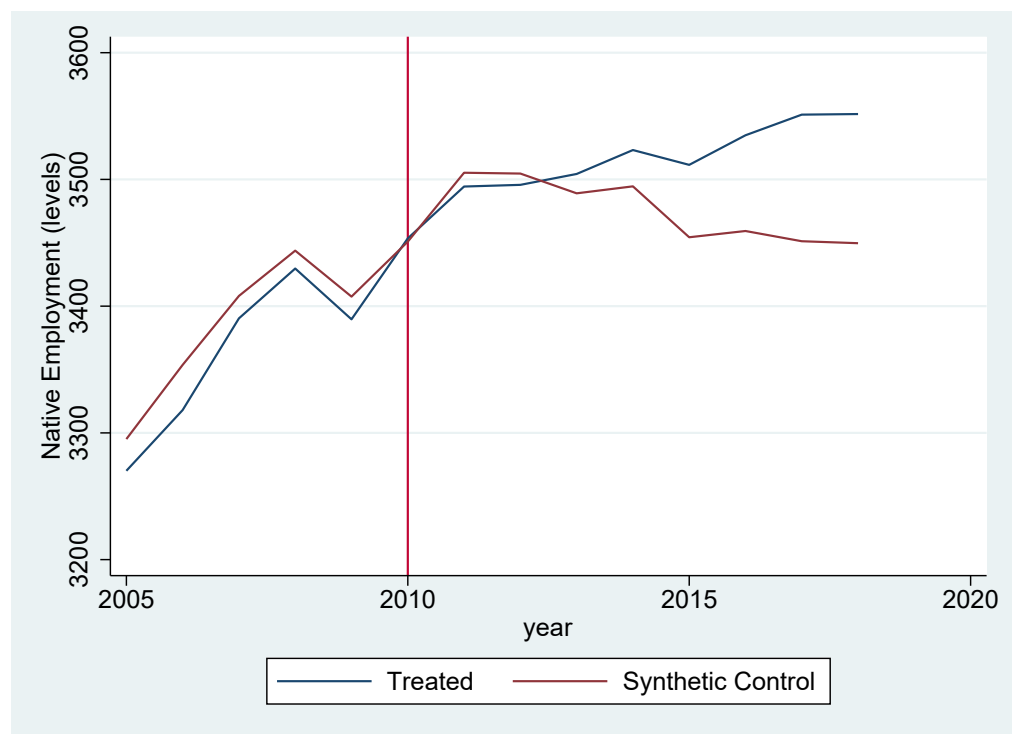

(B) Native Log Wage in German Municipalities

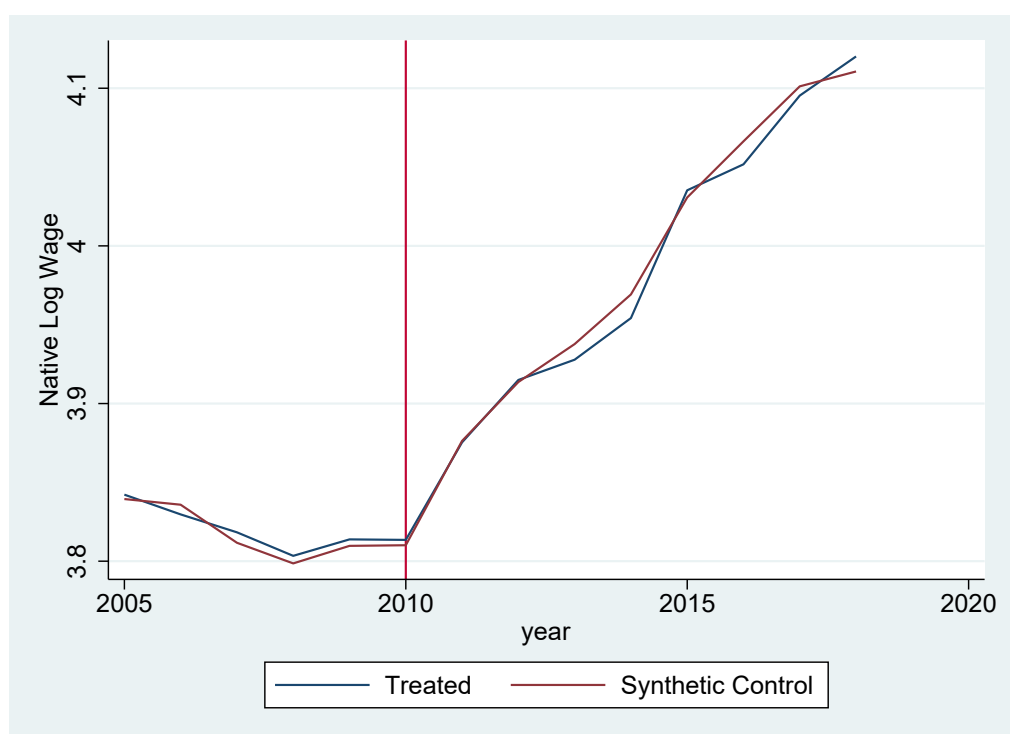

Notes: This figure uses synthetic control group matching to show how native employment and native log wages differ between East German border municipalities and the synthetic control group. Panel (A) reports the share of native employment by 2010 employment, Panel (B) reports log native wages. Treated municipalities are all municipalities located up to $40 \mathrm{~km}$ from the nearest road border crossing to the Czech Republic or Poland. Control variables are: Share of workers in 3 skill groups (2010), share of foreign workers (2010), number of workers (2010), rural regions (2010), share of workers in two age groups (2010), share of female workers (2010), share of manufacturing firms (2010), share of service firms (2010), growth in EU employment in 2004-2010, log wage (2008, 2009, 2010). East Germany only. Source: Establishment History Panel (BHP). 
Figure A.2.7: Czech Worker Inflow to German Municipalities by Distance (in km)

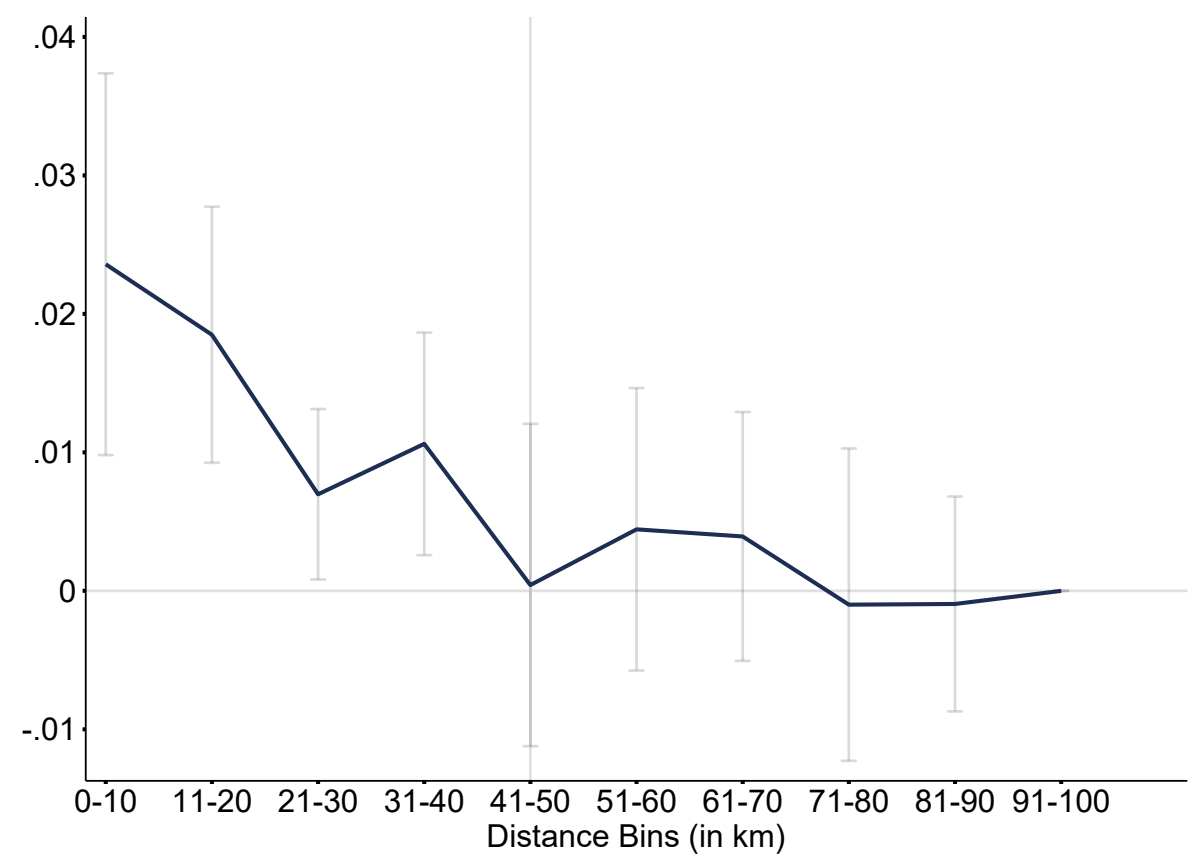

Notes: This figure shows regression coefficients on the inflow of Czech workers by airline distance in $\mathrm{km}$ from the nearest road border crossing to the Czech Republic. I regress the outcome variable (pooled over 2011-2017) on dummies for 9 distance bin categories, and I omit municipalities located in the distance bin $90-100 \mathrm{~km}$. The regression includes year and municipality FE, and I cluster standard errors at the municipality level. $15 \%$ sample of German social security data, not restricted to matched municipalities but to all municipalities located up to $100 \mathrm{~km}$ from the nearest border crossing. West Germany only. Source: Integrated Employment Biographies (IEB), aggregated on municipality level. 
Figure A.2.8: Native Wages and Employment in German Municipalities by Distance

(A) Native Employment by 2010 Employment by Distance to the Border

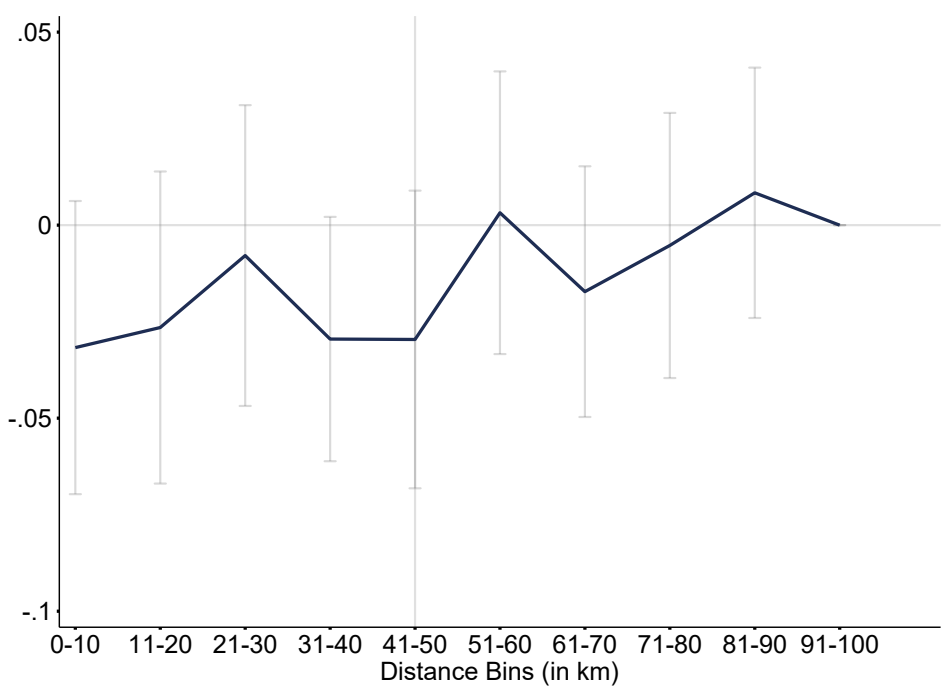

(B) Log Native Wage by Distance to the Border

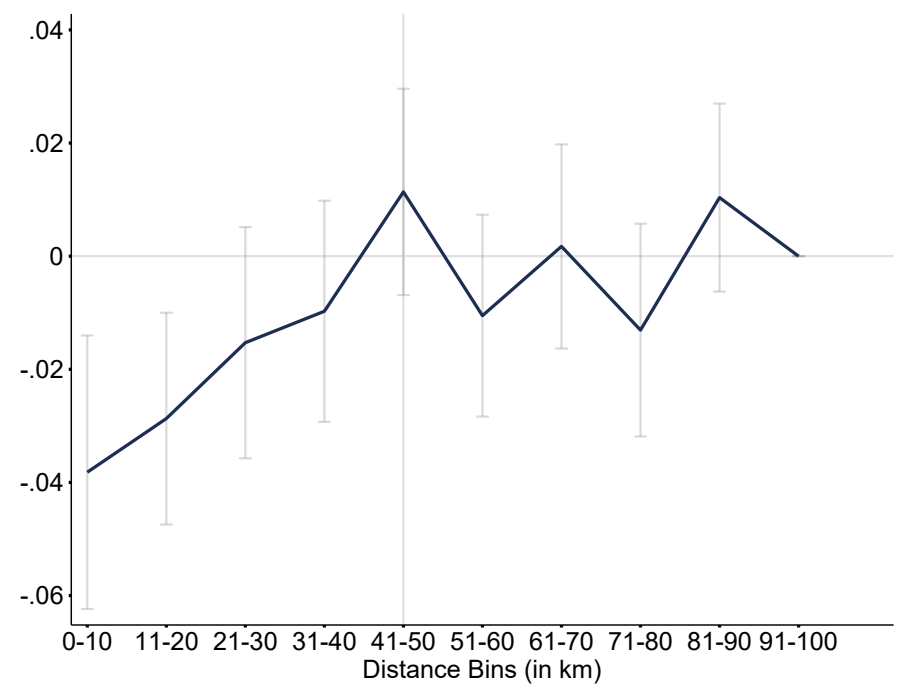

Notes: This figure shows regression coefficients on native employment (Panel (A)) and log native wages (Panel (B)) by airline distance in $\mathrm{km}$ from the nearest road border crossing to the Czech Republic. I regress the outcome variable (pooled over 2011-2017) on dummies for 9 distance bin categories, and I omit municipalities located in the distance bin $90-100 \mathrm{~km}$. The regression includes year FE, and I cluster standard errors at the municipality level. 15\% sample of German social security data, not restricted to matched municipalities but to all municipalities located up to $100 \mathrm{~km}$ from the nearest border crossing. West Germany only. Source: Integrated Employment Biographies (IEB), aggregated on municipality level. 
Chapter 2: Tables 
Table A.2.1: Sorting into Industries by Czech vs. German Workers

\begin{tabular}{|c|c|c|}
\hline & $\begin{array}{c}(1) \\
\text { Natives } \\
2010\end{array}$ & $\begin{array}{c}(2) \\
\text { Czechs } \\
2012\end{array}$ \\
\hline Agriculture & $\begin{array}{c}0.63 \\
{[7.94]}\end{array}$ & $\begin{array}{c}1.81 \\
{[13.4]}\end{array}$ \\
\hline Mining, Energy & $\begin{array}{c}0.75 \\
{[8.63]}\end{array}$ & $\begin{array}{c}0.64 \\
{[7.95]}\end{array}$ \\
\hline Food Manufacturing & $\begin{array}{c}3.74 \\
{[19.0]}\end{array}$ & $\begin{array}{c}5.35 \\
{[22.5]}\end{array}$ \\
\hline Consumption Goods & $\begin{array}{c}4.62 \\
{[21.0]}\end{array}$ & $\begin{array}{c}1.36 \\
{[11.6]}\end{array}$ \\
\hline Production Goods & $\begin{array}{l}8.65 \\
{[28.1]}\end{array}$ & $\begin{array}{c}10.2 \\
{[30.2]}\end{array}$ \\
\hline Investment Goods & $\begin{array}{c}12.4 \\
{[33.0]}\end{array}$ & $\begin{array}{c}17.6 \\
{[38.1]}\end{array}$ \\
\hline Construction & $\begin{array}{c}6.54 \\
{[24.7]}\end{array}$ & $\begin{array}{c}9.53 \\
{[29.4]}\end{array}$ \\
\hline Retail & $\begin{array}{c}15.5 \\
{[36.2]}\end{array}$ & $\begin{array}{c}6.81 \\
{[25.2]}\end{array}$ \\
\hline Traffic, Telecommunication & $\begin{array}{c}4.53 \\
{[20.8]}\end{array}$ & $\begin{array}{c}6.72 \\
{[25.0]}\end{array}$ \\
\hline Credit, Insurance & $\begin{array}{c}2.52 \\
{[15.7}\end{array}$ & $\begin{array}{l}0.091 \\
{[3.01]}\end{array}$ \\
\hline Restaurants & $\begin{array}{c}4.69 \\
{[21.1]}\end{array}$ & $\begin{array}{c}17.8 \\
{[38.3]}\end{array}$ \\
\hline Education & $\begin{array}{c}3.21 \\
{[17.6]}\end{array}$ & $\begin{array}{c}0.45 \\
{[6.72]}\end{array}$ \\
\hline Health & $\begin{array}{c}12.2 \\
{[32.8]}\end{array}$ & $\begin{array}{c}3.81 \\
{[19.2]}\end{array}$ \\
\hline Commercial Services & $\begin{array}{c}10.8 \\
{[31.0]}\end{array}$ & $\begin{array}{c}14.0 \\
{[34.7]}\end{array}$ \\
\hline Other Services & $\begin{array}{c}3.48 \\
{[18.3]}\end{array}$ & $\begin{array}{c}3.63 \\
{[18.7]}\end{array}$ \\
\hline Non-Profit & $\begin{array}{c}1.39 \\
{[11.7]}\end{array}$ & $\begin{array}{c}0.18 \\
{[4.26]}\end{array}$ \\
\hline Public Administration & $\begin{array}{c}4.35 \\
{[20.4]}\end{array}$ & $\begin{array}{l}0.091 \\
{[3.01]}\end{array}$ \\
\hline Number of Observations & 58503 & 1109 \\
\hline
\end{tabular}

Notes: This table shows the distribution across industries of Czech workers (2012) and native workers (2010) in the German border region in \%. 15\% worker sample of the German administrative social-security data. I show the distribution of Czech workers across industries in 2012, because this is a year where a substantial number of them is already commuting across the border. In contrast, German workers' industry distribution is reported in 2010, to ensure that it is not yet influenced by the inflow. West Germany only. Standard deviations in bregkets. Source: Integrated Employment Biographies (IEB). 
Table A.2.2: Sorting into Occupations by Czech vs. German Workers

\begin{tabular}{lcc}
\hline & $(1)$ & $(2)$ \\
& Natives & Czechs \\
& 2010 & 2012 \\
\hline Agriculture, gardening, work with animals & 1.05 & 2.72 \\
& {$[10.2]$} & {$[16.3]$} \\
Simple, manual tasks & 16.2 & 26.3 \\
& {$[36.9]$} & {$[44.1]$} \\
Qualified, manual tasks & 16.5 & 35.2 \\
& {$[37.1]$} & {$[47.8]$} \\
Technician & 3.63 & 0.84 \\
& {$[18.7]$} & {$[9.15]$} \\
Engineer & 1.29 & 0.28 \\
Simple services & {$[11.3]$} & {$[5.30]$} \\
Qualified services & 17.7 & 25.0 \\
& {$[38.1]$} & {$[43.3]$} \\
Semi-professions & 5.71 & 1.22 \\
& {$[23.2]$} & {$[11.0]$} \\
Professions & 6.76 & 2.44 \\
Simple commercial and administrative tasks & {$[25.1]$} & {$[15.4]$} \\
Qualified commercial and administrative tasks & 1.21 & 1.41 \\
Manager & {$[29.6]$} & {$[11.8$} \\
Not classified & {$[37.5]$} & {$[13.5]$} \\
Number of Observations & 1.70 & 0.094 \\
& {$[12.9]$} & {$[3.06]$} \\
& 1.64 & 0 \\
& {$[12.7]$} & {$[0]$} \\
& 58503 & 1109 \\
\hline
\end{tabular}

Notes: This table shows the distribution across occupations of Czech workers (2012) and native workers (2010) in the German border region in \%. 15\% worker sample of the German administrative social-security data. I show the distribution of Czech workers across occupations in 2012, because this is a year where a substantial number of them is already commuting across the border. In contrast, German workers' occupational distribution is reported in 2010, to ensure that it is not yet influenced by the inflow. West Germany only. Standard deviations in brackets. Source: Integrated Employment Biographies (IEB). 
Table A.2.3: Industries in Matched West German Municipalities in 2010

(1)

Control Regions Treatment Regions

Share firms in manufacturing sector

Share firms in service sector

Share firms in construction sector

Share firms in mining sector

Share firms in electric sector

Share firms in agriculture sector

Number of Municipalities
12.1

[8.53]

68.9

[10.5]

12.6

[5.93]

0.12

[0.53]

0.54

[1.45]

5.64

[6.38]

243
11.9

[4.40]

69.9

[8.87]

13.1

[6.57]

0.38

[1.18]

0.55

[1.04]

3.97

[3.60]

243

Notes: This table reports industry shares (in \%) of matched treated and control municipalities in West Germany in the year before the policy change. Regions are matched using propensity score matching. The following variables enter the regression to compute propensity scores: Age shares (2010), skill shares (2010), share of female workers (2010), share of foreign workers (2010), share of firms in manufacturing sector (2010), share of firms in service sector (2010), employment in levels (2010), growth in EU8 employment 2004-2010, log wage (2008-2010). Matching occurs within cells of region type and I exclude municipalities in the same commuting zone as potential controls. Treated municipalities are all municipalities located up to $40 \mathrm{~km}$ from the nearest road border crossing to the Czech Republic (measured by airline distance from municipality centroid). West Germany only. Standard deviations in brackets. Source: Establishment History Panel (BHP). 
(1)

Control Regions Treatment Regions

Panel A: Employment

Native employment (levels))

Share foreign workers in $\%$

Share foreign workers from EU in \%

Share full-time workers in \%

Panel B: Wages

Native average wages

Average wages

Panel C: Workforce Characteristics

Share workers aged 15-29 in \%

Share workers aged 30-49 in \%

Share female workers in $\%$

Share high-skilled workers in \%

Share medium-skilled workers in $\%$

Share low-skilled workers in \%

Panel D: Regional Characteristics

Share rural regions in \%

Distance to CZ border (km)

Number of Municipalities

$\begin{array}{cc}200621.9 & 199966.6 \\ {[420387.8]} & {[417652.3]} \\ 1.13 & 1.00 \\ {[2.71]} & {[1.69]} \\ 0.66 & 0.58 \\ {[2.42]} & {[0.90]} \\ 65.7 & 64.3 \\ {[8.93]} & {[8.99]} \\ & \\ 53.6 & 51.5 \\ {[5.79]} & {[6.63]} \\ 53.3 & 51.4 \\ {[5.73]} & {[6.63]}\end{array}$

14.9

[3.76]

46.4

[4.25]

46.4

[10.6]

10.1

[3.92]

82.9

[4.90]

5.82

$[2.51]$

$[2.57]$

61

$[0.49]$

92.8

$[104.2]$

356

Notes: This table presents characteristics of matched East German treated and control municipalities in the year before the policy change. Regions are matched using propensity score matching. The following variables enter the regression to compute propensity scores: Age shares (2010), skill shares (2010), share of female workers (2010), share of foreign workers (2010), share of firms in manufacturing sector (2010), share of firms in service sector (2010), employment in levels (2010), growth in EU8 employment 20042010, log wage (2008-2010). Matching occurs within cells of region type and I exclude municipalities in the same commuting zone as potential controls. High-skilled workers have a university degree, medium-skilled workers have at least vocational training, lowskilled workers have no vocational training. Treated municipalities are all municipalities located up to $40 \mathrm{~km}$ from the nearest road border crossing to the Czech Republic or Poland (measured by airline distance from municipality centroid). East Germany only. Standard deviations in brackets. Source: Establishment History Panel (BHP). 
Table A.2.5: Industries in Matched East German Municipalities in 2010

(1)

Control Regions Treatment Regions

Share firms in manufacturing sector

Share firms in service sector

Share firms in construction sector

Share firms in mining sector

Share firms in electric sector

Share firms in agriculture sector

Number of Municipalities
8.51

$[5.57]$

67.6

[11.2]

15.2

[6.69]

0.33

[1.34]

0.44

[1.03]

7.80

[8.05]

356
9.25

[5.25]

68.6

[10.4]

15.2

[6.21]

0.16

[0.67]

0.44

[1.56]

6.32

[7.16]

356

Notes: This table reports industry shares (in \%) of matched treated and control municipalities in East Germany in year before policy change. Regions are matched using propensity score matching. The following variables enter the regression to compute propensity scores: Age shares (2010), skill shares (2010), share of female workers (2010), share of foreign workers (2010), share of firms in manufacturing sector (2010), share of firms in service sector (2010), employment in levels (2010), growth in EU8 employment 2004-2010, log wage (2008-2010). Matching occurs within cells of region type and I exclude municipalities in the same commuting zone as potential controls. Treated municipalities are all municipalities located up to $40 \mathrm{~km}$ from the nearest road border crossing to the Czech Republic or Poland (measured by airline distance from municipality centroid). East Germany only. Standard deviations in brackets. Source: Establishment History Panel (BHP). 
Table A.2.6: Labor Market Outcomes in Czech Republic: Regression Results

\begin{tabular}{|c|c|c|c|c|}
\hline & $\begin{array}{l}(1) \\
\text { Unemployment } \\
\text { Rate }\end{array}$ & $\begin{array}{c}(2) \\
\text { Unemployment } \\
\text { Rate } \\
\text { Men }\end{array}$ & $\begin{array}{c}(3) \\
\text { Unemployment } \\
\text { Rate } \\
\text { Women }\end{array}$ & $\begin{array}{c}(4) \\
\text { Vacancies }\end{array}$ \\
\hline $2005^{*}$ Treat & $\begin{array}{c}-0.13 \\
(0.13)\end{array}$ & $\begin{array}{l}-0.24 \\
(0.15)\end{array}$ & $\begin{array}{l}-0.17 \\
(0.17)\end{array}$ & $\begin{array}{c}0.21 \\
(0.92)\end{array}$ \\
\hline $2006^{*}$ Treat & $\begin{array}{l}-0.23 \\
(0.12)\end{array}$ & $\begin{array}{c}-0.34 \\
(0.16)^{*}\end{array}$ & $\begin{array}{l}-0.17 \\
(0.16)\end{array}$ & $\begin{array}{l}-0.77 \\
(1.86)\end{array}$ \\
\hline $2007^{*}$ Treat & $\begin{array}{l}-0.12 \\
(0.11)\end{array}$ & $\begin{array}{c}-0.070 \\
(0.14)\end{array}$ & $\begin{array}{l}-0.26 \\
(0.15)\end{array}$ & $\begin{array}{l}-2.33 \\
(2.95)\end{array}$ \\
\hline $2008 *$ Treat & $\begin{array}{c}-0.043 \\
(0.10)\end{array}$ & $\begin{array}{l}-0.14 \\
(0.14)\end{array}$ & $\begin{array}{l}-0.11 \\
(0.14)\end{array}$ & $\begin{array}{l}-2.48 \\
(2.00)\end{array}$ \\
\hline $2009 *$ Treat & $\begin{array}{c}0.024 \\
(0.093)\end{array}$ & $\begin{array}{c}-0.32 \\
(0.12)^{*}\end{array}$ & $\begin{array}{c}0.24 \\
(0.13)\end{array}$ & $\begin{array}{c}0.59 \\
(1.04)\end{array}$ \\
\hline $2011^{*}$ Treat & $\begin{array}{c}-0.11 \\
(0.091)\end{array}$ & $\begin{array}{l}-0.17 \\
(0.12)\end{array}$ & $\begin{array}{l}-0.19 \\
(0.13)\end{array}$ & $\begin{array}{c}0.63 \\
(0.74)\end{array}$ \\
\hline $2014^{*}$ Treat & $\begin{array}{c}-0.61 \\
(0.11)^{* *}\end{array}$ & $\begin{array}{c}-0.73 \\
(0.14)^{* *}\end{array}$ & $\begin{array}{c}-0.53 \\
(0.15)^{* *}\end{array}$ & $\begin{array}{c}2.36 \\
(1.06)^{*}\end{array}$ \\
\hline $2015^{*}$ Treat & $\begin{array}{c}-0.46 \\
(0.11)^{* *}\end{array}$ & $\begin{array}{c}-0.38 \\
(0.14)^{* *}\end{array}$ & $\begin{array}{c}-0.58 \\
(0.15)^{* *}\end{array}$ & $\begin{array}{c}4.56 \\
(4.22)\end{array}$ \\
\hline $2016^{*}$ Treat & $\begin{array}{c}-0.51 \\
(0.11)^{* *}\end{array}$ & $\begin{array}{c}-0.54 \\
(0.14)^{* *}\end{array}$ & $\begin{array}{c}-0.59 \\
(0.15)^{* *}\end{array}$ & $\begin{array}{c}6.91 \\
(4.55)\end{array}$ \\
\hline $2017^{*}$ Treat & $\begin{array}{c}-0.68 \\
(0.12)^{* *}\end{array}$ & $\begin{array}{c}-0.66 \\
(0.15)^{* *}\end{array}$ & $\begin{array}{c}-0.76 \\
(0.15)^{* *}\end{array}$ & $\begin{array}{c}9.95 \\
(7.06)\end{array}$ \\
\hline Observations & 32267 & 31253 & 31434 & 25929 \\
\hline$R^{2}$ & 0.364 & 0.302 & 0.227 & 0.036 \\
\hline Mean of dep. var & 6.99 & 6.92 & 7.52 & 14.1 \\
\hline Municipality FE & Yes & Yes & Yes & Yes \\
\hline Year FE & Yes & Yes & Yes & Yes \\
\hline
\end{tabular}

Notes: This table reports event study coefficients for matched Czech municipalities before and after the opening of the German labor market for Czech workers in 2011. Column (1) reports event study coefficients for the unemployment rate, Column (2) reports event study coefficients for men's unemployment rate, Column (3) reports event study coefficients for women's unemployment rate, and Column (4) reports coefficients for vacancies. Vacancies reports number of vacancies reported at the employment offices on December 31 in a given year. Regressions control for year and municipality fixed effects. In all specifications, standard errors are clustered at the municipality level. *, ** and *** correspond to 10, 5 and 1 percent significance levels, respectively. Municipality data for the Czech Republic, provided by Czech Statistical Office. 
Table A.2.7: Worker Inflow and Labor Market Outcomes in Germany: Regression Results

\begin{tabular}{|c|c|c|c|c|}
\hline & $\begin{array}{c}(1) \\
\text { Share EU8 } \\
\text { Workers }\end{array}$ & $\begin{array}{c}(2) \\
\text { Share Czech } \\
\text { Workers }\end{array}$ & $\begin{array}{c}(3) \\
\text { Employment } \\
\text { Natives }\end{array}$ & $\begin{array}{c}(4) \\
\text { Log Wage } \\
\text { Natives }\end{array}$ \\
\hline $2007^{*}$ Treat & $\begin{array}{c}0.000010 \\
(0.0018)\end{array}$ & $\begin{array}{l}0.00093 \\
(0.0012)\end{array}$ & $\begin{array}{l}0.0073 \\
(0.017)\end{array}$ & $\begin{array}{l}0.0063 \\
(0.010)\end{array}$ \\
\hline $2008 *$ Treat & $\begin{array}{l}0.00043 \\
(0.0011)\end{array}$ & $\begin{array}{c}0.00064 \\
(0.00081)\end{array}$ & $\begin{array}{l}-0.016 \\
(0.015)\end{array}$ & $\begin{array}{c}-0.0060 \\
(0.010)\end{array}$ \\
\hline $2009^{*}$ Treat & $\begin{array}{c}0.00031 \\
(0.00093)\end{array}$ & $\begin{array}{c}0.00057 \\
(0.00068)\end{array}$ & $\begin{array}{c}0.0019 \\
(0.0093)\end{array}$ & $\begin{array}{l}-0.0082 \\
(0.0080)\end{array}$ \\
\hline $2011^{*}$ Treat & $\begin{array}{c}0.0069 \\
(0.0018)^{* * *}\end{array}$ & $\begin{array}{c}0.0075 \\
(0.0015)^{* * *}\end{array}$ & $\begin{array}{c}-0.000028 \\
(0.0070)\end{array}$ & $\begin{array}{l}-0.015 \\
(0.010)\end{array}$ \\
\hline $2012^{*}$ Treat & $\begin{array}{c}0.0074 \\
(0.0035)^{* *}\end{array}$ & $\begin{array}{c}0.014 \\
(0.0020)^{* * *}\end{array}$ & $\begin{array}{l}-0.019 \\
(0.019)\end{array}$ & $\begin{array}{l}-0.017 \\
(0.011)\end{array}$ \\
\hline $2013^{*}$ Treat & $\begin{array}{c}0.012 \\
(0.0035)^{* * *}\end{array}$ & $\begin{array}{c}0.019 \\
(0.0025)^{* * *}\end{array}$ & $\begin{array}{l}-0.012 \\
(0.019)\end{array}$ & $\begin{array}{c}-0.024 \\
(0.011)^{* *}\end{array}$ \\
\hline $2014^{*}$ Treat & $\begin{array}{c}0.016 \\
(0.0038)^{* * *}\end{array}$ & $\begin{array}{c}0.023 \\
(0.0027)^{* * *}\end{array}$ & $\begin{array}{l}-0.0025 \\
(0.018)\end{array}$ & $\begin{array}{c}-0.024 \\
(0.011)^{* *}\end{array}$ \\
\hline $2015 *$ Treat & $\begin{array}{c}0.021 \\
(0.0044)^{* * *}\end{array}$ & $\begin{array}{c}0.029 \\
(0.0031)^{* * *}\end{array}$ & $\begin{array}{l}0.0063 \\
(0.019)\end{array}$ & $\begin{array}{c}-0.026 \\
(0.012)^{* *}\end{array}$ \\
\hline $2015^{*}$ Treat & $\begin{array}{c}0.026 \\
(0.0047)^{* * *}\end{array}$ & $\begin{array}{c}0.033 \\
(0.0034)^{* * *}\end{array}$ & $\begin{array}{c}0.010 \\
(0.021)\end{array}$ & $\begin{array}{c}-0.027 \\
(0.011)^{* *}\end{array}$ \\
\hline $2016^{*}$ Treat & $\begin{array}{c}0.029 \\
(0.0048)^{* * *}\end{array}$ & $\begin{array}{c}0.036 \\
(0.0033)^{* * *}\end{array}$ & $\begin{array}{c}0.013 \\
(0.022)\end{array}$ & $\begin{array}{c}-0.024 \\
(0.011)^{* *}\end{array}$ \\
\hline Observations & 5344 & 5344 & 5346 & 5346 \\
\hline$R^{2}$ & 0.224 & 0.211 & 0.082 & 0.513 \\
\hline Mean of dep. var & 0.026 & 0.015 & 1.03 & 4.12 \\
\hline Municipality FE & Yes & Yes & Yes & Yes \\
\hline Year FE & Yes & Yes & Yes & Yes \\
\hline
\end{tabular}

Notes: This table reports event study coefficients for matched German municipalities before and after the opening of the German labor market for Czech workers in 2011. Column (1) reports event study coefficients for the share of EU8 workers by total employment, Column (2) reports event study coefficients for the share of Czech workers by total employment, Column (3) reports event study coefficients for native employment, and Column (4) reports coefficients for native log wages. Native employment is defined as the share of native employment in a given year by native employment in 2010. Regressions control for year and municipality fixed effects. In all specifications, standard errors are clustered at the municipality level. *, ** and *** correspond to 10, 5 and 1 percent significance levels, respectively. West Germany only. Source: Integrated Employment Biographies (IEB) \& Establishment History Panel (BHP). 
Table A.2.8: Regression Results for Regional-Level Event Study East Germany

\begin{tabular}{|c|c|c|c|c|c|}
\hline & $\begin{array}{c}(1) \\
\text { Share EU8 } \\
\text { Workers }\end{array}$ & $\begin{array}{c}(2) \\
\text { Share Czech } \\
\text { Workers }\end{array}$ & $\begin{array}{c}(3) \\
\text { Share Polish } \\
\text { Workers }\end{array}$ & $\begin{array}{c}(4) \\
\text { Employment } \\
\text { Natives }\end{array}$ & $\begin{array}{c}(5) \\
\text { Log Wage } \\
\text { Natives }\end{array}$ \\
\hline $2007^{*}$ Treat & $\begin{array}{l}-0.0014 \\
(0.0012)\end{array}$ & $\begin{array}{l}-0.00017 \\
(0.00016)\end{array}$ & $\begin{array}{l}-0.0012 \\
(0.0011)\end{array}$ & $\begin{array}{c}-0.032 \\
(0.013)^{* *}\end{array}$ & $\begin{array}{c}0.0047 \\
(0.0062)\end{array}$ \\
\hline $2008 *$ Treat & $\begin{array}{c}-0.0010 \\
(0.00088)\end{array}$ & $\begin{array}{l}-0.00014 \\
(0.00012)\end{array}$ & $\begin{array}{c}-0.0012 \\
(0.00081)\end{array}$ & $\begin{array}{c}-0.021 \\
(0.010)^{* *}\end{array}$ & $\begin{array}{l}-0.0012 \\
(0.0063)\end{array}$ \\
\hline $2009 *$ Treat & $\begin{array}{l}-0.00011 \\
(0.00069)\end{array}$ & $\begin{array}{c}-0.00020 \\
(0.00012)^{*}\end{array}$ & $\begin{array}{c}-0.000090 \\
(0.00067)\end{array}$ & $\begin{array}{c}-0.021 \\
(0.0082)^{* * *}\end{array}$ & $\begin{array}{l}-0.0025 \\
(0.0049)\end{array}$ \\
\hline $2011^{*}$ Treat & $\begin{array}{l}0.00036 \\
(0.0019)\end{array}$ & $\begin{array}{c}0.00041 \\
(0.00018)^{* *}\end{array}$ & $\begin{array}{c}-0.000021 \\
(0.0019)\end{array}$ & $\begin{array}{c}-0.010 \\
(0.0061)^{*}\end{array}$ & $\begin{array}{l}-0.0088 \\
(0.0055)\end{array}$ \\
\hline $2012^{*}$ Treat & $\begin{array}{c}0.0041 \\
(0.0021)^{*}\end{array}$ & $\begin{array}{c}0.0010 \\
(0.00031)^{* * *}\end{array}$ & $\begin{array}{c}0.0034 \\
(0.0020)^{*}\end{array}$ & $\begin{array}{c}-0.010 \\
(0.0085)\end{array}$ & $\begin{array}{l}-0.0050 \\
(0.0069)\end{array}$ \\
\hline $2013^{*}$ Treat & $\begin{array}{c}0.0053 \\
(0.0024)^{* *}\end{array}$ & $\begin{array}{c}0.0011 \\
(0.00042)^{* * *}\end{array}$ & $\begin{array}{c}0.0044 \\
(0.0023)^{*}\end{array}$ & $\begin{array}{l}-0.0098 \\
(0.0095)\end{array}$ & $\begin{array}{c}-0.011 \\
(0.0060)^{*}\end{array}$ \\
\hline $2014^{*}$ Treat & $\begin{array}{c}0.0068 \\
(0.0022)^{* * *}\end{array}$ & $\begin{array}{c}0.0023 \\
(0.00054)^{* * *}\end{array}$ & $\begin{array}{c}0.0055 \\
(0.0020)^{* * *}\end{array}$ & $\begin{array}{l}-0.013 \\
(0.012)\end{array}$ & $\begin{array}{c}-0.012 \\
(0.0067)^{*}\end{array}$ \\
\hline $2015^{*}$ Treat & $\begin{array}{c}0.0094 \\
(0.0027)^{* * *}\end{array}$ & $\begin{array}{c}0.0030 \\
(0.00091)^{* * *}\end{array}$ & $\begin{array}{c}0.0074 \\
(0.0026)^{* * *}\end{array}$ & $\begin{array}{l}-0.020 \\
(0.013)\end{array}$ & $\begin{array}{c}0.0019 \\
(0.0066)\end{array}$ \\
\hline $2015 *$ Treat & $\begin{array}{c}0.012 \\
(0.0033)^{* * *}\end{array}$ & $\begin{array}{c}0.0045 \\
(0.0011)^{* * *}\end{array}$ & $\begin{array}{c}0.0088 \\
(0.0031)^{* * *}\end{array}$ & $\begin{array}{c}-0.026 \\
(0.014)^{*}\end{array}$ & $\begin{array}{l}-0.0044 \\
(0.0068)\end{array}$ \\
\hline $2016 *$ Treat & $\begin{array}{c}0.017 \\
(0.0038)^{* * *}\end{array}$ & $\begin{array}{c}0.0062 \\
(0.0013)^{* * *}\end{array}$ & $\begin{array}{c}0.012 \\
(0.0036)^{* * *}\end{array}$ & $\begin{array}{c}-0.031 \\
(0.016)^{*}\end{array}$ & $\begin{array}{c}0.000036 \\
(0.0069)\end{array}$ \\
\hline Observations & 7324 & 7324 & 7324 & 7832 & 7827 \\
\hline$R^{2}$ & 0.124 & 0.070 & 0.079 & 0.005 & 0.771 \\
\hline Mean of dep. var & 0.012 & 0.0015 & 0.0093 & 1.01 & 3.94 \\
\hline Municipality FE & Yes & Yes & Yes & Yes & Yes \\
\hline Year FE & Yes & Yes & Yes & Yes & Yes \\
\hline
\end{tabular}

Notes: This table reports event study coefficients for matched East German municipalities before and after the opening of the German labor market for EU8 workers in 2011. Column (1) reports event study coefficients for the share of EU8 workers by total employment, Column (2) reports event study coefficients for the share of Czech workers by total employment, Column (3) reports event study coefficients for the share of Polish workers by total employment, Column (4) reports event study coefficients for native employment, and Column (5) reports coefficients for native log wages. Native employment is defined as the share of native employment in a given year by native employment in 2010. Regressions control for year and municipality fixed effects. In all specifications, standard errors are clustered at the municipality level. *, ** and $* * *$ correspond to 10,5 and 1 percent significance levels, respectively. East Germany only. Source: Integrated Employment Biographies (IEB) \& Establishment History Panel (BHP). 
Table A.2.9: Labor Market Outcomes of Native Incumbent Workers in Germany

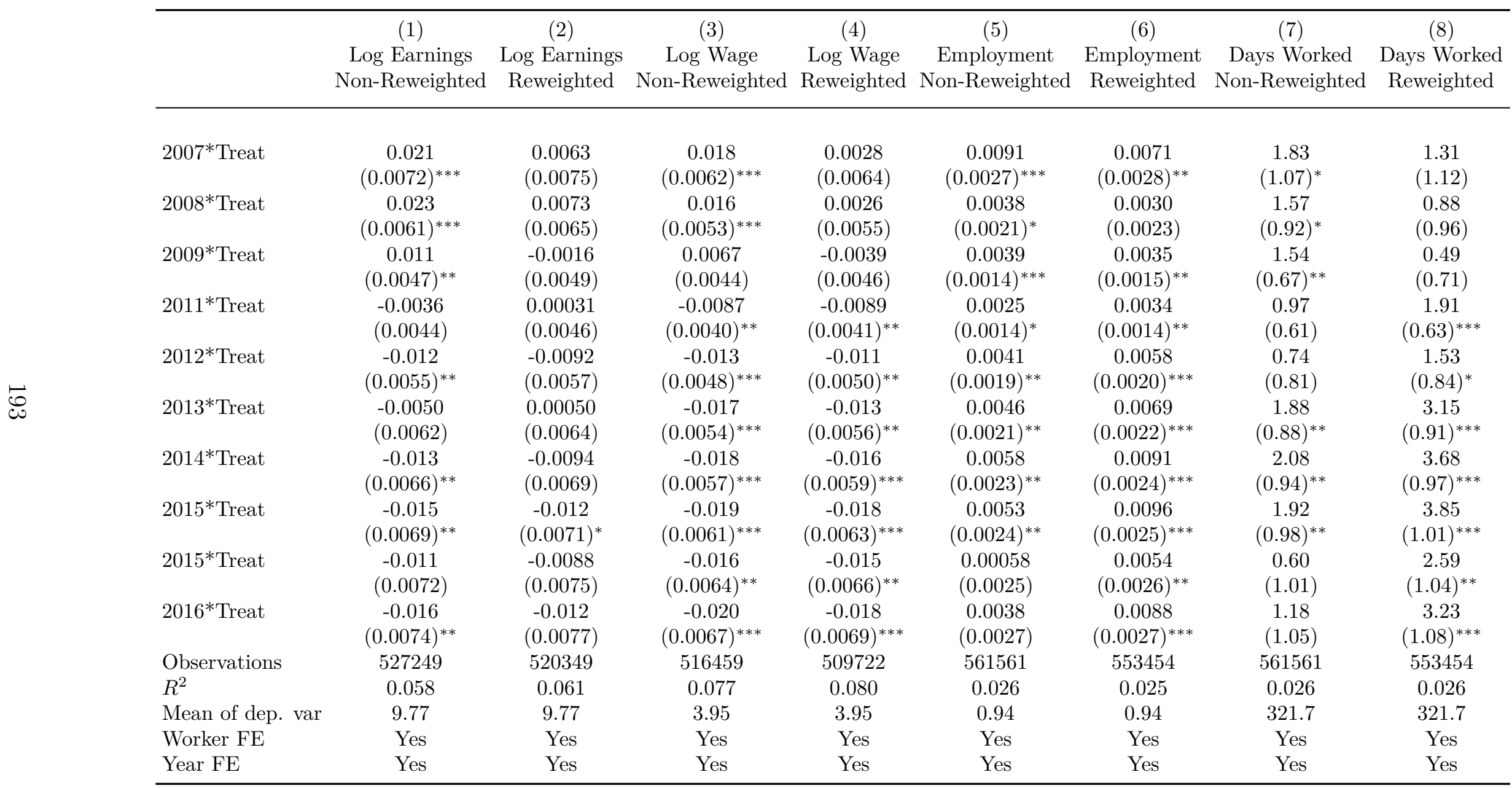

Notes: This table reports event study coefficients for matched incumbent German workers before and after the opening of the German labor market for Czech workers in 2011. Columns (1) and (2) report event study coefficients for log earnings without and with reweighting, respectively. Columns (3) and (4) report event study coefficients for log wage without and with reweighting, respectively. Columns (5) and (6) report event study coefficients for employment without and with reweighting, respectively. Columns (7) and (8) report event study coefficients for days worked without and with reweighting, respectively. Regressions control for year and individual fixed effects. In all specifications, standard errors are clustered at the worker level. ${ }^{*}, * *$ and ${ }^{* * *}$ correspond to 10, 5 and 1 percent signficance levels, respectively. Source: Integrated Employment Biographies (IEB). 
Table A.2.10: Labor Market Outcomes of Native Incumbent Movers in Germany

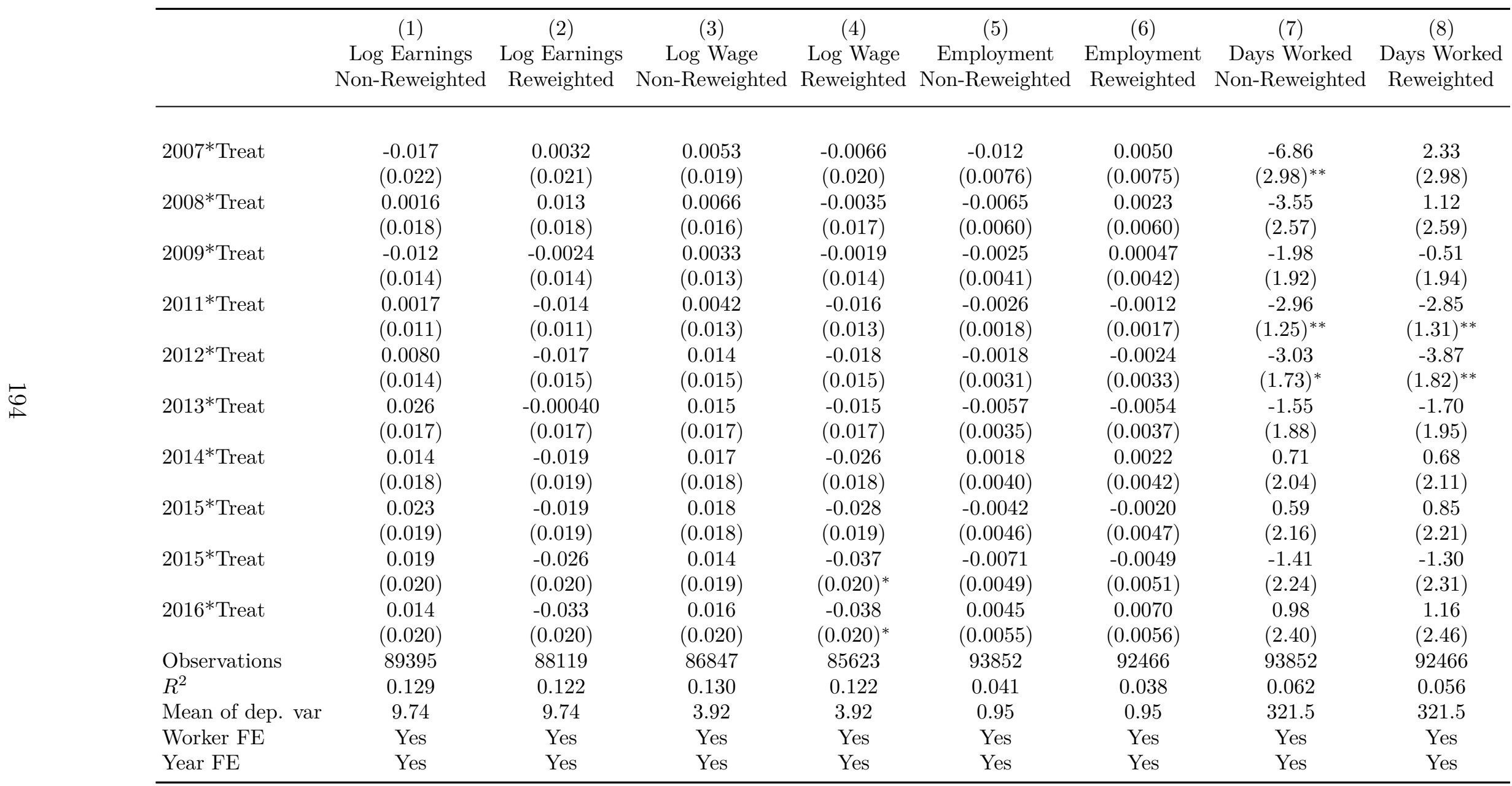

Notes: This table reports event study coefficients for matched incumbent German movers before and after the opening of the German labor market for Czech workers in 2011. Workers in both treated and control municipalities move away from their respective municipality after 2011; to be more precise, they move to a different commuting zone not in the matched regions. Columns (1) and (2) report event study coefficients for log earnings without and with reweighting, respectively. Columns (3) and (4) report event study coefficients for log wage without and with reweighting, respectively. Columns (5) and (6) report event study coefficients for employment without and with reweighting, respectively. Columns (7) and (8) report event study coefficients for days worked without and with reweighting, respectively. Regressions control for year and individual fixed effects. In all specifications, standard errors are clustered at the worker level. *, ** and *** correspond to 10,5 and 1 percent signficance levels, respectively. Source: Integrated Employment Biographies (IEB). 
Table A.2.11: Labor Market Outcomes of Native Incumbent Workers in Germany By Tenure

\begin{tabular}{|c|c|c|c|c|c|c|}
\hline & $\begin{array}{c}(1) \\
\text { Log Wage } \\
<1 \text { Year Tenure }\end{array}$ & $\begin{array}{c}(2) \\
\text { Log Wage } \\
>=1 \text { Year Tenure }\end{array}$ & $\begin{array}{c}(3) \\
\text { Log Wage } \\
>=3 \text { Years Tenure }\end{array}$ & $\begin{array}{c}(4) \\
\text { Days Worked } \\
<1 \text { Year Tenure }\end{array}$ & $\begin{array}{c}(5) \\
\text { Days Worked } \\
>=1 \text { Year Tenure }\end{array}$ & $\begin{array}{c}(6) \\
\text { Days Worked } \\
>=3 \text { Years Tenure }\end{array}$ \\
\hline $2007^{*}$ Treat & $\begin{array}{l}-0.044 \\
(0.030)\end{array}$ & $\begin{array}{c}0.0099 \\
(0.0061)\end{array}$ & $\begin{array}{l}-0.0057 \\
(0.0050)\end{array}$ & $\begin{array}{c}6.43 \\
(3.98)\end{array}$ & $\begin{array}{c}0.54 \\
(1.15)\end{array}$ & $\begin{array}{c}-1.88 \\
(0.71)^{* * *}\end{array}$ \\
\hline $2008^{*}$ Treat & $\begin{array}{l}-0.026 \\
(0.028)\end{array}$ & $\begin{array}{c}0.0076 \\
(0.0051)\end{array}$ & $\begin{array}{l}-0.0050 \\
(0.0038)\end{array}$ & $\begin{array}{c}4.94 \\
(3.78)\end{array}$ & $\begin{array}{c}0.25 \\
(0.95)\end{array}$ & $\begin{array}{l}-0.54 \\
(0.43)\end{array}$ \\
\hline $2009^{*}$ Treat & $\begin{array}{l}-0.031 \\
(0.028)\end{array}$ & $\begin{array}{c}0.0012 \\
(0.0038)\end{array}$ & $\begin{array}{l}-0.0028 \\
(0.0031)\end{array}$ & $\begin{array}{c}4.29 \\
(3.28)\end{array}$ & $\begin{array}{l}-0.14 \\
(0.63)\end{array}$ & $\begin{array}{l}0.011 \\
(0.38)\end{array}$ \\
\hline $2011^{*}$ Treat & $\begin{array}{c}-0.045 \\
(0.019)^{* *}\end{array}$ & $\begin{array}{l}-0.0035 \\
(0.0038)\end{array}$ & $\begin{array}{l}-0.0018 \\
(0.0037)\end{array}$ & $\begin{array}{c}6.46 \\
(2.63)^{* *}\end{array}$ & $\begin{array}{c}1.27 \\
(0.61)^{* *}\end{array}$ & $\begin{array}{c}0.56 \\
(0.62)\end{array}$ \\
\hline $2012^{*}$ Treat & $\begin{array}{l}-0.033 \\
(0.022)\end{array}$ & $\begin{array}{l}-0.0076 \\
(0.0048)\end{array}$ & $\begin{array}{l}-0.0062 \\
(0.0045)\end{array}$ & $\begin{array}{c}7.06 \\
(3.20)^{* *}\end{array}$ & $\begin{array}{c}0.75 \\
(0.83)\end{array}$ & $\begin{array}{c}0.55 \\
(0.88)\end{array}$ \\
\hline $2013^{*}$ Treat & $\begin{array}{c}-0.053 \\
(0.023)^{* *}\end{array}$ & $\begin{array}{c}-0.0074 \\
(0.0054)\end{array}$ & $\begin{array}{c}-0.0056 \\
(0.0051)\end{array}$ & $\begin{array}{c}8.77 \\
(3.35)^{* * *}\end{array}$ & $\begin{array}{c}2.35 \\
(0.92)^{* *}\end{array}$ & $\begin{array}{c}1.57 \\
(0.97)\end{array}$ \\
\hline $2014^{*}$ Treat & $\begin{array}{c}-0.072 \\
(0.024)^{* * *}\end{array}$ & $\begin{array}{l}-0.0088 \\
(0.0058)\end{array}$ & $\begin{array}{l}-0.0032 \\
(0.0056)\end{array}$ & $\begin{array}{c}9.01 \\
(3.48)^{* * *}\end{array}$ & $\begin{array}{c}2.93 \\
(0.98)^{* * *}\end{array}$ & $\begin{array}{c}2.22 \\
(1.05)^{* *}\end{array}$ \\
\hline $2015^{*}$ Treat & $\begin{array}{c}-0.082 \\
(0.025)^{* * *}\end{array}$ & $\begin{array}{l}-0.0087 \\
(0.0062)\end{array}$ & $\begin{array}{l}-0.0056 \\
(0.0060)\end{array}$ & $\begin{array}{c}3.87 \\
(3.59)\end{array}$ & $\begin{array}{c}3.88 \\
(1.02)^{* * *}\end{array}$ & $\begin{array}{c}2.66 \\
(1.11)^{* *}\end{array}$ \\
\hline $2015^{*}$ Treat & $\begin{array}{c}-0.082 \\
(0.026)^{* * *}\end{array}$ & $\begin{array}{c}-0.0050 \\
(0.0065)\end{array}$ & $\begin{array}{c}-0.0041 \\
(0.0063)\end{array}$ & $\begin{array}{c}1.73 \\
(3.64)\end{array}$ & $\begin{array}{c}2.76 \\
(1.06)^{* * *}\end{array}$ & $\begin{array}{c}2.56 \\
(1.17)^{* *}\end{array}$ \\
\hline $2016^{*}$ Treat & $\begin{array}{c}-0.10 \\
(0.027)^{* * *}\end{array}$ & $\begin{array}{l}-0.0061 \\
(0.0069)\end{array}$ & $\begin{array}{r}-0.00093 \\
(0.0067)\end{array}$ & $\begin{array}{l}-0.19 \\
(3.73)\end{array}$ & $\begin{array}{c}3.78 \\
(1.10)^{* * *}\end{array}$ & $\begin{array}{c}3.59 \\
(1.24)^{* * *}\end{array}$ \\
\hline Observations & 54838 & 454884 & 326445 & 66737 & 486717 & 339999 \\
\hline$R^{2}$ & 0.123 & 0.075 & 0.051 & 0.056 & 0.031 & 0.046 \\
\hline Mean of dep. var & 3.72 & 3.98 & 4.07 & 272.8 & 328.4 & 342.0 \\
\hline Worker FE & Yes & Yes & Yes & Yes & Yes & Yes \\
\hline Year FE & Yes & Yes & Yes & Yes & Yes & Yes \\
\hline
\end{tabular}

Notes: This table reports event study coefficients for matched incumbent German workers by tenure before and after the opening of the German labor market for Czech workers in 2011. Columns (1), (2), and (3) report event study coefficients for log wages with reweighting. Column (1) reports results for workers with less than 1 year tenure, Column (2) reports results for workers with more than 1 year tenure, and Column (3) reports results for workers with more than 3 years tenure. Columns (4), (5), and (6) report event study coefficients for days worked with reweighting. Column (4) reports results for workers with less than 1 year tenure, Column (5) reports results for workers with more than 1 year tenure, and Column (6) reports results for workers with more than 3 years tenure. Regressions control for year and individual fixed effects. In all specifications, standard errors are clustered at the worker level. *, ** and *** correspond to 10, 5 and 1 percent signficance levels, respectively. Source: Integrated Employment Biographies (IEB). 
Table A.2.12: Labor Market Outcomes of Native Incumbent Workers in Germany By Skill

\begin{tabular}{|c|c|c|c|c|c|c|}
\hline & $\begin{array}{c}(1) \\
\text { Log Wage } \\
\text { No Vocational Training }\end{array}$ & $\begin{array}{c}(2) \\
\text { Log Wage } \\
\text { Vocational Training }\end{array}$ & $\begin{array}{c}(3) \\
\text { Log Wage } \\
\text { University Degree }\end{array}$ & $\begin{array}{c}(4) \\
\text { Days Worked } \\
\text { No Vocational Training }\end{array}$ & $\begin{array}{c}(5) \\
\text { Days Worked } \\
\text { Vocational Training }\end{array}$ & $\begin{array}{c}\quad(6) \\
\text { Days Worked } \\
\text { University Degree }\end{array}$ \\
\hline $2007^{*}$ Treat & $\begin{array}{l}0.0071 \\
(0.015)\end{array}$ & $\begin{array}{c}0.0039 \\
(0.0064)\end{array}$ & $\begin{array}{c}0.024 \\
(0.032)\end{array}$ & $\begin{array}{l}1.20 \\
(3.00)\end{array}$ & $\begin{array}{c}1.05 \\
(0.92)\end{array}$ & $\begin{array}{l}-6.08 \\
(4.21)\end{array}$ \\
\hline $2008^{*}$ Treat & $\begin{array}{l}0.0073 \\
(0.012)\end{array}$ & $\begin{array}{c}0.0032 \\
(0.0058)\end{array}$ & $\begin{array}{c}-0.0089 \\
(0.027)\end{array}$ & $\begin{array}{c}3.87 \\
(2.63)\end{array}$ & $\begin{array}{l}-0.85 \\
(0.86)\end{array}$ & $\begin{array}{l}-4.52 \\
(4.22)\end{array}$ \\
\hline $2009^{*}$ Treat & $\begin{array}{l}0.0067 \\
(0.010)\end{array}$ & $\begin{array}{l}-0.0059 \\
(0.0050)\end{array}$ & $\begin{array}{c}-0.0074 \\
(0.022)\end{array}$ & $\begin{array}{c}4.38 \\
(1.89)^{* *}\end{array}$ & $\begin{array}{l}-1.12 \\
(0.73)\end{array}$ & $\begin{array}{c}0.46 \\
(3.51)\end{array}$ \\
\hline $2011^{*}$ Treat & $\begin{array}{c}-0.018 \\
(0.010)^{*}\end{array}$ & $\begin{array}{c}-0.012 \\
(0.0045)^{* * *}\end{array}$ & $\begin{array}{l}-0.014 \\
(0.018)\end{array}$ & $\begin{array}{c}4.64 \\
(1.86)^{* *}\end{array}$ & $\begin{array}{l}-0.093 \\
(0.66)\end{array}$ & $\begin{array}{c}3.62 \\
(2.81)\end{array}$ \\
\hline $2012^{*}$ Treat & $\begin{array}{c}-0.0070 \\
(0.015)\end{array}$ & $\begin{array}{c}-0.016 \\
(0.0052)^{* * *}\end{array}$ & $\begin{array}{l}0.0031 \\
(0.021)\end{array}$ & $\begin{array}{l}-0.82 \\
(2.88)\end{array}$ & $\begin{array}{l}-0.26 \\
(0.78)\end{array}$ & $\begin{array}{c}3.82 \\
(3.21)\end{array}$ \\
\hline $2013^{*}$ Treat & $\begin{array}{r}-0.0069 \\
(0.016)\end{array}$ & $\begin{array}{c}-0.019 \\
(0.0057)^{* * *}\end{array}$ & $\begin{array}{l}0.0092 \\
(0.023)\end{array}$ & $\begin{array}{l}-1.30 \\
(3.24)\end{array}$ & $\begin{array}{c}1.20 \\
(0.83)\end{array}$ & $\begin{array}{c}3.44 \\
(3.37)\end{array}$ \\
\hline $2014^{*}$ Treat & $\begin{array}{c}-0.0049 \\
(0.017)\end{array}$ & $\begin{array}{c}-0.021 \\
(0.0061)^{* * *}\end{array}$ & $\begin{array}{l}-0.0038 \\
(0.024)\end{array}$ & $\begin{array}{c}0.54 \\
(3.41)\end{array}$ & $\begin{array}{c}1.69 \\
(0.86)^{* *}\end{array}$ & $\begin{array}{c}5.35 \\
(3.53)\end{array}$ \\
\hline $2015^{*}$ Treat & $\begin{array}{c}-0.0076 \\
(0.019)\end{array}$ & $\begin{array}{c}-0.020 \\
(0.0063)^{* * *}\end{array}$ & $\begin{array}{c}-0.0060 \\
(0.026)\end{array}$ & $\begin{array}{c}3.41 \\
(3.58)\end{array}$ & $\begin{array}{c}1.46 \\
(0.87)^{*}\end{array}$ & $\begin{array}{c}4.76 \\
(3.50)\end{array}$ \\
\hline $2015^{*}$ Treat & $\begin{array}{l}-0.014 \\
(0.019)\end{array}$ & $\begin{array}{c}-0.015 \\
(0.0066)^{* *}\end{array}$ & $\begin{array}{l}-0.016 \\
(0.027)\end{array}$ & $\begin{array}{l}1.15 \\
(3.69)\end{array}$ & $\begin{array}{c}1.53 \\
(0.89)^{*}\end{array}$ & $\begin{array}{c}2.74 \\
(3.49)\end{array}$ \\
\hline $2016^{*}$ Treat & $\begin{array}{c}-0.0066 \\
(0.020)\end{array}$ & $\begin{array}{c}-0.017 \\
(0.0068)^{* *}\end{array}$ & $\begin{array}{l}-0.028 \\
(0.029)\end{array}$ & $\begin{array}{c}2.36 \\
(3.78)\end{array}$ & $\begin{array}{c}0.75 \\
(0.91)\end{array}$ & $\begin{array}{l}1.96 \\
(3.50)\end{array}$ \\
\hline Observations & 79638 & 402717 & 27367 & 107456 & 417722 & 28276 \\
\hline$R^{2}$ & 0.063 & 0.038 & 0.048 & 0.102 & 0.006 & 0.010 \\
\hline Mean of dep. var & 3.40 & 4.02 & 4.51 & 251.8 & 338.8 & 338.4 \\
\hline Worker FE & Yes & Yes & Yes & Yes & Yes & Yes \\
\hline Year FE & Yes & Yes & Yes & Yes & Yes & Yes \\
\hline
\end{tabular}

Notes: This table reports event study coefficients for matched incumbent German workers by skill before and after the opening of the German labor market for Czech workers in 2011. Columns (1), (2), and (3) report event study coefficients for log wages with reweighting. Column (1) reports results for workers without vocational training, Column (2) reports results for workers with vocational training, and Column (3) reports results for workers with a university degree. Columns (4), (5), and (6) report event study coefficients for days worked with reweighting. Column (4) reports results for workers without vocational training, Column (5) reports results for workers with vocational training, and Column (6) reports results for workers with a university degree. Regressions control for year and individual fixed effects. In all specifications, standard errors are clustered at the worker level. *, ** and *** correspond to 10, 5 and 1 percent signficance levels, respectively. Source: Integrated Employment Biographies (IEB). 
Table A.2.13: Robustness I: Inflow of EU8/Czech Workers

\begin{tabular}{|c|c|c|c|c|c|}
\hline & $\begin{array}{c}(1) \\
\text { Baseline }\end{array}$ & $\begin{array}{c}(2) \\
\text { Rest of Bavaria } \\
\text { as } \\
\text { Control }\end{array}$ & $\begin{array}{c}(3) \\
\text { 60km } \\
\text { Threshold }\end{array}$ & $\begin{array}{l}(4) \\
\text { Matching w/o } \\
\text { 40-100km } \\
\text { Controls }\end{array}$ & $\begin{array}{l}(5) \\
\text { Matching with } \\
\text { Commuting } \\
\text { Zones }\end{array}$ \\
\hline \multicolumn{6}{|c|}{ Panel A: Share EU8 Workers } \\
\hline $2007^{*}$ Treat & $\begin{array}{c}0.000010 \\
(0.0018)\end{array}$ & $\begin{array}{c}0.0029 \\
(0.0012)^{* *}\end{array}$ & $\begin{array}{l}-0.0015 \\
(0.0017)\end{array}$ & $\begin{array}{l}-0.0017 \\
(0.0028)\end{array}$ & $\begin{array}{l}0.00037 \\
(0.0018)\end{array}$ \\
\hline $2008 *$ Treat & $\begin{array}{l}0.00043 \\
(0.0011)\end{array}$ & $\begin{array}{c}0.0013 \\
(0.00076)^{*}\end{array}$ & $\begin{array}{l}0.00031 \\
(0.0014)\end{array}$ & $\begin{array}{l}0.00050 \\
(0.0016)\end{array}$ & $\begin{array}{l}0.00080 \\
(0.0015)\end{array}$ \\
\hline $2009 *$ Treat & $\begin{array}{c}0.00031 \\
(0.00093)\end{array}$ & $\begin{array}{l}-0.00057 \\
(0.00071)\end{array}$ & $\begin{array}{c}0.0015 \\
(0.0012)\end{array}$ & $\begin{array}{l}0.00087 \\
(0.0013)\end{array}$ & $\begin{array}{c}0.0011 \\
(0.0016)\end{array}$ \\
\hline $2011^{*}$ Treat & $\begin{array}{c}0.0069 \\
(0.0018)^{* * *}\end{array}$ & $\begin{array}{c}0.0041 \\
(0.0015)^{* * *}\end{array}$ & $\begin{array}{c}0.0041 \\
(0.0016)^{* *}\end{array}$ & $\begin{array}{c}0.0059 \\
(0.0023)^{* *}\end{array}$ & $\begin{array}{c}0.0037 \\
(0.0025)\end{array}$ \\
\hline $2012^{*}$ Treat & $\begin{array}{c}0.0074 \\
(0.0035)^{* *}\end{array}$ & $\begin{array}{c}0.0067 \\
(0.0017)^{* * *}\end{array}$ & $\begin{array}{c}0.0058 \\
(0.0026)^{* *}\end{array}$ & $\begin{array}{c}0.011 \\
(0.0030)^{* * *}\end{array}$ & $\begin{array}{c}0.0054 \\
(0.0041)\end{array}$ \\
\hline $2013^{*}$ Treat & $\begin{array}{c}0.012 \\
(0.0035)^{* * *}\end{array}$ & $\begin{array}{c}0.011 \\
(0.0022)^{* * *}\end{array}$ & $\begin{array}{c}0.011 \\
(0.0027)^{* * *}\end{array}$ & $\begin{array}{c}0.014 \\
(0.0035)^{* * *}\end{array}$ & $\begin{array}{c}0.012 \\
(0.0035)^{* * *}\end{array}$ \\
\hline $2014^{*}$ Treat & $\begin{array}{c}0.016 \\
(0.0038)^{* * *}\end{array}$ & $\begin{array}{c}0.013 \\
(0.0025)^{* * *}\end{array}$ & $\begin{array}{c}0.014 \\
(0.0028)^{* * *}\end{array}$ & $\begin{array}{c}0.016 \\
(0.0039)^{* * *}\end{array}$ & $\begin{array}{c}0.016 \\
(0.0037)^{* * *}\end{array}$ \\
\hline $2015^{*}$ Treat & $\begin{array}{c}0.021 \\
(0.0044)^{* * *}\end{array}$ & $\begin{array}{c}0.017 \\
(0.0029)^{* * *}\end{array}$ & $\begin{array}{c}0.016 \\
(0.0035)^{* * *}\end{array}$ & $\begin{array}{c}0.018 \\
(0.0054)^{* * *}\end{array}$ & $\begin{array}{c}0.020 \\
(0.0045)^{* * *}\end{array}$ \\
\hline $2015^{*}$ Treat & $\begin{array}{c}0.026 \\
(0.0047)^{* * *}\end{array}$ & $\begin{array}{c}0.022 \\
(0.0033)^{* * *}\end{array}$ & $\begin{array}{c}0.020 \\
(0.0037)^{* * *}\end{array}$ & $\begin{array}{c}0.027 \\
(0.0044)^{* * *}\end{array}$ & $\begin{array}{c}0.025 \\
(0.0043)^{* * *}\end{array}$ \\
\hline $2016^{*}$ Treat & $\begin{array}{c}0.029 \\
(0.0048)^{* * *}\end{array}$ & $\begin{array}{c}0.025 \\
(0.0035)^{* * *}\end{array}$ & $\begin{array}{c}0.023 \\
(0.0037)^{* * *}\end{array}$ & $\begin{array}{c}0.032 \\
(0.0044)^{* * *}\end{array}$ & $\begin{array}{c}0.030 \\
(0.0044)^{* * *}\end{array}$ \\
\hline Observations & 5344 & 23087 & 8140 & 5643 & 5601 \\
\hline$R^{2}$ & 0.224 & 0.214 & 0.173 & 0.192 & 0.208 \\
\hline Mean of dep. var & 0.026 & 0.015 & 0.023 & 0.025 & 0.026 \\
\hline \multicolumn{6}{|c|}{ Panel B: Share Czech Workers } \\
\hline $2007 *$ Treat & $\begin{array}{l}0.00093 \\
(0.0012)\end{array}$ & $\begin{array}{c}0.0016 \\
(0.0011)\end{array}$ & $\begin{array}{c}0.00077 \\
(0.00079)\end{array}$ & $\begin{array}{l}0.00064 \\
(0.0011)\end{array}$ & $\begin{array}{l}0.00082 \\
(0.0011)\end{array}$ \\
\hline $2008^{*}$ Treat & $\begin{array}{c}0.00064 \\
(0.00081)\end{array}$ & $\begin{array}{c}0.00052 \\
(0.00062)\end{array}$ & $\begin{array}{c}0.00041 \\
(0.00054)\end{array}$ & $\begin{array}{c}0.00065 \\
(0.00079)\end{array}$ & $\begin{array}{c}0.00074 \\
(0.00079)\end{array}$ \\
\hline $2009 *$ Treat & $\begin{array}{c}0.00057 \\
(0.00068)\end{array}$ & $\begin{array}{l}-0.00036 \\
(0.00054)\end{array}$ & $\begin{array}{c}0.00035 \\
(0.00046)\end{array}$ & $\begin{array}{c}0.00038 \\
(0.00067)\end{array}$ & $\begin{array}{c}0.00029 \\
(0.00068)\end{array}$ \\
\hline $2011^{*}$ Treat & $\begin{array}{c}0.0075 \\
(0.0015)^{* * *}\end{array}$ & $\begin{array}{c}0.0048 \\
(0.0013)^{* * *}\end{array}$ & $\begin{array}{c}0.0049 \\
(0.0010)^{* * *}\end{array}$ & $\begin{array}{c}0.0077 \\
(0.0014)^{* * *}\end{array}$ & $\begin{array}{c}0.0074 \\
(0.0014)^{* * *}\end{array}$ \\
\hline $2012^{*}$ Treat & $\begin{array}{c}0.014 \\
(0.0020)^{* * *}\end{array}$ & $\begin{array}{c}0.0090 \\
(0.0015)^{* * *}\end{array}$ & $\begin{array}{c}0.0095 \\
(0.0014)^{* * *}\end{array}$ & $\begin{array}{c}0.013 \\
(0.0019)^{* * *}\end{array}$ & $\begin{array}{c}0.013 \\
(0.0019)^{* * *}\end{array}$ \\
\hline $2013^{*}$ Treat & $\begin{array}{c}0.019 \\
(0.0025)^{* * *}\end{array}$ & $\begin{array}{c}0.014 \\
(0.0020)^{* * *}\end{array}$ & $\begin{array}{c}0.013 \\
(0.0017)^{* * *}\end{array}$ & $\begin{array}{c}0.018 \\
(0.0024)^{* * *}\end{array}$ & $\begin{array}{c}0.017 \\
(0.0025)^{* * *}\end{array}$ \\
\hline $2014^{*}$ Treat & $\begin{array}{c}0.023 \\
(0.0027)^{* * *}\end{array}$ & $\begin{array}{c}0.018 \\
(0.0022)^{* * *}\end{array}$ & $\begin{array}{c}0.016 \\
(0.0019)^{* * *}\end{array}$ & $\begin{array}{c}0.022 \\
(0.0026)^{* * *}\end{array}$ & $\begin{array}{c}0.022 \\
(0.0026)^{* * *}\end{array}$ \\
\hline $2015^{*}$ Treat & $\begin{array}{c}0.029 \\
(0.0031)^{\text {*** }}\end{array}$ & $\begin{array}{c}0.024 \\
(0.0026)^{* * *}\end{array}$ & $\begin{array}{c}0.020 \\
(0.0022)^{* * *}\end{array}$ & $\begin{array}{c}0.028 \\
(0.0029)^{* * *}\end{array}$ & $\begin{array}{c}0.028 \\
(0.0030)^{* * *}\end{array}$ \\
\hline $2015^{*}$ Treat & $\begin{array}{c}0.033 \\
(0.0034)^{* * *}\end{array}$ & $\begin{array}{c}0.028 \\
(0.0030)^{* * *}\end{array}$ & $\begin{array}{c}0.024 \\
(0.0025)^{* * *}\end{array}$ & $\begin{array}{c}0.033 \\
(0.0033)^{* * *}\end{array}$ & $\begin{array}{c}0.032 \\
(0.0033)^{* * *}\end{array}$ \\
\hline $2016^{*}$ Treat & $\begin{array}{c}0.036 \\
(0.0033)^{* * *}\end{array}$ & $\begin{array}{c}0.031 \\
(0.0030)^{* * *}\end{array}$ & $\begin{array}{c}0.027 \\
(0.0024)^{* * *}\end{array}$ & $\begin{array}{c}0.035 \\
(0.0032)^{* * *}\end{array}$ & $\begin{array}{c}0.034 \\
(0.0032)^{* * *}\end{array}$ \\
\hline Observations & 5344 & 23087 & 8140 & 5643 & 5601 \\
\hline$R^{2}$ & 0.211 & 0.181 & 0.157 & 0.213 & 0.213 \\
\hline Mean of dep. var & 0.015 & 0.0042 & 0.011 & 0.015 & 0.015 \\
\hline
\end{tabular}

Notes: This table reports event study coefficients for matched German municipalities before and after the opening of the German labor market for Czech workers in 2011. Panel A reports event study coefficients for the share of EU8 workers by total employment. Panel B reports event study coefficients for the share of Czech workers by total employment. Column (1) reports results when using the rest of Bavaria as control group. Column (2) reports results when changing the definition of treated municipalities to all municipalities located up to $60 \mathrm{~km}$ from the nearest road border crossing to the Czech Republic. Column (3) reports results when deliberately excluding control municipalities located $40-100 \mathrm{~km}$ from the nearest Czech border crossing. Column (4) reports results when allowing for control municipalities in the same commuting zones as treatment municipalities. Regressions control for municipality and year fixed effects. In all specifications, standard errors are clustered at the municipality level. *, ** and $* * *$ correspond to 10,5 and 1 percent significance levels, respectively. West Germany only. Source: Integrated Employment Biographies (IEB) \& Establishment History Panel (BHP). 
Table A.2.14: Robustness II: Regional Native Wages and Employment

\begin{tabular}{|c|c|c|c|c|c|}
\hline & $\begin{array}{c}(1) \\
\text { Baseline }\end{array}$ & $\begin{array}{c}(2) \\
\text { Rest of Bavaria } \\
\text { as Control }\end{array}$ & $\begin{array}{c}(3) \\
60 \mathrm{~km} \\
\text { Threshold }\end{array}$ & $\begin{array}{c}(4) \\
\text { Matching w/o } \\
\text { 40-100km Controls }\end{array}$ & $\begin{array}{c}(5) \\
\text { Matching with } \\
\text { Commuting Zones }\end{array}$ \\
\hline \multicolumn{6}{|c|}{ Panel A: Native Log Wages } \\
\hline $2007^{*}$ Treat & $\begin{array}{c}0.0063 \\
(0.010)\end{array}$ & $\begin{array}{c}-0.000021 \\
(0.0054)\end{array}$ & $\begin{array}{c}0.0093 \\
(0.0078)\end{array}$ & $\begin{array}{c}0.033 \\
(0.013)^{* * *}\end{array}$ & $\begin{array}{c}0.0011 \\
(0.0099)\end{array}$ \\
\hline $2008 *$ Treat & $\begin{array}{c}-0.0060 \\
(0.010)\end{array}$ & $\begin{array}{l}-0.0017 \\
(0.0053)\end{array}$ & $\begin{array}{l}0.00050 \\
(0.0075)\end{array}$ & $\begin{array}{c}0.013 \\
(0.012)\end{array}$ & $\begin{array}{l}-0.015 \\
(0.010)\end{array}$ \\
\hline $2009^{*}$ Treat & $\begin{array}{l}-0.0082 \\
(0.0080)\end{array}$ & $\begin{array}{l}-0.0046 \\
(0.0044)\end{array}$ & $\begin{array}{l}-0.0028 \\
(0.0063)\end{array}$ & $\begin{array}{c}0.016 \\
(0.011)\end{array}$ & $\begin{array}{c}-0.010 \\
(0.0098)\end{array}$ \\
\hline $2011 *$ Treat & $\begin{array}{l}-0.015 \\
(0.010)\end{array}$ & $\begin{array}{c}-0.011 \\
(0.0049)^{* *}\end{array}$ & $\begin{array}{l}-0.0022 \\
(0.0074)\end{array}$ & $\begin{array}{c}-0.00031 \\
(0.013)\end{array}$ & $\begin{array}{l}-0.017 \\
(0.011)\end{array}$ \\
\hline $2012^{*}$ Treat & $\begin{array}{l}-0.017 \\
(0.011)\end{array}$ & $\begin{array}{l}-0.0064 \\
(0.0058)\end{array}$ & $\begin{array}{l}-0.0048 \\
(0.0078)\end{array}$ & $\begin{array}{c}-0.0028 \\
(0.015)\end{array}$ & $\begin{array}{c}-0.0093 \\
(0.012)\end{array}$ \\
\hline $2013^{*}$ Treat & $\begin{array}{c}-0.024 \\
(0.011)^{* *}\end{array}$ & $\begin{array}{l}-0.0083 \\
(0.0060)\end{array}$ & $\begin{array}{c}-0.010 \\
(0.0082)\end{array}$ & $\begin{array}{c}-0.0062 \\
(0.014)\end{array}$ & $\begin{array}{l}-0.015 \\
(0.012)\end{array}$ \\
\hline $2014^{*}$ Treat & $\begin{array}{c}-0.024 \\
(0.011)^{* *}\end{array}$ & $\begin{array}{c}-0.015 \\
(0.0063)^{* *}\end{array}$ & $\begin{array}{c}-0.012 \\
(0.0087)\end{array}$ & $\begin{array}{l}-0.012 \\
(0.015)\end{array}$ & $\begin{array}{l}-0.014 \\
(0.013)\end{array}$ \\
\hline $2015^{*}$ Treat & $\begin{array}{c}-0.026 \\
(0.012)^{* *}\end{array}$ & $\begin{array}{c}-0.010 \\
(0.0067)\end{array}$ & $\begin{array}{c}-0.014 \\
(0.0090)\end{array}$ & $\begin{array}{l}-0.010 \\
(0.015)\end{array}$ & $\begin{array}{r}-0.0041 \\
(0.014)\end{array}$ \\
\hline $2015^{*}$ Treat & $\begin{array}{c}-0.027 \\
(0.011)^{* *}\end{array}$ & $\begin{array}{c}-0.014 \\
(0.0067)^{* *}\end{array}$ & $\begin{array}{c}-0.013 \\
(0.0088)\end{array}$ & $\begin{array}{l}-0.017 \\
(0.016)\end{array}$ & $\begin{array}{l}-0.014 \\
(0.013)\end{array}$ \\
\hline $2016^{*}$ Treat & $\begin{array}{c}-0.024 \\
(0.011)^{* *}\end{array}$ & $\begin{array}{c}-0.011 \\
(0.0066)\end{array}$ & $\begin{array}{l}-0.0072 \\
(0.0091)\end{array}$ & $\begin{array}{l}-0.013 \\
(0.015)\end{array}$ & $\begin{array}{l}-0.010 \\
(0.014)\end{array}$ \\
\hline Observations & 5346 & 22616 & 8140 & 5653 & 5607 \\
\hline & 0.513 & 0.603 & 0.515 & 0.397 & 0.419 \\
\hline Mean of dep. var & 4.12 & 4.17 & 4.14 & 4.12 & 4.12 \\
\hline \multicolumn{6}{|c|}{ Panel B: Native Employment Share by 2010 Employment } \\
\hline $2007^{*}$ Treat & $\begin{array}{l}0.0073 \\
(0.017)\end{array}$ & $\begin{array}{c}0.016 \\
(0.0097)^{*}\end{array}$ & $\begin{array}{c}-0.0083 \\
(0.014)\end{array}$ & $\begin{array}{c}0.014 \\
(0.016)\end{array}$ & $\begin{array}{c}-0.0049 \\
(0.015)\end{array}$ \\
\hline $2008^{*}$ Treat & $\begin{array}{l}-0.016 \\
(0.015)\end{array}$ & $\begin{array}{c}0.0025 \\
(0.0088)\end{array}$ & $\begin{array}{c}-0.024 \\
(0.013)^{*}\end{array}$ & $\begin{array}{l}-0.011 \\
(0.015)\end{array}$ & $\begin{array}{l}-0.019 \\
(0.015)\end{array}$ \\
\hline $2009^{*}$ Treat & $\begin{array}{c}0.0019 \\
(0.0093)\end{array}$ & $\begin{array}{l}0.00081 \\
(0.0063)\end{array}$ & $\begin{array}{c}0.0020 \\
(0.0072)\end{array}$ & $\begin{array}{c}0.0037 \\
(0.0098)\end{array}$ & $\begin{array}{c}-0.00025 \\
(0.0090)\end{array}$ \\
\hline $2011^{*}$ Treat & $\begin{array}{c}-0.000028 \\
(0.0070)\end{array}$ & $\begin{array}{c}-0.0073 \\
(0.0045)^{*}\end{array}$ & $\begin{array}{l}-0.013 \\
(0.012)\end{array}$ & $\begin{array}{c}0.0031 \\
(0.0091)\end{array}$ & $\begin{array}{c}0.0031 \\
(0.0092)\end{array}$ \\
\hline $2012^{*}$ Treat & $\begin{array}{l}-0.019 \\
(0.019)\end{array}$ & $\begin{array}{c}-0.016 \\
(0.0060)^{* * *}\end{array}$ & $\begin{array}{l}-0.016 \\
(0.013)\end{array}$ & $\begin{array}{l}-0.017 \\
(0.012)\end{array}$ & $\begin{array}{c}-0.0094 \\
(0.013)\end{array}$ \\
\hline $2013^{*}$ Treat & $\begin{array}{l}-0.012 \\
(0.019)\end{array}$ & $\begin{array}{c}-0.019 \\
(0.0076)^{* *}\end{array}$ & $\begin{array}{l}0.0075 \\
(0.011)\end{array}$ & $\begin{array}{r}-0.0079 \\
(0.013)\end{array}$ & $\begin{array}{c}-0.00070 \\
(0.014)\end{array}$ \\
\hline $2014^{*}$ Treat & $\begin{array}{r}-0.0025 \\
(0.018)\end{array}$ & $\begin{array}{c}-0.027 \\
(0.0092)^{* * *}\end{array}$ & $\begin{array}{l}0.0098 \\
(0.012)\end{array}$ & $\begin{array}{l}-0.012 \\
(0.015)\end{array}$ & $\begin{array}{c}0.00041 \\
(0.015)\end{array}$ \\
\hline $2015^{*}$ Treat & $\begin{array}{l}0.0063 \\
(0.019)\end{array}$ & $\begin{array}{c}-0.027 \\
(0.011)^{* *}\end{array}$ & $\begin{array}{c}0.022 \\
(0.014)\end{array}$ & $\begin{array}{c}-0.0085 \\
(0.017)\end{array}$ & $\begin{array}{l}0.0083 \\
(0.016)\end{array}$ \\
\hline $2015^{*}$ Treat & $\begin{array}{c}0.010 \\
(0.021)\end{array}$ & $\begin{array}{c}-0.024 \\
(0.013)^{*}\end{array}$ & $\begin{array}{c}0.034 \\
(0.015)^{* *}\end{array}$ & $\begin{array}{l}0.0077 \\
(0.018)\end{array}$ & $\begin{array}{c}0.018 \\
(0.017)\end{array}$ \\
\hline $2016 *$ Treat & $\begin{array}{c}0.013 \\
(0.022)\end{array}$ & $\begin{array}{c}-0.023 \\
(0.013)^{*}\end{array}$ & $\begin{array}{c}0.040 \\
(0.016)^{* *}\end{array}$ & $\begin{array}{c}0.011 \\
(0.018)\end{array}$ & $\begin{array}{c}0.024 \\
(0.018)\end{array}$ \\
\hline Observations & 5346 & 22616 & 8140 & 5654 & 5610 \\
\hline$R^{2}$ & 0.082 & 0.212 & 0.083 & 0.102 & 0.089 \\
\hline Mean of dep. var & 1.03 & 1.04 & 1.03 & 1.03 & 1.03 \\
\hline
\end{tabular}

Notes: This table reports event study coefficients for matched German municipalities before and after the opening of the German labor market for Czech workers in 2011. Panel A reports event study coefficients for native log wages. Panel B reports event study coefficients for the share of native employment by total employment in 2010. Column (1) reports results when using the rest of Bavaria as control group. Column (2) reports results when changing the definition of treated municipalities to all municipalities located up to $60 \mathrm{~km}$ from the nearest road border crossing to the Czech Republic. Column (3) reports results when deliberately excluding control municipalities located $40-100 \mathrm{~km}$ from the nearest Czech border crossing. Column (4) reports results when allowing for control municipalities in the same commuting zones as treatment municipalities. Regressions control for municipality and year fixed effects. In all specifications, standard errors are clustered at the municipality level. *, ** and ${ }^{* * *}$ correspond to 10,5 and 1 percent significance levels, respectively. West Germany only. Source: Integrated Employment Biographies (IEB) \& Establishment History Panel (BHP). 
Table A.2.15: Robustness III: Worker-Level Results Without Construction and Health Sectors

\begin{tabular}{|c|c|c|c|c|c|c|c|c|}
\hline & $\begin{array}{c}(1) \\
\text { Log Earnings } \\
\text { Non-Reweighted }\end{array}$ & $\begin{array}{c}(2) \\
\text { Log Earnings } \\
\text { Reweighted }\end{array}$ & $\begin{array}{c}(3) \\
\text { Log Wage } \\
\text { Non-Reweighted }\end{array}$ & $\begin{array}{c}(4) \\
\text { Log Wage } \\
\text { Reweighted }\end{array}$ & $\begin{array}{c}(5) \\
\text { Employment } \\
\text { Non-Reweighted }\end{array}$ & $\begin{array}{l}\quad(6) \\
\text { Employment } \\
\text { Reweighted }\end{array}$ & $\begin{array}{c}(7) \\
\text { Days Worked } \\
\text { Non-Reweighted }\end{array}$ & $\begin{array}{c}(8) \\
\text { Days Worked } \\
\text { Reweighted }\end{array}$ \\
\hline \multirow[t]{2}{*}{$2007 *$ Treat } & 0.019 & 0.00036 & 0.017 & -0.0025 & 0.011 & 0.0090 & 2.04 & 1.46 \\
\hline & $(0.0080)^{* *}$ & $(0.0084)$ & $(0.0069)^{* *}$ & $(0.0072)$ & $(0.0030)^{* * *}$ & $(0.0031)^{* * *}$ & $(1.18)^{*}$ & $(1.24)$ \\
\hline \multirow[t]{2}{*}{$2008^{*}$ Treat } & 0.022 & 0.0026 & 0.012 & -0.0049 & 0.0051 & 0.0037 & 1.89 & 0.92 \\
\hline & $(0.0068)^{* * *}$ & $(0.0072)$ & $(0.0059)^{* *}$ & $(0.0062)$ & $(0.0024)^{* *}$ & $(0.0025)$ & $(1.01)^{*}$ & $(1.07)$ \\
\hline \multirow[t]{2}{*}{$2009^{*}$ Treat } & 0.011 & -0.0045 & 0.0037 & -0.0084 & 0.0039 & 0.0033 & 1.69 & 0.32 \\
\hline & $(0.0052)^{* *}$ & $(0.0056)$ & $(0.0049)$ & $(0.0051)^{*}$ & $(0.0016)^{* *}$ & $(0.0017)^{* *}$ & $(0.74)^{* *}$ & $(0.79)$ \\
\hline \multirow[t]{2}{*}{ 2011*Treat } & -0.00053 & 0.00083 & -0.0079 & -0.010 & 0.0022 & 0.0033 & 0.93 & 1.84 \\
\hline & $(0.0049)$ & $(0.0051)$ & $(0.0044)^{*}$ & $(0.0046)^{* *}$ & $(0.0016)$ & $(0.0016)^{* *}$ & $(0.68)$ & $(0.70)^{* * *}$ \\
\hline \multirow[t]{2}{*}{$2012^{*}$ Treat } & -0.0084 & -0.0085 & -0.011 & -0.012 & 0.0044 & 0.0059 & 0.75 & 1.46 \\
\hline & $(0.0061)$ & $(0.0063)$ & $(0.0054)^{* *}$ & $(0.0055)^{* *}$ & $(0.0021)^{* *}$ & $(0.0022)^{* * *}$ & $(0.89)$ & $(0.93)$ \\
\hline \multirow[t]{2}{*}{$2013^{*}$ Treat } & 0.00057 & 0.0020 & -0.015 & -0.015 & 0.0047 & 0.0068 & 2.08 & 3.25 \\
\hline & $(0.0069)$ & $(0.0071)$ & $(0.0060)^{* *}$ & $(0.0062)^{* *}$ & $(0.0024)^{*}$ & $(0.0025)^{* * *}$ & $(0.99)^{* *}$ & $(1.02)^{* * *}$ \\
\hline \multirow[t]{2}{*}{$2014 *$ Treat } & -0.0020 & -0.0038 & -0.013 & -0.016 & 0.0059 & 0.0090 & 2.84 & 4.27 \\
\hline & $(0.0074)$ & $(0.0077)$ & $(0.0064)^{* *}$ & $(0.0067)^{* *}$ & $(0.0026)^{* *}$ & $(0.0026)^{* * *}$ & $(1.04)^{* * *}$ & $(1.08)^{* * *}$ \\
\hline \multirow[t]{2}{*}{$2015^{*}$ Treat } & -0.0044 & -0.0071 & -0.013 & -0.018 & 0.0062 & 0.010 & 2.56 & 4.40 \\
\hline & $(0.0077)$ & $(0.0080)$ & $(0.0069)^{*}$ & $(0.0071)^{* *}$ & $(0.0027)^{* *}$ & $(0.0028)^{* * *}$ & $(1.09)^{* *}$ & $(1.12)^{* * *}$ \\
\hline \multirow[t]{2}{*}{$2015^{*}$ Treat } & 0.0012 & -0.0020 & -0.0086 & -0.014 & 0.0021 & 0.0068 & 1.29 & 3.25 \\
\hline & $(0.0081)$ & $(0.0084)$ & $(0.0072)$ & $(0.0074)^{*}$ & $(0.0028)$ & $(0.0029)^{* *}$ & (1.13) & $(1.16)^{* * *}$ \\
\hline \multirow[t]{2}{*}{$2016 *$ Treat } & -0.0027 & -0.0053 & -0.010 & -0.015 & 0.0047 & 0.010 & 1.96 & 4.00 \\
\hline & $(0.0083)$ & $(0.0086)$ & $(0.0076)$ & $(0.0078)^{* *}$ & $(0.0030)$ & $(0.0030)^{* * *}$ & $(1.17)^{*}$ & $(1.20)^{* * *}$ \\
\hline Observations & 424866 & 418816 & 416284 & 410376 & 452265 & 445148 & 452265 & 445148 \\
\hline$R^{2}$ & 0.057 & 0.059 & 0.075 & 0.077 & 0.026 & 0.025 & 0.025 & 0.025 \\
\hline Mean of dep. var & 9.78 & 9.78 & 3.96 & 3.96 & 0.94 & 0.94 & 322.5 & 322.5 \\
\hline Worker FE & Yes & Yes & Yes & Yes & Yes & Yes & Yes & Yes \\
\hline Year FE & Yes & Yes & Yes & Yes & Yes & Yes & Yes & Yes \\
\hline
\end{tabular}

Notes: This table reports event study coefficients for matched incumbent German workers before and after the opening of the German labor market for Czech workers in 2011 when excluding health and construction sectors. Columns (1) and (2) report event study coefficients for log earnings without and with reweighting, respectively. Columns (3) and (4) report event study coefficients for log wage without and with reweighting, respectively. Columns (5) and (6) report event study coefficients for employment without and with reweighting, respectively. Columns (7) and (8) report event study coefficients for days worked without and with reweighting, respectively. Regressions control for year and individual fixed effects. In all specifications, standard errors are clustered at the worker level. ${ }^{*},{ }^{* *}$ and ${ }^{* * *}$ correspond to 10,5 and 1 percent signficance levels, respectively. Source: Integrated Employment Biographies (IEB). 
Table A.2.16: Robustness IV: Worker-Level Results Without Construction and Health Sectors by Tenure

\begin{tabular}{|c|c|c|c|c|c|c|}
\hline & $\begin{array}{c}(1) \\
\text { Log Wage } \\
<1 \text { Year Tenure }\end{array}$ & $\begin{array}{c}(2) \\
\text { Log Wage } \\
>=1 \text { Year Tenure }\end{array}$ & $\begin{array}{c}(3) \\
\text { Log Wage } \\
>=3 \text { Years Tenure }\end{array}$ & $\begin{array}{c}(4) \\
\text { Days Worked } \\
<1 \text { Year Tenure }\end{array}$ & $\begin{array}{c}(5) \\
\text { Days Worked } \\
>=1 \text { Year Tenure }\end{array}$ & $\begin{array}{c}(6) \\
\text { Days Worked } \\
>=3 \text { Years Tenure }\end{array}$ \\
\hline $2007^{*}$ Treat & $\begin{array}{l}-0.046 \\
(0.034)\end{array}$ & $\begin{array}{c}0.0047 \\
(0.0068)\end{array}$ & $\begin{array}{c}-0.012 \\
(0.0055)^{* *}\end{array}$ & $\begin{array}{c}5.56 \\
(4.45)\end{array}$ & $\begin{array}{c}0.86 \\
(1.26)\end{array}$ & $\begin{array}{c}-2.15 \\
(0.77)^{* * *}\end{array}$ \\
\hline $2008^{*}$ Treat & $\begin{array}{l}-0.036 \\
(0.031)\end{array}$ & $\begin{array}{l}0.00041 \\
(0.0057)\end{array}$ & $\begin{array}{c}-0.012 \\
(0.0042)^{* * *}\end{array}$ & $\begin{array}{c}1.60 \\
(4.22)\end{array}$ & $\begin{array}{c}0.85 \\
(1.06)\end{array}$ & $\begin{array}{l}-0.43 \\
(0.47)\end{array}$ \\
\hline $2009^{*}$ Treat & $\begin{array}{l}-0.046 \\
(0.031)\end{array}$ & $\begin{array}{l}-0.0018 \\
(0.0043)\end{array}$ & $\begin{array}{c}-0.0067 \\
(0.0034)^{*}\end{array}$ & $\begin{array}{c}3.98 \\
(3.68)\end{array}$ & $\begin{array}{l}-0.15 \\
(0.70)\end{array}$ & $\begin{array}{c}0.10 \\
(0.41)\end{array}$ \\
\hline $2011^{*}$ Treat & $\begin{array}{c}-0.044 \\
(0.022)^{* *}\end{array}$ & $\begin{array}{l}-0.0056 \\
(0.0042)\end{array}$ & $\begin{array}{l}-0.0015 \\
(0.0041)\end{array}$ & $\begin{array}{c}6.58 \\
(2.93)^{* *}\end{array}$ & $\begin{array}{c}1.09 \\
(0.67)\end{array}$ & $\begin{array}{c}1.01 \\
(0.68)\end{array}$ \\
\hline $2012^{*}$ Treat & $\begin{array}{l}-0.032 \\
(0.024)\end{array}$ & $\begin{array}{c}-0.0095 \\
(0.0053)^{*}\end{array}$ & $\begin{array}{c}-0.0083 \\
(0.0050)^{*}\end{array}$ & $\begin{array}{c}8.68 \\
(3.57)^{* *}\end{array}$ & $\begin{array}{c}0.34 \\
(0.92)\end{array}$ & $\begin{array}{c}1.01 \\
(0.97)\end{array}$ \\
\hline $2013^{*}$ Treat & $\begin{array}{c}-0.057 \\
(0.026)^{* *}\end{array}$ & $\begin{array}{l}-0.0095 \\
(0.0061)\end{array}$ & $\begin{array}{l}-0.0063 \\
(0.0057)\end{array}$ & $\begin{array}{c}10.3 \\
(3.74)^{* * *}\end{array}$ & $\begin{array}{c}2.15 \\
(1.03)^{* *}\end{array}$ & $\begin{array}{c}2.15 \\
(1.08)^{* *}\end{array}$ \\
\hline $2014^{*}$ Treat & $\begin{array}{c}-0.072 \\
(0.027)^{* * *}\end{array}$ & $\begin{array}{l}-0.0092 \\
(0.0065)\end{array}$ & $\begin{array}{l}-0.0013 \\
(0.0062)\end{array}$ & $\begin{array}{c}10.3 \\
(3.86)^{* * *}\end{array}$ & $\begin{array}{c}3.33 \\
(1.10)^{* * *}\end{array}$ & $\begin{array}{c}3.22 \\
(1.16)^{* * *}\end{array}$ \\
\hline $2015^{*}$ Treat & $\begin{array}{c}-0.090 \\
(0.028)^{* * *}\end{array}$ & $\begin{array}{l}-0.0089 \\
(0.0070)\end{array}$ & $\begin{array}{l}-0.0037 \\
(0.0066)\end{array}$ & $\begin{array}{c}5.27 \\
(3.98)\end{array}$ & $\begin{array}{c}4.23 \\
(1.14)^{* * *}\end{array}$ & $\begin{array}{c}3.69 \\
(1.23)^{\text {*** }}\end{array}$ \\
\hline $2015^{*}$ Treat & $\begin{array}{c}-0.093 \\
(0.029)^{* * *}\end{array}$ & $\begin{array}{l}-0.0033 \\
(0.0073)\end{array}$ & $\begin{array}{l}-0.0031 \\
(0.0070)\end{array}$ & $\begin{array}{c}2.87 \\
(4.03)\end{array}$ & $\begin{array}{c}3.25 \\
(1.18)^{* * *}\end{array}$ & $\begin{array}{c}3.59 \\
(1.29)^{\text {*** }}\end{array}$ \\
\hline $2016^{*}$ Treat & $\begin{array}{c}-0.11 \\
(0.030)^{* * *}\end{array}$ & $\begin{array}{l}-0.0034 \\
(0.0077)\end{array}$ & $\begin{array}{c}0.0033 \\
(0.0075)\end{array}$ & $\begin{array}{c}0.30 \\
(4.13)\end{array}$ & $\begin{array}{c}4.50 \\
(1.23)^{* * *}\end{array}$ & $\begin{array}{c}4.79 \\
(1.37)^{* * *}\end{array}$ \\
\hline Observations & 44388 & 365988 & 265601 & 53889 & 391259 & 276551 \\
\hline$R^{2}$ & 0.126 & 0.072 & 0.048 & 0.060 & 0.031 & 0.047 \\
\hline Mean of dep. var & 3.69 & 3.99 & 4.08 & 273.6 & 329.3 & 342.4 \\
\hline Worker FE & Yes & Yes & Yes & Yes & Yes & Yes \\
\hline Year FE & Yes & Yes & Yes & Yes & Yes & Yes \\
\hline
\end{tabular}

Notes: This table reports event study coefficients for matched incumbent German workers by tenure before and after the opening of the German labor market for Czech workers in 2011. Excluding health and construction sectors. Columns (1), (2), and (3) report event study coefficients for log wages with reweighting. Column (1) reports results for workers with less than 1 year tenure, Column (2) reports results for workers with more than 1 year tenure, and Column (3) reports results for workers with more than 3 years tenure. Columns (4), (5), and (6) report event study coefficients for days worked with reweighting. Column (4) reports results for workers with less than 1 year tenure, Column (5) reports results for workers with more than 1 year tenure, and Column (6) reports results for workers with more than 3 years tenure. Regressions control for year and individual fixed effects. In all specifications, standard errors are clustered at the worker level. $*{ }^{* *}$ and $* * *$ correspond to 10, 5 and 1 percent signficance levels, respectively. Source: Integrated Employment Biographies (IEB). 
Table A.2.17: Robustness V: Worker Level Results Without Construction and Health Sectors by Skill

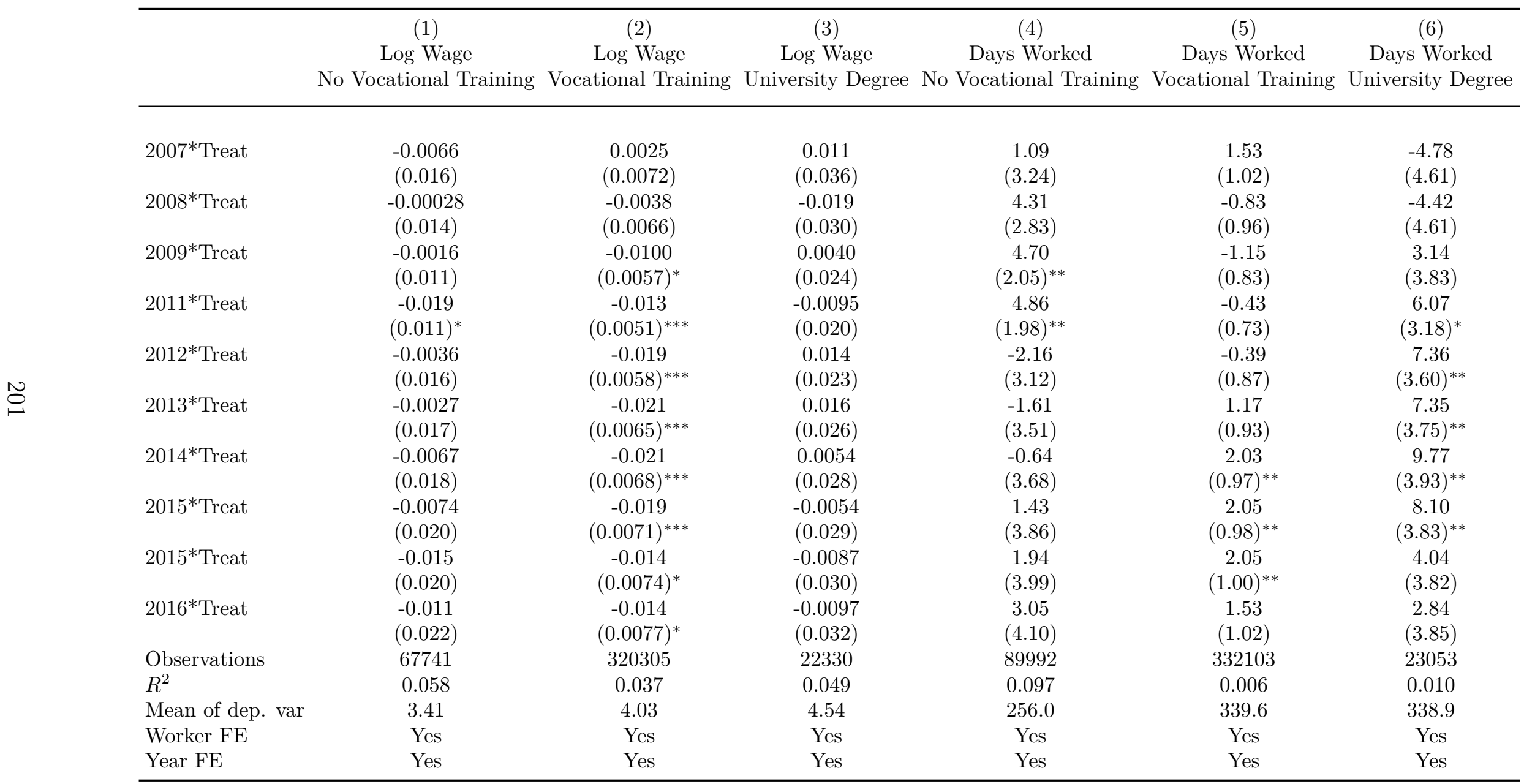

Notes: This table reports event study coefficients for matched incumbent German workers by skill before and after the opening of the German labor market for Czech workers in 2011. Excluding health and construction sectors. Columns (1), (2), and (3) report event study coefficients for log wages with reweighting. Column (1) reports results for workers without vocational training, Column (2) reports results for workers with vocational training, and Column (3) reports results for workers with a university degree. Columns (4), (5), and (6) report event study coefficients for days worked with reweighting. Column (4) reports results for workers without vocational training, Column (5) reports results for workers with vocational training, and Column (6) reports results for workers with a university degree. Regressions control for year and individual fixed effects. In all specifications, standard errors are clustered at the worker level. *** and ${ }^{* * *}$ correspond to 10,5 and 1 percent signficance levels, respectively. Source: Integrated Employment Biographies (IEB). 


\section{Appendix: Chapter 3}

Chapter 3: Figures 


\section{Figure A.3.1: Binscatter Plots: AKM Establishment Effects}

(A) AKM Effects vs. Share of Female Em-(B) AKM Effects vs. Share of Female Employees Pre Displ. ployees Post Displ.
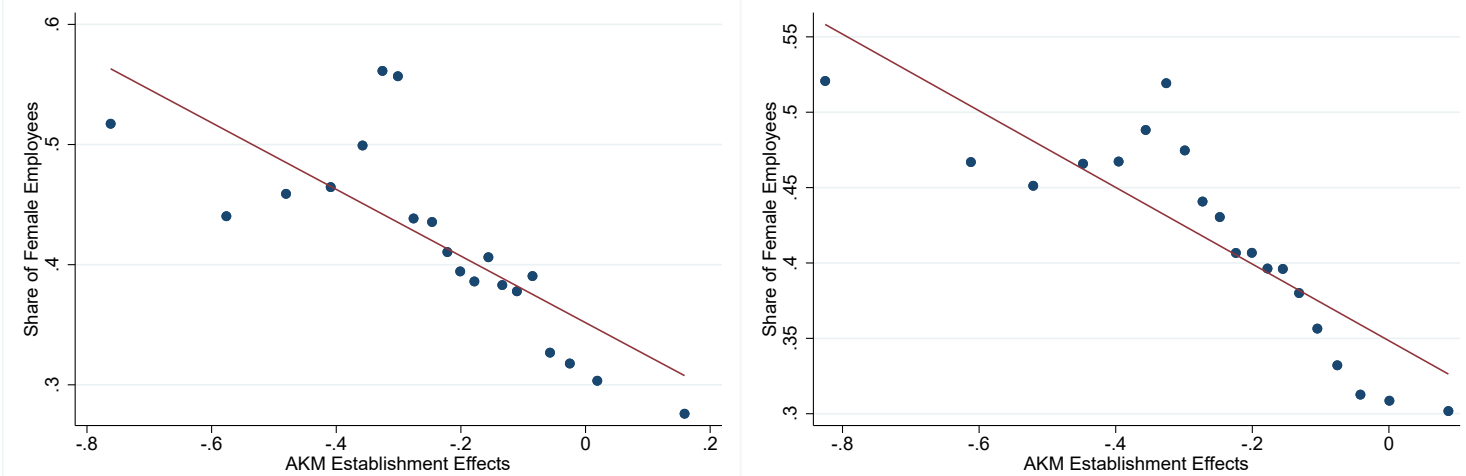

(C) AKM Effects vs. Establishment Size Pre(D) AKM Effects vs. Establishment Size Displ.

Post Displ.
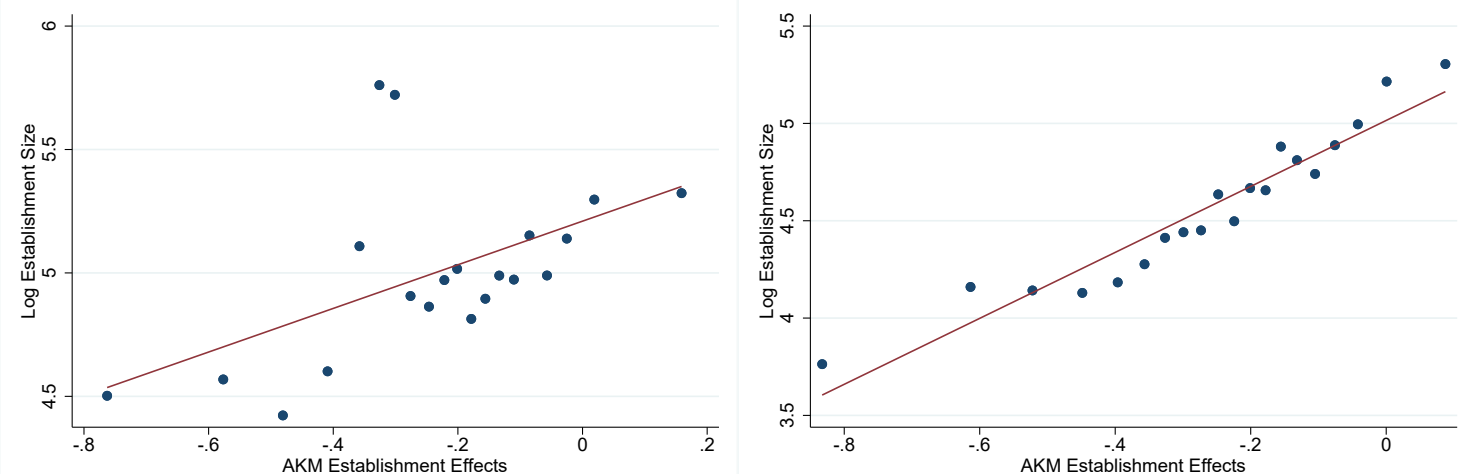

Notes: This figure shows different binscatter plots for AKM establishment effects vs. the share of female employees in an establishment (Panels (A-B)), and AKM establishment effects vs. establishment size (Panels (C-D)). The underlying sample are married couples before and after job displacement, respectively. The data span the observation period 1997-2017. 
Figure A.3.2: Robustness Checks: Adjusting Sample Restrictions

(A) Earnings r.t. $\mathrm{t}=\mathrm{c}-1$ - 10 Yrs Post Displ. (B) Log Wage Full-time - 10 Yrs Post Displ.
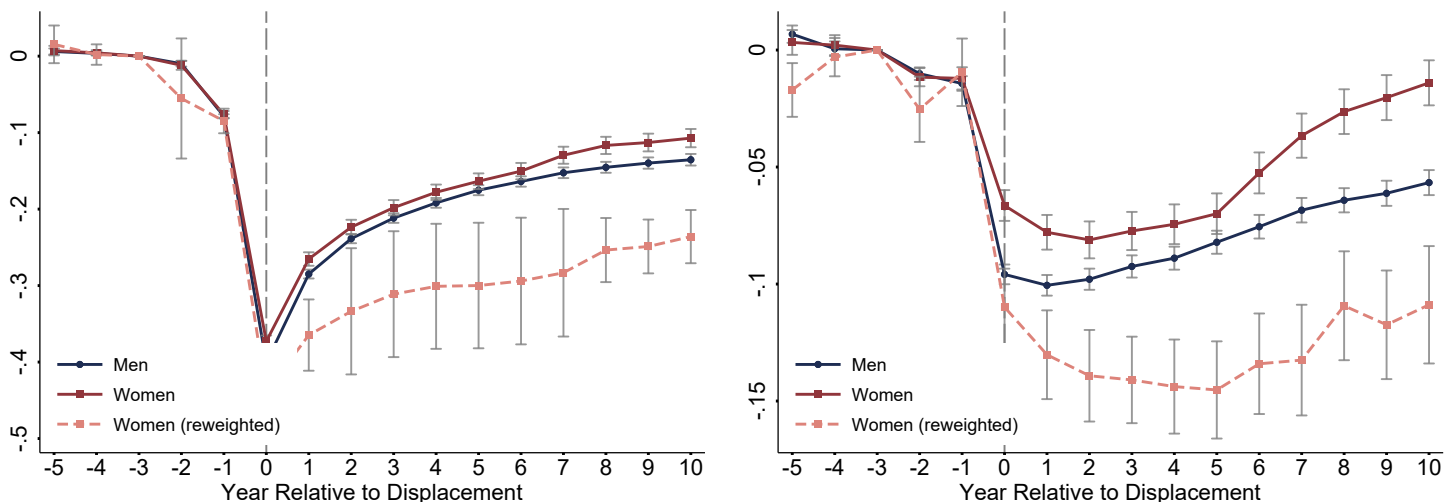

(C) Earnings r.t. $\mathrm{t}=\mathrm{c}-1$ - Shorter Tenure

(D) Log Wage Full-time - Shorter Tenure
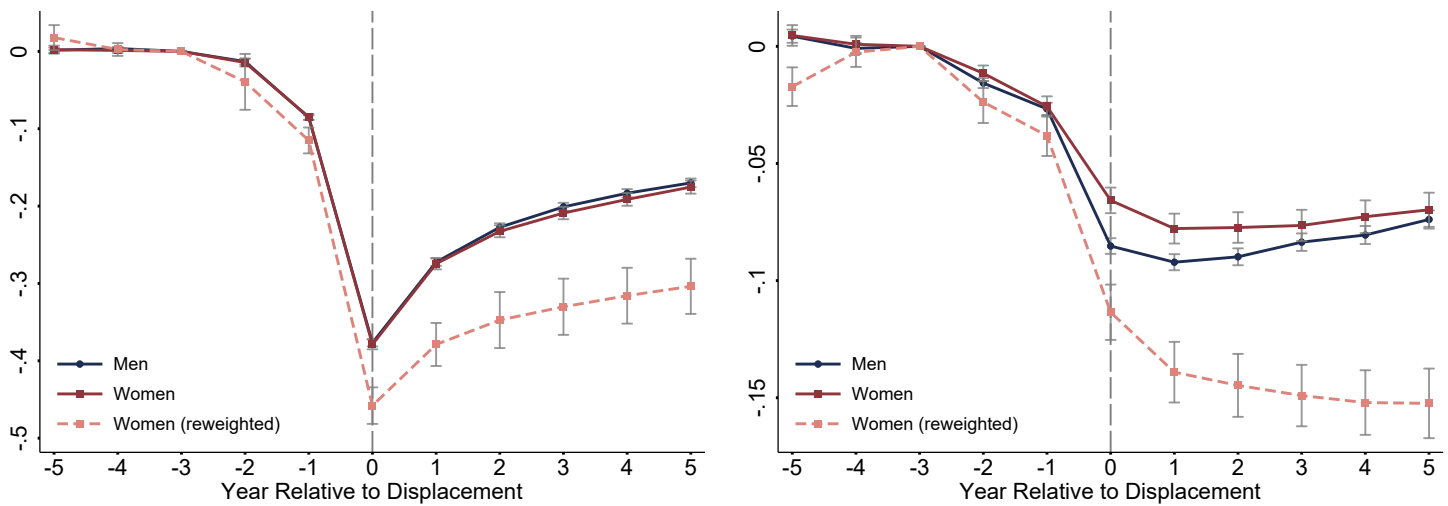

(E) Earnings r.t. $\quad \mathrm{t}=\mathrm{c}-1 \quad$ - Mahalanobis(F) Log Wage Full-time - Mahalanobis Match.

Match.
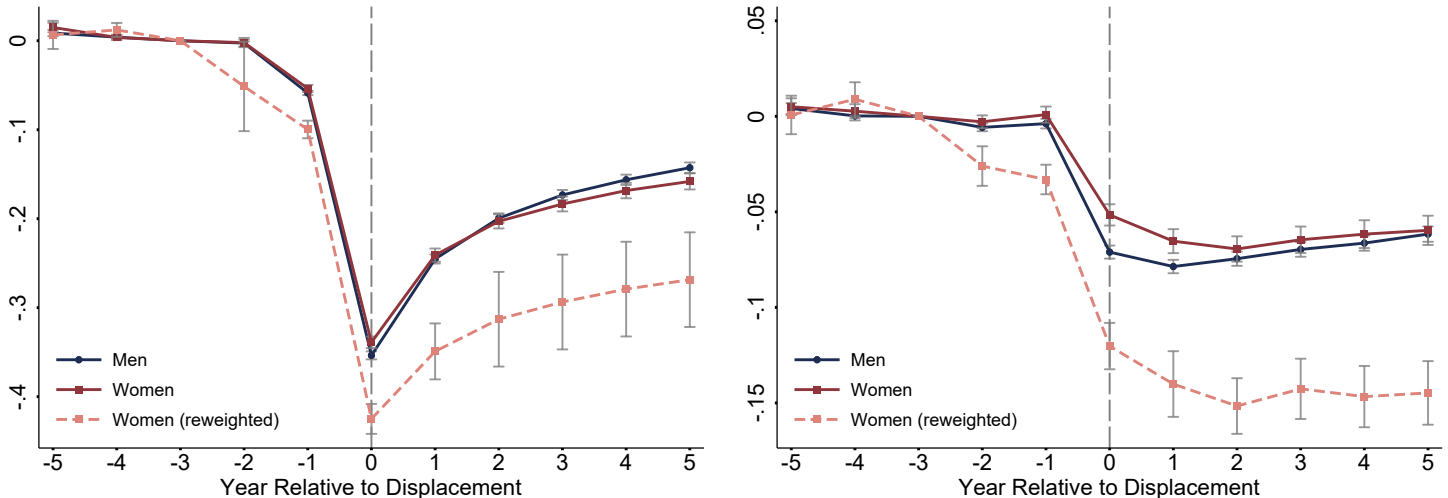

Notes: This figure shows how earnings relative to $t=c-1$ and full-time log wages differ for men and women before and after displacement for different robustness specifications. Panels (A)-(B) show eventstudy coefficients for a sample of workers which are observable up to 10 years after job loss. Panels (C)-(D) show eventstudy coefficients for a sample of workers with at least 1 year of tenure in $t=c$. Panels $(E)-(F)$ show eventstudy coefficients for a sample of workers matched via Mahalanobis in combination with exact matching of pre-displacement earnings deciles. The three lines correspond to three event study regressions: Men only, women only, and women reweighted with individual and establishment characteristics. All regressions include controls for person FE, year FE, years since separation, and age polynomials. Vertical bars indicate the estimated $95 \%$ confidence interval based on standard errors clustered at the individual level. Workers are displaced in 2002-2012, and they are observed from 1997-2017. 
Figure A.3.3: Robustness Checks: Alternative Reweighting and Matching

(A) Earnings r.t. $\mathrm{t}=\mathrm{c}-1$ - Rew. w. Occ.

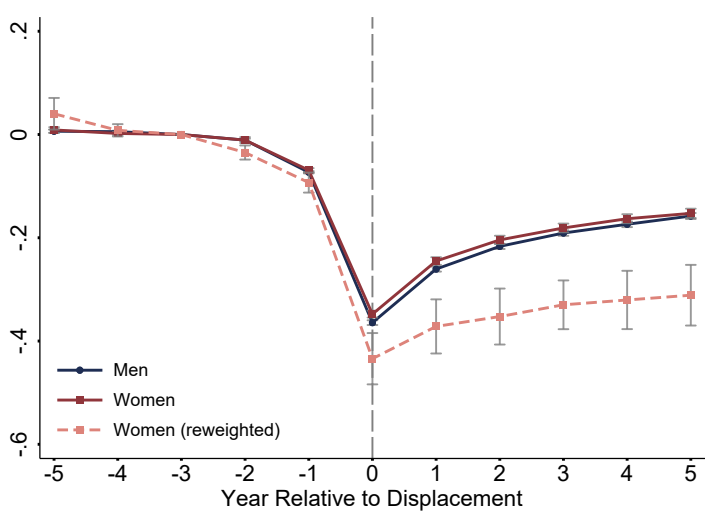

(C) Earnings r.t. $t=c-1$ - Displ. Estab. FE

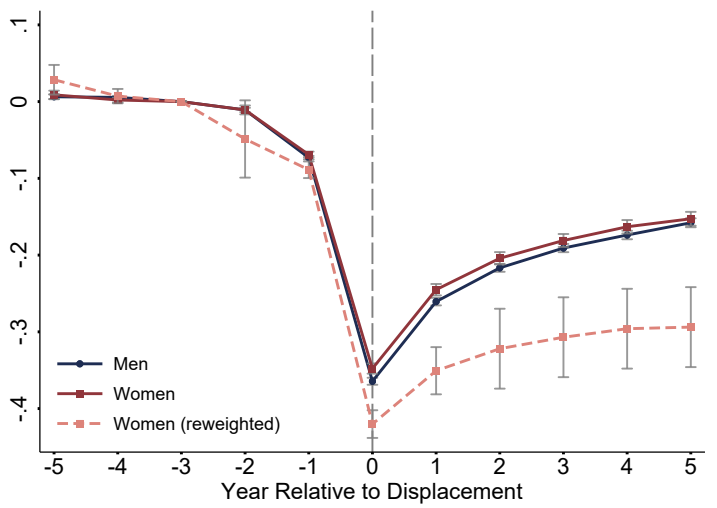

(E) Earnings r.t. $\mathrm{t}=\mathrm{c}-1$ - No Wages

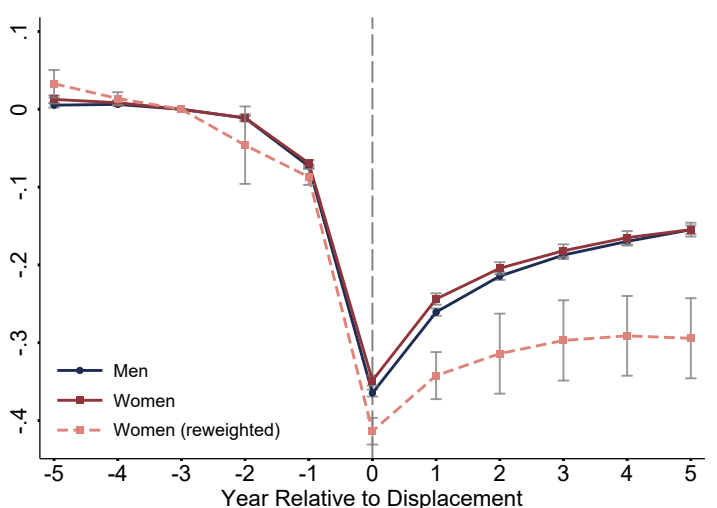

(B) Log Wage Full-time - Rew. w. Occ.

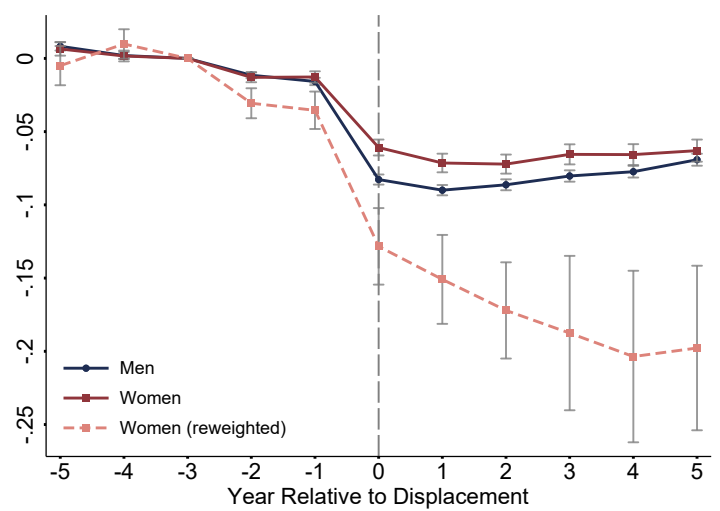

(D) Log Wage Full-time - Displ. Estab. FE

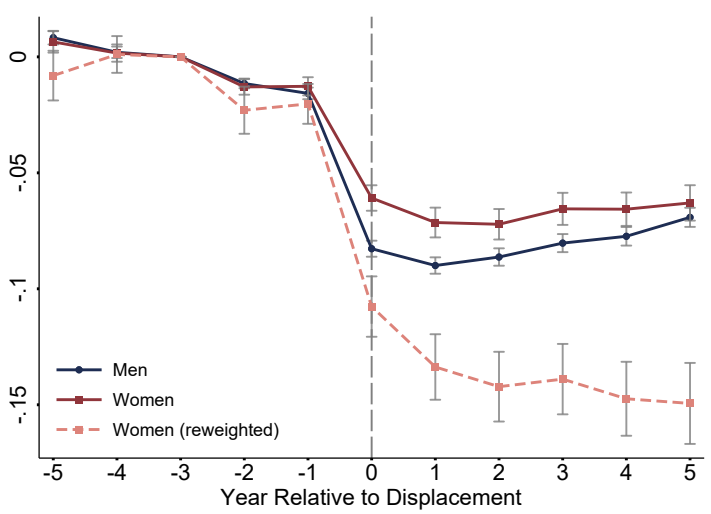

(F) Log Wage Full-time - No Wages

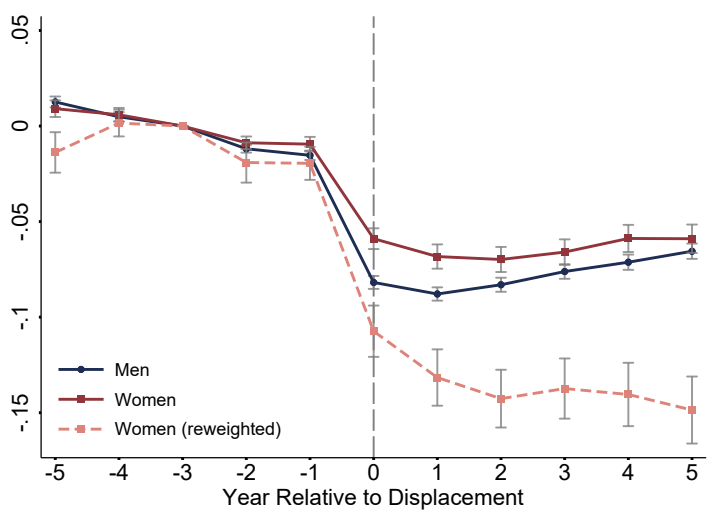

Notes: This figure shows how earnings relative to $\mathrm{t}=\mathrm{c}-1$ and full-time log wages differ for men and women before and after displacement for different robustness specifications. Panels (A)-(B) show eventstudy coefficients for our baseline sample of workers, where we add 1-digit occupations as controls to our reweighting algorithm. Panels (C)-(D) show eventstudy coefficients for our baseline sample of workers, where we add displacement establishment fixed effects to the regression specifications. Panels (E)-(F) show eventstudy coefficients for a sample of workers matched using our baseline propensity score matching algorithm but without matching on pre-displacement wages. The three lines correspond to three event study regressions: Men only, women only, and women reweighted with individual and establishment characteristics. All regressions include controls for person FE, year FE, years since separation, and age polynomials. Vertical bars indicate the estimated $95 \%$ confidence interval based on standard errors clustered at the individual level. Workers are displaced in 2002-2012, and they are observed from $1997-2017$. 
Figure A.3.4: Robustness Checks: Reweighting Men to Women, Non-Couples

(A) Earnings r.t. $\mathrm{t}=\mathrm{c}-1$ - Men to Women

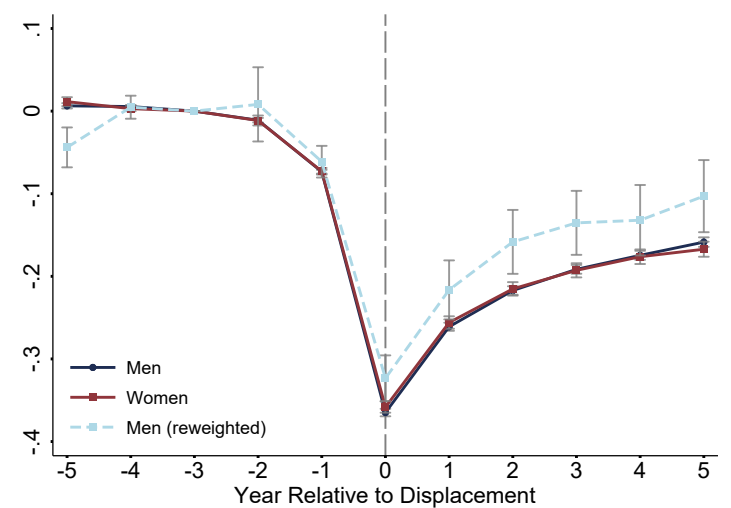

(C) Earnings r.t. $\mathrm{t}=\mathrm{c}-1$ - Non-Couples

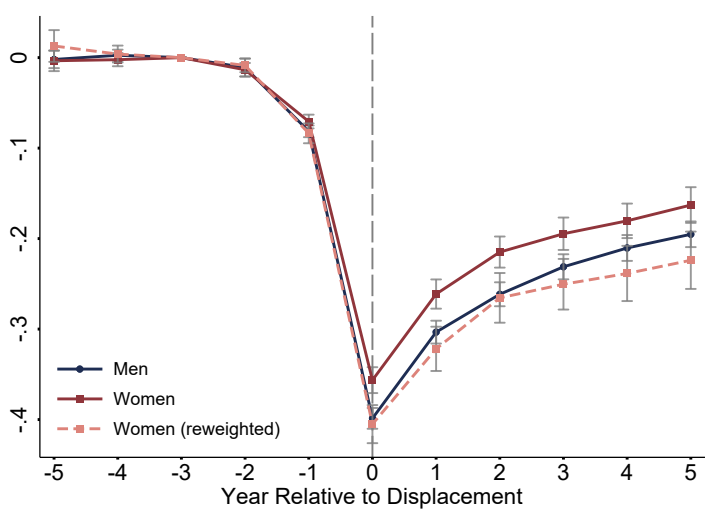

(B) Log Wage Full-time - Men to Women

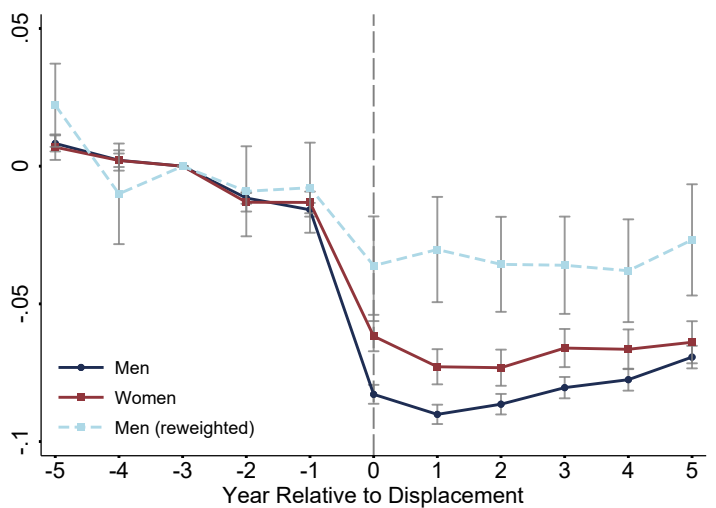

(D) Log Wage Full-time - Non-Couples

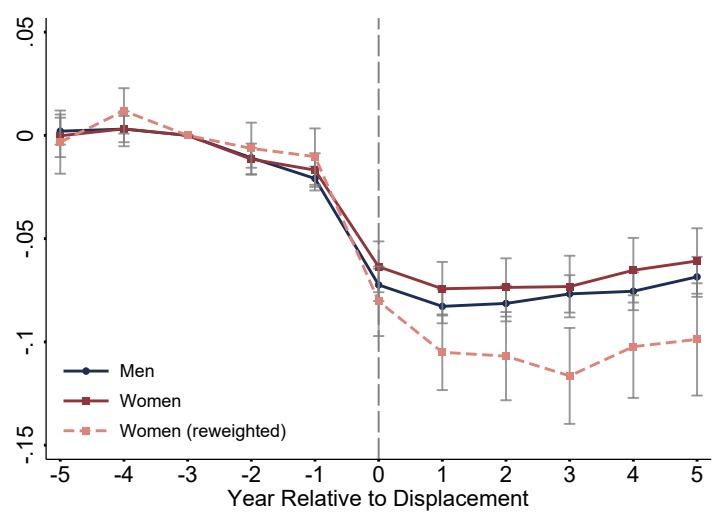

(E) Earnings r.t. $\quad t=c-1$ - Couples + Non-(F) Log Wage Full-time - Couples + NonCouples

Couples
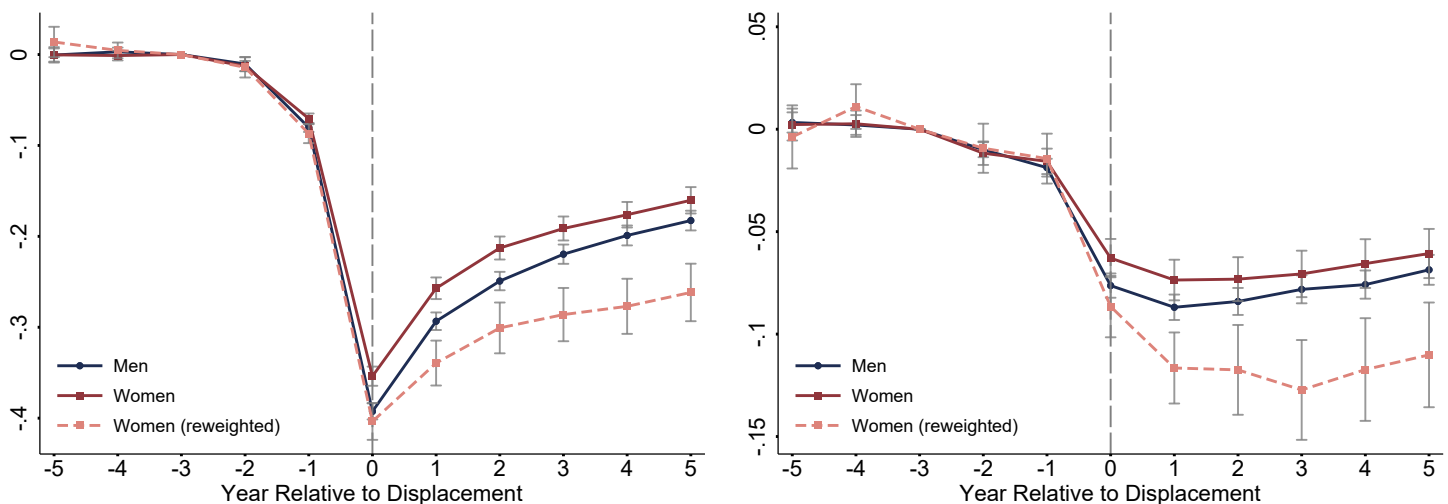

Notes: This figure shows how earnings relative to $\mathrm{t}=-2$ and full-time log wages differ for men and women before and after displacement for different robustness specifications. Panels (A)-(B) show eventstudy coefficients for our baseline sample of workers, where we reweight men to women with respect to individual characteristics and 1-digit industries. Panels (C)-(D) show eventstudy coefficients for a sample of workers not identified in the couple data. Panels (E)-(F) show eventstudy coefficients for a combined sample of workers in the couple data and not in the couple data. The three lines correspond to three event study regressions: Men only, women only, and women reweighted with individual and establishment characteristics. All regressions include controls for person FE, year FE, years since separation, and age polynomials. Vertical bars indicate the estimated $95 \%$ confidence interval based on standard errors clustered at the individual level. Workers are displaced in 2002-2012, and they are observed from 1997-2017. 
Figure A.3.5: Log Earnings and Days Worked - East vs. West Germany

(A) Log Earnings - West Germany

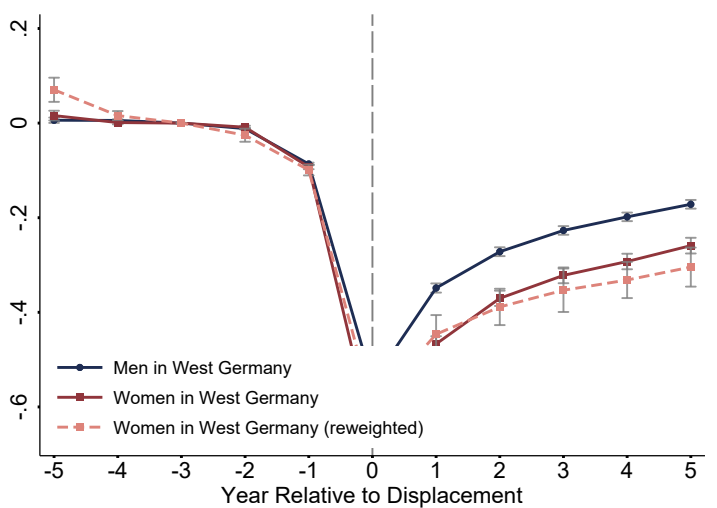

(B) Log Earnings - East Germany

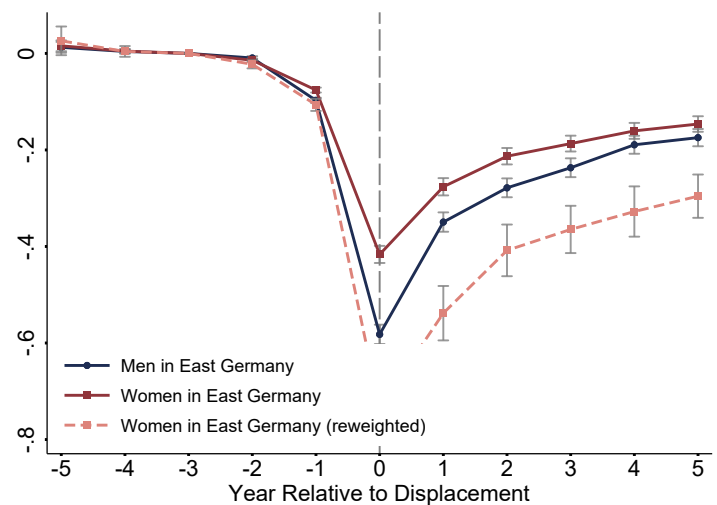

(C) Days Worked in Full-time Job - West(D) Days Worked in Full-time Job - East Ger-

Germany

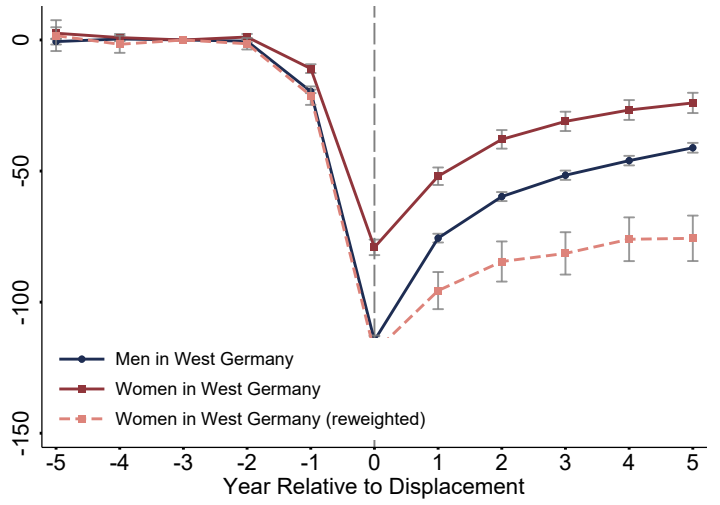

many

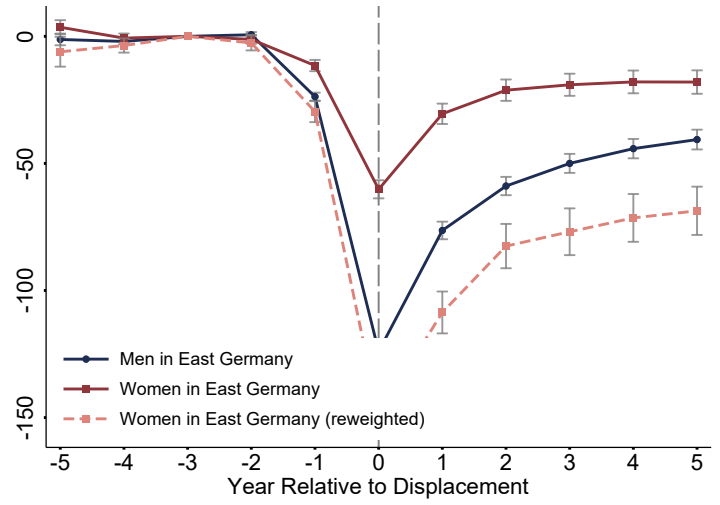

(E) Days Worked in Minijob - West Germany(F) Days Worked in Minijob - East Germany
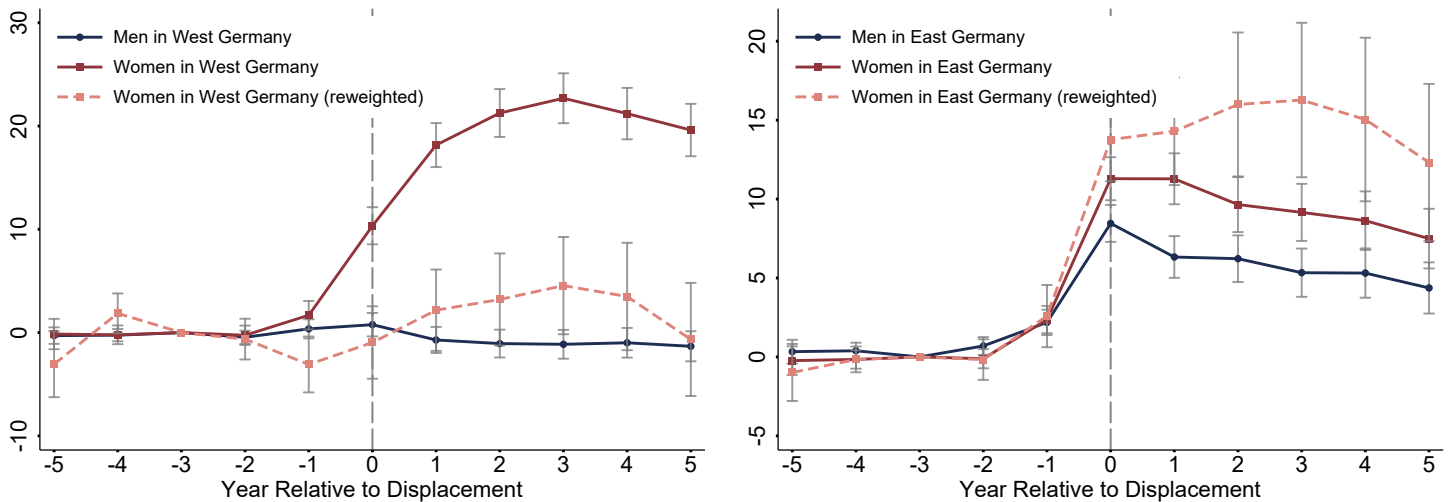

Notes: This figure shows how labor market characteristics before and after displacement differ for men and women working in West and East Germany in $t=-1$, respectively. Panels (A), (C), and (E) show eventstudy coefficients for log earnings, days worked in full-time job and days worked in minijob for West Germany. Panels (B), (D), and $(\mathrm{F})$ show eventstudy coefficients for log earnings, days worked in full-time job and days worked in minijob for East Germany. The three lines correspond to three event study regressions: Men only, women only, and women reweighted with individual and establishment characteristics. Women in West (East) Germany are reweighted to men in West (East) Germany. All regressions include controls for person FE, year FE, years since separation, and age polynomials. Vertical bars indicate the estimated $95 \%$ confidence interval based on standard errors clustered at the individual level. Workers are displaced in 2002-2012, and they are observed from 1997-2017. 
Figure A.3.6: The Gender Gap and Children

(A) Earnings Relative to $\mathrm{t}=\mathrm{c}-1$

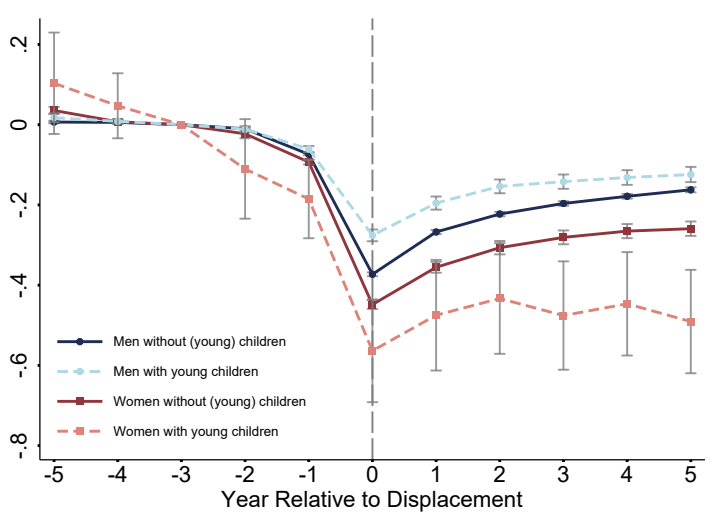

(C) Days Worked Full-time

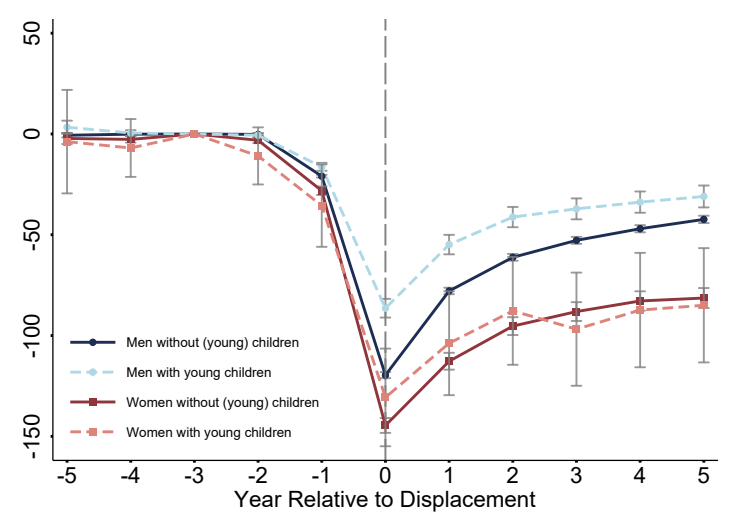

(B) Daily Log Wage

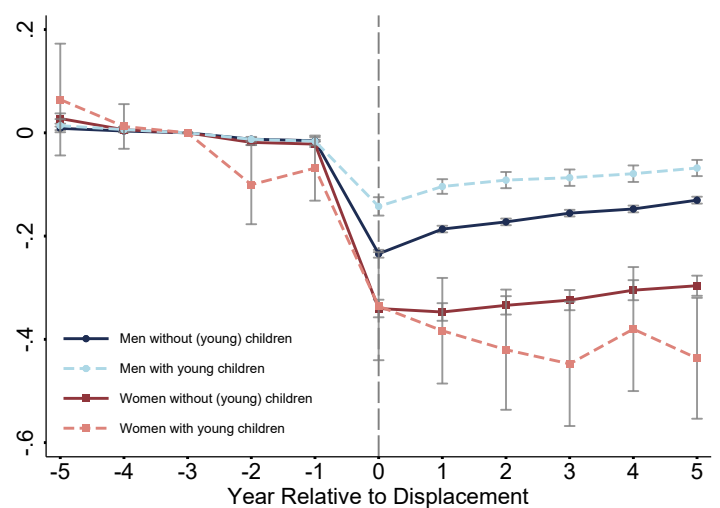

(D) Days Worked Part-time

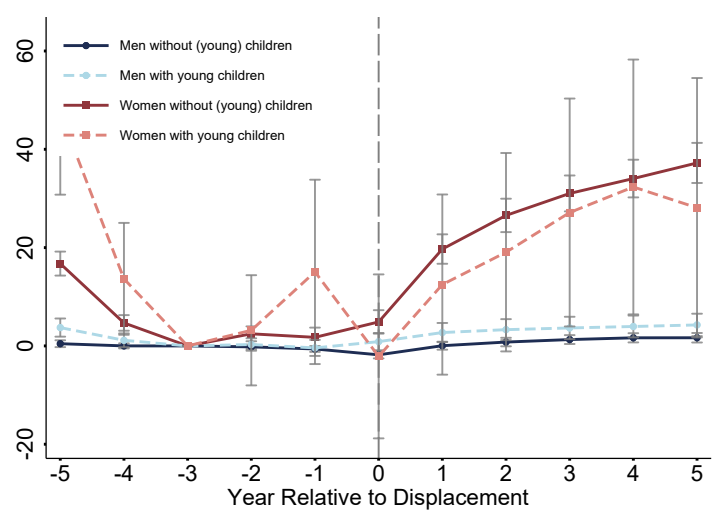

Notes: This figure shows how labor market outcomes before and after displacement differ for men and women with older and younger children. Panels (A)-(D) show eventstudy coefficients for earnings relative to $\mathrm{t}=\mathrm{c}-1$, log wage, days worked in full-time employment, and days worked in part-time employment. The four lines correspond to four event study regressions: Men with no children or children older than 6 only, women with no children and children older than 6 only, men with children younger than 7, women with children younger than 7 . In reweighting, men with no or older children are the baseline group, to which we reweight the other three groups using individual and establishment characteristics. All regressions include controls for person FE, year FE, years since separation, and age polynomials. Vertical bars indicate the estimated $95 \%$ confidence interval based on standard errors clustered at the individual level. Commuting distance is measured on the municipality level, and is recorded on December 31 each year. Workers are displaced in 2002-2012, and they are observed from 1997-2017. 
Chapter 3: Tables 
Table A.3.1: Summary Statistics for Displaced Workers and Matched Controls in $\mathrm{t}=\mathrm{c}$
$(1)$
(2)
(3)
(4)

Non-Displaced Displaced Non-Displaced Displaced

\begin{tabular}{|c|c|c|c|c|}
\hline & Women & Women & Men & Men \\
\hline \multicolumn{5}{|c|}{ Panel A: Individual Characteristics } \\
\hline \multirow{2}{*}{ Years of education } & 11.4 & 11.4 & 11.3 & 11.3 \\
\hline & {$[1.5]$} & {$[1.5]$} & {$[1.6]$} & {$[1.6]$} \\
\hline \multirow[t]{2}{*}{ Potential experience } & 22.4 & 22.8 & 21.8 & 21.9 \\
\hline & {$[6.2]$} & {$[6.1]$} & {$[6.2]$} & {$[6.2]$} \\
\hline \multirow[t]{2}{*}{ Tenure with current employer } & 7.5 & 7.5 & 7.7 & 7.7 \\
\hline & {$[4.1]$} & {$[4.1]$} & {$[4.4]$} & {$[4.5]$} \\
\hline \multirow[t]{2}{*}{ Log wage in $t=c-2$} & 4.2 & 4.2 & 4.5 & 4.5 \\
\hline & {$[0.485]$} & {$[0.471]$} & {$[0.360]$} & {$[0.356]$} \\
\hline \multirow[t]{2}{*}{ Earnings in $t=c-1$} & 26999.8 & 26623.3 & 37167.9 & 36677.8 \\
\hline & {$[12004.7]$} & {$[11881.2]$} & {$[12715.9]$} & {$[12881.5]$} \\
\hline \multirow[t]{2}{*}{ Total yearly income } & 25675.6 & 24451.5 & 35585.8 & 33729.2 \\
\hline & {$[11834.4]$} & {$[11831.6]$} & {$[13077.3]$} & {$[13388.0]$} \\
\hline \multirow[t]{2}{*}{ Days Worked in Year } & 363.2 & 343.0 & 363.1 & 343.2 \\
\hline & {$[14.0]$} & {$[48.2]$} & {$[13.2]$} & {$[46.7]$} \\
\hline \multirow[t]{2}{*}{ Days Worked in Full-time Job } & 239.4 & 226.9 & 356.3 & 335.5 \\
\hline & {$[172.2]$} & {$[162.0]$} & {$[50.3]$} & {$[64.4]$} \\
\hline \multirow[t]{2}{*}{ Couple } & 1 & 1 & 1 & 1 \\
\hline & {$[0]$} & {$[0]$} & {$[0]$} & {$[0]$} \\
\hline \multicolumn{5}{|c|}{ Panel B: Establishment Characteristics } \\
\hline \multirow[t]{2}{*}{ Firmsize } & 572.4 & 513.1 & 277.4 & 281.3 \\
\hline & {$[1177.0]$} & {$[867.8]$} & {$[714.4]$} & {$[616.4]$} \\
\hline \multirow[t]{2}{*}{ Share female workers } & 0.602 & 0.616 & 0.287 & 0.279 \\
\hline & {$[0.240]$} & {$[0.239]$} & {$[0.212]$} & {$[0.212]$} \\
\hline \multirow[t]{2}{*}{ Share full-time workers } & 0.636 & 0.649 & 0.806 & 0.829 \\
\hline & {$[0.269]$} & {$[0.278]$} & {$[0.183]$} & {$[0.180]$} \\
\hline Number of Observations & 31806 & 31806 & 48849 & 48849 \\
\hline
\end{tabular}

Notes: Characteristics of displaced and non-displaced workers in year prior to displacement year. Workers satisfy the following baseline restrictions: The individual is aged 24 to 50, has at least two years of tenure, she was not in marginal employment in the four years preceding displacement, and she works in an establishment which has at least 30 employees. Each displaced worker is assigned a non-displaced worker via 1:1 propensity score matching within gender, year and industry cells. Non-displaced workers come from a random sample of workers who satisfy the same baseline restrictions. Standard deviations in brackets. 
Table A.3.2: Industry Distribution for Displaced Workers and Matched Controls in $\mathrm{t}=\mathrm{c}$

\begin{tabular}{|c|c|c|c|c|c|}
\hline & $\begin{array}{l}\text { (1) } \\
\text { All Workers } \\
\text { Women }\end{array}$ & $\begin{array}{c}(2) \\
\text { Baseline Sample } \\
\text { Women }\end{array}$ & $\begin{array}{c}(3) \\
\text { Reweighted } \\
\text { Women }\end{array}$ & $\begin{array}{l}(4) \\
\text { All Workers } \\
\text { Men }\end{array}$ & $\begin{array}{c}(5) \\
\text { Baseline Sample } \\
\text { Men }\end{array}$ \\
\hline Agriculture & $\begin{array}{l}0.0074 \\
{[0.086]}\end{array}$ & $\begin{array}{l}0.0020 \\
{[0.045]}\end{array}$ & $\begin{array}{c}0.00097 \\
{[0.031]}\end{array}$ & $\begin{array}{c}0.012 \\
{[0.108]}\end{array}$ & $\begin{array}{l}0.0015 \\
{[0.039]}\end{array}$ \\
\hline Mining, Energy & $\begin{array}{l}0.0050 \\
{[0.070]}\end{array}$ & $\begin{array}{c}0 \\
{[0]}\end{array}$ & $\begin{array}{c}0 \\
{[0]}\end{array}$ & $\begin{array}{c}0.017 \\
{[0.131]}\end{array}$ & $\begin{array}{c}0 \\
{[0]}\end{array}$ \\
\hline Food Manufacturing & $\begin{array}{c}0.027 \\
{[0.162]}\end{array}$ & $\begin{array}{c}0.050 \\
{[0.218]}\end{array}$ & $\begin{array}{c}0.028 \\
{[0.166]}\end{array}$ & $\begin{array}{c}0.022 \\
{[0.148]}\end{array}$ & $\begin{array}{c}0.039 \\
{[0.194]}\end{array}$ \\
\hline Consumption Goods & $\begin{array}{c}0.031 \\
{[0.174]}\end{array}$ & $\begin{array}{c}0.086 \\
{[0.281]}\end{array}$ & $\begin{array}{c}0.069 \\
{[0.253]}\end{array}$ & $\begin{array}{c}0.038 \\
{[0.192]}\end{array}$ & $\begin{array}{c}0.084 \\
{[0.278]}\end{array}$ \\
\hline Production Goods & $\begin{array}{c}0.023 \\
{[0.151]}\end{array}$ & $\begin{array}{c}0.038 \\
{[0.191]}\end{array}$ & $\begin{array}{c}0.083 \\
{[0.276]}\end{array}$ & $\begin{array}{c}0.069 \\
{[0.253]}\end{array}$ & $\begin{array}{c}0.096 \\
{[0.294]}\end{array}$ \\
\hline Investment Goods & $\begin{array}{c}0.046 \\
{[0.210]}\end{array}$ & $\begin{array}{c}0.073 \\
{[0.260]}\end{array}$ & $\begin{array}{c}0.138 \\
{[0.345]}\end{array}$ & $\begin{array}{c}0.166 \\
{[0.372]}\end{array}$ & $\begin{array}{c}0.171 \\
{[0.377]}\end{array}$ \\
\hline Construction & $\begin{array}{c}0.016 \\
{[0.124]}\end{array}$ & $\begin{array}{c}0 \\
{[0]}\end{array}$ & $\begin{array}{c}0 \\
{[0]}\end{array}$ & $\begin{array}{c}0.075 \\
{[0.263]}\end{array}$ & $\begin{array}{c}0 \\
{[0]}\end{array}$ \\
\hline Retail & $\begin{array}{c}0.180 \\
{[0.384]}\end{array}$ & $\begin{array}{c}0.215 \\
{[0.411]}\end{array}$ & $\begin{array}{c}0.123 \\
{[0.329]}\end{array}$ & $\begin{array}{c}0.136 \\
{[0.343]}\end{array}$ & $\begin{array}{c}0.148 \\
{[0.355]}\end{array}$ \\
\hline Traffic, Telecommunication & $\begin{array}{c}0.035 \\
{[0.184]}\end{array}$ & $\begin{array}{c}0.043 \\
{[0.203]}\end{array}$ & $\begin{array}{c}0.102 \\
{[0.302]}\end{array}$ & $\begin{array}{c}0.077 \\
{[0.267]}\end{array}$ & $\begin{array}{c}0.088 \\
{[0.284]}\end{array}$ \\
\hline Credit, Insurance & $\begin{array}{c}0.038 \\
{[0.190]}\end{array}$ & $\begin{array}{c}0.023 \\
{[0.150]}\end{array}$ & $\begin{array}{c}0.013 \\
{[0.114]}\end{array}$ & $\begin{array}{c}0.028 \\
{[0.164]}\end{array}$ & $\begin{array}{c}0.015 \\
{[0.122]}\end{array}$ \\
\hline Restaurants & $\begin{array}{c}0.055 \\
{[0.228]}\end{array}$ & $\begin{array}{c}0.019 \\
{[0.137]}\end{array}$ & $\begin{array}{l}0.0088 \\
{[0.094]}\end{array}$ & $\begin{array}{c}0.032 \\
{[0.176]}\end{array}$ & $\begin{array}{l}0.0082 \\
{[0.090]}\end{array}$ \\
\hline Education & $\begin{array}{c}0.052 \\
{[0.221]}\end{array}$ & $\begin{array}{c}0.126 \\
{[0.332]}\end{array}$ & $\begin{array}{c}0.025 \\
{[0.155]}\end{array}$ & $\begin{array}{c}0.026 \\
{[0.160]}\end{array}$ & $\begin{array}{c}0.026 \\
{[0.160]}\end{array}$ \\
\hline Health & $\begin{array}{c}0.191 \\
{[0.393]}\end{array}$ & $\begin{array}{c}0.060 \\
{[0.238]}\end{array}$ & $\begin{array}{c}0.012 \\
{[0.108]}\end{array}$ & $\begin{array}{c}0.045 \\
{[0.207]}\end{array}$ & $\begin{array}{c}0.012 \\
{[0.109]}\end{array}$ \\
\hline Commercial Services & $\begin{array}{c}0.150 \\
{[0.358]}\end{array}$ & $\begin{array}{c}0.151 \\
{[0.358]}\end{array}$ & $\begin{array}{c}0.337 \\
{[0.473]}\end{array}$ & $\begin{array}{c}0.169 \\
{[0.374]}\end{array}$ & $\begin{array}{c}0.251 \\
{[0.434]}\end{array}$ \\
\hline Other Services & $\begin{array}{c}0.053 \\
{[0.223]}\end{array}$ & $\begin{array}{c}0.024 \\
{[0.154]}\end{array}$ & $\begin{array}{c}0.032 \\
{[0.176]}\end{array}$ & $\begin{array}{c}0.035 \\
{[0.184]}\end{array}$ & $\begin{array}{c}0.029 \\
{[0.169]}\end{array}$ \\
\hline Non-Profit & $\begin{array}{c}0.024 \\
{[0.153]}\end{array}$ & $\begin{array}{c}0.025 \\
{[0.155]}\end{array}$ & $\begin{array}{c}0.015 \\
{[0.123]}\end{array}$ & $\begin{array}{c}0.013 \\
{[0.113]}\end{array}$ & $\begin{array}{c}0.015 \\
{[0.121]}\end{array}$ \\
\hline Public Administration & $\begin{array}{c}0.067 \\
{[0.250]}\end{array}$ & $\begin{array}{c}0.064 \\
{[0.245]}\end{array}$ & $\begin{array}{c}0.014 \\
{[0.116]}\end{array}$ & $\begin{array}{c}0.040 \\
{[0.197]}\end{array}$ & $\begin{array}{c}0.014 \\
{[0.119]}\end{array}$ \\
\hline Number of Observations & 3939514 & 31806 & 31806 & 4178728 & 48849 \\
\hline
\end{tabular}

This table summarizes the industry distribution of different samples of (displaced) men and women. Columns (1) and (4) show characteristics of a random sample of workers in Germany 2003-2012. Columns (2) and (5) represent all displaced workers in the couple dataset fulfilling our baseline restrictions. We measure characteristics in $t=c$. We exclude individuals working in the construction and mining sectors. Column (3) contains women in the couple dataset reweighted to men. Variables with * are used in reweighting. Standard deviations in brackets. 
Table A.3.3: Top 10 3-Digit Occupations in the Five Years Before Displacement

\begin{tabular}{|c|c|c|c|c|c|c|c|c|}
\hline \multirow[b]{2}{*}{ Occupation } & \multirow[b]{2}{*}{ Code } & \multirow[b]{2}{*}{ Percent } & \multirow[t]{2}{*}{$\begin{array}{c}(2) \\
\text { Women }\end{array}$} & \multirow[b]{2}{*}{ Code } & \multirow[b]{2}{*}{ Percent } & \multicolumn{2}{|c|}{$\begin{array}{c}(3) \\
\text { Women - Reweighted }\end{array}$} & \multirow[b]{2}{*}{ Percent } \\
\hline & & & & & & Occupation & Code & \\
\hline Qualified Office Employee & 781 & 7.3 & Qualified Office Employee & 781 & 27.1 & Qualified Office Employee & 781 & 30.6 \\
\hline Trucker & 714 & 6.5 & Salesperson & 682 & 11.6 & Salesperson & 682 & 5.0 \\
\hline Warehouseman & 744 & 3.9 & Cleaner & 933 & 4.3 & Cleaner & 933 & 3.9 \\
\hline Data Processing Expert & 774 & 3.0 & Nursery Worker & 864 & 2.8 & Accountant & 772 & 2.8 \\
\hline Bricklayer & 441 & 2.8 & Despatcher & 522 & 2.3 & Purchasing Agent & 681 & 2.6 \\
\hline Helper & 531 & 2.8 & Purchasing Agent & 681 & 2.2 & Data Processing Expert & 774 & 2.5 \\
\hline Technician & 628 & 2.4 & Warehouseman & 744 & 2.1 & Stenographer & 782 & 2.5 \\
\hline Stockman & 741 & 2.4 & Helper & 531 & 1.9 & Manager & 751 & 2.2 \\
\hline Salesperson & 682 & 2.3 & Chef & 411 & 1.6 & Warehouseman & 744 & 1.9 \\
\hline Electrician & 311 & 2.1 & Secondary School Teacher & 873 & 1.6 & Despatcher & 522 & 1.8 \\
\hline
\end{tabular}

Notes: Table reports top 10 3-digit source occupation codes by gender. We define source occupation as a worker's most frequent occupation in the five years before displacement. 
Table A.3.4: Top 10 3-Digit Occupations in the Five Years After Displacement

\begin{tabular}{|c|c|c|c|c|c|c|c|c|}
\hline \multirow[b]{2}{*}{ Occupation } & \multirow[b]{2}{*}{ Code } & \multirow[b]{2}{*}{ Percent } & \multirow[t]{2}{*}{$\begin{array}{c}(2) \\
\text { Women }\end{array}$} & \multirow[b]{2}{*}{ Code } & \multirow[b]{2}{*}{ Percent } & \multicolumn{3}{|c|}{$\begin{array}{c}(3) \\
\text { Women - Reweighted }\end{array}$} \\
\hline & & & & & & Occupation & Code & Percent \\
\hline Trucker & 714 & 7.4 & Qualified Office Employee & 781 & 25.1 & Qualified Office Employee & 781 & 27.8 \\
\hline Qualified Office Employee & 781 & 6.4 & Salesperson & 682 & 12.1 & Salesperson & 682 & 6.0 \\
\hline Warehouseman & 744 & 4.1 & Cleaner & 933 & 5.5 & Cleaner & 933 & 4.9 \\
\hline Data Processing Expert & 774 & 3.0 & Nursery Worker & 864 & 3.2 & Accountant & 772 & 3.5 \\
\hline Manager & 751 & 2.9 & Warehouseman & 744 & 2.3 & Purchasing Agent & 681 & 2.9 \\
\hline Stockman & 741 & 2.6 & Purchasing Agent & 681 & 2.3 & Manager & 751 & 2.6 \\
\hline Bricklayer & 441 & 2.4 & Social Worker & 861 & 2.1 & Warehouseman & 744 & 2.3 \\
\hline Salesperson & 682 & 2.3 & Chef & 411 & 1.9 & Data Processing Expert & 774 & 2.0 \\
\hline Electrician & 311 & 2.2 & Accountant & 772 & 1.8 & Stenographer & 782 & 1.6 \\
\hline Technician & 628 & 2.1 & Despatcher & 522 & 1.6 & Helper & 531 & 1.4 \\
\hline
\end{tabular}

Notes: Table reports top 10 3-digit destination occupation codes by gender. We define destination occupation as a worker's most frequent occupation in the five years after displacement. 
Table A.3.5: Robustness Checks: More Outcomes

\begin{tabular}{|c|c|c|c|c|c|c|c|c|c|c|}
\hline & $\begin{array}{c}(1) \\
\text { Baseline }\end{array}$ & $\begin{array}{l}(2) \\
10 \text { Years } \\
\text { Post Displ. }\end{array}$ & $\begin{array}{l}(3) \\
\text { Shorter } \\
\text { Tenure } \\
\text { Restr. }\end{array}$ & $\begin{array}{l}(4) \\
\text { Mahalanobis } \\
\text { And Exact } \\
\text { Matching }\end{array}$ & $\begin{array}{c}(5) \\
\text { Reweight. } \\
\text { With } \\
\text { Occupations }\end{array}$ & $\begin{array}{l}(6) \\
\text { Displ. } \\
\text { Estab. } \\
\text { FE }\end{array}$ & $\begin{array}{l}\quad(7) \\
\text { Matching } \\
\text { Without } \\
\text { Wages }\end{array}$ & $\begin{array}{l}(8) \\
\text { Reweight. } \\
\text { Men to } \\
\text { Women }\end{array}$ & $\begin{array}{c}(9) \\
\text { Non } \\
\text { Couples }\end{array}$ & $\begin{array}{c}(10) \\
\text { Couples } \\
+ \\
\text { Non-Couples }\end{array}$ \\
\hline \multicolumn{11}{|l|}{ Panel A: Days Worked } \\
\hline $\begin{array}{l}\text { Observations } \\
R^{2} \\
\text { Mean Dep. Var Men }\end{array}$ & $\begin{array}{c}-7.05 \\
(2.13)^{* *} \\
80655 \\
0.001 \\
-67.66 \\
(.585)\end{array}$ & $\begin{array}{c}-2.17 \\
(2.63) \\
55107 \\
0.000 \\
-49.787 \\
(.751)\end{array}$ & $\begin{array}{c}-12.5 \\
(2.05)^{* *} \\
93755 \\
0.002 \\
-69.259 \\
(.553)\end{array}$ & $\begin{array}{c}-3.36 \\
(2.15) \\
80707 \\
0.000 \\
-67.125 \\
(.582)\end{array}$ & $\begin{array}{c}-10.4 \\
(5.48) \\
80423 \\
0.002 \\
-67.66 \\
(.585)\end{array}$ & $\begin{array}{c}-5.85 \\
(1.93)^{* *} \\
77144 \\
0.330 \\
-67.66 \\
(.585)\end{array}$ & $\begin{array}{c}-6.36 \\
(2.20)^{* *} \\
80706 \\
0.001 \\
-67.588 \\
(.586)\end{array}$ & $\begin{array}{c}5.76 \\
(3.51) \\
78695 \\
0.000 \\
-67.676 \\
(.586)\end{array}$ & $\begin{array}{c}3.08 \\
(3.50) \\
16422 \\
0.000 \\
-81.858 \\
(1.376)\end{array}$ & $\begin{array}{c}-3.46 \\
(3.45) \\
96158 \\
0.000 \\
-78.058 \\
(.567)\end{array}$ \\
\hline \multicolumn{11}{|c|}{ Panel B: Days Worked Part-time } \\
\hline $\begin{array}{l}\text { Observations } \\
R^{2} \\
\text { Mean Dep. Var Men }\end{array}$ & $\begin{array}{c}11.3 \\
(1.66)^{* *} \\
80655 \\
0.003 \\
-.154 \\
(.559)\end{array}$ & $\begin{array}{c}25.6 \\
(2.59)^{* *} \\
55107 \\
0.012 \\
1.18 \\
(.702)\end{array}$ & $\begin{array}{c}12.6 \\
(1.58)^{* *} \\
93755 \\
0.003 \\
.03 \\
(.522)\end{array}$ & $\begin{array}{l}2.08 \\
(1.45) \\
80707 \\
0.000 \\
-.297 \\
(.523)\end{array}$ & $\begin{array}{c}12.0 \\
(2.97)^{* *} \\
80423 \\
0.003 \\
-.154 \\
(.559)\end{array}$ & $\begin{array}{c}9.34 \\
(1.56)^{* *} \\
77144 \\
0.300 \\
-.154 \\
(.559)\end{array}$ & $\begin{array}{c}6.27 \\
(1.83)^{* *} \\
80706 \\
0.001 \\
-.127 \\
(.555)\end{array}$ & $\begin{array}{c}22.5 \\
(4.37)^{* *} \\
78695 \\
0.005 \\
.04 \\
(.547)\end{array}$ & $\begin{array}{c}7.64 \\
(2.28)^{* *} \\
16422 \\
0.001 \\
-1.736 \\
(1.145)\end{array}$ & $\begin{array}{c}10.5 \\
(2.28)^{* *} \\
96158 \\
0.002 \\
-1.682 \\
(.497)\end{array}$ \\
\hline \multicolumn{11}{|c|}{ Panel C: Days Worked in Minijob } \\
\hline $\begin{array}{l}\text { Female } \\
\text { Observations } \\
R^{2} \\
\text { Mean Dep. Var Men }\end{array}$ & $\begin{array}{c}4.88 \\
(1.51)^{* *} \\
80655 \\
0.001 \\
1.086 \\
(.448)\end{array}$ & $\begin{array}{c}2.77 \\
(1.95) \\
55107 \\
0.000 \\
1.202 \\
(.516)\end{array}$ & $\begin{array}{c}3.31 \\
(1.41)^{*} \\
93755 \\
0.000 \\
1.123 \\
(.419)\end{array}$ & $\begin{array}{c}7.75 \\
(1.31)^{* *} \\
80707 \\
0.002 \\
.838 \\
(.448)\end{array}$ & $\begin{array}{c}4.85 \\
(4.13) \\
80423 \\
0.001 \\
1.086 \\
(.448)\end{array}$ & $\begin{array}{c}7.81 \\
(1.59)^{* *} \\
77144 \\
0.252 \\
1.086 \\
(.448)\end{array}$ & $\begin{array}{c}3.16 \\
(1.59)^{*} \\
80706 \\
0.000 \\
1.428 \\
(.446)\end{array}$ & $\begin{array}{c}12.8 \\
(2.59)^{* *} \\
78695 \\
0.004 \\
1.071 \\
(.445)\end{array}$ & $\begin{array}{l}2.69 \\
(2.18) \\
16422 \\
0.000 \\
2.352 \\
(.914)\end{array}$ & $\begin{array}{l}0.16 \\
(2.03) \\
96158 \\
0.000 \\
2.032 \\
(.393)\end{array}$ \\
\hline
\end{tabular}

Panel D: $\log ($ Earnings $)$

\begin{tabular}{lcccccccccc} 
Female & -0.13 & -0.13 & -0.18 & -0.13 & -0.20 & -0.16 & -0.13 & -0.13 & -0.036 & -0.044 \\
& $(0.017)^{* *}$ & $(0.021)^{* *}$ & $(0.017)^{* *}$ & $(0.016)^{* *}$ & $(0.045)^{* *}$ & $(0.016)^{* *}$ & $(0.016)^{* *}$ & $(0.024)^{* *}$ & $(0.022)$ & $(0.020)^{*}$ \\
Observations & 76321 & 52601 & 88465 & 76361 & 76090 & 72813 & 76363 & 74435 & 15279 & 90732 \\
$R^{2}$ & 0.005 & 0.004 & 0.009 & 0.005 & 0.011 & 0.349 & 0.005 & 0.005 & 0.000 & 0.001 \\
Mean Dep. Var Men & -.41 & -.319 & -.419 & -.392 & -.405 & -.41 & -.4 & -.406 & -.456 & -.443 \\
& $(.004)$ & $(.005)$ & $(.004)$ & $(.004)$ & $(.004)$ & $(.004)$ & $(.004)$ & $(.004)$ & $(.01)$ & $(.004)$ \\
\hline
\end{tabular}

Notes: Each column in this table represents a different robustness check. All specifications are estimated using weights. Column (1) reports the baseline time of displacement). Column (4) reports results when using Mahalanobis matching in combination with exact matching of pre-displacement earnings deciles. Column (5) reports results when reweighting with 1-digit occupations in addition to industries and individual characteristics. Column (6) reports regression coefficients controlling for pre-displacement establishment fixed effects. Column (7) reports regression coefficients for a sample of treated and control workers, regression coefficients for a dataset of non-couples. Column (10) reports regression coefficients for a combined dataset of couples and non-couples in our sample. We cluster standard errors at displacement establishment level (constant within matched worker pairs). Workers in our sample are displaced in 2002-2012, and they are observed from $1996-2017 . *$ and $* *$ correspond to 5 and 1 percent signficance levels, respectively. 
Table A.3.6: Robustness Checks: Varying Estimation Samples

\begin{tabular}{|c|c|c|c|c|c|c|}
\hline & $\begin{array}{c}(1) \\
\text { Baseline }\end{array}$ & $\begin{array}{c}(2) \\
\text { West } \\
\text { Germany }\end{array}$ & $\begin{array}{c}(3) \\
\text { East } \\
\text { Germany }\end{array}$ & $\begin{array}{c}(4) \\
\text { Complete } \\
\text { Closures }\end{array}$ & $\begin{array}{c}(5) \\
\text { Mass } \\
\text { Layoffs }\end{array}$ & $\begin{array}{c}(6) \\
\text { Stricter } \\
\text { Baseline } \\
\text { Restrictions }\end{array}$ \\
\hline \multicolumn{7}{|c|}{ Panel A: Earnings Rel. to Year -2} \\
\hline $\begin{array}{l}\text { Female } \\
\text { Observations } \\
R^{2} \\
\text { Mean Dep. Var Men }\end{array}$ & $\begin{array}{l}-0.092 \\
(0.012)^{* *} \\
80655 \\
0.007 \\
-.258 \\
(.002)\end{array}$ & $\begin{array}{c}-0.10 \\
(0.019)^{* *} \\
58373 \\
0.007 \\
-.259 \\
(.003)\end{array}$ & $\begin{array}{c}-0.052 \\
(0.014)^{* *} \\
22280 \\
0.003 \\
-.257 \\
(.005)\end{array}$ & $\begin{array}{c}-0.092 \\
(0.016)^{* *} \\
24819 \\
0.008 \\
-.262 \\
(.004)\end{array}$ & $\begin{array}{c}-0.092 \\
(0.017)^{* *} \\
55836 \\
0.006 \\
-.257 \\
(.004)\end{array}$ & $\begin{array}{c}-0.22 \\
(0.071)^{* *} \\
35473 \\
0.012 \\
-.277 \\
(.003)\end{array}$ \\
\hline \multicolumn{7}{|l|}{ Panel B: Log Wages } \\
\hline $\begin{array}{l}\text { Female } \\
\text { Observations } \\
R^{2} \\
\text { Mean Dep. Var Men }\end{array}$ & $\begin{array}{c}-0.13 \\
(0.013)^{* *} \\
73598 \\
0.010 \\
-.201 \\
(.003)\end{array}$ & $\begin{array}{c}-0.11 \\
(0.015)^{* *} \\
53292 \\
0.007 \\
-.206 \\
(.003)\end{array}$ & $\begin{array}{c}-0.17 \\
(0.026)^{* *} \\
20304 \\
0.017 \\
-.183 \\
(.006)\end{array}$ & $\begin{array}{c}-0.17 \\
(0.021)^{* *} \\
23007 \\
0.016 \\
-.213 \\
(.005)\end{array}$ & $\begin{array}{c}-0.12 \\
(0.017)^{* *} \\
50591 \\
0.007 \\
-.195 \\
(.005)\end{array}$ & $\begin{array}{c}-0.16 \\
(0.042)^{* *} \\
32229 \\
0.012 \\
-.213 \\
(.004)\end{array}$ \\
\hline \multicolumn{7}{|c|}{ Panel C: Log Full-time Wages } \\
\hline $\begin{array}{l}\text { Female } \\
\text { Observations } \\
R^{2} \\
\text { Mean Dep. Var Men }\end{array}$ & $\begin{array}{c}-0.039 \\
(0.0084)^{* *} \\
52996 \\
0.003 \\
-.094 \\
(.002)\end{array}$ & $\begin{array}{c}-0.034 \\
(0.011)^{* *} \\
38692 \\
0.002 \\
-.097 \\
(.002)\end{array}$ & $\begin{array}{c}-0.056 \\
(0.013)^{* *} \\
14303 \\
0.007 \\
-.083 \\
(.003)\end{array}$ & $\begin{array}{c}-0.060 \\
(0.015)^{* *} \\
16975 \\
0.007 \\
-.108 \\
(.003)\end{array}$ & $\begin{array}{c}-0.031 \\
(0.010)^{* *} \\
36021 \\
0.002 \\
-.084 \\
(.003)\end{array}$ & $\begin{array}{c}-0.069 \\
(0.023)^{* *} \\
28518 \\
0.009 \\
-.1 \\
(.002)\end{array}$ \\
\hline
\end{tabular}

Panel D: Days Worked Full-time

\begin{tabular}{lcccccc} 
Female & -23.1 & -21.9 & -24.0 & -25.9 & -21.7 & -27.3 \\
& $(2.84)^{* *}$ & $(3.57)^{* *}$ & $(4.26)^{* *}$ & $(4.99)^{* *}$ & $(3.52)^{* *}$ & $(7.85)^{* *}$ \\
Observations & 80655 & 58373 & 22280 & 24819 & 55836 & 35473 \\
$R^{2}$ & 0.005 & 0.004 & 0.005 & 0.006 & 0.004 & 0.007 \\
Mean Dep. Var Men & -75.47 & -75.15 & -76.682 & -72.364 & -77 & -80.036 \\
& $(.766)$ & $(.851)$ & $(1.721)$ & $(1.295)$ & $(1.295)$ & $(.947)$ \\
\hline
\end{tabular}

Notes: Each column in this table represents a different robustness check. All specifications are estimated using weights. Column (1) reports the baseline coefficients. Column (2) reports results workers working in West Germany in $\mathrm{t}=\mathrm{c}$. Column $(3)$ reports results workers working in East Germany in $\mathrm{t}=\mathrm{c}$. (5) reports results for workers displaced from a mass-layoff, excluding workers displaced from a complete establishment closure. Column (6) reports results for workers applying the same baseline restrictions as in Schmieder et al. (2020). These are: the worker is between age 24 and 50 , works full-time at a West German establishment with at least 50 employees, and has at least 3 years of tenure. For Columns (2) and (3), we reweight women in West (East) Germany to men in West (East) Germany. We cluster our sample are displaced in 2002-2012, and they are observed from 1996-2017. ${ }^{*}$ and ${ }^{* *}$ correspond to 5 and 1 percent signficance levels, respectively. 


\section{Appendix: Chapter 4}

\section{Chapter 4: Figures}

Figure A.4.1: Distribution of the Share of Same-Nationality Working Age Population

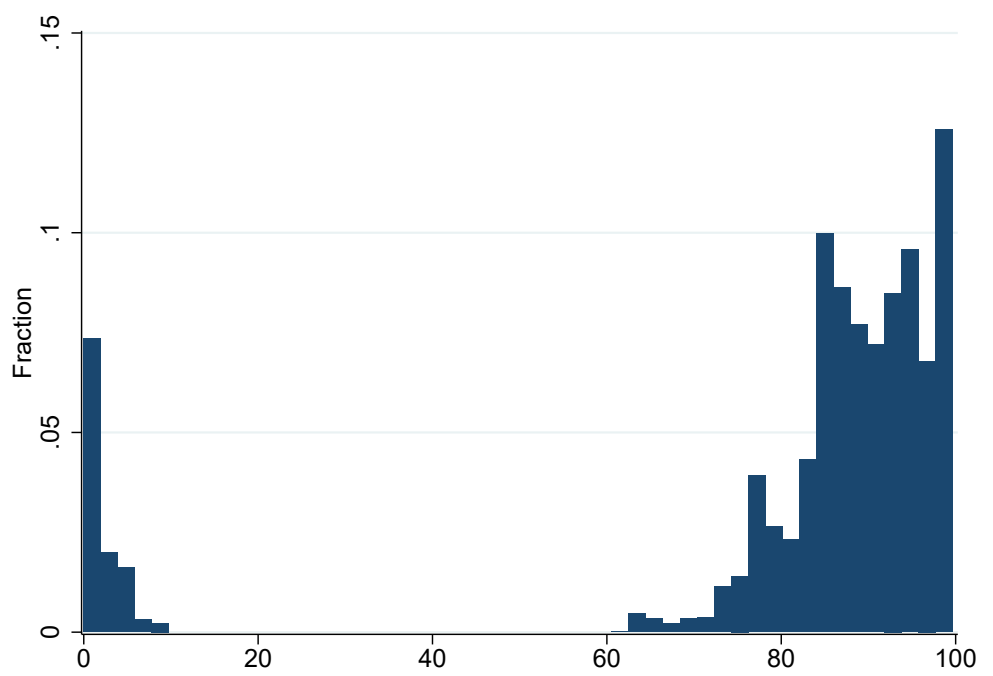

Notes: This figure shows the distribution of the share of same-nationality working age population in a county in $t=-1$ for our sample of displaced workers. For migrants, the share ranges from $0-10 \%$; for natives, it ranges from $60-100 \%$. Workers in our sample are displaced in 2001-2011, and they are observed from 1996-2017. In $t=-1$, we observe 17,605 displaced migrants and 129,701 displaced natives. Source: Destatis. 
Chapter 4: Tables 
Table A.4.1: Comparing Displaced Workers in $t=-1$ to a Random Sample of Workers

\begin{tabular}{|c|c|c|c|c|c|}
\hline & $\begin{array}{l}\text { (1) } \\
\text { All Workers } \\
\text { Migrants }\end{array}$ & $\begin{array}{c}(2) \\
\text { Baseline Sample } \\
\text { Migrants }\end{array}$ & $\begin{array}{c}(3) \\
\text { Reweighted } \\
\text { Migrants }\end{array}$ & $\begin{array}{c}(4) \\
\text { All Workers } \\
\text { Natives }\end{array}$ & $\begin{array}{c}(5) \\
\text { Baseline Sample } \\
\text { Natives }\end{array}$ \\
\hline \multicolumn{6}{|c|}{ Panel A: Individual Characteristics } \\
\hline Years of Education & $\begin{array}{c}11.2 \\
{[2.05]}\end{array}$ & $\begin{array}{c}11.2 \\
{[1.61]}\end{array}$ & $\begin{array}{c}12.1 \\
{[2.20]}\end{array}$ & $\begin{array}{c}12.0 \\
{[1.94]}\end{array}$ & $\begin{array}{c}12.3 \\
{[1.77]}\end{array}$ \\
\hline Age & $\begin{array}{c}37.8 \\
{[12.5]}\end{array}$ & $\begin{array}{c}37.9 \\
{[6.68]}\end{array}$ & $\begin{array}{c}39.8 \\
{[6.71]}\end{array}$ & $\begin{array}{c}40.4 \\
{[13.3]}\end{array}$ & $\begin{array}{c}39.4 \\
{[6.71]}\end{array}$ \\
\hline Tenure & $\begin{array}{c}2.37 \\
{[2.07]}\end{array}$ & $\begin{array}{l}6.38 \\
{[2.56]}\end{array}$ & $\begin{array}{c}6.05 \\
{[2.34]}\end{array}$ & $\begin{array}{c}2.93 \\
{[2.17]}\end{array}$ & $\begin{array}{c}6.20 \\
{[2.43]}\end{array}$ \\
\hline Real Daily Wage & $\begin{array}{c}57.5 \\
{[48.8]}\end{array}$ & $\begin{array}{c}89.2 \\
{[30.8]}\end{array}$ & $\begin{array}{l}105.2 \\
{[37.5]}\end{array}$ & $\begin{array}{c}68.7 \\
{[53.0]}\end{array}$ & $\begin{array}{l}102.3 \\
{[36.7]}\end{array}$ \\
\hline Total Yearly Earnings & $\begin{array}{c}13620.3 \\
{[16493.5]}\end{array}$ & $\begin{array}{c}30194.9 \\
{[11844.1]}\end{array}$ & $\begin{array}{c}35928.0 \\
{[14285.7]}\end{array}$ & $\begin{array}{c}20661.7 \\
{[18855.8]}\end{array}$ & $\begin{array}{c}35477.8 \\
{[14189.6]}\end{array}$ \\
\hline Days per year working & $\begin{array}{c}214.8 \\
{[158.6]}\end{array}$ & $\begin{array}{l}335.5 \\
{[53.9]}\end{array}$ & $\begin{array}{l}338.7 \\
{[51.1]}\end{array}$ & $\begin{array}{c}281.9 \\
{[135.1]}\end{array}$ & $\begin{array}{l}344.2 \\
{[45.6]}\end{array}$ \\
\hline \multicolumn{6}{|c|}{ Panel B: Regional Characteristics } \\
\hline Lives in City & $\begin{array}{c}0.64 \\
{[0.48]}\end{array}$ & $\begin{array}{c}0.80 \\
{[0.40]}\end{array}$ & $\begin{array}{c}0.58 \\
{[0.49]}\end{array}$ & $\begin{array}{c}0.44 \\
{[0.50]}\end{array}$ & $\begin{array}{c}0.57 \\
{[0.50]}\end{array}$ \\
\hline Lives in East Germany & $\begin{array}{l}0.063 \\
{[0.24]}\end{array}$ & $\begin{array}{l}0.041 \\
{[0.20]}\end{array}$ & $\begin{array}{l}0.060 \\
{[0.24]}\end{array}$ & $\begin{array}{c}0.19 \\
{[0.39]}\end{array}$ & $\begin{array}{c}0.25 \\
{[0.43]}\end{array}$ \\
\hline \multicolumn{6}{|c|}{ Panel C: Establishment Characteristics } \\
\hline Size of establishment & $\begin{array}{c}1000.3 \\
{[3922.8]}\end{array}$ & $\begin{array}{c}291.1 \\
{[490.4]}\end{array}$ & $\begin{array}{c}334.0 \\
{[640.6]}\end{array}$ & $\begin{array}{c}782.1 \\
{[3473.1]}\end{array}$ & $\begin{array}{c}347.2 \\
{[636.8]}\end{array}$ \\
\hline Share Migrant Workers & $\begin{array}{c}0.30 \\
{[0.27]}\end{array}$ & $\begin{array}{c}0.24 \\
{[0.19]}\end{array}$ & $\begin{array}{c}0.18 \\
{[0.18]}\end{array}$ & $\begin{array}{c}0.053 \\
{[0.086]}\end{array}$ & $\begin{array}{c}0.075 \\
{[0.095]}\end{array}$ \\
\hline Share High-Skilled Workers & $\begin{array}{l}0.099 \\
{[0.16]}\end{array}$ & $\begin{array}{l}0.079 \\
{[0.12]}\end{array}$ & $\begin{array}{c}0.13 \\
{[0.18]}\end{array}$ & $\begin{array}{c}0.13 \\
{[0.17]}\end{array}$ & $\begin{array}{c}0.12 \\
{[0.16]}\end{array}$ \\
\hline Share Marginally Employed Workers & $\begin{array}{c}0.21 \\
{[0.28]}\end{array}$ & $\begin{array}{l}0.059 \\
{[0.13]}\end{array}$ & $\begin{array}{l}0.049 \\
{[0.11]}\end{array}$ & $\begin{array}{c}0.17 \\
{[0.26]}\end{array}$ & $\begin{array}{c}0.041 \\
{[0.095]}\end{array}$ \\
\hline Displaced from Complete Closure & 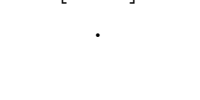 & $\begin{array}{c}0.32 \\
{[0.47]}\end{array}$ & $\begin{array}{c}0.32 \\
{[0.47]}\end{array}$ & . & $\begin{array}{c}0.32 \\
{[0.47]}\end{array}$ \\
\hline Number of Observations & 574167 & 17605 & 17605 & 5882551 & 129701 \\
\hline
\end{tabular}

Notes: This table summarizes characteristics of different samples of (displaced) migrants and natives. Columns (1) and (4) show characteristics of a random 2-percent sample of workers subject to social security in Germany 2000-2010. Columns (2) and (5) represent all displaced workers in our baseline sample. We measure characteristics in $\mathrm{t}=-1$. Column (3) reports migrants in our sample reweighted to natives. Standard deviations in brackets. Source: IEB, BBSR. 
Table A.4.2: Workers' Distribution Across Industries in $t=-1$

\begin{tabular}{|c|c|c|c|c|}
\hline & $\begin{array}{c}(1) \\
\text { Nondisplaced } \\
\text { Migrants }\end{array}$ & $\begin{array}{c}\text { (2) } \\
\text { Displaced } \\
\text { Migrants }\end{array}$ & $\begin{array}{c}(3) \\
\text { Nondisplaced } \\
\text { Natives }\end{array}$ & $\begin{array}{c}(4) \\
\text { Displaced } \\
\text { Natives }\end{array}$ \\
\hline Agriculture & $\begin{array}{c}0.00023 \\
{[0.015]}\end{array}$ & $\begin{array}{c}0.00023 \\
{[0.015]}\end{array}$ & $\begin{array}{c}0.00084 \\
{[0.029]}\end{array}$ & $\begin{array}{c}0.00084 \\
{[0.029]}\end{array}$ \\
\hline Mining, Energy & $\begin{array}{l}0.034 \\
{[0.18]}\end{array}$ & $\begin{array}{l}0.034 \\
{[0.18]}\end{array}$ & $\begin{array}{l}0.023 \\
{[0.15]}\end{array}$ & $\begin{array}{l}0.023 \\
{[0.15]}\end{array}$ \\
\hline Food Manufacturing & $\begin{array}{l}0.064 \\
{[0.24]}\end{array}$ & $\begin{array}{l}0.064 \\
{[0.24]}\end{array}$ & $\begin{array}{l}0.037 \\
{[0.19]}\end{array}$ & $\begin{array}{l}0.037 \\
{[0.19]}\end{array}$ \\
\hline Consumption Goods & $\begin{array}{c}0.10 \\
{[0.30]}\end{array}$ & $\begin{array}{c}0.10 \\
{[0.30]}\end{array}$ & $\begin{array}{l}0.070 \\
{[0.25]}\end{array}$ & $\begin{array}{l}0.070 \\
{[0.25]}\end{array}$ \\
\hline Production Goods & $\begin{array}{c}0.12 \\
{[0.33]}\end{array}$ & $\begin{array}{c}0.12 \\
{[0.33]}\end{array}$ & $\begin{array}{l}0.084 \\
{[0.28]}\end{array}$ & $\begin{array}{l}0.084 \\
{[0.28]}\end{array}$ \\
\hline Investment Goods & $\begin{array}{c}0.16 \\
{[0.37]}\end{array}$ & $\begin{array}{c}0.16 \\
{[0.37]}\end{array}$ & $\begin{array}{c}0.15 \\
{[0.36]}\end{array}$ & $\begin{array}{c}0.15 \\
{[0.36]}\end{array}$ \\
\hline Construction & $\begin{array}{l}0.039 \\
{[0.19]}\end{array}$ & $\begin{array}{l}0.039 \\
{[0.19]}\end{array}$ & $\begin{array}{l}0.086 \\
{[0.28]}\end{array}$ & $\begin{array}{l}0.086 \\
{[0.28]}\end{array}$ \\
\hline Retail & $\begin{array}{c}0.11 \\
{[0.32]}\end{array}$ & $\begin{array}{c}0.11 \\
{[0.32]}\end{array}$ & $\begin{array}{c}0.13 \\
{[0.34]}\end{array}$ & $\begin{array}{c}0.13 \\
{[0.34]}\end{array}$ \\
\hline Traffic, Telecommunication & $\begin{array}{l}0.075 \\
{[0.26]}\end{array}$ & $\begin{array}{l}0.075 \\
{[0.26]}\end{array}$ & $\begin{array}{l}0.069 \\
{[0.25]}\end{array}$ & $\begin{array}{l}0.069 \\
{[0.25]}\end{array}$ \\
\hline Credit, Insurance & $\begin{array}{l}0.0043 \\
{[0.066]}\end{array}$ & $\begin{array}{l}0.0043 \\
{[0.066]}\end{array}$ & $\begin{array}{l}0.015 \\
{[0.12]}\end{array}$ & $\begin{array}{l}0.015 \\
{[0.12]}\end{array}$ \\
\hline Restaurants & $\begin{array}{l}0.021 \\
{[0.14]}\end{array}$ & $\begin{array}{l}0.021 \\
{[0.14]}\end{array}$ & $\begin{array}{l}0.0052 \\
{[0.072]}\end{array}$ & $\begin{array}{l}0.0052 \\
{[0.072]}\end{array}$ \\
\hline Education & $\begin{array}{l}0.0022 \\
{[0.046]}\end{array}$ & $\begin{array}{l}0.0022 \\
{[0.046]}\end{array}$ & $\begin{array}{l}0.020 \\
{[0.14]}\end{array}$ & $\begin{array}{l}0.020 \\
{[0.14]}\end{array}$ \\
\hline Health & $\begin{array}{l}0.0051 \\
{[0.071]}\end{array}$ & $\begin{array}{l}0.0051 \\
{[0.071]}\end{array}$ & $\begin{array}{l}0.012 \\
{[0.11]}\end{array}$ & $\begin{array}{l}0.012 \\
{[0.11]}\end{array}$ \\
\hline Commercial Services & $\begin{array}{c}0.23 \\
{[0.42]}\end{array}$ & $\begin{array}{c}0.23 \\
{[0.42]}\end{array}$ & $\begin{array}{c}0.24 \\
{[0.43]}\end{array}$ & $\begin{array}{c}0.24 \\
{[0.43]}\end{array}$ \\
\hline Other Services & $\begin{array}{l}0.022 \\
{[0.15]}\end{array}$ & $\begin{array}{l}0.022 \\
{[0.15]}\end{array}$ & $\begin{array}{l}0.028 \\
{[0.16]}\end{array}$ & $\begin{array}{l}0.028 \\
{[0.16]}\end{array}$ \\
\hline Non-Profit & $\begin{array}{l}0.0092 \\
{[0.095]}\end{array}$ & $\begin{array}{l}0.0092 \\
{[0.095]}\end{array}$ & $\begin{array}{l}0.013 \\
{[0.11]}\end{array}$ & $\begin{array}{l}0.013 \\
{[0.11]}\end{array}$ \\
\hline Public Administration & $\begin{array}{l}0.0022 \\
{[0.047]}\end{array}$ & $\begin{array}{l}0.0022 \\
{[0.047]}\end{array}$ & $\begin{array}{l}0.018 \\
{[0.13]}\end{array}$ & $\begin{array}{l}0.018 \\
{[0.13]}\end{array}$ \\
\hline Number of Observations & 17605 & 17605 & 129701 & 129701 \\
\hline
\end{tabular}

Notes: Distribution across industries of displaced and nondisplaced workers in the year prior to the displacement year. Workers satisfy the following baseline restrictions: Aged 24 to 50, working fulltime in pre-displacement year, at least 3 years of tenure, and establishment has at least 50 employees. Nondisplaced sample of workers are matched to displaced workers using propensity score matching within year and industry cells. Non-displaced sample of workers is a random sample of workers (one per displaced worker) that satisfy the same baseline restrictions. Standard deviations in brackets. Source: IEB. 
Table A.4.3: Workers' Distribution Across Occupations in $t=-1$

\begin{tabular}{lcccc}
\hline & $(1)$ & $(2)$ & $(3)$ & $(4)$ \\
& $\begin{array}{c}\text { Nondisplaced } \\
\text { Migrants }\end{array}$ & $\begin{array}{c}\text { Displaced } \\
\text { Migrants }\end{array}$ & $\begin{array}{c}\text { Nondisplaced } \\
\text { Natives }\end{array}$ & $\begin{array}{c}\text { Displaced } \\
\text { Natives }\end{array}$ \\
\hline Agriculture, gardening, work with animals & 0.0066 & 0.0043 & 0.0072 & 0.0041 \\
& {$[0.081]$} & {$[0.065]$} & {$[0.085]$} & {$[0.064]$} \\
Simple, manual tasks & 0.42 & 0.46 & 0.22 & 0.24 \\
& {$[0.49]$} & {$[0.50]$} & {$[0.41]$} & {$[0.42]$} \\
Qualified, manual tasks & 0.18 & 0.17 & 0.24 & 0.26 \\
& {$[0.38]$} & {$[0.38]$} & {$[0.43]$} & {$[0.44]$} \\
Technician & 0.025 & 0.029 & 0.073 & 0.075 \\
& {$[0.16]$} & {$[0.17]$} & {$[0.26]$} & {$[0.26]$} \\
Engineer & 0.017 & 0.015 & 0.043 & 0.038 \\
Simple services & {$[0.13]$} & {$[0.12]$} & {$[0.20]$} & {$[0.19]$} \\
& 0.23 & 0.20 & 0.14 & 0.12 \\
Qualified services & {$[0.42]$} & {$[0.40]$} & {$[0.35]$} & {$[0.33]$} \\
Semi-professions & 0.013 & 0.012 & 0.019 & 0.017 \\
Professions & {$[0.11]$} & {$[0.11]$} & {$[0.14]$} & {$[0.13]$} \\
Simple commercial and admin. tasks & 0.0050 & 0.0047 & 0.016 & 0.015 \\
Qualified commercial and admin. tasks & {$[0.071]$} & {$[0.069]$} & {$[0.13]$} & {$[0.12]$} \\
Manager & 0.0039 & 0.0041 & 0.0084 & 0.011 \\
& {$[0.062]$} & {$[0.064]$} & {$[0.091]$} & {$[0.10]$} \\
Not classified & 0.023 & 0.021 & 0.039 & 0.035 \\
Number of Observations & {$[0.15]$} & {$[0.14]$} & {$[0.19]$} & {$[0.18]$} \\
& 0.065 & 0.061 & 0.16 & 0.16 \\
Notes: Din & {$[0.25]$} & {$[0.24]$} & {$[0.37]$} & {$[0.36]$} \\
& 0.010 & 0.012 & 0.029 & 0.029 \\
& {$[0.10]$} & {$[0.11]$} & {$[0.17]$} & {$[0.17]$} \\
& 0.0026 & 0.0025 & 0.0032 & 0.0030 \\
& {$[0.050]$} & {$[0.050]$} & {$[0.057]$} & {$[0.055]$} \\
& 17605 & 17605 & 129701 & 129701 \\
\hline
\end{tabular}

Notes: Distribution across occupations according to Blossfeld (1987) of displaced and nondisplaced workers in the year prior to the displacement year. Workers satisfy the following baseline restrictions: Aged 24 to 50, working fulltime in pre-displacement year, at least 3 years of tenure, and establishment has at least 50 employees. Non-displaced sample of workers are matched to displaced workers using propensity score matching within year and industry cells. Non-displaced sample of workers is a random sample of workers (one per displaced worker) that satisfy the same baseline restrictions. Standard deviations in brackets. Source: IEB. 
Table A.4.4: Event Study Regression Table with Reweighting: Labor Market Outcomes

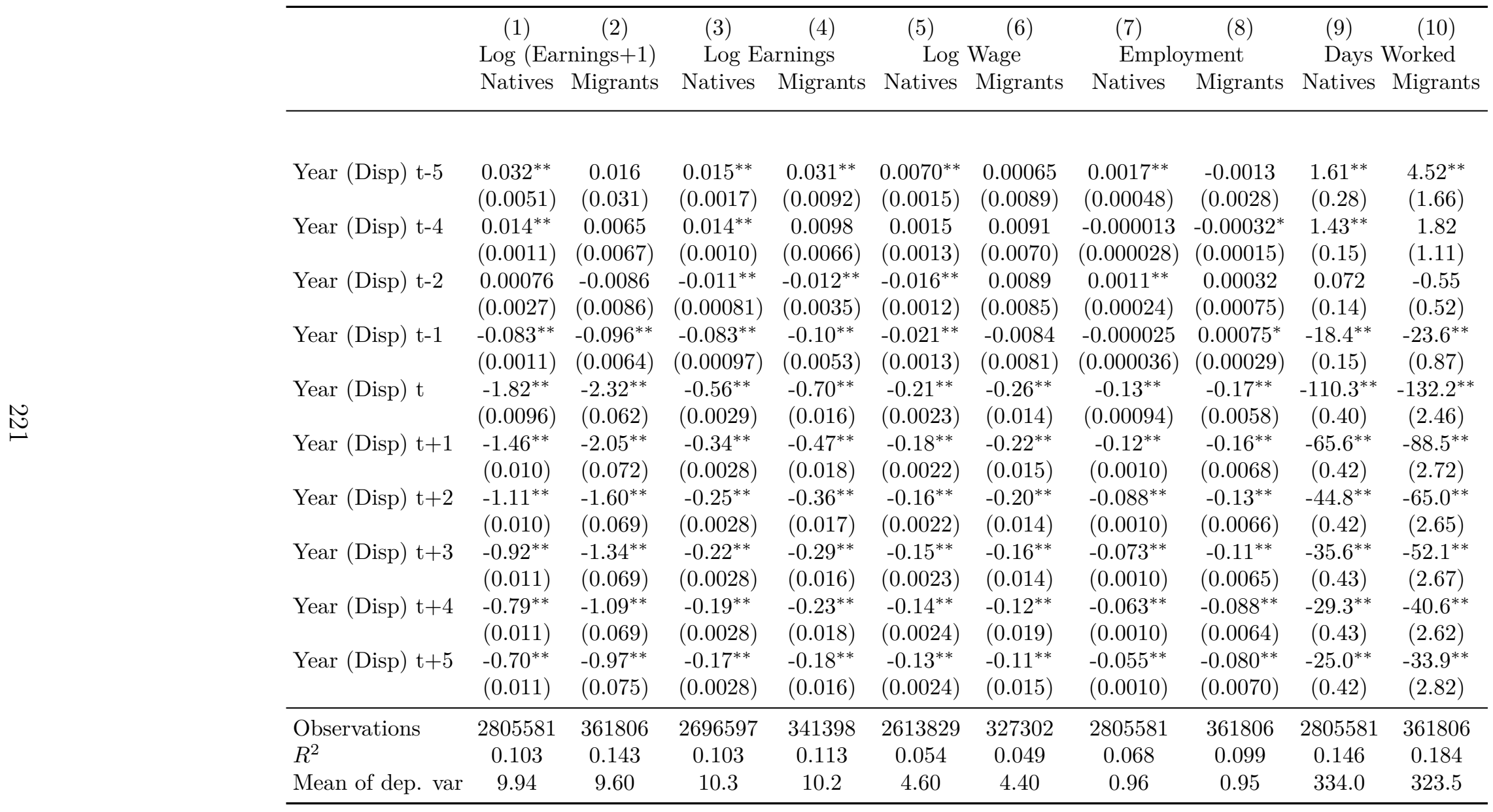

Notes: The table returns coefficients $\alpha_{j}$ from regression equation 4.1. Year $t=-3$ is omitted as the baseline cateogry The outcome variables are log (earnings +1 ) (Columns (1) and (2)), log earnings (Columns (3) and (4)), log wage (Columns (5) and (6)), employment (Columns (7) and (8)), and days worked (Columns (9) and (10)). In all columns, we control for year since displacement, year, and age polynomials. Standard errors are clustered at the individual level. Migrants are reweighted to natives using individual characteristics, industries, and occupations. ${ }^{* *}$ and ${ }^{*}$ refer to statistical significance at the 0.01 and 0.05 percent level, respectively. Source: IEB. 
Table A.4.5: Event Study Regression Table without Reweighting: Labor Market Outcomes

\begin{tabular}{|c|c|c|c|c|c|c|c|c|c|c|}
\hline & $(1)$ & $(2)$ & \multirow{2}{*}{\multicolumn{2}{|c|}{$\begin{array}{l}(3) \\
\log \text { Earnings }\end{array}$}} & \multirow{2}{*}{\multicolumn{2}{|c|}{$\begin{array}{l}(5) \\
\text { Log Wage }\end{array}$}} & $(7)$ & $(8)$ & (9) & (10) \\
\hline & \multicolumn{2}{|c|}{ Log (Earnings+1) } & & & & & \multicolumn{2}{|c|}{ Employment } & \multicolumn{2}{|c|}{ Days Worked } \\
\hline & Natives & Migrants & Natives & Migrants & Natives & Migrants & Natives & Migrants & Natives & Migrants \\
\hline \multirow[t]{2}{*}{ Year (Disp) t-5 } & & & & & & $0.013^{* *}$ & & & & $1.92^{*}$ \\
\hline & $(0.0051)$ & $(0.015)$ & $(0.0017)$ & $(0.0054)$ & $(0.0015)$ & $(0.0039)$ & $(0.00048)$ & $(0.0014)$ & $(0.28)$ & $(0.86)$ \\
\hline \multirow[t]{2}{*}{ Year (Disp) t-4 } & $0.014^{* *}$ & $0.014^{* *}$ & $0.014^{* *}$ & $0.014^{* *}$ & 0.0015 & 0.0036 & -0.000013 & 0.000017 & $1.43^{* *}$ & $1.79^{* *}$ \\
\hline & $(0.0011)$ & $(0.0030)$ & $(0.0010)$ & $(0.0029)$ & $(0.0013)$ & $(0.0030)$ & $(0.000028)$ & $(0.000076)$ & $(0.15)$ & $(0.45)$ \\
\hline \multirow[t]{2}{*}{ Year (Disp) t-2 } & 0.00076 & -0.012 & $-0.011^{* *}$ & $-0.016^{* *}$ & $-0.016^{* *}$ & $-0.017^{* *}$ & $0.0011^{* *}$ & 0.00032 & 0.072 & -0.24 \\
\hline & $(0.0027)$ & $(0.0063)$ & $(0.00081)$ & $(0.0023)$ & $(0.0012)$ & $(0.0026)$ & $(0.00024)$ & $(0.000$ & $(0$. & $(0.35)$ \\
\hline \multirow[t]{2}{*}{ Year (Disp) t-1 } & $-0.083^{* *}$ & $-0.12^{* *}$ & $-0.083^{* *}$ & $-0.12^{* *}$ & $-0.021^{* *}$ & $-0.025^{* *}$ & -0.000025 & -0.000047 & $-18.4^{* *}$ & $-27.0^{* *}$ \\
\hline & $(0.0011)$ & $(0.0032)$ & $(0.00097)$ & $(0.0028)$ & $(0.0013)$ & $(0.0029)$ & $(0.000036)$ & $(0.00014)$ & $(0.1$ & $(0.47)$ \\
\hline \multirow[t]{2}{*}{ Year (Disp) t } & $-1.82^{* *}$ & $-2.68^{* *}$ & $-0.56^{* *}$ & $-0.91^{* *}$ & $-0.21^{* *}$ & $-0.43^{* *}$ & $-0.13^{* *}$ & $-0.19^{* *}$ & $-110.3^{* *}$ & $-149.4^{* *}$ \\
\hline & $(0.0096)$ & $(0.030)$ & $(0.0029)$ & $(0.0099)$ & $(0.0023)$ & $(0.0090)$ & $(0.00094)$ & $(0.0030)$ & $(0.40)$ & $(1.16)$ \\
\hline \multirow[t]{2}{*}{ Year (Disp) t+1 } & $-1.46^{* *}$ & $-2.27^{* *}$ & $-0.34^{* *}$ & $-0.62^{* *}$ & $-0.18^{* *}$ & $-0.33^{* *}$ & $-0.12^{* *}$ & $-0.18^{* *}$ & $-65.6^{* *}$ & $-96.6^{* *}$ \\
\hline & $(0.010)$ & $(0.033)$ & $(0.0028)$ & & $(0.0022)$ & $(0.0078)$ & & $(0.00$ & & $(1.30)$ \\
\hline \multirow[t]{2}{*}{ Year (Disp) $t+2$} & $-1.11^{* *}$ & $-1.69^{* *}$ & $-0.25^{* *}$ & $-0.47^{* *}$ & $-0.16^{* *}$ & $-0.29^{* *}$ & $-0.088^{* *}$ & $-0.13^{* *}$ & $-44.8^{* *}$ & $-67.6^{* *}$ \\
\hline & $(0.010)$ & $(0.033)$ & $(0.0028)$ & $(0.010)$ & $(0.0022)$ & $(0.0077)$ & $(0.0010)$ & $(0.0032)$ & & $(1.32)$ \\
\hline \multirow[t]{2}{*}{ Year (Disp) $t+3$} & $-0.92^{* *}$ & $-1.39^{* *}$ & $-0.22^{* *}$ & $-0.39^{* *}$ & $-0.15^{* *}$ & $-0.26^{* *}$ & $-0.073^{* *}$ & $-0.11^{* *}$ & $-35.6^{* *}$ & $-53.5^{* *}$ \\
\hline & $(0.011)$ & $(0.034)$ & $(0.0028)$ & $(0.010)$ & $(0.0023)$ & $(0.0078)$ & $(0.0010)$ & $(0.0033)$ & $(0.43)$ & $(1.34)$ \\
\hline \multirow[t]{2}{*}{ Year (Disp) t+4 } & $-0.79^{* *}$ & $-1.11^{* *}$ & $-0.19^{* *}$ & $-0.31^{* *}$ & $-0.14^{* *}$ & $-0.22^{* *}$ & $-0.063^{* *}$ & $-0.086^{* *}$ & $-29.3^{* *}$ & $-40.7^{* *}$ \\
\hline & & $(0.034)$ & $(0.0028)$ & & & $(0.0078)$ & & & & $(1.34)$ \\
\hline \multirow[t]{2}{*}{ Year (Disp) t+5 } & $-0.70^{* *}$ & $-0.97^{* *}$ & $-0.17^{* *}$ & $-0.27^{* *}$ & $-0.13^{* *}$ & $-0.20^{* *}$ & $-0.055^{* *}$ & $-0.075^{* *}$ & $-25.0^{* *}$ & $-34.8^{* *}$ \\
\hline & $(0.011)$ & $(0.033)$ & $(0.0028)$ & $(0.0100)$ & $(0.0024)$ & $(0.0079)$ & $(0.0010)$ & $(0.0032)$ & $(0.42)$ & $(1.33)$ \\
\hline Observations & 2805581 & 376467 & 2696597 & 355810 & 2613829 & 341462 & 2805581 & 376467 & 2805581 & 376467 \\
\hline$R^{2}$ & 0.103 & 0.162 & 0.103 & 0.147 & 0.054 & 0.078 & 0.068 & 0.103 & 0.146 & 0.203 \\
\hline Mean of dep. var & 9.94 & 9.60 & 10.3 & 10.2 & 4.60 & 4.40 & 0.96 & 0.95 & 334.0 & 323.5 \\
\hline
\end{tabular}

Notes: The table returns coefficients $\alpha_{j}$ from regression equation 4.1. Year $t=-3$ is omitted as the baseline cateogry. The outcome variables are log (earnings+1) (Columns (1) and (2)), log earnings (Columns (3) and (4)), log wage (Columns (5) and (6)), employment (Columns (7) and (8)), and days worked (Columns (9) and (10)). In all columns, we control for year since displacement, year, and age polynomials. Standard errors are clustered at the individual level. All regression results reported are without reweighting migrants to natives. ${ }^{* *}$ and ${ }^{*}$ refer to statistical significance at the 0.01 and 0.05 percent level, respectively. Source: IEB. 
Table A.4.6: Event Study Regression Table: Days Worked

\begin{tabular}{|c|c|c|c|c|c|c|}
\hline & (1) & $(2)$ & $(3)$ & $(4)$ & $(5)$ & $(6)$ \\
\hline & \multicolumn{3}{|c|}{ Days Worked Full-time } & \multicolumn{3}{|c|}{ Days Worked Part-time } \\
\hline & Natives & Migrants & Migrants & Natives & Migrants & Migrants \\
\hline & Non-re & weighted & Reweighted & Non-re & weighted & Reweighted \\
\hline \multirow[t]{2}{*}{ Year (Disp) t-5 } & $1.61^{* *}$ & 1.71 & $4.88^{*}$ & $0.59^{* *}$ & 0.83 & 2.19 \\
\hline & $(0.33)$ & $(1.02)$ & $(2.03)$ & $(0.17)$ & $(0.70)$ & $(1.25)$ \\
\hline \multirow[t]{2}{*}{ Year (Disp) t-4 } & $1.55^{* *}$ & $2.10^{* *}$ & $2.95^{*}$ & $0.53^{* *}$ & 0.45 & 0.86 \\
\hline & $(0.19)$ & $(0.58)$ & $(1.32)$ & $(0.13)$ & $(0.52)$ & $(0.88)$ \\
\hline \multirow[t]{2}{*}{ Year (Disp) t-2 } & $-0.57^{* *}$ & $-0.99^{*}$ & $-1.44^{*}$ & -0.097 & -0.53 & 0.053 \\
\hline & $(0.17)$ & $(0.47)$ & $(0.67)$ & $(0.12)$ & $(0.50)$ & $(0.88)$ \\
\hline \multirow[t]{2}{*}{ Year (Disp) t-1 } & $-20.8^{* *}$ & $-32.1^{* *}$ & $-26.4^{* *}$ & $0.32^{*}$ & 0.21 & 0.89 \\
\hline & $(0.21)$ & $(0.63)$ & $(1.04)$ & $(0.15)$ & $(0.63)$ & $(1.12)$ \\
\hline \multirow[t]{2}{*}{ Year (Disp) t } & $-120.6^{* *}$ & $-175.8^{* *}$ & $-147.4^{* *}$ & $1.48^{* *}$ & $1.74^{*}$ & 1.25 \\
\hline & $(0.44)$ & $(1.27)$ & $(2.63)$ & $(0.18)$ & $(0.70)$ & $(1.26)$ \\
\hline \multirow{2}{*}{ Year (Disp) t+1 } & $-76.0^{* *}$ & $-121.0^{* *}$ & $-102.6^{* *}$ & $2.81^{* *}$ & $5.28^{* *}$ & $3.92^{* *}$ \\
\hline & $(0.47)$ & $(1.46)$ & $(2.97)$ & $(0.20)$ & $(0.76)$ & $(1.38)$ \\
\hline \multirow[t]{2}{*}{ Year (Disp) t+2 } & $-54.2^{* *}$ & $-90.0^{* *}$ & $-76.9^{* *}$ & $3.20^{* *}$ & $6.86^{* *}$ & $4.71^{* *}$ \\
\hline & $(0.48)$ & $(1.53)$ & $(2.91)$ & $(0.21)$ & $(0.80)$ & $(1.25)$ \\
\hline \multirow[t]{2}{*}{ Year (Disp) $t+3$} & $-44.8^{* *}$ & $-73.2^{* *}$ & $-62.8^{* *}$ & $3.50^{* *}$ & $7.27^{* *}$ & $6.15^{* *}$ \\
\hline & $(0.49)$ & $(1.57)$ & $(2.97)$ & $(0.22)$ & $(0.83)$ & $(1.24)$ \\
\hline \multirow[t]{2}{*}{ Year (Disp) t+4 } & $-38.2^{* *}$ & $-58.8^{* *}$ & $-53.1^{* *}$ & $3.64^{* *}$ & $7.81^{* *}$ & $8.37^{* *}$ \\
\hline & $(0.50)$ & $(1.59)$ & $(3.17)$ & $(0.23)$ & $(0.87)$ & $(1.99)$ \\
\hline \multirow[t]{2}{*}{ Year (Disp) t+5 } & $-33.5^{* *}$ & $-52.8^{* *}$ & $-46.2^{* *}$ & $3.55^{* *}$ & $8.47^{* *}$ & $7.46^{* *}$ \\
\hline & $(0.50)$ & $(1.60)$ & $(3.33)$ & $(0.24)$ & $(0.90)$ & $(1.39)$ \\
\hline Observations & 2805581 & 376467 & 361806 & 2805581 & 376467 & 361806 \\
\hline$R^{2}$ & 0.159 & 0.234 & 0.201 & 0.007 & 0.029 & 0.026 \\
\hline Mean of dep. var & 326.3 & 310.2 & 310.2 & 5.05 & 9.93 & 9.93 \\
\hline
\end{tabular}

Notes: The table returns coefficients $\alpha_{j}$ from regression equation 4.1. Year $t=-3$ is omitted as the baseline cateogry. The outcome variables are days worked part-time (Columns (1), (2), and (3)), and days worked part-time (Columns (4),(5), and (6)). In all columns, we control for year since displacement, year, and age polynomials. Standard errors are clustered at the individual level. Regression results in Columns (3) and (6) are from regression models where we reweight migrants to natives. ** and $*$ refer to statistical significance at the 0.01 and 0.05 percent level, respectively. Source: IEB. 
Table A.4.7: Event Study Regression Table with Reweighting: Geographic Mobility

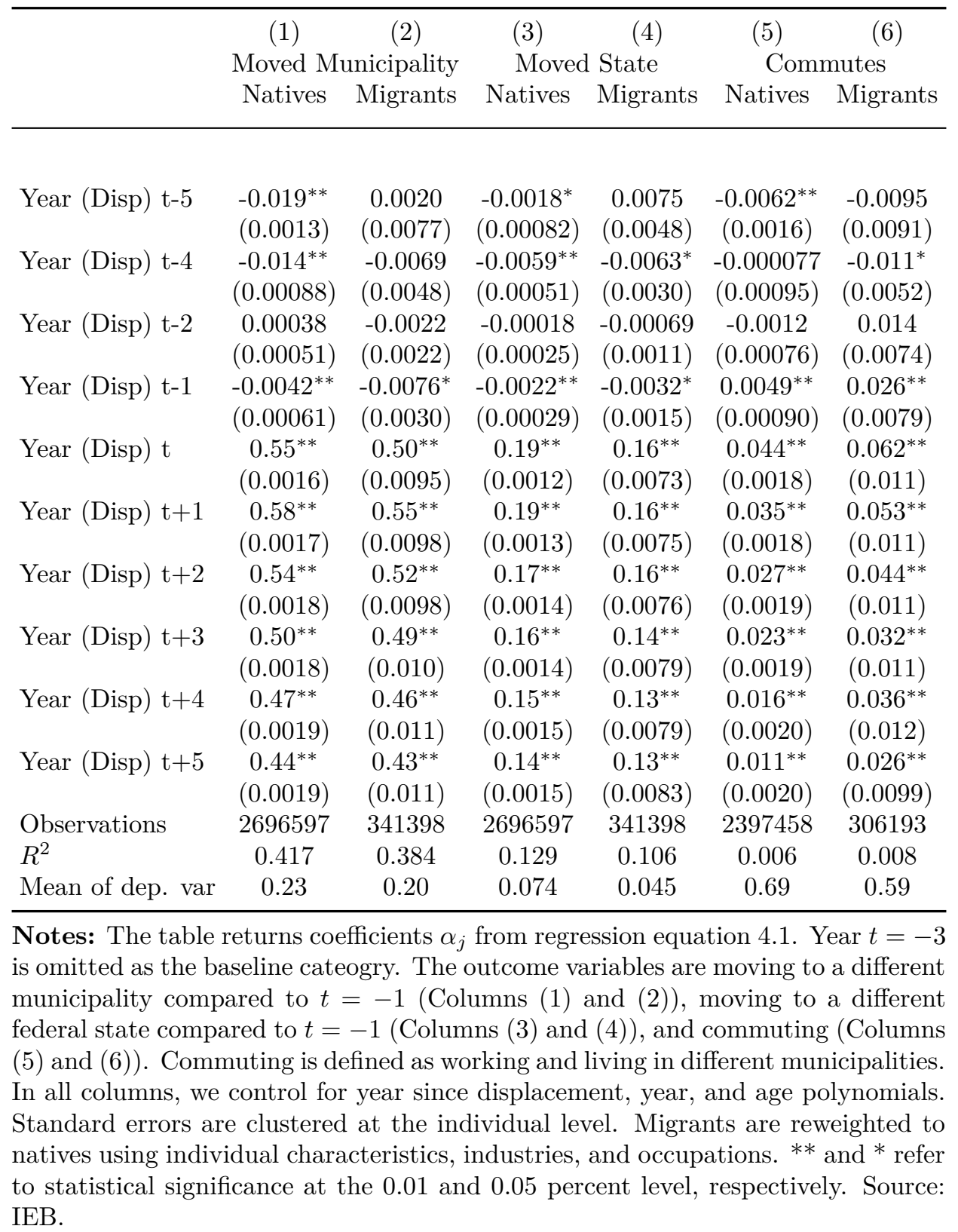


Table A.4.8: Event Study Regression Table without Reweighting: Geographic Mobility

\begin{tabular}{|c|c|c|c|c|c|c|}
\hline & \multirow{2}{*}{\multicolumn{2}{|c|}{$\begin{array}{c}(1) \\
\text { Moved Municipality }\end{array}$}} & \multirow{2}{*}{\multicolumn{2}{|c|}{$\begin{array}{l}(3) \quad(4) \\
\text { Moved State }\end{array}$}} & \multirow{2}{*}{\multicolumn{2}{|c|}{$\begin{array}{c}(5) \quad(6) \\
\text { Commutes }\end{array}$}} \\
\hline & & & & & & \\
\hline & Natives & Migrants & Natives & Migrants & Natives & Migrants \\
\hline \multirow[t]{2}{*}{ Year (Disp) t-5 } & & & & & $-0.0062^{* *}$ & 0.0049 \\
\hline & $(0.0013)$ & $(0.0035)$ & $(0.00082)$ & $(0.0018)$ & $(0.0016)$ & $(0.0041)$ \\
\hline \multirow[t]{2}{*}{ Year (Disp) t-4 } & $-0.014^{* *}$ & $-0.013^{* *}$ & $-0.0059^{* *}$ & $-0.0053^{* *}$ & -0.000077 & -0.0011 \\
\hline & $(0.00088)$ & $(0.0022)$ & $(0.00051)$ & $(0.0011)$ & $(0.00095)$ & $(0.0026)$ \\
\hline \multirow[t]{2}{*}{ Year (Disp) t-2 } & 0.0003 & -0.00040 & -0.000 & 0.00 & -0.0012 & 0.0013 \\
\hline & $(0.000$ & $(0.0013)$ & $(0.00025)$ & $(0.00056)$ & $(0.00076)$ & $(0.0020)$ \\
\hline \multirow[t]{2}{*}{ Year (Disp) t-1 } & $-0.0042^{* *}$ & -0.0027 & $-0.0022^{* *}$ & -0.0011 & $0.0049^{* *}$ & 0.0040 \\
\hline & $(0.00061)$ & $(0.0016)$ & $(0.00029)$ & $(0.00065)$ & $(0.00090)$ & $(0.0024)$ \\
\hline \multirow[t]{2}{*}{ Year (Disp) $t$} & $0.55^{* *}$ & $0.47^{* *}$ & $0.19^{* *}$ & $0.11^{* *}$ & $0.044^{* *}$ & $0.064^{* *}$ \\
\hline & $(0.0016)$ & $(0.0044)$ & $(0.0012)$ & $(0.0026)$ & $(0.0018)$ & $(0.0056)$ \\
\hline \multirow[t]{2}{*}{ Year (Disp) t+1 } & $0.58^{* *}$ & $0.52^{* *}$ & $0.19^{* *}$ & $0.12^{* *}$ & $0.035^{* *}$ & $0.054^{* *}$ \\
\hline & $(0.00$ & $(0.00$ & $(0.00$ & $(0.0030)$ & $(0.0018)$ & $(0.0057)$ \\
\hline \multirow[t]{2}{*}{ Year (Disp) $t+2$} & $0.54^{* *}$ & $0.50^{* *}$ & $0.17^{* *}$ & $0.11^{* *}$ & $0.027^{* *}$ & $0.047^{* *}$ \\
\hline & $(0.0018)$ & $(0.0049)$ & $(0.0014)$ & $(0.0032)$ & $(0.0019)$ & $(0.0058)$ \\
\hline \multirow[t]{2}{*}{ Year (Disp) $t+3$} & $0.50^{* *}$ & $0.46^{* *}$ & $0.16^{* *}$ & $0.11^{* *}$ & $0.023^{* *}$ & $0.037^{* *}$ \\
\hline & $(0.0018)$ & $(0.0051)$ & $(0.0014)$ & $(0.0033)$ & $(0.0019)$ & $(0.0060)$ \\
\hline \multirow[t]{2}{*}{ Year (Disp) $t+4$} & $0.47^{* *}$ & $0.44^{* *}$ & $0.15^{* *}$ & $0.097^{* *}$ & $0.016^{* *}$ & $0.039^{* *}$ \\
\hline & & $(0.0053)$ & $(0.0015)$ & $(0.0034)$ & $(0.0020)$ & $(0.0061)$ \\
\hline \multirow[t]{2}{*}{ Year (Disp) $t+5$} & $0.44^{* *}$ & $0.40^{* *}$ & $0.14^{* *}$ & $0.091^{* *}$ & $0.011^{* *}$ & $0.033^{* *}$ \\
\hline & & & & & & $(0.0062)$ \\
\hline Observations & 2696597 & 355810 & 2696597 & 355810 & 2397458 & 320149 \\
\hline$R^{2}$ & 0.417 & 0.372 & 0.129 & 0.079 & 0.006 & 0.010 \\
\hline Mean of dep. var & 0.23 & 0.20 & 0.074 & 0.045 & 0.69 & 0.59 \\
\hline
\end{tabular}

Notes: The table returns coefficients $\alpha_{j}$ from regression equation 4.1. Year $t=-3$ is omitted as the baseline cateogry. The outcome variables are moving to a different municipality compared to $t=-1$ (Columns (1) and (2)), moving to a different federal state compared to $t=-1$ (Columns (3) and (4)), and commuting (Columns (5) and (6)). Commuting is defined as working and living in different municipalities. In all columns, we control for year since displacement, year, and age polynomials. Standard errors are clustered at the individual level. ** and $*$ refer to statistical significance at the 0.01 and 0.05 percent level, respectively. Source: IEB. 
Table A.4.9: Event Study Regression Table with Reweighting: Establishment Characteristics

\begin{tabular}{|c|c|c|c|c|c|c|c|c|}
\hline & (1) & (2) & (3) & (4) & $(5)$ & (6) & (7) & \\
\hline & \multicolumn{2}{|c|}{$\begin{array}{l}\text { Ave. Estab } \\
\text { Wages }\end{array}$} & \multicolumn{2}{|c|}{$\begin{array}{l}\text { AKM } \\
\text { Effect }\end{array}$} & \multicolumn{2}{|c|}{$\begin{array}{l}\text { Share Marg. } \\
\text { Employed }\end{array}$} & \multicolumn{2}{|c|}{$\begin{array}{c}\text { Share Migrant } \\
\text { Workers }\end{array}$} \\
\hline & Natives & Migrants & Natives & Migrants & Natives & Migrants & Natives & Migrants \\
\hline Year (Disp) t-5 & & & & & & & $\begin{array}{c}0.00097^{* *} \\
(0.00022)\end{array}$ & \\
\hline Year (Disp) t-4 & & $\begin{array}{l}-0.30 \\
(0.23)\end{array}$ & & & & $\begin{array}{r}-0.00052 \\
(0.0015)\end{array}$ & $\begin{array}{l}0.00082^{* *} \\
(0.00015)\end{array}$ & \\
\hline Year (Disp) t-2 & & & $\begin{array}{l}0.00027^{*} \\
(0.00012)\end{array}$ & $\begin{array}{c}0.00082 \\
(0.00049)\end{array}$ & & $\begin{array}{l}-0.0010 \\
(0.0013)\end{array}$ & & \\
\hline Year (Disp) t-1 & & $\begin{array}{l}1.98 \\
(0.2\end{array}$ & $\begin{array}{l}0.000095 \\
(0.00011)\end{array}$ & $\begin{array}{c}0.0013^{*} \\
(0.00053)\end{array}$ & $\begin{array}{l}-0.0015^{* *} \\
(0.00022)\end{array}$ & $\begin{array}{c}-0.0044^{* *} \\
(0.0014)\end{array}$ & $\begin{array}{c}-0.00034^{* *} \\
(0.00013)\end{array}$ & $\begin{array}{c}-0.0042^{* *} \\
(0.0014)\end{array}$ \\
\hline Year (Disp) t & & $\begin{array}{l}-0.72 \\
(0.76)\end{array}$ & & $\begin{array}{l}-0.09 \\
(0.00\end{array}$ & $\begin{array}{r}0.03 \\
(0.00\end{array}$ & $\begin{array}{l}0.05 \\
(0.00\end{array}$ & $\begin{array}{l}-0.0 \\
0.00\end{array}$ & $\begin{array}{c}-0.022^{* * *} \\
(0.0041)\end{array}$ \\
\hline Year (Disp) $t+1$ & $\begin{array}{l}-3.45^{* *} \\
(0.11)\end{array}$ & $\begin{array}{l}-1.73^{*} \\
(0.77)\end{array}$ & $\begin{array}{l}-0.083^{* *} \\
(0.00088)\end{array}$ & $\begin{array}{l}-0.100^{* *} \\
(0.0049)\end{array}$ & $\begin{array}{c}0.037^{* *} \\
(0.00058)\end{array}$ & $\begin{array}{l}0.044^{* *} \\
(0.0035)\end{array}$ & $\begin{array}{l}-0.011^{* *} \\
(0.00035)\end{array}$ & $\begin{array}{l}-0.022^{* *} \\
(0.0035)\end{array}$ \\
\hline Year (Disp) $t+2$ & $\begin{array}{c}-3.56^{* *} \\
(0.12)\end{array}$ & $\begin{array}{c}-2.70^{* *} \\
(0.79)\end{array}$ & $\begin{array}{l}-0.081^{* *} \\
(0.00091)\end{array}$ & $\begin{array}{l}-0.10^{* *} \\
(0.0053)\end{array}$ & $\begin{array}{c}0.036^{* *} \\
(0.00060)\end{array}$ & $\begin{array}{l}0.047^{* *} \\
(0.0035)\end{array}$ & $\begin{array}{c}-0.010^{* *} \\
(0.00036)\end{array}$ & $\begin{array}{l}-0.013^{* *} \\
(0.0034)\end{array}$ \\
\hline Year (Disp) $t+3$ & $\begin{array}{l}-2.99^{* *} \\
(0.13)\end{array}$ & $\begin{array}{l}-1.47 \\
(0.86)\end{array}$ & $\begin{array}{l}-0.076^{* *} \\
(0.00093)\end{array}$ & $\begin{array}{l}-0.097^{* *} \\
(0.0053)\end{array}$ & $\begin{array}{c}0.034^{* *} \\
(0.00062)\end{array}$ & $\begin{array}{l}0.038^{* *} \\
(0.0035)\end{array}$ & $\begin{array}{l}-0.010^{* *} \\
(0.00037)\end{array}$ & $\begin{array}{l}-0.0092^{*} \\
(0.0038)\end{array}$ \\
\hline Year (Disp) $t+4$ & $\begin{array}{l}-2.86^{* *} \\
(0.14)\end{array}$ & $\begin{array}{l}-0.93 \\
(0.84)\end{array}$ & $\begin{array}{l}-0.073^{* *} \\
(0.00096)\end{array}$ & $\begin{array}{l}-0.087^{* *} \\
(0.0051)\end{array}$ & $\begin{array}{c}0.032^{* *} \\
(0.00063)\end{array}$ & $\begin{array}{l}0.033^{* *} \\
(0.0037)\end{array}$ & $\begin{array}{l}-0.0098^{* *} \\
(0.00038)\end{array}$ & $\begin{array}{l}-0.0084^{*} \\
(0.0039)\end{array}$ \\
\hline Year (Disp) $t+5$ & $\begin{array}{c}-2.61^{* *} \\
(0.14)\end{array}$ & $\begin{array}{l}-0.46 \\
(0.91)\end{array}$ & $\begin{array}{c}-0.070^{* *} \\
(0.00097)\end{array}$ & $\begin{array}{l}-0.082^{* *} \\
(0.0051)\end{array}$ & $\begin{array}{c}0.031^{* *} \\
(0.00065)\end{array}$ & $\begin{array}{c}0.031^{* *} \\
(0.0038)\end{array}$ & $\begin{array}{l}-0.0090^{* *} \\
(0.00040)\end{array}$ & $\begin{array}{l}-0.0079^{*} \\
(0.0040)\end{array}$ \\
\hline & 25791 & 3200 & 2360559 & 2970 & 2368993 & 301326 & 2579373 & 321237 \\
\hline$R^{2}$ & & 0.0 & & & & 0.053 & 0.016 & 0.018 \\
\hline Mean of dep. var & 96.7 & 90.9 & -0.22 & -0.21 & 0.062 & 0.091 & 0.067 & 0.22 \\
\hline
\end{tabular}

Notes: The table returns coefficients $\alpha_{j}$ from regression equation 4.1. Year $t=-3$ is omitted as the baseline cateogry. The outcome variables are average establishment wages (Columns (1) and (2)), AKMstyle establishment fixed effects (Columns (3) and (4)), the share of marginally employed workers in an establishment (columns 5 and 6), and the share of migrant workers in an establishment (Columns (7) and (8)). In all columns, we control for year since displacement, year, and age polynomials. Standard errors are clustered at the individual level. Migrants are reweighted to natives using individual characteristics, industries, and occupations. ${ }^{* *}$ and ${ }^{*}$ refer to statistical significance at the 0.01 and 0.05 percent level, respectively. Source: IEB. 
Table A.4.10: Event Study Regression Table without Reweighting: Establishment Characteristics

\begin{tabular}{|c|c|c|c|c|c|c|c|c|}
\hline & (1) & (2) & (3) & (4) & (5) & (6) & (7) & $(8)$ \\
\hline & \multicolumn{2}{|c|}{$\begin{array}{l}\text { Ave. Estab } \\
\text { Wages }\end{array}$} & \multicolumn{2}{|c|}{$\begin{array}{c}\text { Estab } \\
\text { FE }\end{array}$} & \multicolumn{2}{|c|}{$\begin{array}{l}\text { Share Marg. } \\
\text { Employed }\end{array}$} & \multicolumn{2}{|c|}{$\begin{array}{c}\text { Share Migrant } \\
\text { Workers }\end{array}$} \\
\hline & Natives & Migrants & Natives & Migrants & Natives & Migrants & Natives & Migrants \\
\hline Year (Disp) t-5 & $0.84^{* *}$ & $1.08^{* *}$ & -0.00026 & $0.0053^{* *}$ & 0.00068 & -0.00018 & $0.00097^{* *}$ & $0.0027^{*}$ \\
\hline & $(0.061)$ & $(0.15)$ & $(0.00049)$ & $(0.0015)$ & $(0.00047)$ & (0.0015) & $(0.00022)$ & $(0.0012)$ \\
\hline Year (Disp) t-4 & $\begin{array}{l}0.32^{* *} \\
(0.041)\end{array}$ & $\begin{array}{l}0.41^{* *} \\
(0.098)\end{array}$ & $\begin{array}{c}0.00038 \\
(0.00025)\end{array}$ & $\begin{array}{c}0.0015 \\
(0.00083)\end{array}$ & $\begin{array}{c}0.00048 \\
(0.00028)\end{array}$ & $\begin{array}{l}-0.00029 \\
(0.00094)\end{array}$ & $\begin{array}{l}0.00082^{* *} \\
(0.00015)\end{array}$ & $\begin{array}{c}0.0012 \\
(0.00079)\end{array}$ \\
\hline Year (Disp) t-2 & $\begin{array}{c}-0.094^{* *} \\
(0.028)\end{array}$ & $\begin{array}{l}-0.080 \\
(0.066)\end{array}$ & $\begin{array}{c}0.00027^{*} \\
(0.00012)\end{array}$ & $\begin{array}{c}-0.00024 \\
(0.00044)\end{array}$ & $\begin{array}{c}-0.00043^{*} \\
(0.00019)\end{array}$ & $\begin{array}{c}-0.00024 \\
(0.00062)\end{array}$ & $\begin{array}{c}0.0013^{* *} \\
(0.00011)\end{array}$ & $\begin{array}{c}0.00045 \\
(0.00056)\end{array}$ \\
\hline Year (Disp) t-1 & $\begin{array}{l}0.70^{* *} \\
(0.039)\end{array}$ & $\begin{array}{l}1.06^{* *} \\
(0.092)\end{array}$ & $\begin{array}{c}0.000095 \\
(0.00011)\end{array}$ & $\begin{array}{r}-0.000019 \\
(0.00041)\end{array}$ & $\begin{array}{l}-0.0015^{* *} \\
(0.00022)\end{array}$ & $\begin{array}{l}-0.0041^{* *} \\
(0.00074)\end{array}$ & $\begin{array}{c}-0.00034^{* *} \\
(0.00013)\end{array}$ & $\begin{array}{l}-0.0019^{* *} \\
(0.00064)\end{array}$ \\
\hline Year (Disp) t & $\begin{array}{c}-2.35^{* *} \\
(0.11)\end{array}$ & $\begin{array}{c}-5.51^{* *} \\
(0.32)\end{array}$ & $\begin{array}{c}-0.081^{* *} \\
(0.00087)\end{array}$ & $\begin{array}{l}-0.12^{* *} \\
(0.0031)\end{array}$ & $\begin{array}{c}0.039^{* *} \\
(0.00060)\end{array}$ & $\begin{array}{c}0.091^{* *} \\
(0.0026)\end{array}$ & $\begin{array}{l}-0.013^{* *} \\
(0.00034)\end{array}$ & $\begin{array}{c}-0.025^{* *} \\
(0.0022)\end{array}$ \\
\hline Year (Disp) $t+1$ & $\begin{array}{c}-3.45^{* *} \\
(0.11)\end{array}$ & $\begin{array}{c}-6.47^{* *} \\
(0.31)\end{array}$ & $\begin{array}{c}-0.083^{* *} \\
(0.00088)\end{array}$ & $\begin{array}{c}-0.13^{* *} \\
(0.0031)\end{array}$ & $\begin{array}{c}0.037^{* *} \\
(0.00058)\end{array}$ & $\begin{array}{c}0.073^{* *} \\
(0.0024)\end{array}$ & $\begin{array}{c}-0.011^{* *} \\
(0.00035)\end{array}$ & $\begin{array}{l}-0.023^{* *} \\
(0.0022)\end{array}$ \\
\hline Year (Disp) $t+2$ & $\begin{array}{c}-3.56^{* *} \\
(0.12)\end{array}$ & $\begin{array}{c}-6.59^{* *} \\
(0.33)\end{array}$ & $\begin{array}{l}-0.081^{* *} \\
(0.00091)\end{array}$ & $\begin{array}{l}-0.12^{* *} \\
(0.0032)\end{array}$ & $\begin{array}{c}0.036^{* *} \\
(0.00060)\end{array}$ & $\begin{array}{l}0.068^{* *} \\
(0.0024)\end{array}$ & $\begin{array}{c}-0.010^{* *} \\
(0.00036)\end{array}$ & $\begin{array}{c}-0.019^{* *} \\
(0.0023)\end{array}$ \\
\hline Year (Disp) $t+3$ & $\begin{array}{c}-2.99^{* *} \\
(0.13)\end{array}$ & $\begin{array}{c}-5.96^{* *} \\
(0.36)\end{array}$ & $\begin{array}{l}-0.076^{* *} \\
(0.00093)\end{array}$ & $\begin{array}{l}-0.12^{* *} \\
(0.0033)\end{array}$ & $\begin{array}{c}0.034^{* *} \\
(0.00062)\end{array}$ & $\begin{array}{c}0.061^{* *} \\
(0.0024)\end{array}$ & $\begin{array}{l}-0.010^{* *} \\
(0.00037)\end{array}$ & $\begin{array}{l}-0.015^{* *} \\
(0.0023)\end{array}$ \\
\hline Year (Disp) $t+4$ & $\begin{array}{c}-2.86^{* *} \\
(0.14)\end{array}$ & $\begin{array}{c}-5.38^{* *} \\
(0.38)\end{array}$ & $\begin{array}{c}-0.073^{* *} \\
(0.00096)\end{array}$ & $\begin{array}{l}-0.11^{* *} \\
(0.0034)\end{array}$ & $\begin{array}{c}0.032^{* *} \\
(0.00063)\end{array}$ & $\begin{array}{c}0.053^{* *} \\
(0.0024)\end{array}$ & $\begin{array}{c}-0.0098^{* *} \\
(0.00038)\end{array}$ & $\begin{array}{l}-0.018^{* *} \\
(0.0025)\end{array}$ \\
\hline Year (Disp) $t+5$ & $\begin{array}{c}-2.61^{* *} \\
(0.14)\end{array}$ & $\begin{array}{c}-4.58^{* *} \\
(0.39)\end{array}$ & $\begin{array}{c}-0.070^{* *} \\
(0.00097)\end{array}$ & $\begin{array}{l}-0.10^{* *} \\
(0.0034)\end{array}$ & $\begin{array}{c}0.031^{* *} \\
(0.00065)\end{array}$ & $\begin{array}{c}0.050^{* *} \\
(0.0025)\end{array}$ & $\begin{array}{c}-0.0090^{* *} \\
(0.00040)\end{array}$ & $\begin{array}{l}-0.015^{* *} \\
(0.0025)\end{array}$ \\
\hline Observations & 2579140 & 333965 & 2360559 & 310842 & 2368993 & 315137 & 2579373 & 335221 \\
\hline & 0.109 & 0.103 & 0.074 & 0.100 & 0.041 & 0.068 & 0.016 & 0.022 \\
\hline Mean of dep. var & 96.7 & 90.9 & -0.22 & -0.21 & 0.062 & 0.091 & 0.067 & 0.22 \\
\hline
\end{tabular}

Notes: The table returns coefficients $\alpha_{j}$ from regression equation 4.1. Year $t=-3$ is omitted as the baseline cateogry. The outcome variables are average establishment wages (Columns (1) and (2)), AKMstyle establishment fixed effects (Columns (3) and (4)), the share of marginally employed workers in an establishment (Columns (5) and (6)), and the share of migrant workers in an establishment (Columns (7) and (8)). In all columns, we control for year since displacement, year, and age polynomials. Standard errors are clustered at the individual level. ** and * refer to statistical significance at the 0.01 and 0.05 percent level, respectively. Source: IEB. 
Table A.4.11: Robustness Check: Restricting to Baseline Years up to 2007 (Pre Financial Crisis)

\begin{tabular}{|c|c|c|c|c|c|c|c|c|}
\hline & $(1)$ & (2) & (3) & (4) & (5) & $(6)$ & (7) & $(8)$ \\
\hline & \multicolumn{2}{|c|}{ Log (Earnings) } & \multicolumn{2}{|c|}{ Log Wage } & \multicolumn{2}{|c|}{ Employment } & \multicolumn{2}{|c|}{ Days Worked } \\
\hline & Natives & Migrants & Natives & Migrants & Natives & Migrants & Natives & Migrants \\
\hline \multirow[t]{2}{*}{ Year (Disp) t-5 } & & & & 0.0014 & & -0.0012 & $2.13^{* *}$ & $6.02^{* *}$ \\
\hline & $(($ & $(0.010)$ & $(0.0016)$ & $(0.010)$ & $(0.000$ & $(0.00$ & $(0.31)$ & $(1.91)$ \\
\hline \multirow[t]{2}{*}{ Year (Disp) t-4 } & $014^{* *}$ & $0.015^{*}$ & 0.00039 & 0.01 & -0.000023 & $-0.00045^{* *}$ & $1.46^{* *}$ & $2.95^{*}$ \\
\hline & $(0.0011)$ & $(0.0072)$ & $(0.0014)$ & $(0.0081)$ & $(0.000024)$ & $(0.00016)$ & $(0.17)$ & $(1.2)$ \\
\hline \multirow[t]{2}{*}{ Year (Disp) t-2 } & $-0.011^{* *}$ & $-0.014^{* *}$ & $-0.016^{* *}$ & 0.0089 & $0.0014^{* *}$ & 0.00046 & 0.11 & -0.65 \\
\hline & $(0.00091)$ & $(0.0039)$ & $(0.0013)$ & $(0.0097)$ & $(0.00028)$ & $(0.00087)$ & $(0.16)$ & $(0.60)$ \\
\hline \multirow[t]{2}{*}{ Year (Disp) t-1 } & $-0.085^{* *}$ & $-0.11^{* *}$ & $-0.020^{* *}$ & -0.0063 & -0.0000051 & $0.00092^{* *}$ & $-18.8^{* *}$ & $-24.1^{* *}$ \\
\hline & $(0.001$ & $(0.006$ & $(0.0015)$ & $(0.0094)$ & $(0.000036)$ & $(0.00033)$ & $(0.17)$ & $(1.01)$ \\
\hline \multirow[t]{2}{*}{ Year (Disp) t } & $-0.58^{* *}$ & $-0.70^{* *}$ & $-0.22^{* *}$ & $-0.24^{* *}$ & $-0.14^{* *}$ & $-0.18^{* *}$ & $-114.1^{* *}$ & $-135.2^{* *}$ \\
\hline & $(0.0032)$ & & $(0.002$ & $(0.016)$ & & $(0.00$ & & $(2.86)$ \\
\hline \multirow[t]{2}{*}{ Year (Disp) t+1 } & $-0.36^{* *}$ & $-0.50^{* *}$ & $-0.19^{* *}$ & $-0.23^{* *}$ & $-0.12^{* *}$ & $-0.17^{* *}$ & $-68.9^{* *}$ & $-92.3^{* *}$ \\
\hline & & $(0.021)$ & $(0.0024)$ & $(0.018)$ & $(0.0011)$ & $(0.0078)$ & $(0.47)$ & \\
\hline \multirow[t]{2}{*}{ Year (Disp) $t+2$} & $-0.27^{* *}$ & $-0.37^{* *}$ & $-0.17^{* *}$ & $-0.21^{* *}$ & $-0.094^{* *}$ & $-0.14^{* *}$ & $-47.4^{* *}$ & $-67.6^{* *}$ \\
\hline & $(0.00$ & $(0.02$ & $(0.00$ & & & $(0.0$ & $(0.48)$ & $(3.0$ \\
\hline \multirow[t]{2}{*}{ Year (Disp) $t+3$} & $-0.23^{* *}$ & $-0.30^{* *}$ & $-0.16^{* *}$ & $-0.17^{* *}$ & $-0.078^{* *}$ & $-0.11^{* *}$ & $-37.5^{* *}$ & $-53.8^{* *}$ \\
\hline & $(0.0032)$ & $(0.019)$ & & & & & $(0.49)$ & $(3.12)$ \\
\hline \multirow[t]{2}{*}{ Year (Disp) t+4 } & $-0.19^{* *}$ & $-0.24^{* *}$ & $-0.15^{* *}$ & $-0.12^{* *}$ & $-0.067^{* *}$ & $-0.092^{* *}$ & $-30.8^{* *}$ & $-42.4^{* *}$ \\
\hline & & & $(0.0027)$ & $(0.022)$ & $(0.0012)$ & $(0.0075)$ & $(0.49)$ & $(3.05)$ \\
\hline \multirow[t]{2}{*}{ Year (Disp) t +5} & $-0.17^{* *}$ & $-0.17^{* *}$ & $-0.14^{* *}$ & $-0.10^{* *}$ & $-0.059^{* *}$ & $-0.089^{* *}$ & $-26.1^{* *}$ & $-36.1^{* *}$ \\
\hline & & $(0.019)$ & $(0.0027)$ & $(0.017)$ & $(0.0012)$ & $(0.0083)$ & $(0.48)$ & $(3.31)$ \\
\hline Observations & 2215070 & 265244 & 2144405 & 254099 & 2311627 & 282494 & 2311627 & 282494 \\
\hline$R^{2}$ & 0.104 & 0.115 & 0.050 & 0.049 & 0.072 & 0.104 & 0.153 & 0.190 \\
\hline Mean of dep. var & 10.4 & 10.2 & 4.62 & 4.42 & 0.96 & 0.94 & 332.5 & 321.3 \\
\hline
\end{tabular}

Notes: The table returns coefficients $\alpha_{j}$ from regression equation 4.1. The sample is restricted to pre financial crisis baseline years, e.g., all years up to 2007. Year $t=-3$ is omitted as the baseline cateogry. The outcome variables are log (earnings) (Columns (1) and (2)), log wage (Columns (3) and (4)), employment (Columns (5) and (6)), and days worked (Columns (7) and (8)). In all columns, we control for year since displacement, year, and age polynomials. Standard errors are clustered at the individual level. Migrants are reweighted to natives using individual characteristics, industries, and occupations. ** and ${ }^{*}$ refer to statistical significance at the 0.01 and 0.05 percent level, respectively. Source: IEB. 
Table A.4.12: Robustness Check: Restricting Sample to Workplace in West Germany at Time of Displacement

\begin{tabular}{|c|c|c|c|c|c|c|c|c|}
\hline & $(1)$ & $(2)$ & (3) & (4) & (5) & $(6)$ & (7) & (8) \\
\hline & \multicolumn{2}{|c|}{ Log (Earnings) } & \multicolumn{2}{|c|}{ Log Wage } & \multicolumn{2}{|c|}{ Employment } & \multicolumn{2}{|c|}{ Days Worked } \\
\hline & Natives & Migrants & Natives & Migrants & Natives & Migrants & Natives & Migrants \\
\hline \multirow[t]{2}{*}{ Year (Disp) t-5 } & $0.025^{* *}$ & 0.0081 & $0.014^{* *}$ & -0.056 & $0.0037^{* *}$ & -0.0043 & $3.40^{* *}$ & 11.3 \\
\hline & $(0.0030)$ & $(0.037)$ & $(0.0022)$ & $(0.034)$ & $(0.00081)$ & $(0.019)$ & $(0.49)$ & $(8.19)$ \\
\hline \multirow[t]{2}{*}{ Year (Disp) t-4 } & $0.018^{* *}$ & 0.059 & $0.0039^{*}$ & 0.017 & $-0.00012^{* *}$ & -0.00030 & $2.11^{* *}$ & $12.0^{*}$ \\
\hline & $(0.0018)$ & $(0.034)$ & $(0.0018)$ & $(0.025)$ & $(0.000043)$ & $(0.00079)$ & $(0.27)$ & $(5.18)$ \\
\hline \multirow[t]{2}{*}{ Year (Disp) t-2 } & $-0.015^{* *}$ & -0.018 & $-0.020^{* *}$ & -0.0017 & 0.00068 & 0.0033 & -0.35 & 1.55 \\
\hline & $(0.0014)$ & $(0.017)$ & $(0.0017)$ & $(0.022)$ & $(0.00040)$ & $(0.0022)$ & $(0.24)$ & $(1.76)$ \\
\hline \multirow[t]{2}{*}{ Year (Disp) t-1 } & $-0.091^{* *}$ & $-0.10^{* *}$ & $-0.026^{* *}$ & -0.031 & 0.000026 & 0.00026 & $-20.0^{* *}$ & $-22.3^{* *}$ \\
\hline & $(0.0016)$ & $(0.019)$ & $(0.0019)$ & $(0.021)$ & $(0.000064)$ & $(0.0015)$ & $(0.27)$ & $(2.96)$ \\
\hline \multirow[t]{2}{*}{ Year (Disp) t } & $-0.61^{* *}$ & $-0.79^{* *}$ & $-0.20^{* *}$ & $-0.20^{* *}$ & $-0.14^{* *}$ & $-0.20^{* *}$ & $-120.4^{* *}$ & $-148.8^{* *}$ \\
\hline & $(0.0049)$ & $(0.092)$ & $(0.0037)$ & $(0.052)$ & $(0.0016)$ & $(0.023)$ & $(0.66)$ & $(12.3)$ \\
\hline \multirow[t]{2}{*}{ Year (Disp) t+1 } & $-0.35^{* *}$ & $-0.56^{* *}$ & $-0.17^{* *}$ & $-0.28^{* *}$ & $-0.12^{* *}$ & $-0.17^{* *}$ & $-70.2^{* *}$ & $-91.9^{* *}$ \\
\hline & $(0.0049)$ & $(0.095)$ & $(0.0034)$ & $(0.058)$ & $(0.0017)$ & $(0.031)$ & $(0.71)$ & $(13.5)$ \\
\hline \multirow[t]{2}{*}{ Year (Disp) t+2 } & $-0.26^{* *}$ & $-0.41^{* *}$ & $-0.15^{* *}$ & $-0.27^{* *}$ & $-0.093^{* *}$ & $-0.15^{* *}$ & $-48.0^{* *}$ & $-66.9^{* *}$ \\
\hline & $(0.0048)$ & $(0.069)$ & $(0.0035)$ & $(0.052)$ & $(0.0017)$ & $(0.023)$ & $(0.72)$ & $(10.5)$ \\
\hline \multirow[t]{2}{*}{ Year (Disp) $t+3$} & $-0.22^{* *}$ & $-0.42^{* *}$ & $-0.14^{* *}$ & $-0.20^{* *}$ & $-0.078^{* *}$ & $-0.13^{* *}$ & $-38.3^{* *}$ & $-67.4^{* *}$ \\
\hline & $(0.0049)$ & $(0.083)$ & $(0.0036)$ & $(0.049)$ & $(0.0018)$ & $(0.023)$ & $(0.73)$ & $(11.4)$ \\
\hline \multirow[t]{2}{*}{ Year (Disp) t+4 } & $-0.19^{* *}$ & $-0.28^{* *}$ & $-0.13^{* *}$ & $-0.15^{* *}$ & $-0.069^{* *}$ & $-0.15^{* *}$ & $-32.0^{* *}$ & $-58.4^{* *}$ \\
\hline & $(0.0048)$ & $(0.062)$ & $(0.0037)$ & $(0.050)$ & $(0.0018)$ & $(0.028)$ & $(0.73)$ & $(11.6)$ \\
\hline \multirow[t]{2}{*}{ Year (Disp) t+5 } & $-0.17^{* *}$ & $-0.21^{* *}$ & $-0.12^{* *}$ & $-0.15^{* *}$ & $-0.061^{* *}$ & $-0.13^{* *}$ & $-27.8^{* *}$ & $-47.6^{* *}$ \\
\hline & $(0.0047)$ & $(0.061)$ & $(0.0038)$ & $(0.046)$ & $(0.0018)$ & $(0.025)$ & $(0.73)$ & $(11.0)$ \\
\hline Observations & 1021363 & 23973 & 983096 & 22811 & 1068103 & 25903 & 1068103 & 25903 \\
\hline$R^{2}$ & 0.110 & 0.135 & 0.054 & 0.061 & 0.074 & 0.118 & 0.164 & 0.209 \\
\hline Mean of dep. var & 10.2 & 10.1 & 4.43 & 4.33 & 0.96 & 0.93 & 328.7 & 313.8 \\
\hline
\end{tabular}

Notes: The table returns coefficients $\alpha_{j}$ from regression equation 4.1. The sample is restricted to workers employed in West Germany at the time of displacement. Year $t=-3$ is omitted as the baseline cateogry. The outcome variables are log (earnings) (Columns (1) and (2)), log wage (Columns (3) and (4)), employment (Columns (5) and (6)), and days worked (Columns (7) and (8)). In all columns, we control for year since displacement, year, and age polynomials. Standard errors are clustered at the individual level. Migrants are reweighted to natives using individual characteristics, industries, and occupations. ${ }^{* *}$ and $*$ refer to statistical significance at the 0.01 and 0.05 percent level, respectively. Source: IEB. 
Table A.4.13: Robustness Check: Reweighting Natives to Migrants

\begin{tabular}{|c|c|c|c|c|c|c|c|c|}
\hline & $\begin{array}{c}(1) \\
\log (E\end{array}$ & $\begin{array}{c}(2) \\
\text { arnings) }\end{array}$ & $\begin{array}{l}(3) \\
\text { Log }\end{array}$ & $\begin{array}{c}\quad(4) \\
\text { Wage }\end{array}$ & $\begin{array}{l}(5) \\
\text { Emplo }\end{array}$ & $\begin{array}{l}(6) \\
y m e n t\end{array}$ & $\begin{array}{l}(7) \\
\text { Days }\end{array}$ & $\begin{array}{c}(8) \\
\text { Worked }\end{array}$ \\
\hline & Natives & Migrants & Natives & Migrants & Natives & Migrants & Natives & Migrants \\
\hline \multirow[t]{2}{*}{ Year (Disp) t-5 } & $0.0066^{*}$ & $0.027^{* *}$ & $0.017^{* *}$ & $0.013^{* *}$ & -0.00033 & 0.00012 & $-1.27^{*}$ & $1.92^{*}$ \\
\hline & $(0.0033)$ & $(0.0054)$ & $(0.0025)$ & $(0.0039)$ & $(0.00088)$ & $(0.0014)$ & $(0.52)$ & $(0.86)$ \\
\hline \multirow[t]{2}{*}{ Year (Disp) t-4 } & $0.015^{* *}$ & $0.014^{* *}$ & $0.0084^{* *}$ & 0.0036 & $0.00031^{* *}$ & 0.000017 & $1.13^{* *}$ & $1.79^{* *}$ \\
\hline & $(0.0021)$ & $(0.0029)$ & $(0.0022)$ & $(0.0030)$ & $(0.000045)$ & $(0.000076)$ & $(0.28)$ & $(0.45)$ \\
\hline \multirow[t]{2}{*}{ Year (Disp) t-2 } & $-0.018^{* *}$ & $-0.016^{* *}$ & $-0.022^{* *}$ & $-0.017^{* *}$ & $0.0016^{* *}$ & 0.00032 & -0.011 & -0.24 \\
\hline & $(0.0017)$ & $(0.0023)$ & $(0.0018)$ & $(0.0026)$ & $(0.00041)$ & $(0.00057)$ & $(0.24)$ & $(0.35)$ \\
\hline \multirow[t]{2}{*}{ Year (Disp) t-1 } & $-0.10^{* *}$ & $-0.12^{* *}$ & $-0.028^{* *}$ & $-0.025^{* *}$ & $-0.00072^{* *}$ & -0.000047 & $-21.8^{* *}$ & $-27.0^{* *}$ \\
\hline & $(0.0020)$ & $(0.0028)$ & $(0.0020)$ & $(0.0029)$ & $(0.000072)$ & $(0.00014)$ & $(0.27)$ & $(0.47)$ \\
\hline \multirow[t]{2}{*}{ Year (Disp) t } & $-0.66^{* *}$ & $-0.91^{* *}$ & $-0.26^{* *}$ & $-0.43^{* *}$ & $-0.14^{* *}$ & $-0.19^{* *}$ & $-120.4^{* *}$ & $-149.4^{* *}$ \\
\hline & $(0.0050)$ & $(0.0099)$ & $(0.0040)$ & $(0.0090)$ & $(0.0015)$ & $(0.0030)$ & $(0.63)$ & $(1.16)$ \\
\hline \multirow[t]{2}{*}{ Year (Disp) t+1 } & $-0.43^{* *}$ & $-0.62^{* *}$ & $-0.23^{* *}$ & $-0.33^{* *}$ & $-0.12^{* *}$ & $-0.18^{* *}$ & $-74.2^{* *}$ & $-96.6^{* *}$ \\
\hline & $(0.0048)$ & $(0.010)$ & $(0.0036)$ & $(0.0078)$ & $(0.0016)$ & $(0.0033)$ & $(0.66)$ & $(1.30)$ \\
\hline \multirow[t]{2}{*}{ Year (Disp) $t+2$} & $-0.33^{* *}$ & $-0.47^{* *}$ & $-0.21^{* *}$ & $-0.29^{* *}$ & $-0.096^{* *}$ & $-0.13^{* *}$ & $-52.5^{* *}$ & $-67.6^{* *}$ \\
\hline & $(0.0048)$ & $(0.010)$ & $(0.0036)$ & $(0.0077)$ & $(0.0016)$ & $(0.0032)$ & $(0.68)$ & $(1.32)$ \\
\hline \multirow[t]{2}{*}{ Year (Disp) $t+3$} & $-0.29^{* *}$ & $-0.39^{* *}$ & $-0.19^{* *}$ & $-0.26^{* *}$ & $-0.082^{* *}$ & $-0.11^{* *}$ & $-42.5^{* *}$ & $-53.5^{* *}$ \\
\hline & $(0.0048)$ & $(0.010)$ & $(0.0037)$ & $(0.0078)$ & $(0.0016)$ & $(0.0033)$ & $(0.68)$ & $(1.34)$ \\
\hline \multirow[t]{2}{*}{ Year (Disp) t+4 } & $-0.25^{* *}$ & $-0.31^{* *}$ & $-0.18^{* *}$ & $-0.22^{* *}$ & $-0.070^{* *}$ & $-0.086^{* *}$ & $-35.3^{* *}$ & $-40.7^{* *}$ \\
\hline & $(0.0048)$ & $(0.0099)$ & $(0.0037)$ & $(0.0078)$ & $(0.0016)$ & $(0.0033)$ & $(0.67)$ & $(1.34)$ \\
\hline \multirow[t]{2}{*}{ Year (Disp) t +5} & $-0.23^{* *}$ & $-0.27^{* *}$ & $-0.17^{* *}$ & $-0.20^{* *}$ & $-0.063^{* *}$ & $-0.075^{* *}$ & $-30.2^{* *}$ & $-34.8^{* *}$ \\
\hline & $(0.0049)$ & $(0.0100)$ & $(0.0039)$ & $(0.0079)$ & $(0.0016)$ & $(0.0032)$ & $(0.66)$ & $(1.33)$ \\
\hline Observations & 2589001 & 355810 & 2507729 & 341462 & 2696370 & 376467 & 2696370 & 376467 \\
\hline$R^{2}$ & 0.120 & 0.147 & 0.069 & 0.078 & 0.069 & 0.103 & 0.154 & 0.203 \\
\hline Mean of dep. var & 10.3 & 10.2 & 4.60 & 4.40 & 0.96 & 0.95 & 334.0 & 323.5 \\
\hline
\end{tabular}

Notes: The table returns coefficients $\alpha_{j}$ from regression equation 4.1. Year $t=-3$ is omitted as the baseline cateogry. The outcome variables are log (earnings) (Columns (1) and (2)), log wage (Columns (3) and (4)), employment (Columns (5) and (6)), and days worked (columns (7) and (8)). In all columns, we control for year since displacement, year, and age polynomials. Standard errors are clustered at the individual level. Natives are reweighted to migrants using individual characteristics, industries, and occupations. ${ }^{* *}$ and ${ }^{*}$ refer to statistical significance at the 0.01 and 0.05 percent level, respectively. Source: IEB. 
Table A.4.14: Explaining Costs of Job Loss by Local Labor Market Concentration and Controlling for Displacement Establishment

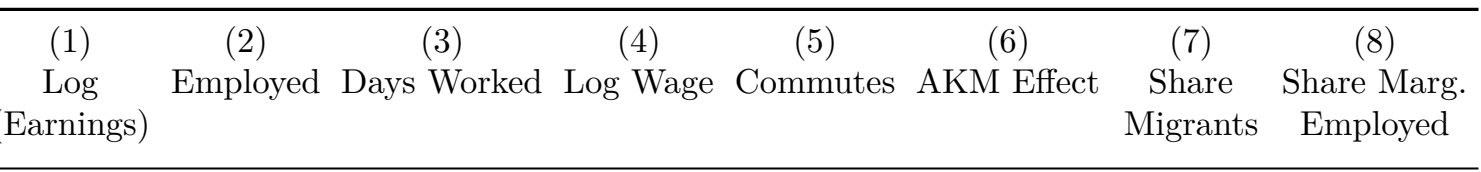

Panel A: Controlling for Individual Characteristics, Industry, and Occupation

\begin{tabular}{|c|c|c|c|c|c|c|c|c|}
\hline Migrant & $\begin{array}{l}-0.20^{* *} \\
(0.016)\end{array}$ & $\begin{array}{l}-0.040^{* *} \\
(0.0049)\end{array}$ & $\begin{array}{c}-22.1^{* *} \\
(2.20)\end{array}$ & $\begin{array}{l}-0.12^{* *} \\
(0.012)\end{array}$ & $\begin{array}{r}-0.00098 \\
(0.0084)\end{array}$ & $\begin{array}{l}-0.032^{* *} \\
(0.0050)\end{array}$ & $\begin{array}{c}0.016^{* *} \\
(0.0029)\end{array}$ & $\begin{array}{c}0.024^{* *} \\
(0.0031)\end{array}$ \\
\hline Observations & 127653 & 133338 & 133338 & 121866 & 121676 & 94866 & 119631 & 119291 \\
\hline$R^{2}$ & 0.063 & 0.031 & 0.048 & 0.057 & 0.036 & 0.189 & 0.043 & 0.034 \\
\hline Mean of dep. var & -0.39 & -0.099 & -61.6 & -0.19 & 0.028 & -0.077 & -0.010 & 0.038 \\
\hline
\end{tabular}

Panel B: Adding Controls for Local Unemployment Rate Change, City Resident and Share of Coethnic Neighbors

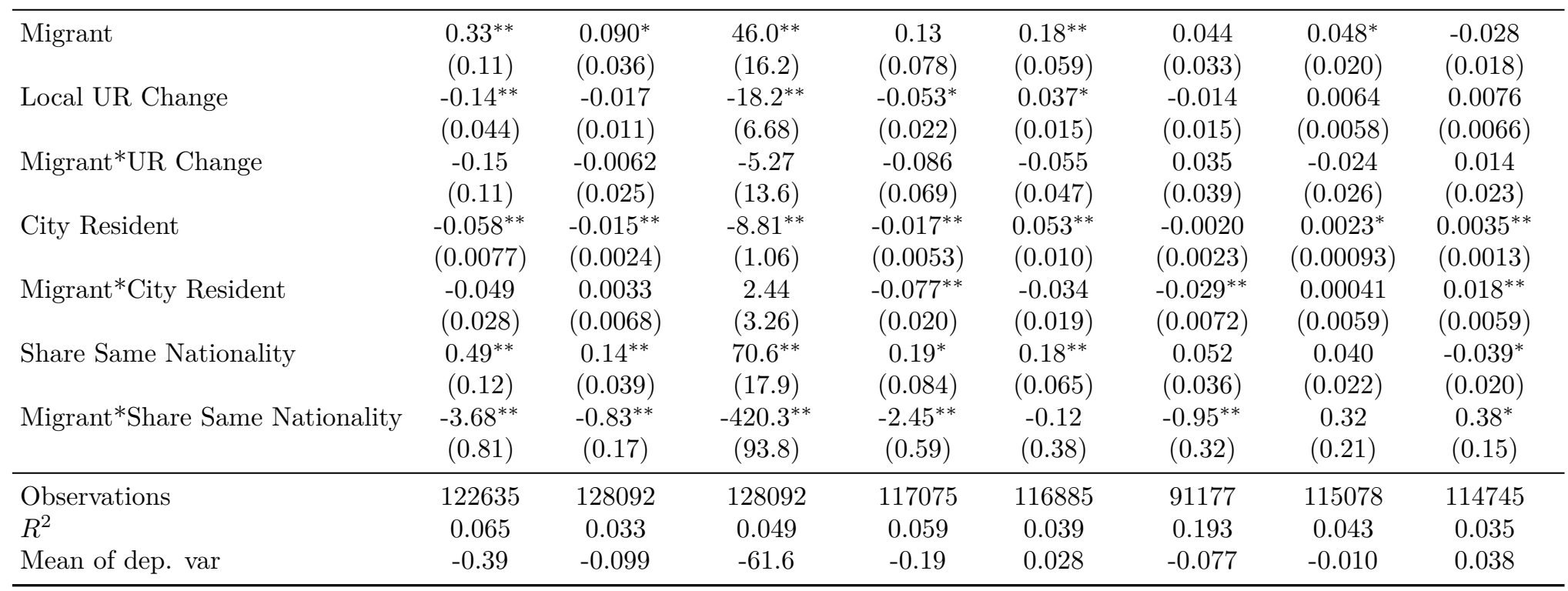

Notes: The table shows the effect of being a migrant on labor market outcomes. All outcome variables are based on the individual difference-in-differences estimate derived from equation 4.2. Panel A shows the results when controlling for individual characteristics, and sorting across industries, and occupations in the year before displacement. Panel B adds controls for local unemployment rate changes reported at the municipality level, city residency, and the share of coethnic working age population in a county, all measured in the year before displacement. The AKM effect is a proxy for wage differentials across firms, based on Abowd et al. (1999). In addition, all regressions control for displacement establishment fixed effects. We cluster standard errors at the baseline county level. ** and * refer to statistical significance at the 1 and 5 percent level, respectively. Workers in our sample are displaced in the period 2001-2011, and they are observed from 1996 to 2017. Source: IEB, BBSR, Destatis. 
Table A.4.15: Explaining Costs of Job Loss by Local Labor Market Concentration - Only Complete Closures

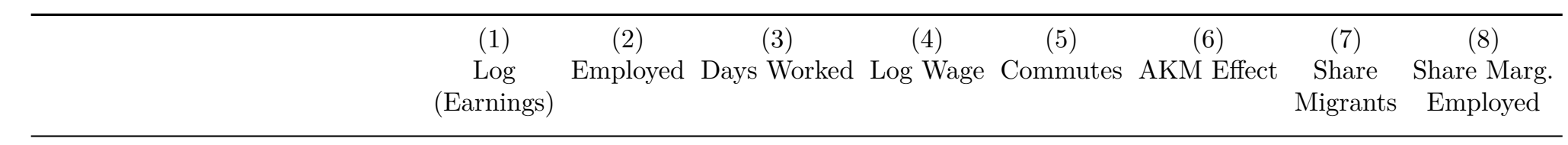

Panel A: Controlling for Individual Characteristics, Industry, and Occupation

\begin{tabular}{|c|c|c|c|c|c|c|c|c|}
\hline Migrant & $\begin{array}{l}-0.18^{* *} \\
(0.024)\end{array}$ & $\begin{array}{l}-0.044^{* *} \\
(0.0067)\end{array}$ & $\begin{array}{c}-19.3^{* *} \\
(3.10)\end{array}$ & $\begin{array}{c}-0.11^{* *} \\
(0.015)\end{array}$ & $\begin{array}{c}-0.0053 \\
(0.013)\end{array}$ & $\begin{array}{l}-0.027 \\
(0.015)\end{array}$ & $\begin{array}{l}-0.0038 \\
(0.0066)\end{array}$ & $\begin{array}{c}0.029^{* *} \\
(0.0053)\end{array}$ \\
\hline Observations & 40851 & 42824 & 42824 & 39568 & 39252 & 26903 & 39135 & 38760 \\
\hline Mean of dep. var & -0.36 & -0.092 & -56.1 & -0.20 & 0.038 & -0.11 & -0.011 & 0.038 \\
\hline
\end{tabular}

Panel B: Adding Controls for Local Unemployment Rate Change, City Resident and Share of Coethnic Neighbors

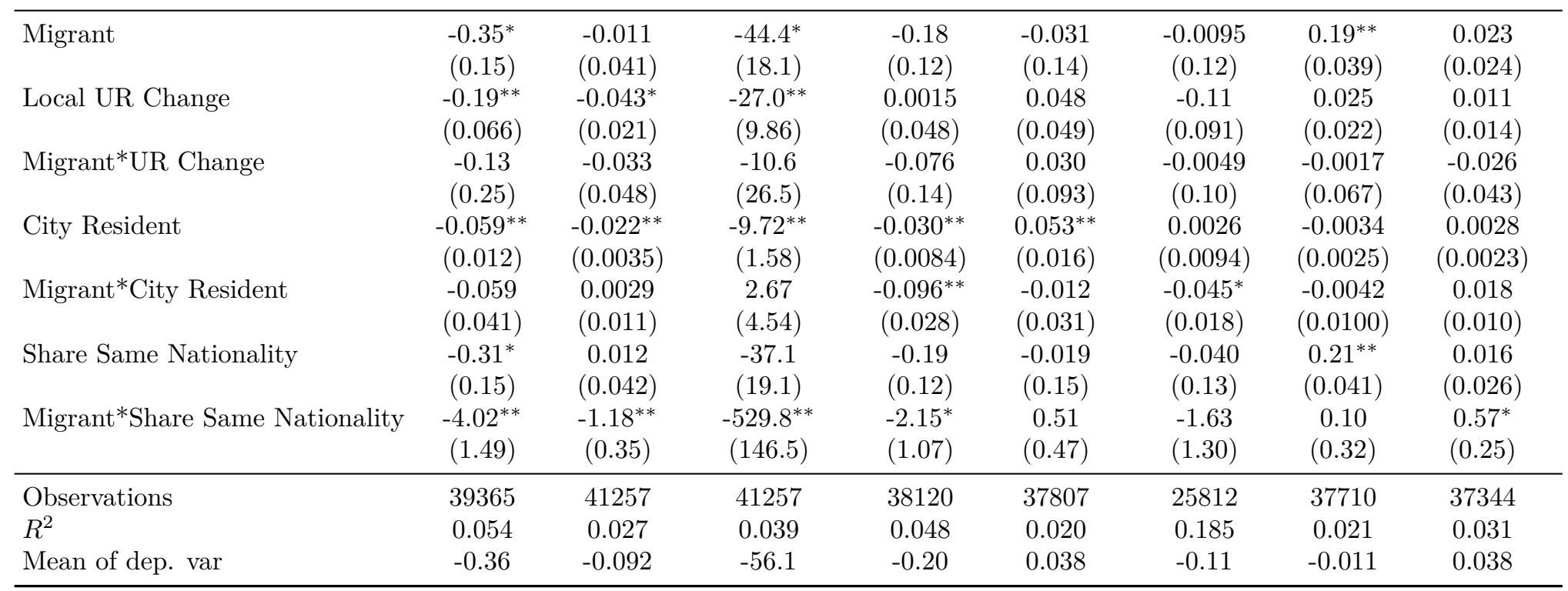

Notes: The table shows the effect of being a migrant on labor market outcomes. All outcome variables are based on the individual difference-in-differences estimate derived from equation 4.2. The sample includes only workers laid off from complete establishment closures. Panel A shows the results when controlling for individual characteristics, and sorting across industries, and occupations in the year before displacement. Panel B adds controls for local unemployment rate changes reported at the municipality level, city residency, and the share of coethnic working age population in a county, all measured in the year before displacement. AKM Effect is a proxy for wage differentials across firms, based on Abowd et al. (1999). We cluster standard errors at the baseline county level. ** and * refer to statistical significance at the 1 and 5 percent level, respectively. Workers in our sample are displaced in the period 2001-2011, and they are observed from 1996 to 2017. Source: IEB, BBSR, Destatis. 
Table A.4.16: Log Earnings Losses by Origin Group

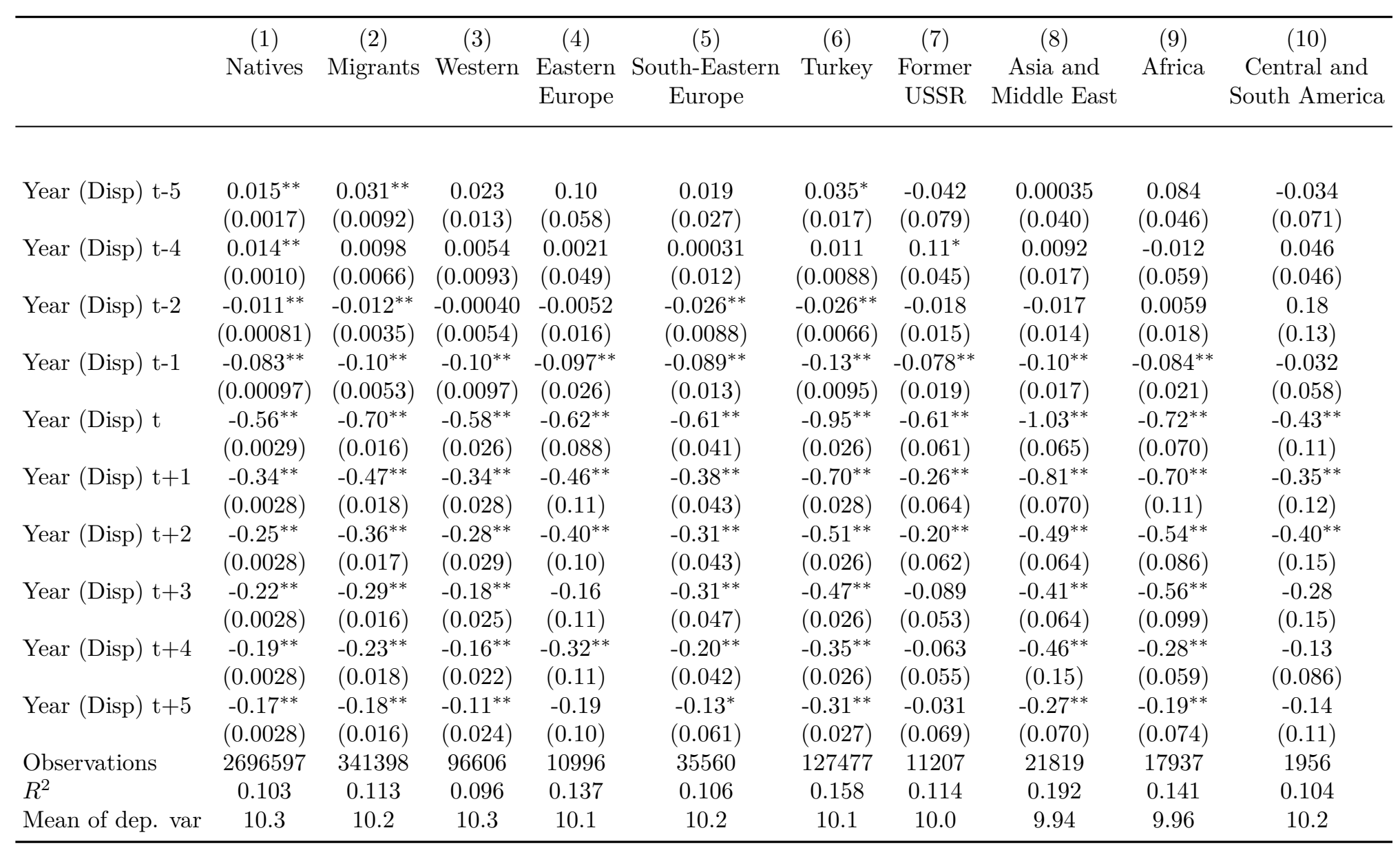

Notes: The table returns coefficients $\alpha_{j}$ from regression equation 4.1. Year $t=-3$ is omitted as the baseline cateogry. The outcome variable in all columns is $\log$ (earnings). In all columns, we control for year since displacement, year, and age polynomials. Standard errors are clustered at the individual level. Migrants in Columns (2) to (10) are reweighted to natives using individual characteristics, industries, and occupations. Migrants' origin groups definition comes from Battisti et. al. (2021). Table A.4.19 provides an overview of the countries within the origin groups. ${ }^{* *}$ and ${ }^{*}$ refer to statistical significance at the 0.01 and 0.05 percent level, respectively. Source: IEB. 
Table A.4.17: Differences in Labor Market Outcomes for Women

\begin{tabular}{|c|c|c|c|c|c|c|c|c|}
\hline & (1) & (2) & & (4) & (5) & (6) & (7) & (8) \\
\hline & \multicolumn{2}{|c|}{ Log (Earnings) } & \multicolumn{2}{|c|}{ Log Wage } & \multicolumn{2}{|c|}{ Employment } & \multicolumn{2}{|c|}{ Days Worked } \\
\hline & Natives & Migrants & Natives & Migrants & Natives & Migrants & Natives & Migrants \\
\hline \multirow[t]{2}{*}{ Year (Disp) t-5 } & $0.026^{* *}$ & 0.020 & $0.013^{* *}$ & -0.012 & $0.0038^{* *}$ & 0.018 & $4.39^{* *}$ & $9.62^{*}$ \\
\hline & $(0.0028)$ & $(0.020)$ & $(0.0023)$ & $(0.014)$ & $(0.00079)$ & $(0.0095)$ & $(0.45)$ & $(4.12)$ \\
\hline \multirow[t]{2}{*}{ Year (Disp) t-4 } & $0.016^{* *}$ & 0.018 & $0.0043^{*}$ & -0.0062 & 0.000022 & 0.00029 & $2.13^{* *}$ & $4.17^{*}$ \\
\hline & $(0.0017)$ & $(0.011)$ & $(0.0017)$ & $(0.010)$ & $(0.000039)$ & $(0.00027)$ & $(0.24)$ & $(1.79)$ \\
\hline \multirow[t]{2}{*}{ Year (Disp) t-2 } & $-0.012^{* *}$ & -0.0080 & $-0.015^{* *}$ & -0.0031 & -0.00034 & -0.0032 & -0.38 & $-2.69^{*}$ \\
\hline & $(0.0014)$ & $(0.0080)$ & $(0.0015)$ & $(0.0083)$ & $(0.00032)$ & $(0.0025)$ & $(0.20)$ & $(1.24)$ \\
\hline \multirow[t]{2}{*}{ Year (Disp) t-1 } & $-0.096^{* *}$ & $-0.11^{* *}$ & $-0.029^{* *}$ & -0.017 & -0.000042 & -0.00046 & $-20.4^{* *}$ & $-25.5^{* *}$ \\
\hline & $(0.0017)$ & $(0.011)$ & $(0.0018)$ & $(0.010)$ & $(0.000050)$ & $(0.00058)$ & $(0.24)$ & $(1.56)$ \\
\hline \multirow[t]{2}{*}{ Year (Disp) t } & $-0.56^{* *}$ & $-0.70^{* *}$ & $-0.24^{* *}$ & $-0.27^{* *}$ & $-0.13^{* *}$ & $-0.18^{* *}$ & $-101.4^{* *}$ & $-132.6^{* *}$ \\
\hline & $(0.0044)$ & $(0.034)$ & $(0.0034)$ & $(0.023)$ & $(0.0013)$ & $(0.0091)$ & $(0.59)$ & $(4.92)$ \\
\hline \multirow[t]{2}{*}{ Year (Disp) t+1 } & $-0.38^{* *}$ & $-0.49^{* *}$ & $-0.23^{* *}$ & $-0.26^{* *}$ & $-0.11^{* *}$ & $-0.17^{* *}$ & $-60.2^{* *}$ & $-83.9^{* *}$ \\
\hline & $(0.0046)$ & $(0.039)$ & $(0.0035)$ & $(0.026)$ & $(0.0015)$ & $(0.011)$ & $(0.63)$ & $(5.16)$ \\
\hline \multirow[t]{2}{*}{ Year (Disp) t+2 } & $-0.31^{* *}$ & $-0.37^{* *}$ & $-0.22^{* *}$ & $-0.22^{* *}$ & $-0.079^{* *}$ & $-0.12^{* *}$ & $-38.9^{* *}$ & $-59.2^{* *}$ \\
\hline & $(0.0047)$ & $(0.044)$ & $(0.0036)$ & $(0.030)$ & $(0.0015)$ & $(0.012)$ & $(0.64)$ & $(5.34)$ \\
\hline \multirow[t]{2}{*}{ Year (Disp) t+3 } & $-0.27^{* *}$ & $-0.32^{* *}$ & $-0.20^{* *}$ & $-0.21^{* *}$ & $-0.059^{* *}$ & $-0.097^{* *}$ & $-28.0^{* *}$ & $-45.0^{* *}$ \\
\hline & $(0.0047)$ & $(0.038)$ & $(0.0038)$ & $(0.029)$ & $(0.0015)$ & $(0.011)$ & $(0.65)$ & $(4.95)$ \\
\hline \multirow[t]{2}{*}{ Year (Disp) t+4 } & $-0.23^{* *}$ & $-0.26^{* *}$ & $-0.19^{* *}$ & $-0.21^{* *}$ & $-0.049^{* *}$ & $-0.076^{* *}$ & $-21.7^{* *}$ & $-33.5^{* *}$ \\
\hline & $(0.0047)$ & $(0.037)$ & $(0.0039)$ & $(0.029)$ & $(0.0015)$ & $(0.011)$ & $(0.65)$ & $(4.84)$ \\
\hline \multirow[t]{2}{*}{ Year (Disp) t+5 } & $-0.21^{* *}$ & $-0.22^{* *}$ & $-0.18^{* *}$ & $-0.18^{* *}$ & $-0.039^{* *}$ & $-0.057^{* *}$ & $-17.5^{* *}$ & $-23.8^{* *}$ \\
\hline & $(0.0048)$ & $(0.037)$ & $(0.0040)$ & $(0.032)$ & $(0.0015)$ & $(0.011)$ & $(0.64)$ & $(4.98)$ \\
\hline Observations & 1347579 & 110135 & 1309314 & 105704 & 1408547 & 120035 & 1408547 & 120035 \\
\hline$R^{2}$ & 0.084 & 0.108 & 0.057 & 0.069 & 0.066 & 0.102 & 0.125 & 0.174 \\
\hline Mean of dep. var & 10.1 & 9.87 & 4.35 & 4.10 & 0.96 & 0.92 & 331.6 & 310.5 \\
\hline
\end{tabular}

Notes: The table returns coefficients $\alpha_{j}$ from regression equation 4.1, estimated using a sample of female workers. Year $t=-3$ is omitted as the baseline cateogry. The outcome variables are log (earnings) (Columns (1) and (2)), log wage (Columns (3) and (4)), employment (Columns (5) and (6)), and days worked (Columns (7) and (8)). In all columns, we control for year since displacement, year, and age polynomials. Standard errors are clustered at the individual level. Migrants are reweighted to natives using individual characteristics, industries, and occupations. ${ }^{* *}$ and $*$ refer to statistical significance at the 0.01 and 0.05 percent level, respectively. Source: IEB. 
Table A.4.18: Robustness Check: Restricting to Baseline Years up to 2003 (Pre Financial Crisis)

\begin{tabular}{|c|c|c|c|c|c|c|c|c|}
\hline & $(1)$ & $(2)$ & (3) & (4) & (5) & $(6)$ & (7) & $(8)$ \\
\hline & \multicolumn{2}{|c|}{ Log (Earnings) } & \multicolumn{2}{|c|}{ Log Wage } & \multicolumn{2}{|c|}{ Employment } & \multicolumn{2}{|c|}{ Days Worked } \\
\hline & Natives & Migrants & Natives & Migrants & Natives & Migrants & Natives & Migrants \\
\hline \multirow[t]{2}{*}{ Year (Disp) t-5 } & $0.018^{* *}$ & $0.042^{* *}$ & $0.0042^{*}$ & -0.0027 & & & $2.66^{* *}$ & $8.44^{* *}$ \\
\hline & $(0.0023)$ & $(0.014)$ & $(0.0019)$ & $(0.012)$ & $(0.00066)$ & $(0.00$ & $(0.39)$ & $(2.47)$ \\
\hline \multirow[t]{2}{*}{ Year (Disp) t-4 } & $0.014^{* *}$ & $0.022^{*}$ & -0.00071 & 0.0099 & -0.000048 & $-0.00042^{*}$ & $1.55^{* *}$ & $4.43^{* *}$ \\
\hline & $(0.0015)$ & $(0.0100)$ & $(0.0016)$ & $(0.010)$ & $(0.000030)$ & $(0.00019)$ & $(0.22)$ & $(1.67)$ \\
\hline \multirow[t]{2}{*}{ Year (Disp) t-2 } & $-0.0084^{* *}$ & $-0.017^{* *}$ & $-0.014^{* *}$ & 0.0077 & $0.0022^{* *}$ & 0.00067 & $0.51^{*}$ & -0.91 \\
\hline & $(0.0012)$ & $(0.0051)$ & $(0.0017)$ & $(0.012)$ & $(0.00041)$ & $(0.0013)$ & $(0.21)$ & $(0.84)$ \\
\hline \multirow[t]{2}{*}{ Year (Disp) t-1 } & $-0.081^{* *}$ & $-0.11^{* *}$ & $-0.024^{* *}$ & -0.016 & -0.0000073 & $0.0013^{*}$ & $-17.6^{* *}$ & $-23.0^{* *}$ \\
\hline & $(0.0013)$ & $(0.0083)$ & $(0.0018)$ & $(0.012)$ & $(0.000040)$ & $(0.00052)$ & $(0.21)$ & $(1.29)$ \\
\hline \multirow[t]{2}{*}{ Year (Disp) t } & $-0.59^{* *}$ & $-0.69^{* *}$ & $-0.20^{* *}$ & $-0.20^{* *}$ & $-0.15^{* *}$ & $-0.18^{* *}$ & $-119.9^{* *}$ & $-138.2^{* *}$ \\
\hline & $(0.0041)$ & $(0.025)$ & $(0.0031)$ & $(0.019)$ & $(0.0013)$ & $(0.0093)$ & $(0.56)$ & \\
\hline \multirow[t]{2}{*}{ Year (Disp) t+1 } & $-0.37^{* *}$ & $-0.51^{* *}$ & $-0.18^{* *}$ & $-0.22^{* *}$ & $-0.13^{* *}$ & $-0.17^{* *}$ & $-72.6^{* *}$ & $-96.1^{* *}$ \\
\hline & $(0.0041)$ & $(0.029)$ & $(0.0030)$ & $(0.022)$ & $(0.0014)$ & $(0.011)$ & $(0.60)$ & $(4.32)$ \\
\hline \multirow[t]{2}{*}{ Year (Disp) $t+2$} & $-0.27^{* *}$ & $-0.38^{* *}$ & $-0.16^{* *}$ & $-0.20^{* *}$ & $-0.10^{* *}$ & $-0.15^{* *}$ & $-50.0^{* *}$ & $-73.1^{* *}$ \\
\hline & $(0.0041)$ & $(0.027)$ & $(0.0031)$ & $(0.020)$ & $(0.0015)$ & $(0.011)$ & $(0.62)$ & $(4.26)$ \\
\hline \multirow[t]{2}{*}{ Year (Disp) $t+3$} & $-0.23^{* *}$ & $-0.30^{* *}$ & $-0.15^{* *}$ & $-0.15^{* *}$ & $-0.083^{* *}$ & $-0.12^{* *}$ & $-39.5^{* *}$ & $-56.6^{* *}$ \\
\hline & $(0.0041)$ & $(0.026)$ & $(0.0033)$ & $(0.020)$ & & $(0.010)$ & $(0.62)$ & $(4.26)$ \\
\hline \multirow[t]{2}{*}{ Year (Disp) $t+4$} & $-0.19^{* *}$ & $-0.25^{* *}$ & $-0.14^{* *}$ & $-0.11^{* *}$ & $-0.071^{* *}$ & $-0.095^{* *}$ & $-32.0^{* *}$ & $-45.3^{* *}$ \\
\hline & & & & & & & & $(4.09)$ \\
\hline \multirow[t]{2}{*}{ Year (Disp) $t+5$} & $-0.17^{* *}$ & $-0.16^{* *}$ & $-0.13^{* *}$ & $-0.11^{* *}$ & $-0.063^{* *}$ & $-0.097^{* *}$ & $-27.0^{* *}$ & $-38.2^{* *}$ \\
\hline & $(0.0040)$ & $(0.025)$ & & & $(0.0015)$ & & & \\
\hline Observations & 1469255 & 150594 & 1418583 & 143951 & 1540502 & 161467 & 1540502 & 161467 \\
\hline$R^{2}$ & 0.103 & 0.112 & 0.049 & 0.046 & 0.077 & 0.109 & 0.162 & 0.198 \\
\hline Mean of dep. var & 10.3 & 10.2 & 4.62 & 4.45 & 0.95 & 0.93 & 329.7 & 317.8 \\
\hline
\end{tabular}

Notes: The table returns coefficients $\alpha_{j}$ from regression equation 4.1. The sample is restricted to pre financial crisis baseline years, e.g., all years up to 2003. Year $t=-3$ is omitted as the baseline cateogry. The outcome variables are log (earnings) (Columns (1) and (2)), log wage (Columns (3) and (4)), employment (Columns (5) and (6)), and days worked (Columns (7) and (8)). In all columns, we control for year since displacement, year, and age polynomials. Standard errors are clustered at the individual level. Migrants are reweighted to natives using individual characteristics, industries, and occupations. ${ }^{* *}$ and ${ }^{*}$ refer to statistical significance at the 0.01 and 0.05 percent level, respectively. Source: IEB. 
Table A.4.19: Overview Origin Groups as in Battisti et al. (2021)

\begin{tabular}{|c|c|c|c|}
\hline & $\begin{array}{c}(1) \\
\text { Group name }\end{array}$ & \multicolumn{2}{|c|}{$\begin{array}{c}(2) \\
\text { Countries } \\
\end{array}$} \\
\hline 1 & Germany & Germany & \\
\hline 2 & $\begin{array}{c}\text { Western incl. Western European } \\
\text { Countries }\end{array}$ & $\begin{array}{c}\text { Australia } \\
\text { Austria } \\
\text { Canada } \\
\text { Denmark } \\
\text { Finland } \\
\text { France } \\
\text { Greece } \\
\text { Italy } \\
\text { Ireland } \\
\text { Netherlands }\end{array}$ & $\begin{array}{c}\text { New Zealand } \\
\text { Norway } \\
\text { Portugal } \\
\text { Samoa } \\
\text { Spain } \\
\text { Sweden } \\
\text { Switzerland } \\
\text { United Kingdom } \\
\text { USA }\end{array}$ \\
\hline 3 & Eastern Europe & $\begin{array}{c}\text { Czech Republic } \\
\text { Hungary } \\
\text { Poland }\end{array}$ & $\begin{array}{l}\text { Slovakia } \\
\text { Slovenia }\end{array}$ \\
\hline 4 & South-Eastern Europe & $\begin{array}{c}\text { Albania } \\
\text { Bosnia and Herzegovina } \\
\text { Bulgaria } \\
\text { Kosovo } \\
\text { Croatia }\end{array}$ & $\begin{array}{c}\text { Former Jugoslavia } \\
\text { Northmazedonia } \\
\text { Mazedonia } \\
\text { Romania } \\
\text { Serbia }\end{array}$ \\
\hline 5 & Turkey & Turkey & \\
\hline 6 & Former USSR & $\begin{array}{c}\text { Armenia } \\
\text { Azerbaijan } \\
\text { Belarus } \\
\text { Estonia } \\
\text { Georgia } \\
\text { Kazakhstan } \\
\text { Kyrgyzstan } \\
\text { Latvia }\end{array}$ & $\begin{array}{c}\text { Lithuania } \\
\text { Moldova } \\
\text { Russian Federation } \\
\text { Tajikistan } \\
\text { Turkmenistan } \\
\text { Ukraine } \\
\text { Uzbekistan }\end{array}$ \\
\hline 7 & Asia and Middle East & & \\
\hline 8 & Africa & & \\
\hline 9 & Central and South America & & \\
\hline 10 & Other & & \\
\hline
\end{tabular}

Notes: This table shows how we assign migrants to origin groups following Battisti et al. (2021).

We use these origin groups for our heterogeneity analysis in table A.4.16.

The category "Other" contains 24 origin countries which rarely appear in our data. These include, amongst others, the Fiji Islands, the Marshall Islands, and Andorra. 


\section{Erklärung}

Hiermit erkläre ich, dass ich die Bestandteile der kumulativen Dissertation selbständig, insbesondere ohne die Hilfe einer Promotionsberaterin oder eines Promotionsberaters angefertigt, dabei keine anderen Hilfsmittel als die im Quellen- und Literaturverzeichnis genannten benutzt und alle aus Quellen und Literatur wörtlich oder sinngemäß entnommenen Stellen als solche kenntlich gemacht habe.

Hiermit versichere ich, dass die Dissertation, Bestandteile der kumulativen Dissertation oder wesentliche Teile derselben nicht bereits einer anderen Prüfungsbehörde zur Erlangung des Doktorgrades vorlagen.

Hiermit erkläre ich, dass die Dissertation nicht in ihrer Gesamtheit veröffentlicht ist. Da es sich um eine kumulative Dissertation handelt, sind einzelne Bestandteile (Kapitel) bereits als Diskussionspapier veröffentlicht bzw. bei einer Fachzeitschrift eingereicht:

Kapitel 4 ist bei der internationalen Fachzeitschrift "European Economic Review" eingereicht. Kapitel 4 ist außerdem Teil des folgenden Diskussionspapiers:

- Illing, Hannah; Koch, Theresa (2021): Who Suffers the Greatest Loss? Costs of Job Displacement for Migrants and Natives. (IAB-Discussion Paper, 08/2021), Nürnberg, 63 S. URL: https://www.iab.de/183/section.aspx/Publikation/ K210427 JCN.

Bamberg, 11.06.2021

Hannah Illing 


\section{Koautorenbeleg für aufsatzbasierte Dissertationen}

Dies ist ein Nachweis über die Anteile der Koautorenschaften in den Kapiteln 3 und 4 meiner Dissertation:

Kapitel 3 der Dissertation: "The Gender Gap in Earnings Losses After Displacement"

Anteile:

- Hannah Illing (33\%)

- Johannes Schmieder (33\%)

- Simon Trenkle $(33 \%)$

Kapitel 4 der Dissertation: "Who Suffers the Greatest Loss? Costs of Job Displacement for Migrants and Natives"

Anteile:

- Hannah Illing (50\%)

- Theresa Koch (50\%)

Bamberg, 11.06.2021

Hannah Illing 